\title{
Development and Evaluation of Novel Metal Reinforced Ceramic Matrix Composites for High Temperature Applications
}

\author{
By \\ Teymoor Mohammadi
}

A thesis submitted to the Faculty of Graduate and Postdoctoral Affairs in partial fulfillment of the requirements for the degree of

Master of Applied Science

In

M.A.Sc. Materials Engineering

Carleton University

Ottawa, Ontario

(C) 2012 
Library and Archives

Canada

Published Heritage

Branch

395 Wellington Street

Ottawa ON K1A ON4

Canada
Bibliothèque et

Archives Canada

Direction du

Patrimoine de l'édition

395 , rue Wellington

Ottawa ON K1A ON4

Canada
Your file Votre référence

ISBN: 978-0-494-94259-8

Our file Notre référence

ISBN: $978-0-494-94259-8$
NOTICE:

The author has granted a nonexclusive license allowing Library and Archives Canada to reproduce, publish, archive, preserve, conserve, communicate to the public by telecommunication or on the Internet, loan, distrbute and sell theses worldwide, for commercial or noncommercial purposes, in microform, paper, electronic and/or any other formats.

The author retains copyright ownership and moral rights in this thesis. Neither the thesis nor substantial extracts from it may be printed or otherwise reproduced without the author's permission.
AVIS:

L'auteur a accordé une licence non exclusive permettant à la Bibliothèque et Archives Canada de reproduire, publier, archiver, sauvegarder, conserver, transmettre au public par télécommunication ou par l'Internet, prêter, distribuer et vendre des thèses partout dans le monde, à des fins commerciales ou autres, sur support microforme, papier, électronique et/ou autres formats.

L'auteur conserve la propriété du droit d'auteur et des droits moraux qui protege cette thèse. $\mathrm{Ni}$ la thèse ni des extraits substantiels de celle-ci ne doivent être imprimés ou autrement reproduits sans son autorisation.
In compliance with the Canadian Privacy Act some supporting forms may have been removed from this thesis.

While these forms may be included in the document page count, their removal does not represent any loss of content from the thesis.
Conformément à la loi canadienne sur la protection de la vie privée, quelques formulaires secondaires ont été enlevés de cette thèse.

Bien que ces formulaires aient inclus dans la pagination, il n'y aura aucun contenu manquant. 
The undersigned recommend to the Faculty of Graduate and Postdoctoral Affairs acceptance of the thesis

\section{Development and Evaluation of Novel Metal Reinforced Ceramic Matrix Composites for High Temperature Applications}

Submitted by Teymoor Mohammadi

B. Eng., B.Sc.

In partial fulfillment of the requirements for the degree of Master of Applied Science

X. Huang, Thesis Supervisor

J. Beddoes, Thesis Co-Supervisor

Metin I. Yaras,

Chair, Dept. of Mechanical and Aerospace Engineering

Carleton University

2012 


\begin{abstract}
For high temperature applications two novel ceramic-matrix composite (CMC) materials are manufactured, by embedding molybdenum (Mo) and Hastelloy X (HX) wire meshes in $7 \mathrm{YSZ}$ ceramic. The mechanical properties and oxidizing behaviour at $1050^{\circ} \mathrm{C}$ were investigated. The designs, fabrication, assessment of the mechanical strength, cyclic and isothermal oxidation of the CMCs are described in this thesis. After manufacturing meshes, NiCrAlY bond coats and 7YSZ were applied via plasma spraying.
\end{abstract}

Bonding strength in some CMC samples are improved by vacuum heat treating, then as-sprayed and heat treated CMCs are subjected to three-point bend and impact tests. Mo and $\mathrm{HX}$ wire mesh incorporation in $7 \mathrm{YSZ}$ increase the strength and the elongation to failure. In particular, Mo wire increases yield load of 7YSZ by at least 3 times and HX wire increases yield by 9 times. Mo/7YSZ CMC degrades and oxidizes after 330 hours at $1050^{\circ} \mathrm{C}$ tests, but $\mathrm{HX} / 7 \mathrm{YSZ}$ shows higher oxidation resistance.

The metallographic analysis shows NiCrAlY bond coat cracks and delaminates from the wires during isothermal tests. Cyclic test, creating larger thermal stresses, worsens the damage. To increase the oxidation and mechanical properties of these composites, a more effective ceramic coating method is recommended. Overall, the advantages of $\mathrm{HX} / 7 \mathrm{YSZ}$ composite suggest further testing and investigation. 


\section{Acknowledgements}

It is a great pleasure to acknowledge that this work was made possible by the support, time and commitment of a number of individuals. First, I would like to express my sincere gratitude to my thesis supervisors, Professor Xiao Huang from the Mechanical and Aerospace Engineering Department at Carleton University, and Professor Jonathan Beddoes from Engineering Department at the University of Manitoba, for providing me with this excellent opportunity to work on this project and their continuous support and guidance throughout this research.

I would also like to offer my sincere appreciation to Dr. Richard Kearsey, the staff at M-13, Dr. Weijie Chen at National Research Council Canada (NRC) for their assistance and generous help.

I want to express my appreciation to the staff in machine shop, plasma spray shop and structural lab in the MAE for their help and support during my experimental works.

Finally, I dedicate this work to my family and especially my wife, my son, and my daughter, who are a source of unwavering love, encouragement and support, and also my brother for his energetic support. 


\section{Table of Contents}

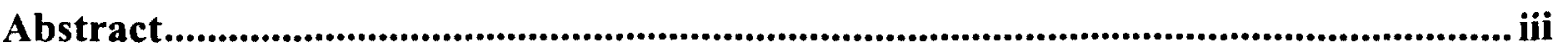

Acknowledgements .............................................................................................................. iv

List of Tables ...................................................................................................................... viii

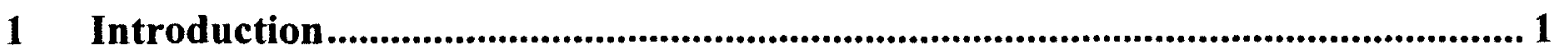

$1.1 \quad$ Gas Turbine Typical Materials ………………................................................... 1

1.2 High Temperature Materials (Superalloys) …………...............................................

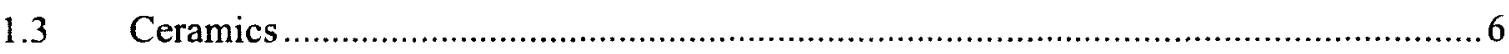

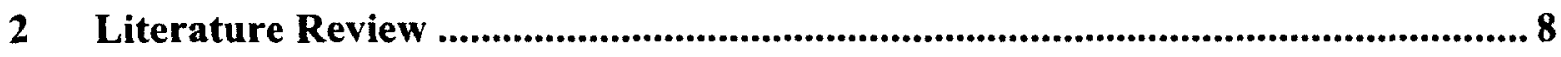

$2.1 \quad$ Gas Turbine High Temperature Materials ................................................................. 8

2.1.1 Nickel-based Polycrystalline and Single Crystal Alloys.......................................... 8

2.1.2 Hot Section Materials and Coatings.................................................................... 17

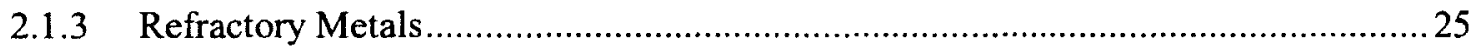

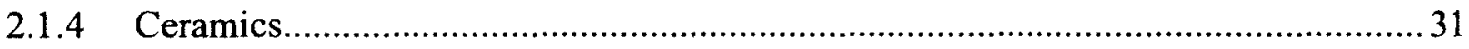

2.1.5 Ceramic Composite Materials ................................................................................ 39

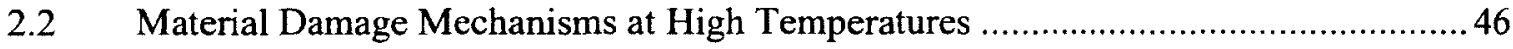

2.2.1 Mechanical Property Degradation …………………………………………….....4

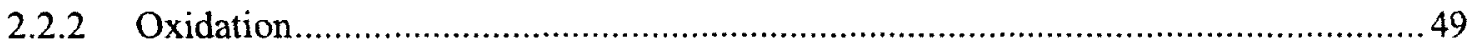

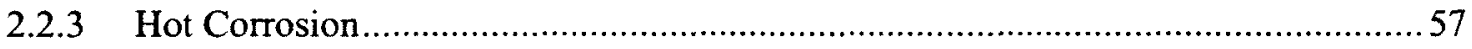

2.3 Plasma Spraying Process ....................................................................................61

$2.4 \quad$ Summary

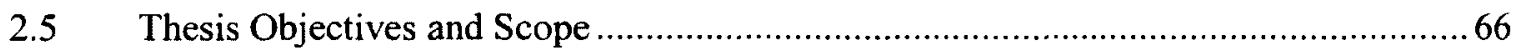

3 Materials and Experimental Procedures ................................................................6 68

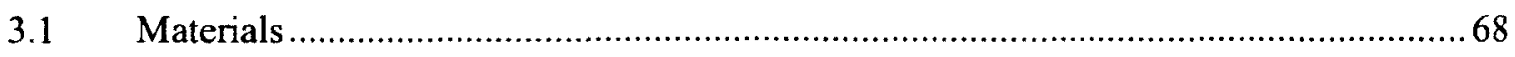

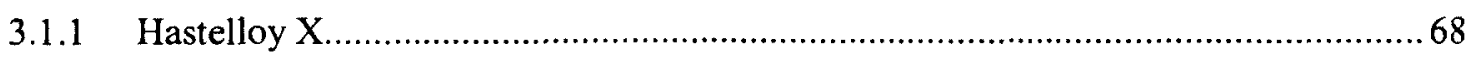

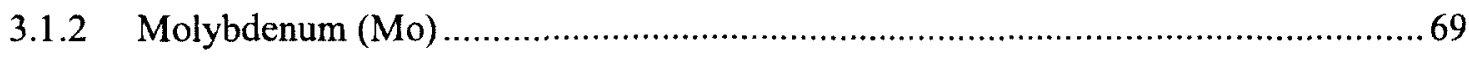




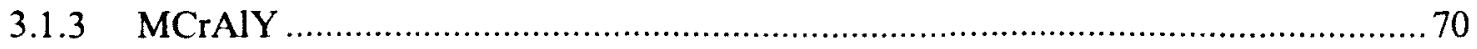

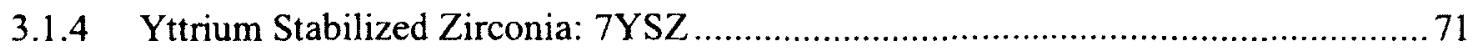

3.2 General Manufacturing Steps to Fabricate Mesh Reinforced CMCs ........................ 72

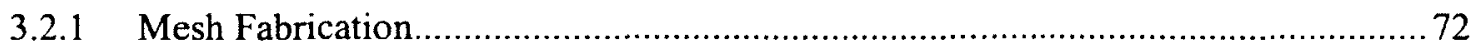

3.2.2 Plasma Spray Coating Process and Parameters ................................................... 77

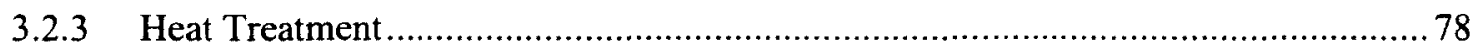

3.3 Detailed Manufacturing Process for Metal Reinforced CMC Samples.......................79

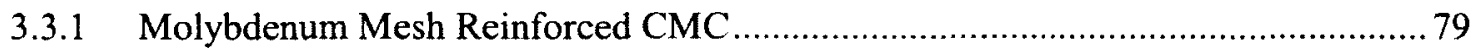

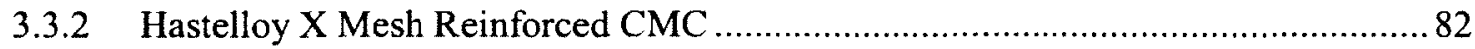

4 Test procedures for Mo/7YSZ and HX/7YSZ ............................................ 85

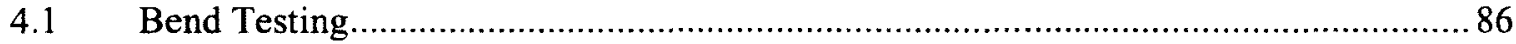

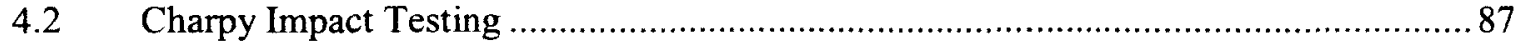

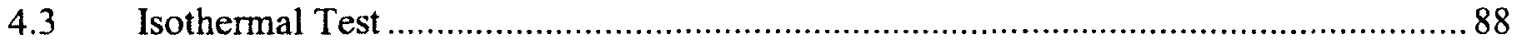

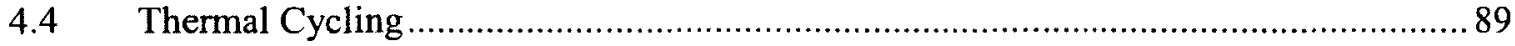

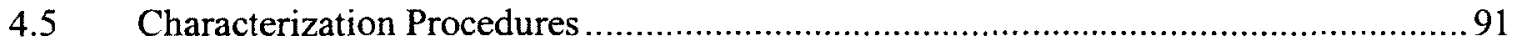

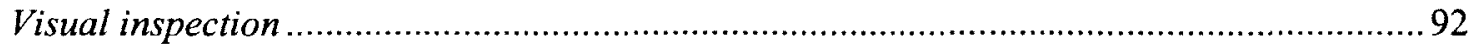

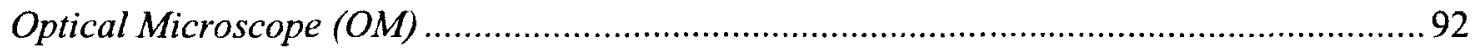

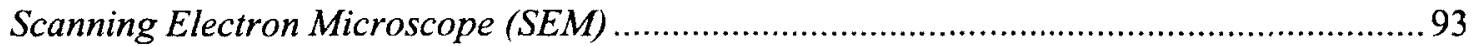

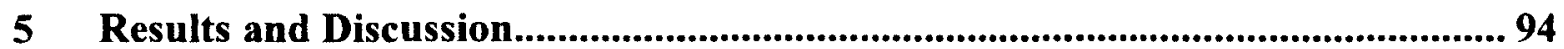

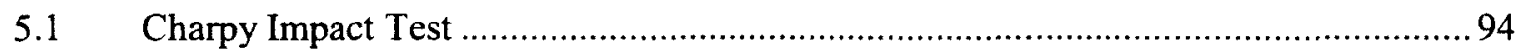

5.1.1 Mo Reinforcement Ceramic Matrix Composite and Monolithic 7YSZ Ceramic ....94

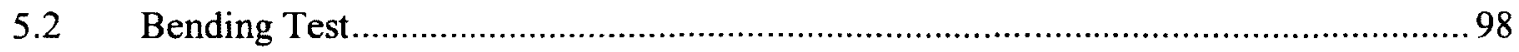

5.2.1 Mo Reinforcement Ceramic Matrix Composite and Pure 7YSZ Ceramic ...............98

5.2.2 Hastelloy X Reinforcement Ceramic Matrix Composite …................................ 102

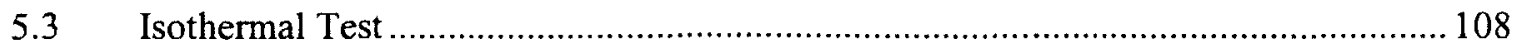

5.3.1 Mo Reinforcement Ceramic Matrix Composite and Reference 7YSZ Samples .... 108 
5.4 Isothermal and Oxidation Tests of HX Reinforcement Ceramic Matrix Composite .112

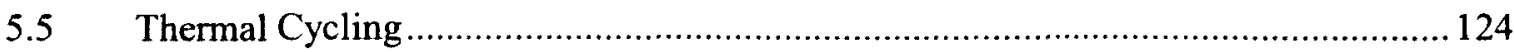

5.5.1 Mo Reinforcement Ceramic Matrix Composite................................................. 124

5.5.2 Thermal Cyclic Oxidation Test of Hastelloy X Reinforcement Ceramic Matrix

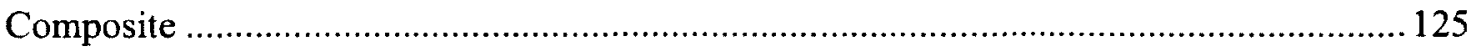

5.6 The Effect of Heat Treatment on Reinforced CMCs ............................................ 139

6 Conclusions and Recommendations ............................................................ 146

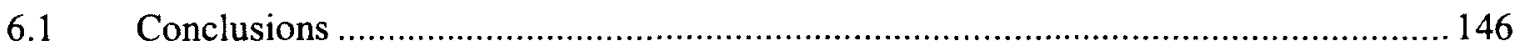

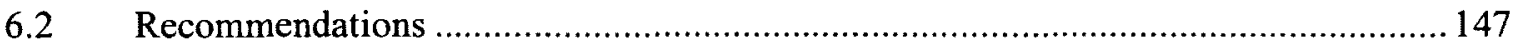

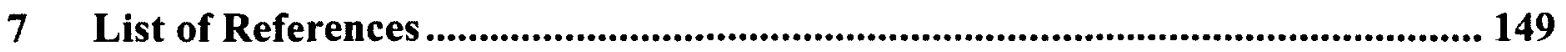




\section{List of Tables}

Table 1: Effects of major alloying elements in nickel-based superalloys [5]...................

Table 2: Atomic and plane spacing in $\mathrm{Ni}_{3} \mathrm{Al}, \mathrm{Ni}_{3} \mathrm{Ti}, \mathrm{Ni}_{3} \mathrm{Ta}$, and $\mathrm{Ni}_{3} \mathrm{Nb}$ as common $\mathrm{Ni}_{3} \mathrm{X}$

phases [5]

Table 3: Physical and mechanical characteristics of some ceramic materials [36]......... 32

Table 4: Summary of selected thermal properties of alumina at various temperatures [42].

Table 5: Typical physical and mechanical properties of $86 \%$ to $99.9 \%$ alumina [ 43$]$.... 35

Table 6: Melting points of selected oxides of alloying elements commonly found in high-

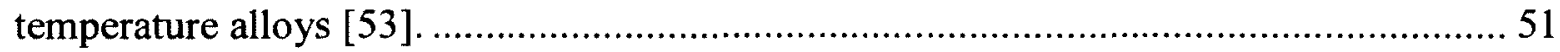

Table 7: Nominal chemical composition of Hastelloy $\mathrm{X}$ in wt. \% [68]..........................68

Table 8: Typical physical properties of Hastelloy X [68]............................................... 69

Table 9: Properties of molybdenum, $99.95 \mathrm{wt} \% \%$ pure, rolled at $1000^{\circ} \mathrm{C}[69] \ldots \ldots \ldots \ldots \ldots . .70$

Table 10: Chemical composition (in wt.\%) of NiCrAlY bond coat. .............................. 71

Table 11: Coefficient of thermal expansion of NiCrAl powder [75] ............................ 71

Table 12: Chemical composition (in wt.\%) of 7YSZ used in this research..................... 72

Table 13: Mechanical and physical properties of YSZ $\left(\sim 8 \mathrm{wt} . \% \mathrm{Y}_{2} \mathrm{O}_{3}\right) \ldots \ldots \ldots \ldots \ldots \ldots \ldots \ldots . . .72$

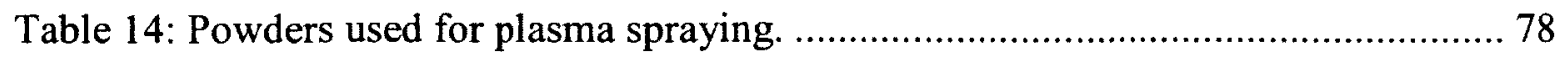

Table 15: Spray parameters for plasma spraying NiCrAlY .......................................... 78

Table 16: Spray parameters for plasma spraying 7YSZ ……..................................... 78

Table 17: Charpy impact energy of impacted samples (the estimated errors is based on

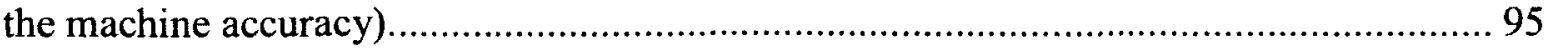

Table 18: Yielding, peak and fracture load of various samples..................................... 99 
Table 19: Bend test results for the solid 7YSZ, as-sprayed and heat treated HX/7YSZ. 103 Table 20: Composition of powder formed in isothermally heated then furnace-cooled specimens in wt. \%, determined by EDS ...................................................... 110

Table 21: Composition of the components in as-sprayed HX/7YSZ composite (in wt. \%) in directly exposed to air section after 500 hours at $1050^{\circ} \mathrm{C}$.

Table 22: Composition of as-sprayed HX/7YSZ CMC (not-directly exposed to air) after 500 hours at $1050^{\circ} \mathrm{C}$ (in wt. \%).

Table 23: Composition of each layer on the cross section of the heat treated HX/7YSZ CMC (not-directly exposed to air) after being exposed to air for 500 hours at $1050^{\circ} \mathrm{C}$ (in wt.\%).

Table 24: Composition of as-sprayed HX/7YSZ CMC (not-directly exposed to air) after 1000 hours at $1050^{\circ} \mathrm{C}$ (in wt. \%).

Table 25: Composition of heat treated HX/7YSZ CMC (not-exposed to air section) after 1000 hours in isothermal oxidation test (in wt. \%).

Table 26: Compositions of the heat treated HX/7YSZ composite (directly exposed section) after 500 cycles in cyclic test at $1050^{\circ} \mathrm{C}$ (in wt.\%).

Table 27: Composition of as-sprayed HX/7YSZ CMC on the cross section after 500 cycles of cyclic test (in wt.\%).

Table 28: Composition of heat treated HX/7YSZ CMC on cross section after 500 cycles of cyclic test (in wt.\%).

Table 29: Composition of as-sprayed HX/7YSZ CMC (not-directly exposed to air) after 1000 cycles of cyclic test (in wt. \%). 
Table 30: Composition of various layers on the heat treated HX/7YSZ CMC (not-directly exposed to air) after 1000 cycles of cyclic test (in wt. \%)........................................ 137 


\section{List of Figures}

Figure 1: Diagram of a typical gas turbine jet engine with typical materials selection for engine components [2].

Figure 2: A typical temperature (in ${ }^{\circ} \mathrm{C}$ ) and stress (in $\mathrm{MPa}$ ) distribution in a first stage AM1 turbine blade [5]. 3

Figure 3: Oxidation resistance and strength for various metallic families [8]..... 5

Figure 4: The Ni-Al-Ti ternary phase diagram showing $\gamma$ and $\gamma^{\prime}$ phase field at $700^{\circ} \mathrm{C}$ $(973 \mathrm{~K})$ and $1300^{\circ} \mathrm{C}(1573 \mathrm{~K})[15]$

Figure 5: The crystal lattices and close-packed plane in common $\mathrm{Ni}_{3} \mathrm{X}$ structure [5].... 12 Figure 6: (a) TEM micrograph of an $\mathrm{M}_{23} \mathrm{C}_{6}$ in a $\gamma^{\prime}$ precipitate in AM1 alloy after creep testing for $100 \mathrm{~h}$ at $1050^{\circ} \mathrm{C}$ and $150 \mathrm{MPa}$, and (b) coherent $\mathrm{M}_{6} \mathrm{C}$ particle at a $\gamma / \gamma^{\prime}$ interface (arrows) in MC2 alloy [5]. 14

Figure 7: Morphology of extracted minor phases in M951 alloy: (a) small island-like boride on carbide, and (b) eutectic boride [17].

Figure 8: TEM micrograph of a Ni-20.7Cr-17Co-0.63Mo-4.75Ti-10Al alloy (at. \%) heat treated at $1180^{\circ} \mathrm{C} \mathrm{AC}+64 \mathrm{~h} 900^{\circ} \mathrm{C} \mathrm{AC}$, showing $\sigma$ phase plates within the grains and cellular $\sigma / \gamma^{\prime}$ colonies at the grain boundaries ( $\sigma$ is the dark phase) [5]. 16

Figure 9: TEM micrograph of different morphology of $\mu$ phase within the $\gamma / \gamma^{\prime}$ matrix: (a) large plates or needles, and (b) small nodules of this phase in MC2 alloy [5].... 17

Figure 10: The development of superalloys and heat resistant coatings [19]. 18

Figure 11: Effect of MCrAlY coatings on fatigue life of nickel-based superalloys: (a) under push-pull loading, and (b) under rotary bending [20]. 19 
Figure 12: Comparison between DBTT (horizontal axis) of aluminide and MCrAlY coatings. An increase of $\mathrm{Al}$ concentration in $\mathrm{NiAl}$ from 25 to $35 \mathrm{wt} . \%$ increases the DBTT of the NiAl coating [18].

Figure 13: Effect of chemical composition on the DBTT (horizontal axis) of the CrAlY coatings [18] 20

Figure 14: Effect of $\mathrm{Y}_{2} \mathrm{O}_{3}$ level in ceramic and bond coat on thermal fatigue resistance $[18]$ 21

Figure 15: Schematic diagram showing the decrease in substrate metal temperature in gas turbine as a result of superalloy development $\left(\sim 80^{\circ} \mathrm{C}\right)$ and applying thermal barrier

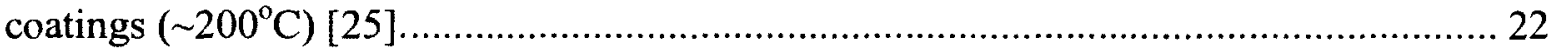

Figure 16: A schematic representation of a TBC's cross section [24]. ....................... 23 Figure 17: The concept behind the application of TBC on the air cooled turbine blade: (a) the temperature distribution on the TBC coated blade, and (b) the temperature distribution on the uncoated blade [19].

Figure 18: The trend of alloy development as compared to the gas temperature feasibility $[19]$

Figure 19: Dependence of ultimate tensile strength of pure refractory metals on temperature [30]. 26

Figure 20: Modulus of elasticity versus test temperature for pure (unalloyed) refractory metals [28].

Figure 21: The $\alpha$-alumina (corundum) crystal structure viewed along: (a) the $<0001>$ direction (c plane), and (b) the <1010> direction (blue spheres: oxygen atoms, and red spheres: aluminum atoms) [40] 
Figure 22: Comparison of thermal conductivity and thermal expansion coefficient between YSZ and other ceramics [46]

Figure 23: Relative material temperature limits: carbon-carbon (C-C), carbon fiber reinforced plastic (CFRP), ceramic matrix composite (CMC), carbon-silicon carbide (C$\mathrm{SiC}$ ), glass-ceramic matrix composite (GCMC), metal matrix composite (MMC), and

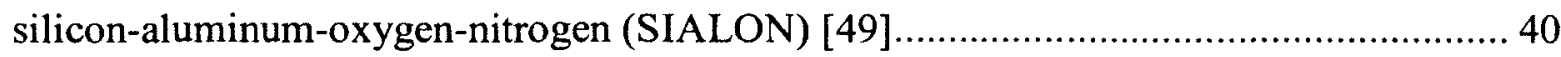

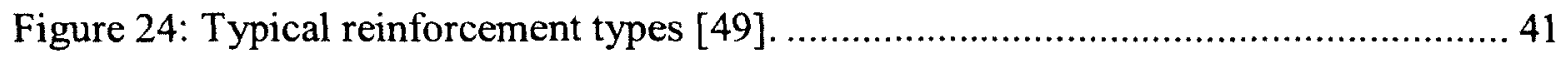

Figure 25: Comparison of polymer/metal with ceramic matrix composites [49]............ 42

Figure 26: Stress-strain for monolithic and ceramic matrix composites [49] .................. 43

Figure 27: Crack dissipation mechanisms [49] .......................................................... 44

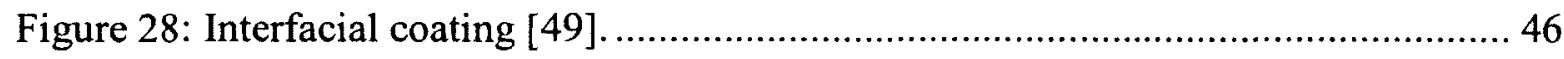

Figure 29: Effect of time and temperature on oxidation of Rene 41 precipitation-hardened

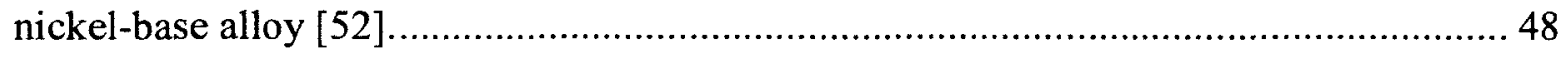

Figure 30: Standard free energies of oxide formation as a function of temperature [53]. 50 Figure 31: Vapor pressure of several refractory metal oxides (exhibiting high vapor

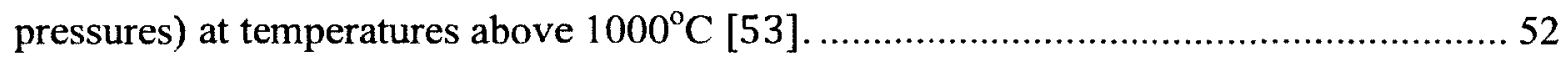

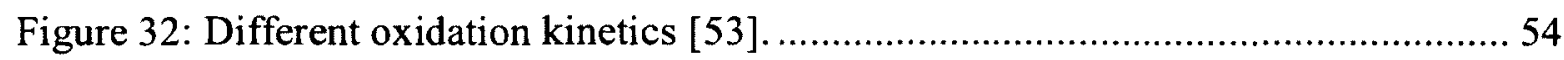

Figure 33: Operating diagram of an airliner engine [9] ............................................ 56

Figure 34: Hot corrosion of a stage 1 blade in PT6 engine: (a) loss of large piece of material near the leading edge of blade, (b) a crack propagation into the remainder material, (c) optical micrograph showing advanced hot corrosion attack, and (d) a secondary crack propagating from the scale into the base material [58]. 58 
Figure 35: Schematic diagram showing factors that determine the transition from

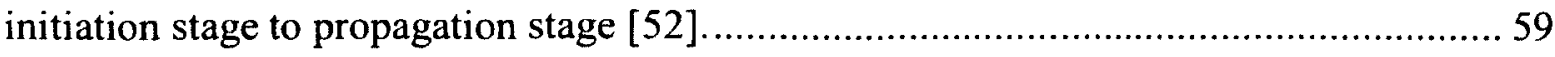

Figure 36: Schematic diagram of an atmospheric plasma process [65] ..........................6 63

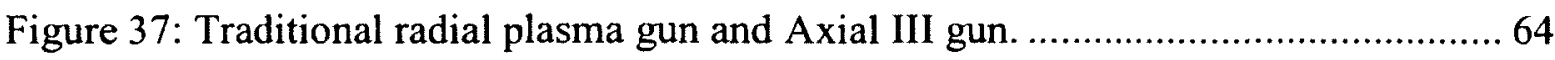

Figure 38: AutoCAD drawing of Mo mesh weaving frame; same weaving frame was

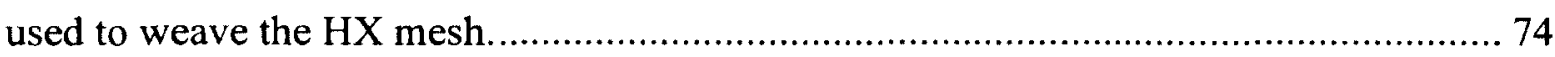

Figure 39: Wooden mesh weaving frame. Inside the frame, Hastelloy $\mathrm{X}$ woven wires are

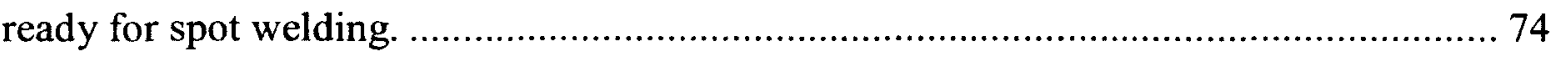

Figure 40: Spot welded Hastelloy X wire mesh: (a) before, and (b) after releasing from

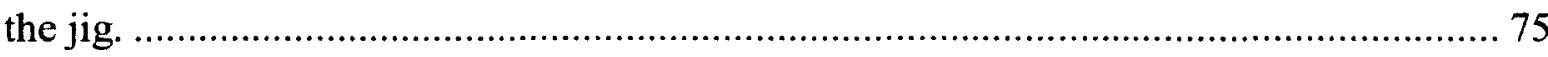

Figure 41: AutoCAD drawing of mesh fixture for plasma spraying when Mo wires are fixed on fixture; same fixture was used to fix the HX mesh in place for plasma spraying.

Figure 42: Mounted Hastelloy X wire meshes on fixture frames made from 308 stainless steel. 76

Figure 43: As-fabricated: (a) Mo mesh and welded junction (inset), and (b) Hastelloy X mesh. 76

Figure 44: Plasma spray system AT-1200HP powder feeder and plasma spray gun. ...... 77

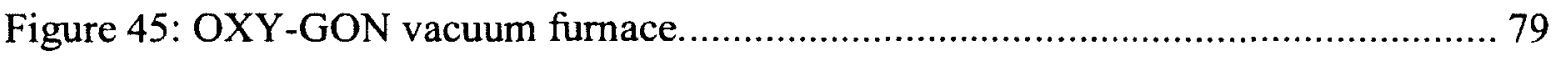

Figure 46: Mo mesh wire after 6 runs of 7YSZ spraying operation.............................. 81

Figure 47: (a) Final Mo/YSZ specimen, and (b) composite dimensions (in $\mathrm{mm}$ )...........81

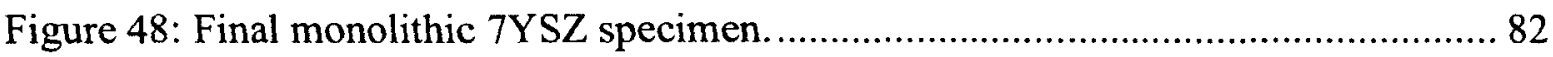

Figure 49: Bare Hastelloy $\mathrm{X}$ mesh in plasma spray set up for NiCrAlY bond coating. ... 82 
Figure 50: Plasma spray operation during 7YSZ coating.

Figure 51: 7YSZ coating results: (a) after 3 runs, and (b) after 4 runs on each side. 83

Figure 52: Final HX/7YSZ specimen's dimensions (in mm).

Figure 53: Sketch showing where the four $2 \times 1 / 2 \times 1 / 4$ inch samples from each $\mathrm{HX} / 7 \mathrm{YSZ}$ original specimen were sectioned from. 85

Figure 54: (a) Sketch showing directly exposed samples and cutting planes revealing (b) transverse and (c) longitudinal cross sections in not-directly exposed to air sections...... 86 Figure 55: Three-point bend test of as-sprayed HX/7YSZ sample using MTS 810 machine. 87

Figure 56: HX/7YSZ samples in a Lindberg Type 51442 electric air furnace at $1050^{\circ} \mathrm{C} .89$

Figure 57: CM 1800 Rapid Temp Furnace at NRC 90

Figure 58: Cyclic test temperature profile for Mo/7YSZ samples. 90 Figure 59: (a) As-sprayed, and (b) heat treated HX/7YSZ CMCs (before cyclic oxidation test) in rapid temp furnace. 91

Figure 60: Cyclic test temperature profile for $\mathrm{HX} / 7 \mathrm{YSZ}$ samples. 91 Figure 61: Charpy impact test specimens: (a) heat treated 7YSZ reference, (b) as-sprayed Mo/YSZ, and (c) heat treated Mo/YSZ. 94 Figure 62: Mo/7YSZ samples after impact test: (a) NiCrAlY coating were detached from broken wires in as-sprayed samples, and (b) vacuum heat treated samples showed better

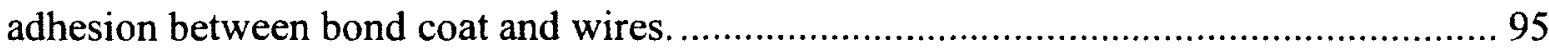

Figure 63: Charpy impact surface of the as-sprayed Mo/7YSZ sample (8X). ............... 96 
Figure 64: SEM micrograph of the Mo/7YSZ Charpy fracture surface at (a) $300 \mathrm{X}$ magnification and (b) $4000 \mathrm{X}$ magnification (indicating the location where $4000 \mathrm{X}$ is taken) 96

Figure 65: Images of samples after bend testing: (a) as-sprayed reference 7YSZ, (b) assprayed Mo/7YSZ, and (c) heat treated Mo/7YSZ 99

Figure 66: Three-point bend test load-displacement curves for as-sprayed and heat treated Mo/7YSZ samples. 100

Figure 67: Enlarged load-displacement curves for as-sprayed and heat treated Mo/7YSZ samples up to $1 \mathrm{~mm}$ elongation. 100

Figure 68: Images of $\mathrm{HX} / 7 \mathrm{YSZ}$ samples after bend test: (a) as-sprayed, and (b) heat

treated 103

Figure 69: (a) Cracking and spallation in as-sprayed HX/7YSZ sample, and (b) transverse cracking in the heat treated samples after bend test. 103

Figure 70: Load-displacement curves combining tests results for HX/7YSZ (as-sprayed and heat treated) and monolithic 7YSZ samples. 104

Figure 71: Enlarged load-displacement curves for HX/7YSZ (as-sprayed and heat treated) and monolithic $7 \mathrm{YSZ}$ samples up to $1 \mathrm{~mm}$ elongation. 104

Figure 72: Three-point bend test load-displacement curves for second pair of as-sprayed and heat treated $\mathrm{HX} / \mathrm{YSZ}$ samples. 105

Figure 73: Enlarged load-displacement curves for second pair of as-sprayed and heat treated $\mathrm{HX} / 7 \mathrm{YSZ}$ samples up to $1 \mathrm{~mm}$ elongation. 105 Figure 74: Load and displacement curve combining tests results for both $\mathrm{HX}$ and Mo reinforced $\mathrm{CMC}$. 
Figure 75: XRD pattern of the green powder taken from the isothermal oxidation tested $\mathrm{Mo} / 7 \mathrm{YSZ}$ specimen (330 hours, $\left.1050^{\circ} \mathrm{C}\right)$. 109

Figure 76: BSE image of the scanned locations: (a) general scan, (b) white spot, and (c) grey spot.

Figure 77: Isothermal tested specimens after 330 hours, showing cracking and separation of the top and bottom layers in Mo/7YSZ samples.

Figure 78: As-sprayed HX/7YSZ sample after 500 hours isothermal oxidation test (directly exposed to air) (30x).

Figure 79: SEM images of as-sprayed HX/7YSZ after 500 hours isothermal test (directlyexposed to air): (a) HX wire, (b) HX, NiCrAlY and interface, and (c) NiCrAlY, 7YSZ and interface.

Figure 80: (a) As-sprayed, and (b) heat treated HX/7YSZ sample after 500 hours isothermal oxidation test (transverse cross section, not exposed to air directly) $(30 x) \ldots 114$ Figure 81: SEM images of as-sprayed HX/7YSZ CMC components after being exposed to air for 500 hours in isothermal oxidation test: (a) HX wire, (b) NiCrAlY coating, and (c) $7 \mathrm{YSZ}$ ceramic $(5 \mathrm{kx})$. 115

Figure 82: SEM images of Hastelloy $\mathrm{X}$ wire in the as-sprayed HX/7YSZ CMC (notdirectly exposed to air): (a) HX wire white spot, and (b) HX wire gray spot after 500 hours in isothermal oxidation. 115 Figure 83: SEM images of as-sprayed CMC sample after 500 hours isothermal test (notdirectly exposed to air): (a) HX-NiCrAlY, and (b) NiCrAlY-7YSZ interfaces. 115 Figure 84: SEM images of heat treated CMC sample after 500 hours isothermal test (notdirectly exposed to air): (a) HX-NiCrAlY, and (b) NiCrAlY-7YSZ interfaces. 116 
Figure 85: SEM images of heat treated HX/7YSZ CMC after 500 hours in isothermal oxidation test (not-directly exposed to air): (a) HX wire, (b) HX-NiCrAlY interface, and (c) NiCrAlY-7YSZ interface.

Figure 86: As-sprayed HX/7YSZ sample after 1000 hours isothermal oxidation test: (a) section directly exposed to air, and (b) cross section (30X)

Figure 87: Heat treated HX/7YSZ samples after 1000 hours isothermal oxidation test: (a) section directly exposed to air, and (b) cross section (30X) 119 Figure 88: Heat treated HX/7YSZ sample cross section after 1000 hours isothermal oxidation test (not-directly exposed to air section) (30X).

Figure 89: SEM images of as-sprayed HX/7YSZ cross section (not-directly exposed to air) after 1000 hours: (a) HX white spot, (b) HX gray spot, (c) HX-NiCrAlY interface, and (d) NiCrAlY-7YSZ interface.

Figure 90: SEM images of different layers of the heat treated HX/7YSZ composite after 1000 hours isothermal test (not-directly exposed to air): (a) HX white spot, (b) HX grey spot, (c) HX-NiCrAlY interface, and (d) NiCrAlY-7YSZ interface. 122 Figure 91: Cyclic oxidation test samples after 100 cycles (220 hours): (a) as-sprayed Mo/7YSZ, (b) heat treated 7YSZ reference, (c) as-sprayed 7YSZ reference, and (d) heat treated Mo/7YSZ. 124

Figure 92: Cyclic oxidation test HX/7YSZ samples after 500 cycles: (a) as-sprayed, and (b) heat treated. 126

Figure 93: As-sprayed HX/7YSZ sample after 500 cycle cyclic oxidation test (directly exposed to air) $(30 \mathrm{x})$ 126 
Figure 94: Cracks in as-sprayed HX/7YSZ sample after 500 cycles in cyclic test (notdirectly exposed to air): (a) longitudinal cross section, and (b) transverse cross section $(30 x)$

Figure 95: Cracks and delamination in heat treated HX/7YSZ sample after 500 cycles in cyclic test (directly exposed to air) (30x). 127

Figure 96: Cracks and delamination in heat treated HX/7YSZ sample after 500 cycles in cyclic test (not-directly exposed to air): (a) longitudinal cross section, and (b) transverse cross section (30X). 128

Figure 97: SEM image of heat treated HX/7YSZ sample after 500 cycles in cyclic test (directly exposed to air): (a) HX wire, (b) NiCrAlY bond coat, and (c) 7YSZ ceramic. 128 Figure 98: SEM images of as-sprayed HX/7YSZ CMC after 500 cycles of cyclic test (not-directly exposed to air): (a) HX white spot, (b) HX grey spot, (c) HX-NiCrAlY interface, and (d) NiCrAlY-7YSZ interface (5kx). 129

Figure 99: SEM images of heat treated HX/7YSZ CMC after 500 cycle of cyclic test (not-directly exposed to air): (a) HX white spot, (b) HX grey spot, (c) HX-NiCrAlY interface, and (d) NiCrAlY-7YSZ interface (5kx).

Figure 100: Cyclic oxidation test HX/7YSZ samples after 1000 cycles: (a) as-sprayed, and (b) heat treated. 133

Figure 101: Cracks and delamination in as-sprayed HX/7YSZ sample after 1000 cycles in cyclic test (directly exposed to air) (30x). 133

Figure 102: As-sprayed HX/7YSZ sample after 1000 cycles of cyclic test (not-directly exposed to air): (a) longitudinal cross section (30X), and (b) transverse cross section $(16 \mathrm{X})$ 
Figure 103: Cracks and delamination in heat treated HX/7YSZ sample after 1000 cycles of cyclic test (directly exposed section) (30x). 134

Figure 104: Cracks and delamination in heat treated HX/7YSZ samples after 1000 cycles of cyclic test (not-directly exposed to air): (a) longitudinal cross section, and (b) transverse cross section (30x). 135

Figure 105: As-sprayed and heat treated HX/7YSZ samples in the (a) as-sprayed, and (b) heat treated conditions, showing curvature after 1000 cycles of oxidation test. 135 Figure 106: As-sprayed HX/7YSZ CMC layers and interfaces (not-directly exposed to air) after 1000 cycles of cyclic test: (a) HX white spot, (b) HX grey spot, (c) HXNiCrAlY interface, and (d)NiCrAlY-7YSZ interface (5kx). 136

Figure 107: Heat treated HX/7YSZ CMC (not-directly exposed to air) after 1000 cycles of cyclic test: (a) HX white spot, (b) HX grey spot, (c) HX-NiCrAlY interface, and (d)NiCrAlY-7YSZ interface (5kx).

Figure 108: (a) Cracks and delamination in non-heat treated Mo/7YSZ CMC, and (b) cracks in heat treated Mo/7YSZ CMC.

Figure 109: (a) Cracks and delamination in non-heat treated HX/7YSZ CMC, and (b) cracks in heat treated $\mathrm{HX} / 7 \mathrm{YSZ} \mathrm{CMC}$. 140

Figure 110: Optical microscope image of the microstructure of the Mo/YSZ composites, showing non-uniformity of NiCrAlY and circumferential cracking around the Mo wires in (a) as-sprayed, and (b) heat treated specimens.

Figure 111: SEM images of not-directly exposed to air section of (a) as-sprayed and (b) heat treated HX/7YSZ after 500 hours isothermal test (30X). 
Figure 112: Directly exposed to air section of (a) as-sprayed and (b) heat treated HX/7YSZ after 1000 hours of isothermal test (30X).

Figure 113: Not-directly exposed to air section of (a) as-sprayed and (b) heat treated HX/7YSZ after 1000 hours isothermal test (30X).

Figure 114: Cracking and delamination in directly exposed to air section of (a) as-sprayed and (b) heat treated HX/7YSZ CMCs after 500 cycles in cyclic test (30X) 144

Figure 115: Cracking and delamination in not- directly exposed to air section of (a) assprayed, and (b) heat treated HX/7YSZ CMCs after 500 cycles of cyclic test (30X)... 144 Figure 116: Cracking and delamination in directly exposed to air section of (a) as-sprayed and (b) heat treated HX/7YSZ CMCs after 1000 cycles of cyclic test (30X). 145

Figure 117: Cracking and delamination in not-directly exposed to air section of (a) assprayed and (b) heat treated HX/7YSZ CMCs after 1000 cycles of cyclic test (30X)... 145 


\section{Nomenclatures}

\begin{tabular}{|c|c|}
\hline APS & Atmospheric plasma spray \\
\hline $\mathrm{BC}$ & Bond coat \\
\hline BSE & Backscattered electron \\
\hline $\mathrm{C}_{\mathrm{p}}$ & Heat capacity \\
\hline $\mathrm{CC}$ & Conventionally cast \\
\hline CFRP & Carbon fiber reinforced plastic \\
\hline $\mathrm{CMC}$ & Ceramic-matrix composite \\
\hline CTE & Coefficient of thermal expansion \\
\hline CVD & Chemical vapor deposition \\
\hline DBTT & Ductile-to-brittle-transition temperature \\
\hline $\mathrm{DC}$ & Direct current \\
\hline DS & Directionally solidified \\
\hline $\mathrm{E}$ & Young's modulus \\
\hline $\mathrm{EDAX}$ & Energy dispersive X-ray spectroscopy \\
\hline EDM & Electric discharge machining \\
\hline EDS & Energy dispersive spectrometer \\
\hline $\mathrm{FCC}$ & Face centered cubic \\
\hline $\mathrm{G}^{\mathrm{o}}$ & Standard free energy \\
\hline $\mathrm{G}$ & Shear modulus \\
\hline GCMC & Glass-ceramic matrix composite \\
\hline GCP & Geometrically close-pack \\
\hline GTE & Gas turbine engines \\
\hline
\end{tabular}


$\mathrm{HCP}$

HIP

HP (or HHP)

HPSN

HX

K

$\mathrm{K}_{\mathrm{IC}}$

MIG

MMC

OM

PMC

PSZ

PWA

RF

R.T.

$\mathrm{SC}$ (or SX)

SE

SIALON

$\mathrm{T}_{\mathrm{m}}$

$T_{\text {oper }}$

TBC

TCP

TEM
Hexagonal-close-packed

Hot isostatic pressing

Hydrothermal hot pressing

Hot-pressed silicon nitride

Hastelloy X

Bulk modulus

Fracture toughness

Metal inert gas

Metal matrix composite

Optical microscope

Polymer matrix composite

Partially stabilized zirconium dioxide

Pratt \& Whitney Aircraft

Radio frequency

Room temperature

Single crystal

Secondary electron

Silicon-aluminum-oxygen-nitrogen

Melting temperature

Operating temperature

Thermal barrier coating

Topologically closed-packed

Transmission electron microscope 


\begin{tabular}{|c|c|}
\hline TF & Thermal fatigue \\
\hline TGO & Thermally grown oxide \\
\hline TIG & Tungsten inert gas \\
\hline TIT & Turbine inlet temperature \\
\hline $\mathrm{TZM}$ & Titanium-zirconium-molybdenum \\
\hline $\mathrm{TZP}$ & Tetragonal zirconia polycrystal \\
\hline YSZ & Yttria stabilized zirconia \\
\hline XRD & X-ray diffraction \\
\hline$\alpha$ & Coefficient of thermal expansion \\
\hline$\gamma_{0}$ & Surface energy \\
\hline$\varepsilon^{\circ}$ & Rate of creep accumulation \\
\hline $\mathrm{k}$ & Thermal conductivity \\
\hline$\rho$ & Density \\
\hline$\rho_{\text {th }}$ & Theoretical density \\
\hline$\tau$ & Homologous temperature \\
\hline 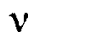 & Poisson's ratio \\
\hline
\end{tabular}




\section{Introduction}

\subsection{Gas Turbine Typical Materials}

Development of turbine material technologies heavily depends on improvements to nickel-based superalloys. These alloys belong to an important class of metallic materials that have a unique combination of high temperature strength, toughness, and resistance to degradation in corrosive or oxidizing environments. The materials are used in hot sections of gas turbine engines (GTEs), shown in Figure 1. The increase of operating temperature is directly related to the efficiency improvement of turbines and engines. Therefore, there is a continuing need to increase the operating temperature of turbines and engines [1]. Increasing turbine inlet temperature (TIT) produces higher useful work available for shaft power or thrust, which results in higher efficiency and reduced fuel costs and emissions. Therefore, for more efficient power plants, there is a demand for hot section materials with greater strength and higher temperature capability.

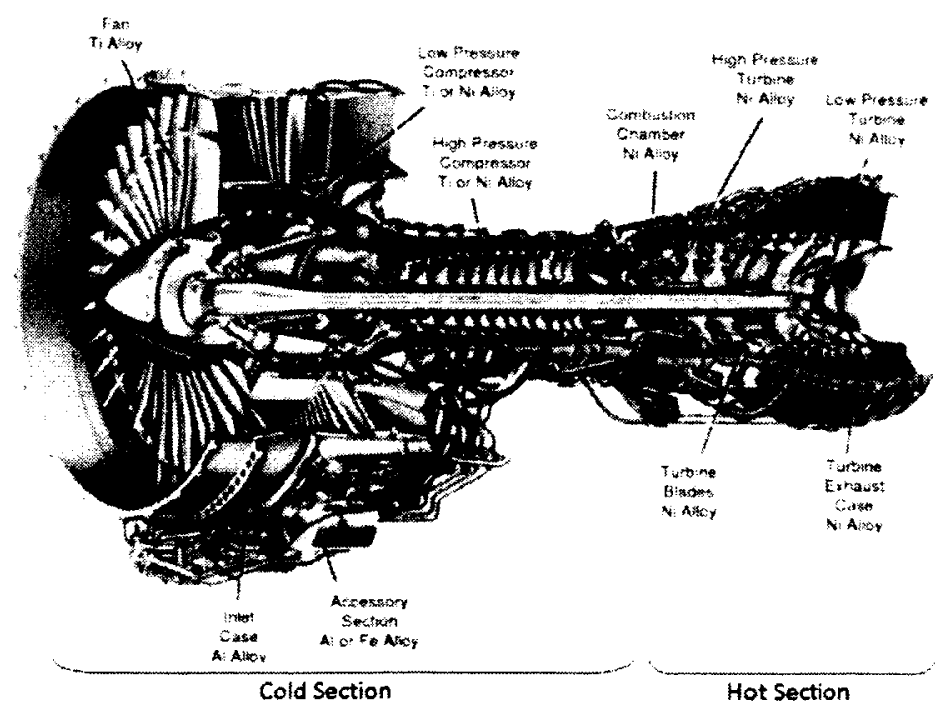

Figure 1: Diagram of a typical gas turbine jet engine with typical materials selection for engine components [2]. 
Ni-based superalloys have been developed progressively to be used in GTE components as the operation temperatures are increasing. These superalloys still need more improvement in high temperature strength and resistance to degradation in corrosive or oxidizing environments with increasing in TIT of the GTEs. Typical operating temperatures for the rim sections of high-pressure turbine discs approach $760^{\circ} \mathrm{C}$ and even as high as $815^{\circ} \mathrm{C}$ for some military applications [3], which requires the use of improved superalloys that tolerate higher temperatures. The alloys used in the high-temperature turbine sections are primarily nickel-based superalloys with modified compositions that have improved mechanical and thermal characteristics. Since the temperature and stress distribution varies in the component profile, the material design of these components is carried out based on the highest local spot temperature [4]. In Figure 2, typical stress and temperature distributions in different zones of the first stage turbine blade are shown [5]. In extreme cases, the localized temperatures near the airfoil tip seen reach as high as $1200^{\circ} \mathrm{C}$, which is approximately $90 \%$ of the melting point of the current Ni-based materials. Operating under these conditions for an extended time requires a suitable material selection [4]. 


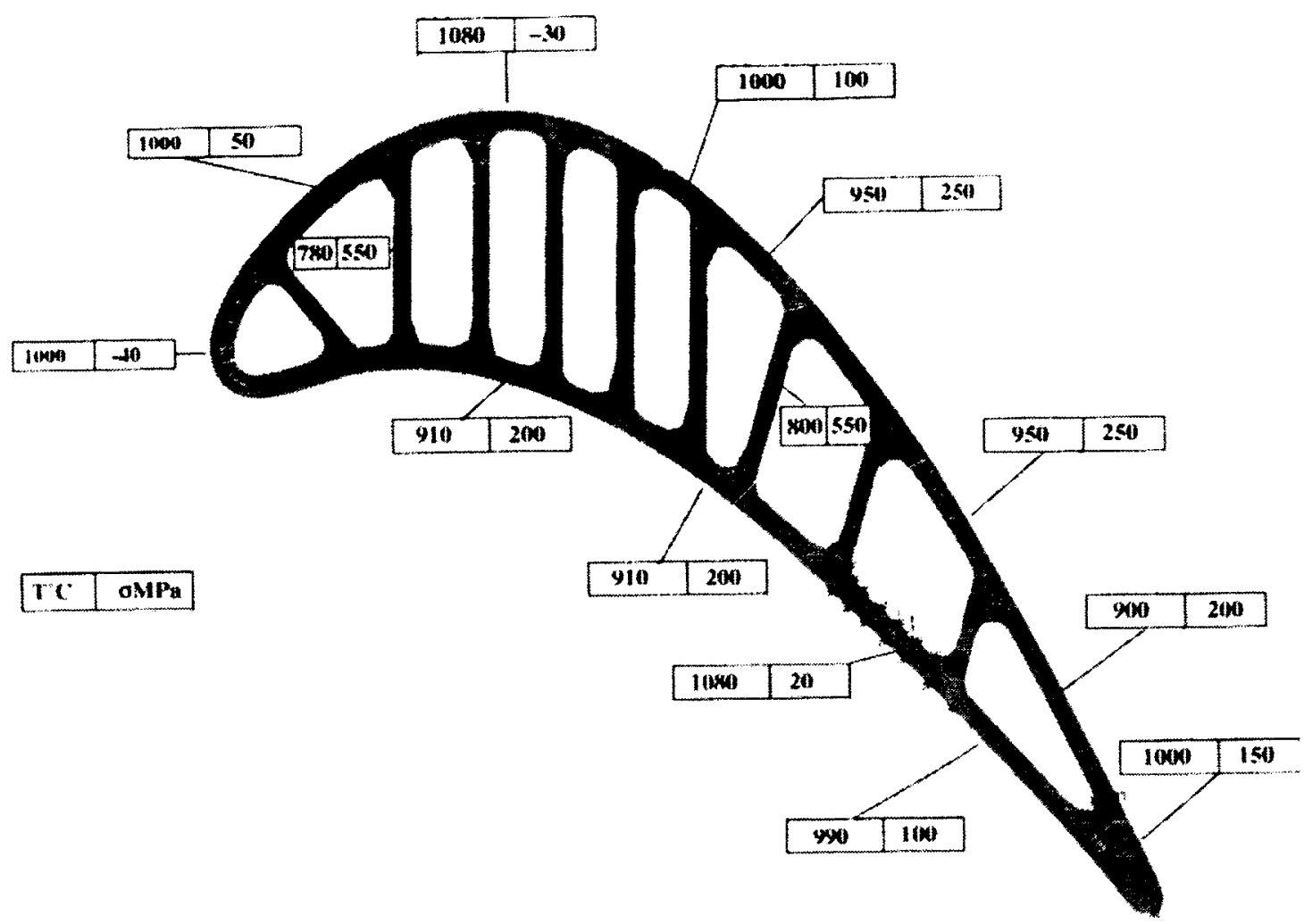

Figure 2: A typical temperature (in ${ }^{\circ} \mathrm{C}$ ) and stress (in $\mathrm{MPa}$ ) distribution in a first stage AM1 turbine blade [5].

\subsection{High Temperature Materials (Superalloys)}

High-temperature materials used in GTE hot sections contain large amounts of alloying elements including chromium and aluminum, providing these materials excellent resistance to mechanical and chemical degradation at high temperatures close to their melting points. These characteristics allow them to be used in the hottest sections of the turbines, rockets, and heat exchangers under the heaviest loads [6].

Materials used at high temperatures must possess various characteristics. The most important of these are the ability to withstand loading at an $T_{\text {oper }}$ close to their $T_{m}$ (the criteria for this characteristic is the homologous temperature $(\tau)$, defined as $T_{\text {oper }} / T_{m}$, 
which is greater than about 0.6 for these materials); resisting mechanical degradation at high temperatures over an extended period of time that requires materials with low creep rates, $\varepsilon^{0}$, and capability to tolerate harsh oxidizing and corrosive operating environments $[6,7]$.

Superalloys are a class of metallic alloys specifically designed for elevated temperature applications. Alloying elements and carefully controlled microstructures give the superalloys proper characteristics to be used for high temperature purposes. One of the definitions of the superalloy is "an alloy developed, usually based on group VIIIA elements, for elevated-temperature service where relatively severe mechanical stressing is encountered, and where high surface stability is frequently required" [6]. In light of this definition, ceramics, although having high temperature stability, are not considered as superalloys due to lack of mechanical tensile strength; refractory metal alloys, such as Mo alloys and W alloys, on the other hand, are often considered as superalloys. As shown in Figure 3, despite having high melting temperature and ability to maintain their mechanical properties at high temperatures, refractory metal alloys have poor oxidation resistance [8]. 


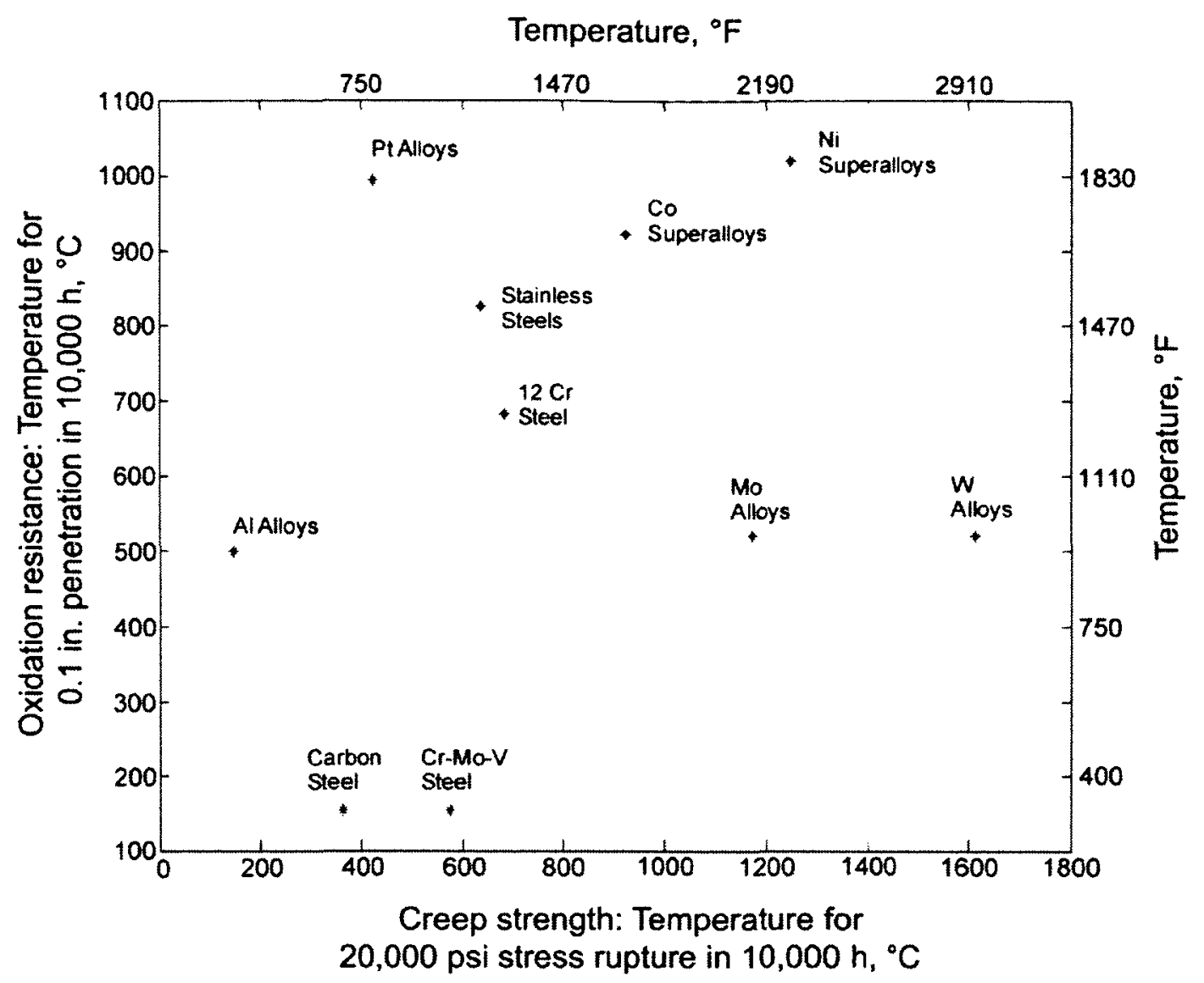

Figure 3: Oxidation resistance and strength for various metallic families [8].

Superalloys used in GTEs, according to their characteristics are used on both stationary parts (e.g. nozzles, blades, guide vanes, seals, etc.) and rotating parts (e.g. discs, shafts, blades, and spacers). Each type of superalloy is chosen based on the working condition of these components to optimize manufacturability, cost, and mechanical, thermal, and environmental properties. These characteristics are directly dependent on the base element of the superalloy and its constituent alloying elements. Superalloys are classified by their base elements as nickel-based superalloys, cobaltbased superalloys, iron-based superalloys, and developed $\mathrm{Ni}-\mathrm{Co}$ based superalloys [9]. 


\subsection{Ceramics}

In addition to superalloys, ceramics are also possible candidates for hot section applications, because they can withstand extreme temperatures. As alternatives to superalloys, ceramic materials have been considered to be able to offer improved performance of gas turbine engines, extending their life span and reducing fuel consumption. However, materials in modern turbines not only must survive temperatures of more than $1,100^{\circ} \mathrm{C}$ for thousands of hours, but must also tolerate the high mechanical stresses, low and high frequency vibrational loading, chemical interaction with adjacent components, oxidation, corrosion, time and stress-dependent effects such as creep, and cyclic fatigue. Monolithic ceramic materials are not able to withstand these conditions and need to be modified before they are considered for critical structural applications. A variety of ceramic materials, such as oxides, borides, carbides, and cermets, have been evaluated for potential use as turbine components. As a result of this evaluation, it has been found that some ceramics have favorable strength and oxidation resistance, but could not survive the thermal shock conditions imposed by turbine engines. Others such as cermets can survive thermal shock and impact conditions but do not have adequate oxidation resistance and stress rupture life [4].

In addition to high temperature and loading concerns, materials for modern turbine applications also have to meet the ever-growing commercial pressures for lower component costs, life-cycle costs, and maintenance costs. In addition, fuel efficiency and emissions are also key commercial and environmental factors that push the development of newer high temperature turbine-engine materials. To meet these demands, a combination of high temperature metallic alloys in combination with ceramics, as 
ceramic-matrix composite (CMC) materials, may offer an efficient compromise between performance requirements and life cycles. As the combination of the properties of the constituents in CMCs may lead to higher metallurgical and mechanical stability at severe turbines operating conditions, the current thesis research was undertaken to manufacture and test two $\mathrm{CMC}$ materials.

To compare the properties of CMC materials to the individual constituents within the $\mathrm{CMC}$ for high temperature applications, the following sections briefly describe the common types of superalloys and ceramics, and compare them to CMCs as constituent parts of the CMCs. 


\section{Literature Review}

\subsection{Gas Turbine High Temperature Materials}

\subsubsection{Nickel-based Polycrystalline and Single Crystal Alloys}

Nickel-based superalloys, as polycrystalline or single crystal alloys, are resistant to loading under static, fatigue, and creep conditions at temperatures higher than $800^{\circ} \mathrm{C}$. Nickel-based superalloys currently are the most complex and widely used superalloys in hottest parts of the GTEs for jet propulsion and electricity generation [9]. These superalloys have been improved over the decades because of the need for GTE materials that can withstand increasing operating temperatures and stresses. In the following sections these superalloys will be described.

\subsubsection{Ni-base Polycrystalline}

Initially, superalloys were made with a nickel base metal and sufficient chromium addition for oxidation resistance. Then came the addition of small amounts of aluminum, titanium, and/or niobium to improve the strength of the alloy by producing coherent stable intermetallic compounds, such as $\gamma^{\prime}\left[\mathrm{Ni}_{3}(\mathrm{Al}, \mathrm{Ti})\right]$ and $\gamma^{\prime \prime}\left[\mathrm{Ni}_{3}(\mathrm{Nb}, \mathrm{Al}, \mathrm{Ti})\right]$ phases, in the matrix [10].

Nickel-based superalloys developed for GTE applications contain about 10 to 13 alloying elements. Adding these elements result in the formation of different phases in Ni-based alloys for specific purposes [9]. In Table 1, alloying elements added to Ni-based superalloys and their effects are summarized. These elements are commonly used in nickel-based superalloys to improve the mechanical and thermal properties of the alloys. 
Table 1: Effects of major alloying elements in nickel-based superalloys [5].

\begin{tabular}{lllll}
\hline Elements & $\begin{array}{l}\text { Matrix } \\
\text { strengthening }\end{array}$ & $\begin{array}{l}\text { Increase in } \gamma^{\prime} \\
\text { volume fraction }\end{array}$ & $\begin{array}{l}\text { Grain } \\
\text { boundaries }\end{array}$ & Other effects \\
\hline $\mathrm{Cr}$ & Moderate & Moderate & $\begin{array}{l}\mathrm{M}_{23} \mathrm{C}_{6} \text { and } \\
\mathrm{M}_{7} \mathrm{C}_{3}\end{array}$ & $\begin{array}{l}\text { Improves corrosion } \\
\text { resistance; promotes TCP } \\
\text { phases }\end{array}$ \\
\hline $\mathrm{Mo}$ & High & Moderate & $\mathrm{M}_{6} \mathrm{C}$ and MC & Increases density \\
\hline $\mathrm{W}$ & High & Moderate & & $\begin{array}{l}\text { Promotes TCP phases such } \\
\text { as } \sigma \text { and } \mu \text { (Mo, } \mathrm{W})\end{array}$ \\
\hline $\mathrm{Ta}$ & High & Large & & \\
\hline $\mathrm{Nb}$ & High & Large & $\mathrm{NbC}$ & Promotes $\gamma^{\prime}$ and $\delta$ phases \\
\hline $\mathrm{Ti}$ & Moderate & Very large & $\mathrm{TiC}$ & \\
\hline $\mathrm{Al}$ & Moderate & Very large & & $\begin{array}{l}\text { Improves oxidation } \\
\text { resistance }\end{array}$ \\
\hline $\mathrm{Fe}$ & & $\beta, \eta, \gamma^{\prime}, \gamma^{\prime \prime}$ or $\delta$ & & $\begin{array}{l}\text { Decreases oxidation } \\
\text { resistance; promotes TCP } \\
\text { phases } \sigma, \text { Laves }\end{array}$ \\
& & & $\begin{array}{l}\text { Raises solidus; may raise or } \\
\text { lower solvus }\end{array}$ \\
\hline $\mathrm{Co}$ & Slight & $\begin{array}{l}\text { Moderate in } \\
\text { some alloys }\end{array}$ & & $\begin{array}{l}\text { Retards coarsening; increases } \\
\text { misfit }\end{array}$ \\
\hline $\mathrm{Re}$ & Moderate & & & \\
\hline $\mathrm{C}$ & Moderate & & Carbides & \\
\hline
\end{tabular}

Thermodynamic driving forces typically result in a preferential partitioning of individual alloying elements to either $\gamma$ or $\gamma^{\prime}$ phase. The atomic diameters of the $\gamma$ formers are about $3-13 \%$ different from that of $\mathrm{Ni}$. These elements are from Group V, VI, and VII. Some of these elements such as $\mathrm{Cr}, \mathrm{Mo}, \mathrm{W}$ and Fe preferentially partition to the matrix gamma phase [11]. In Ni-Al-Cr ternary phase diagram, $\mathrm{NiAl}_{3}$ and $\mathrm{Ni}_{2} \mathrm{Al}_{3}$ phases form during solidification at temperatures higher than $900^{\circ} \mathrm{C}$ and $\mathrm{NiAl}_{3}$ can precipitate as stable phase at temperature lower than $900^{\circ} \mathrm{C} . \mathrm{Ni}_{2} \mathrm{Al}_{3}$, which is often formed at the interfaces, can dissolve about 4 at $\% \mathrm{Cr}$ at $1000^{\circ} \mathrm{C}$. During cooling, the dissolved $\mathrm{Cr}$ will be ejected from $\mathrm{Ni}_{2} \mathrm{Al}_{3}$ phase, forming $\mathrm{AlCr}_{2}$ during solidification. This results in precipitation of $\mathrm{AlCr}_{2}$ coexisting with $\mathrm{NiAl}_{3}$ in $\gamma^{\prime}$ phase [12]. 
Furthermore, carbon shows a high affinity for elements such as $\mathrm{Cr}$ and tends to form primary $\mathrm{MC}$ carbides directly from the liquid during solidification of Ni-based superalloys. Cr from the matrix also can potentially react with the less-stable $\mathrm{TiC}$ and $\mathrm{NbC}$ carbides to form a series of $\mathrm{M}_{23} \mathrm{C}_{6}, \mathrm{M}_{6} \mathrm{C}$, and $\mathrm{M}_{7} \mathrm{C}_{3}$ carbides. With the depletion of $\mathrm{Cr}$ from the matrix surrounding the carbides, $\gamma^{\prime}$ may form at the carbide interfaces [13].

\section{Gamma Matrix $(\gamma-N i)$}

The gamma matrix $(\gamma)$ is an austenitic, continuous solid solution phase with a face centered cubic (FCC) structure that contains a high percentage of elements such as cobalt, chromium, molybdenum and tungsten. The atomic diameters of these elements differ from nickel by $1-13 \%$ leading to lattice expansion, thereby hardening the alloys. The gamma phase in most of the nickel alloys contains $10-20 \mathrm{wt}$. $\%$ chromium, up to about 8 wt. \% aluminum and titanium, 5-10 wt. \% cobalt and small amounts of boron, zirconium, and carbon. Other common solid solution strengthening additions include molybdenum, tungsten, columbium, tantalum, and hafnium.

\section{Gamma prime $\left(\gamma^{\prime}-\mathrm{Ni}_{3} \mathrm{Al}\right)$}

Nickel-based superalloys can also be strengthened by intermetallic compounds precipitated in the austenitic gamma FCC matrix. One of the strengthening precipitates for nickel-based alloys, containing elements such as aluminum and titanium, is $\gamma^{\prime}-\mathrm{Ni}_{3} \mathrm{Al}$. This phase has the FCC structure and is coherent with the matrix. Coherency along with the chemical compatibility allows the $\gamma^{\prime}$ to precipitate homogeneously throughout the matrix and have long-time stability [14]. 
Figure 4 shows the precipitation of $\gamma^{\prime}$ in Ni-Al-Ti ternary phase diagram throughout the $\gamma$ matrix in two ranges of composition at two temperatures, $700^{\circ} \mathrm{C}(973 \mathrm{~K})$ and $\left(1300^{\circ} \mathrm{C}\right) 1573 \mathrm{~K}$. For an alloy with given chemical composition, the fraction of $\gamma^{\prime}$ decreases as temperature increases. This phenomenon is used to dissolve the $\gamma^{\prime}$ at a sufficiently high temperature (a solution treatment) followed by ageing at a lower temperature to generate a uniform and fine dispersion of strengthening precipitates [15]. As shown in ternary phase diagram, the range of composition for $\gamma+\gamma^{\prime}$ is larger at lower temperature $\left(700^{\circ} \mathrm{C}\right)$ than at higher temperatures $\left(1300^{\circ} \mathrm{C}\right)$.
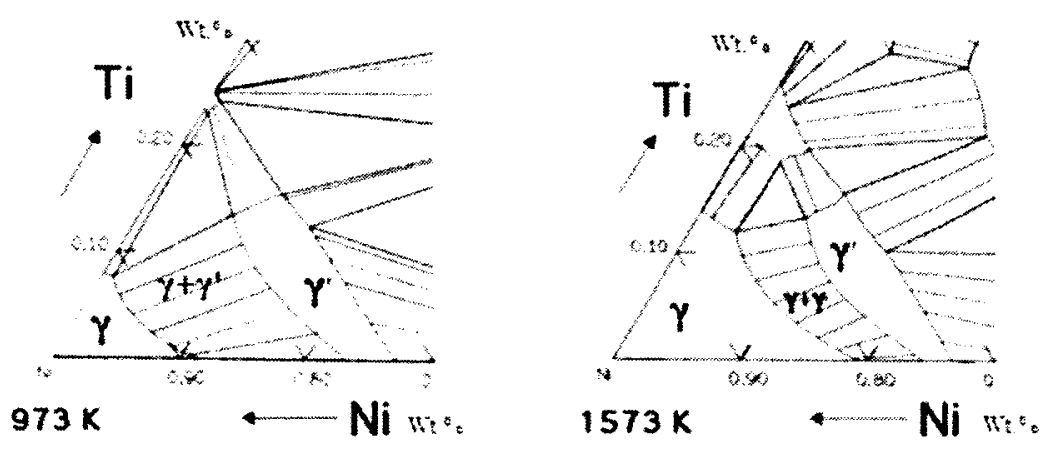

Figure 4: The Ni-Al-Ti ternary phase diagram showing $\gamma$ and $\gamma^{\prime}$ phase field at $700^{\circ} \mathrm{C}$ $(973 \mathrm{~K})$ and $1300^{\circ} \mathrm{C}(1573 \mathrm{~K})[15]$.

Yield strength of alloys hardened by $\gamma^{\prime}$ also increases with increasing volume fraction of $\gamma^{\prime}$ as temperature rises up to about $650^{\circ} \mathrm{C}$. In addition, $\gamma^{\prime}$ is quite ductile and thus imparts strength to the matrix without lowering the fracture toughness of the alloy. In some modern alloys the volume fraction of the precipitated $\gamma^{\prime}$ is around $70 \%$.

Among several $\gamma^{\prime}$ former elements, aluminum is important as it also forms a protective oxide layer on the substrate [9].

The lattice structures of several $\mathrm{Ni}_{3} \mathrm{X}$ phases are shown in Figure 5 to demonstrate the difference between strengthening effect of different alloying elements, and the 
differences between the atomic spacing in these $\mathrm{Ni}_{3} \mathrm{X}$ phases are summarized in Table 2 $[5]$.
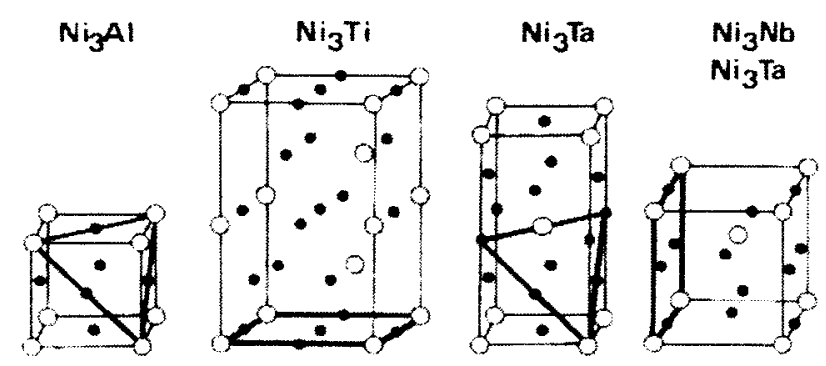

Figure 5: The crystal lattices and close-packed plane in common $\mathrm{Ni}_{3} \mathrm{X}$ structure [5].

Table 2: Atomic and plane spacing in $\mathrm{Ni}_{3} \mathrm{Al}, \mathrm{Ni}_{3} \mathrm{Ti}, \mathrm{Ni}_{3} \mathrm{Ta}$, and $\mathrm{Ni}_{3} \mathrm{Nb}$ as common $\mathrm{Ni}_{3} \mathrm{X}$ phases [5].

\begin{tabular}{lllll}
\hline $\mathrm{Ni}_{3} \mathrm{X}$ phases & $\mathrm{Ni}_{3} \mathrm{Al}$ & $\mathrm{Ni}_{3} \mathrm{Ti}$ & $\mathrm{Ni}_{3} \mathrm{Ta}$ & $\mathrm{Ni}_{3} \mathrm{Nb}$ \\
\hline $\begin{array}{l}\text { Distance between dense planes } \\
(\mathrm{nm})\end{array}$ & 0.2059 & 0.2069 & 0.2124 & 0.2126 \\
\hline $\begin{array}{l}\text { Distance between X atoms } \\
(\mathrm{nm})\end{array}$ & 0.5044 & 0.5093 & 0.5117 & 0.5106 \\
\hline
\end{tabular}

\section{Carbides and other compounds}

Nickel-based solid solution superalloys may obtain additional strengthening from carbide and/or intermetallic compound precipitation at lower temperatures $[5,16]$, but these precipitates exist in small volume fractions. Examples of this class are Hastelloy X and IN-625. In nickel-based alloys, carbides preferably form along grain boundaries, while in cobalt and iron superalloys they prefer intragranular sites. The common forms of carbides in nickel-based alloys are $\mathrm{MC}, \mathrm{M}_{23} \mathrm{C}_{6}$ (Figure 6 a) and $\mathrm{M}_{6} \mathrm{C}$ (Figure $6 \mathrm{~b}$ ). $\mathrm{MC}$ carbides are formed during solidification and distributed heterogeneously throughout the 
microstructure. These carbides have FCC structure and are very strong [9]. M represents reactive and refractory metals, and the carbides assume a formula of $\mathrm{TiC}$ or $\mathrm{TaC}$.

MC carbides are the major source of carbon for the host alloy to be transformed later to $\mathrm{M}_{23} \mathrm{C}_{6}$ and $\mathrm{M}_{6} \mathrm{C}$ carbides during heat treatment or service at temperatures between 760-980 ${ }^{\circ} \mathrm{C}$ [5]. $\mathrm{M}_{23} \mathrm{C}_{6}$ and $\mathrm{M}_{6} \mathrm{C}$ carbides tend to form along grain boundaries, as irregular discontinuous blocky particles; although they also have been observed in plates and regular geometric forms. $\mathrm{M}_{23} \mathrm{C}_{6}$ carbides, formed along the grain boundaries, affect rupture strength of the nickel alloys by obstructing grain boundary sliding. In higher magnitude of load, rupture failure can be initiated either by fracture of these grain boundary $\mathrm{M}_{23} \mathrm{C}_{6}$ particles or by decohesion of the $\mathrm{M}_{23} \mathrm{C}_{6}$ interface [9]. $\mathrm{M}_{6} \mathrm{C}$ can also precipitate in blocky form around grain boundaries, therefore ductility and rupture life of the alloys can be enhanced by reducing the amount of $\mathrm{M}_{23} \mathrm{C}_{6}$ and $\mathrm{M}_{6} \mathrm{C}$ [5].

Because $\mathrm{M}_{23} \mathrm{C}_{6}$ and $\mathrm{M}_{6} \mathrm{C}$ carbides occupy a significantly larger volume along the grain boundaries and are often interconnected, potential degradation of the mechanical properties occurs when $\mathrm{MC}$ carbides undergo phase transformation. Although carbides may serve as crack-initiation sites during fatigue, the presence of discrete carbides at the grain boundaries impedes sliding and damage accumulation during high-temperature creep. In addition, it is often beneficial for grain boundaries that the nickel-based superalloy contains carbides to improve creep strength. However if they precipitate as a continuous grain boundary film, the fracture toughness of the alloy may be reduced together with compromised ductility and rupture strength [13]. 

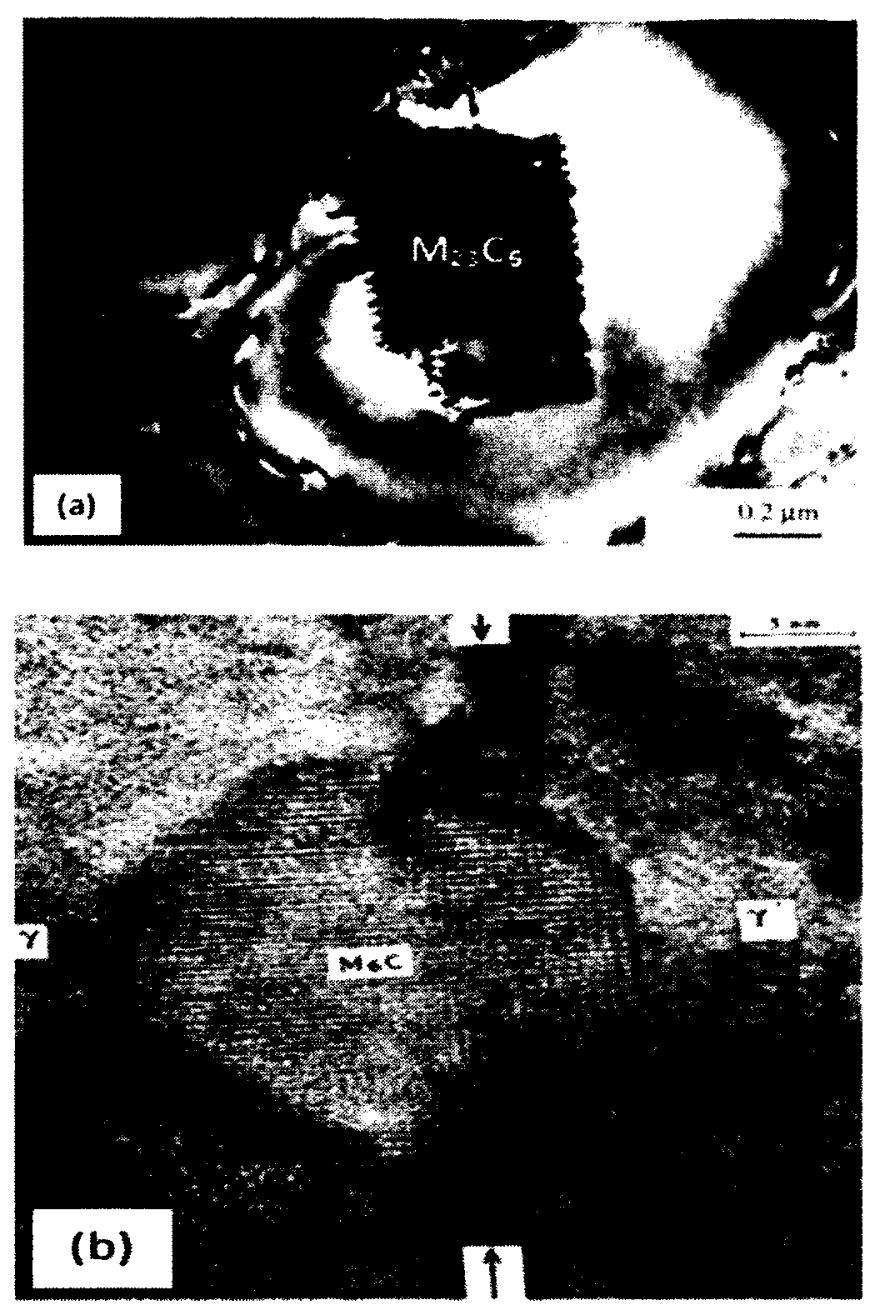

Figure 6: (a) TEM micrograph of an $\mathrm{M}_{23} \mathrm{C}_{6}$ in a $\gamma^{\prime}$ precipitate in $\mathrm{AM} 1$ alloy after creep testing for $100 \mathrm{~h}$ at $1050^{\circ} \mathrm{C}$ and $150 \mathrm{MPa}$, and (b) coherent $\mathrm{M}_{6} \mathrm{C}$ particle at a $\gamma / \gamma^{\prime}$ interface (arrows) in $\mathrm{MC} 2$ alloy [5].

\section{Borides}

Borides are high melting temperatures compounds between boron and less electronegative elements such as $\mathrm{Ni}$ and $\mathrm{Cr}$. Borides tend to segregate to grain boundary regions in superalloys when addition levels are in the range of 50-500 ppm. This blocks the onset of the grain boundary shearing under creep rupture loading [17]. Borides are hard refractory particles at the grain boundaries with shapes varying from blocky to half- 
moon in appearance [9]. Further increase of boron in the alloy composition leads to a drop in rupture life. Two morphologies of borides are shown in Figure 7.
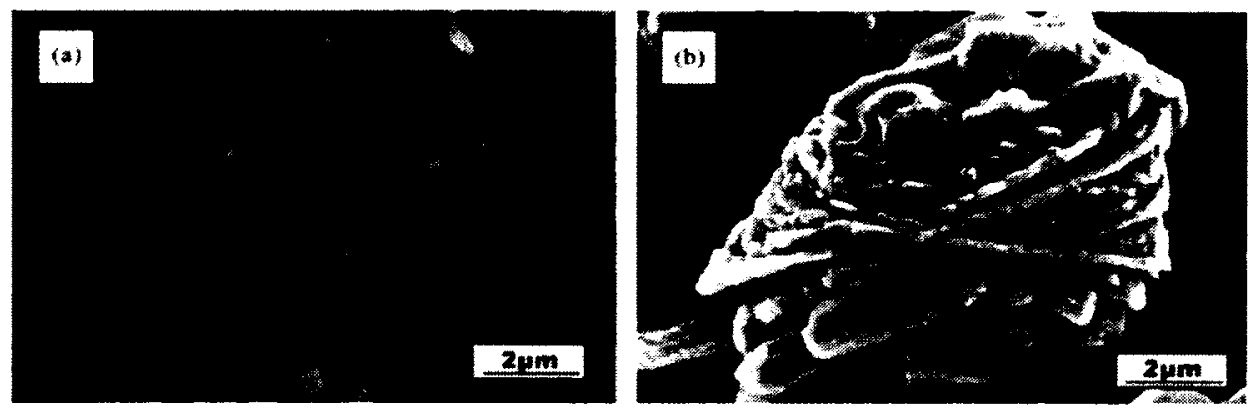

Figure 7: Morphology of extracted minor phases in M951 alloy: (a) small island-like boride on carbide, and (b) eutectic boride [17].

\section{Topologically close packed phases (TCP)}

In certain superalloys, undesirable phases can form either during heat treatment or service; this can shorten the rupture life of the alloys. A class of precipitates belongs to topologically closed pack phases (TCPs) that exist in multiple alloyed systems. The cell structure of these phases has close-packed atoms in layers separated by relatively large interatomic distances. The layers of close packed atoms are displaced from one another by larger atoms, developing a characteristic "topology". Conversely, $\mathrm{Ni}_{3} \mathrm{Al}$ with gamma prime structure is closed-packed in all directions and is therefore called geometrically close-packed (GCP) [11].

Three families of TCP phases can be distinguished. First type is the plate-like sigma $(\sigma)$ phases, which appear as needles on a single-plane microstructure, (see Figure 8) with an hexagonal symmetry such as $\mathrm{Cr}_{46} \mathrm{Fe}_{54}$ or $\mathrm{Ni}_{8}(\mathrm{Cr}, \mathrm{Mo})_{4}(\mathrm{Cr}, \mathrm{Mo}, \mathrm{Ni})_{18}$. Its high hardness and plate-like morphology are sources for crack initiation and propagation, 
leading to low-temperature brittle failure. A second family of TCP phases includes $\mu$ phase (such as $\mathrm{Co}_{7} \mathrm{Mo}_{6}$ ) and Laves with the general formula of $\mathrm{Ni}_{2} \mathrm{X}$, where $\mathrm{X}$ atoms are heavy elements. The $\mu$ phase can occur with different morphologies even in the same specimen. Figure 9 shows large plates, needles and small nodules of $\mu$ phase in MC2 alloy. The third family includes phases such as $\mathrm{P}$ (such as $\mathrm{Mo}_{42} \mathrm{Cr}_{18} \mathrm{Ni}_{40}$ ), $\delta$ (such as NiMo), and $\mathrm{R}$ (such as $\mathrm{Mo}_{31} \mathrm{Cr}_{18} \mathrm{Co}_{50}$ ) [5]. These phases form under specific conditions and can result in lowered rupture strength and ductility [9]. TCPs are potentially damaging for two reasons: they tie up $\gamma$ and $\gamma^{\prime}$ strengthening elements, thus reducing creep strength, and they can act as crack initiators because of their brittle nature [11].

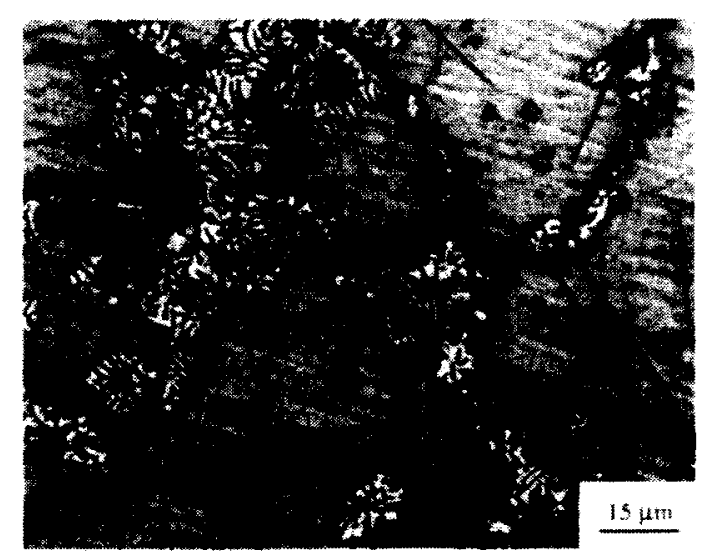

Figure 8: TEM micrograph of a Ni-20.7Cr-17Co-0.63Mo-4.75Ti-10Al alloy (at. \%) heat treated at $1180^{\circ} \mathrm{C} \mathrm{AC}+64 \mathrm{~h} 900^{\circ} \mathrm{C} \mathrm{AC}$, showing $\sigma$ phase plates within the grains and cellular $\sigma / \gamma^{\prime}$ colonies at the grain boundaries ( $\sigma$ is the dark phase) [5]. 

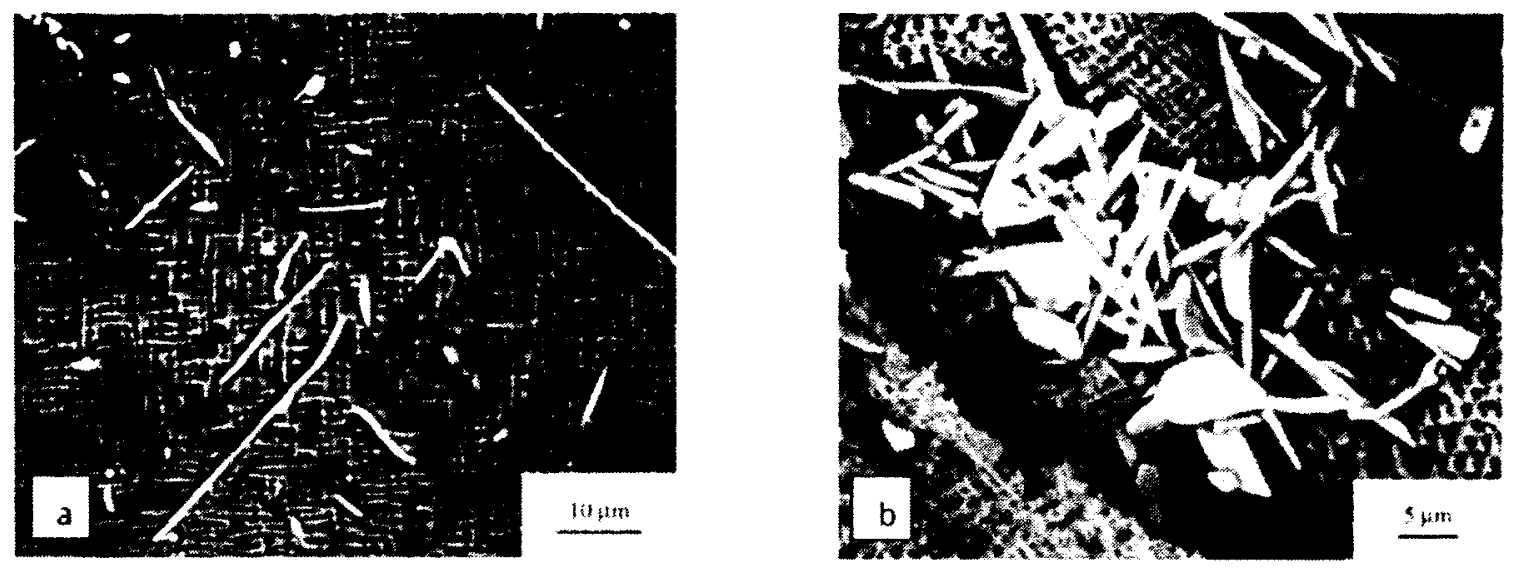

Figure 9: TEM micrograph of different morphology of $\mu$ phase within the $\gamma / \gamma^{\prime}$ matrix: (a) large plates or needles, and (b) small nodules of this phase in MC2 alloy [5].

\subsubsection{Hot Section Materials and Coatings}

Modern gas turbine hot section components are subjected to not only high operating temperatures but also hostile environments. In some superalloys chromium, which is responsible for hot corrosion resistance is reduced to accommodate a higher concentration of strengthening alloying elements such as aluminum, titanium, tantalum or niobium in the matrix. Therefore, these higher strength superalloys are not as well-suited for high temperature oxidation and hot corrosion conditions required of GTE components. Hot section components are coated with high temperature coatings for both environmental protection and thermal insulation.

\subsubsection{Heat Resistant Coatings}

In Figure 10, the advantages of applying high temperature coatings on superalloys substrates are shown. These coatings have increased the service temperature of the superalloys to higher than $1100^{\circ} \mathrm{C}$. High temperature coatings developed for GTE hot section materials are divided in the following groups: ceramic thermal barrier coatings 
(TBCs), diffusion aluminide and MCrAlY overlay (where $\mathrm{M}$ is $\mathrm{Ni}, \mathrm{Co}, \mathrm{Fe}$ or a combination of them). The first two groups of coatings are widely used for turbine blades and vanes, whereas TBCs are applied mostly to the hottest components, such as combustors and first stage vanes [18].

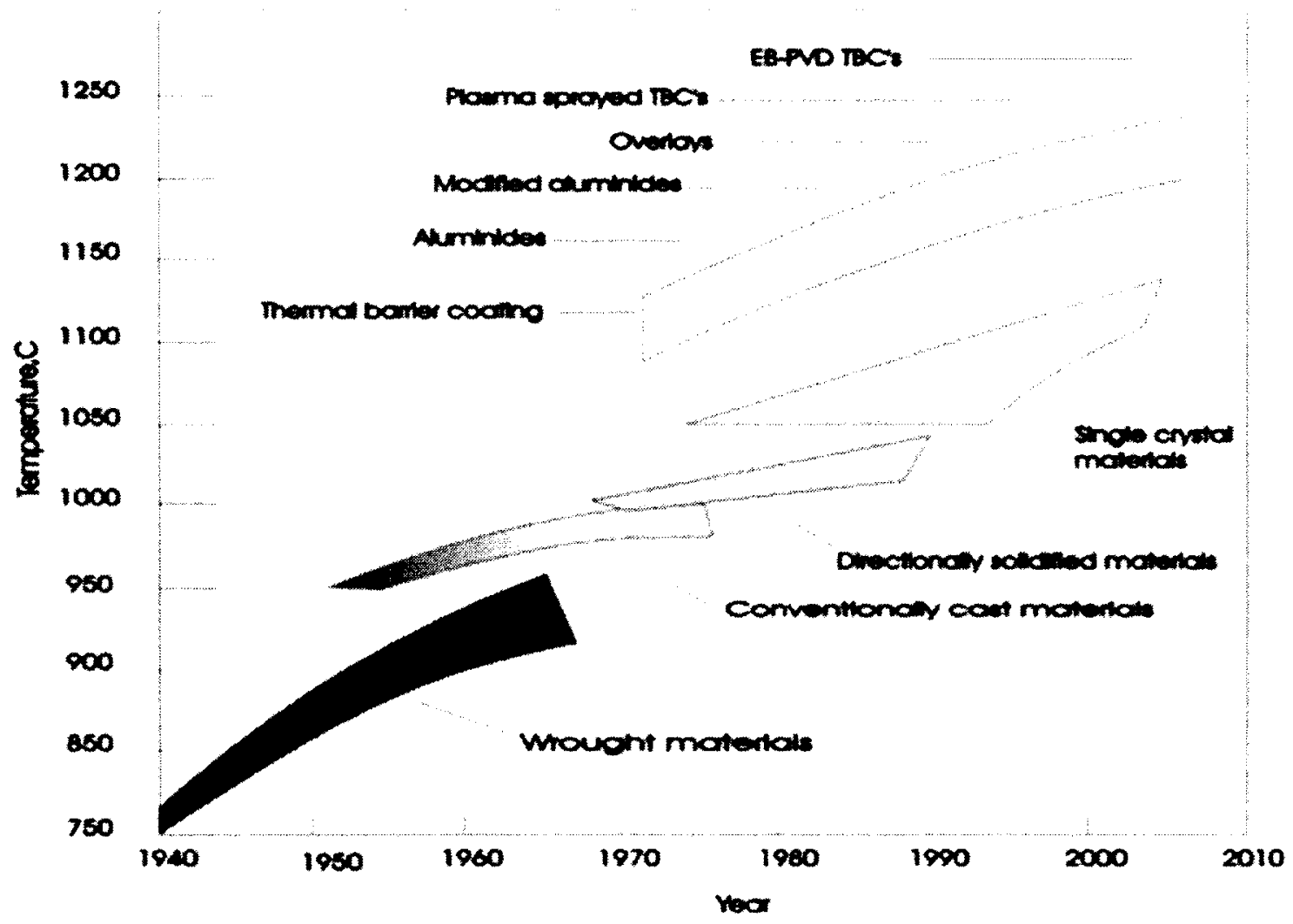

Figure 10: The development of superalloys and heat resistant coatings [19].

Coatings are selected based on oxidation and hot corrosion resistance considerations. However coatings may reduce certain mechanical properties of the substrate materials, such as ductility, tensile, creep rupture and fatigue properties, as shown in Figure 11. The factor that determines whether the strain produced by thermal expansion mismatch and mechanical loads between the coating and substrate can be 
tolerated is the ductile-to-brittle-transition temperature (DBTT) of the coatings [20]. DBTT is determined experimentally and indicates whether the coating-substrate integrity is retained during service condition. Factors affecting DBTT include coating composition and process, coating thickness, superalloy surface finish and strain rate.

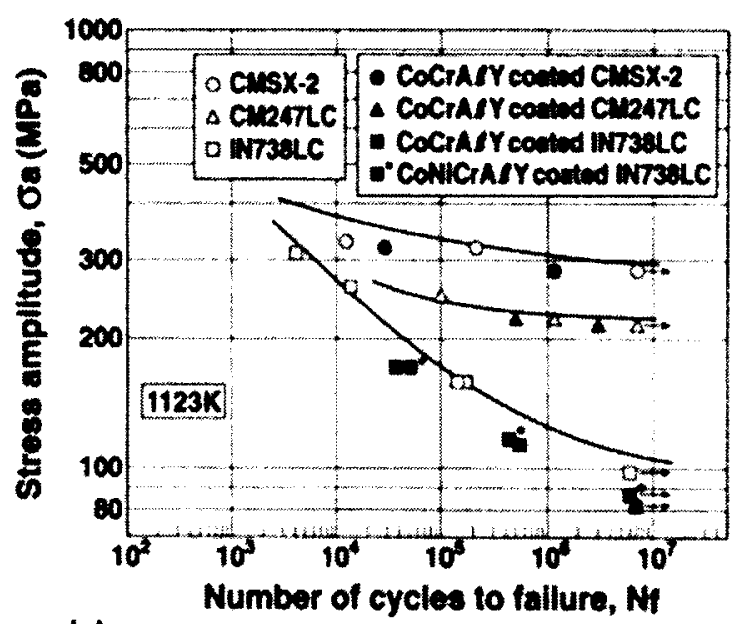

(a)

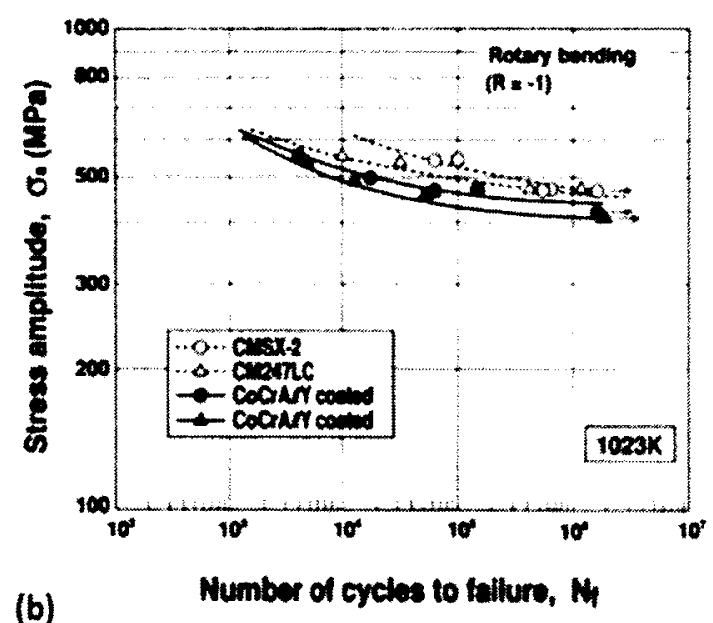

(b)

Figure 11: Effect of MCrAlY coatings on fatigue life of nickel-based superalloys: (a) under push-pull loading, and (b) under rotary bending [20].

Figure 12 shows that MCrAlY overlay coatings have lower DBTT than aluminide coatings. Aluminide coatings are brittle up to about $700^{\circ} \mathrm{C}$ and their DBTT increases as Al concentration in $\mathrm{NiAl}$ increases from 25 to $35 \%$. Also, aluminide coatings on cobaltbase superalloys tend to be more brittle than on nickel-base alloys because the DBTT of cobalt aluminide is generally higher than that of nickel-aluminide (NiAl). The wide range of DBTT of MCrAlY coatings in this figure is due to the flexibility in controlling the chemical composition of the MCrAlY. The effect of coating composition on the ductility of MCrAlY is shown in Figure 13. NiCrAlY coatings have higher ductility than CoCrAlY coatings, hence lower DBTT [18]. NiAl coatings are brittle up to about $700^{\circ} \mathrm{C}$, 
but their DBTT increases with aluminum content. Also shown in the Figure 12 is the effect of the aluminum content, from $25 \%$ to $35 \%$, on DBTT of the coatings.

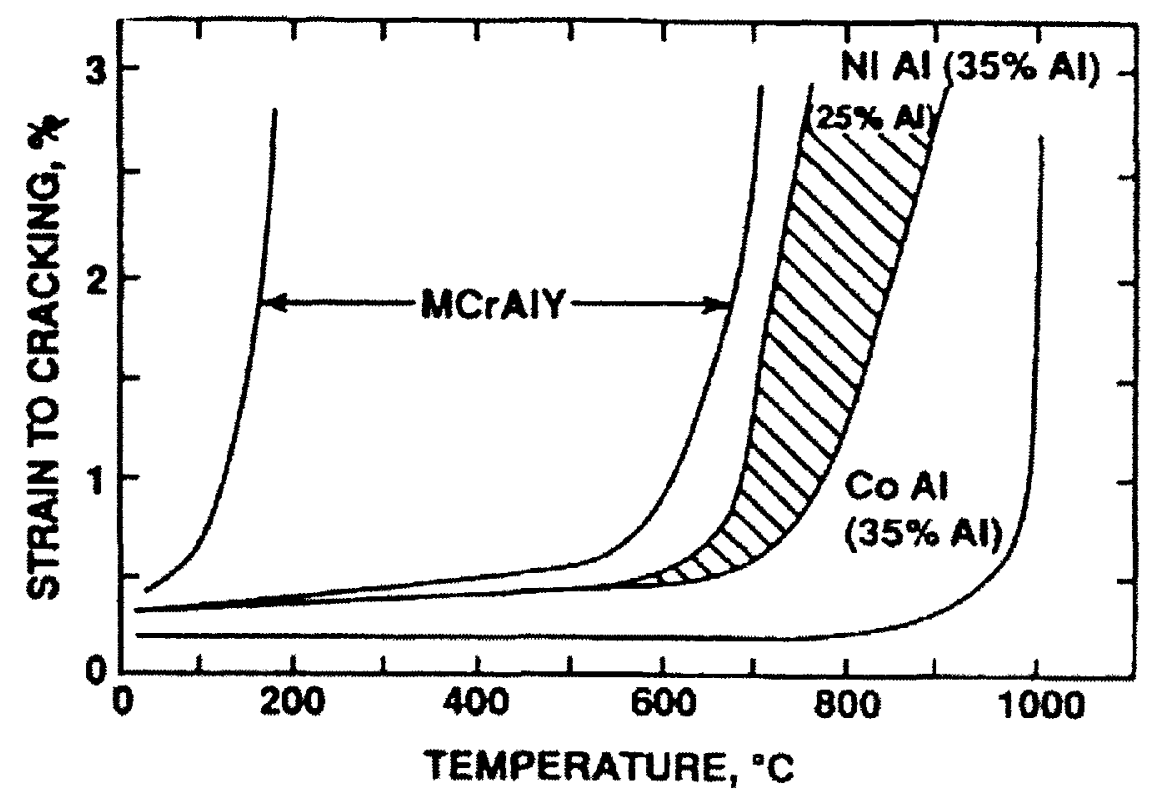

Figure 12: Comparison between DBTT (horizontal axis) of aluminide and MCrAlY coatings. An increase of Al concentration in NiAl from 25 to $35 \mathrm{wt} \%$ increases the DBTT of the NiAl coating [18].

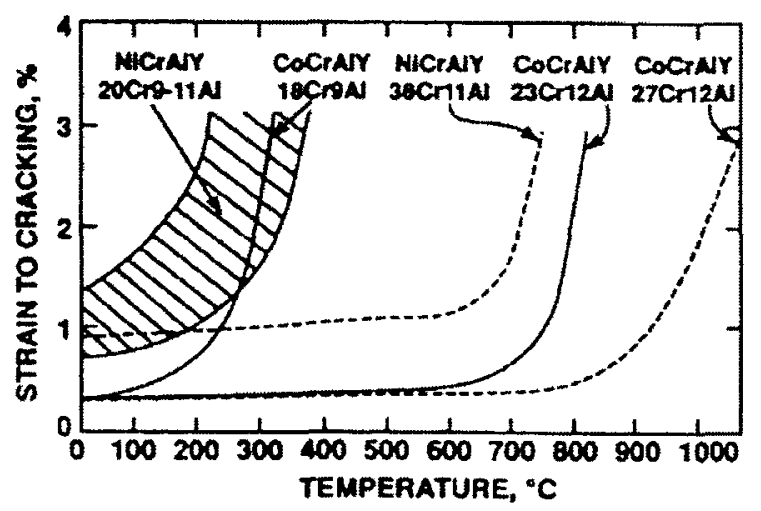

Figure 13: Effect of chemical composition on the DBTT (horizontal axis) of the CrAlY coatings [18].

Experiments also showed that aluminide coatings (NiAl, $\mathrm{CrAl}, \mathrm{SiAl}, \mathrm{PtCrAl})$ and plasma sprayed NiCoCrAlY coating on Ni-based superalloys, such as in IN738LC and 
FSX 414, lower the fatigue strength of the coated specimens. However, there was no direct effect of coating on the tensile properties of the substrate material; the lower fatigue strength was associated with the thermal cycles in inducing surface cracks [18].

\subsubsection{Thermal Barrier Coatings (TBC)}

The most commonly used TBC is $\mathrm{ZrO}_{2}$ doped with 6-8 wt.\% $\mathrm{Y}_{2} \mathrm{O}_{3}$ [21], typically $7 \mathrm{YSZ}$ (yttria stabilized zirconia) with 7 wt. $\% \mathrm{Y}_{2} \mathrm{O}_{3}$ in $\mathrm{ZrO}_{2}$ [22]. This material has a low thermal conductivity $\left(\sim 1 \mathrm{~W} / \mathrm{m}^{2} \mathrm{~K}\right)$, high thermal fatigue resistance (Figure 14) and is applied on top of a MCrAlY or aluminide bond coating [23].

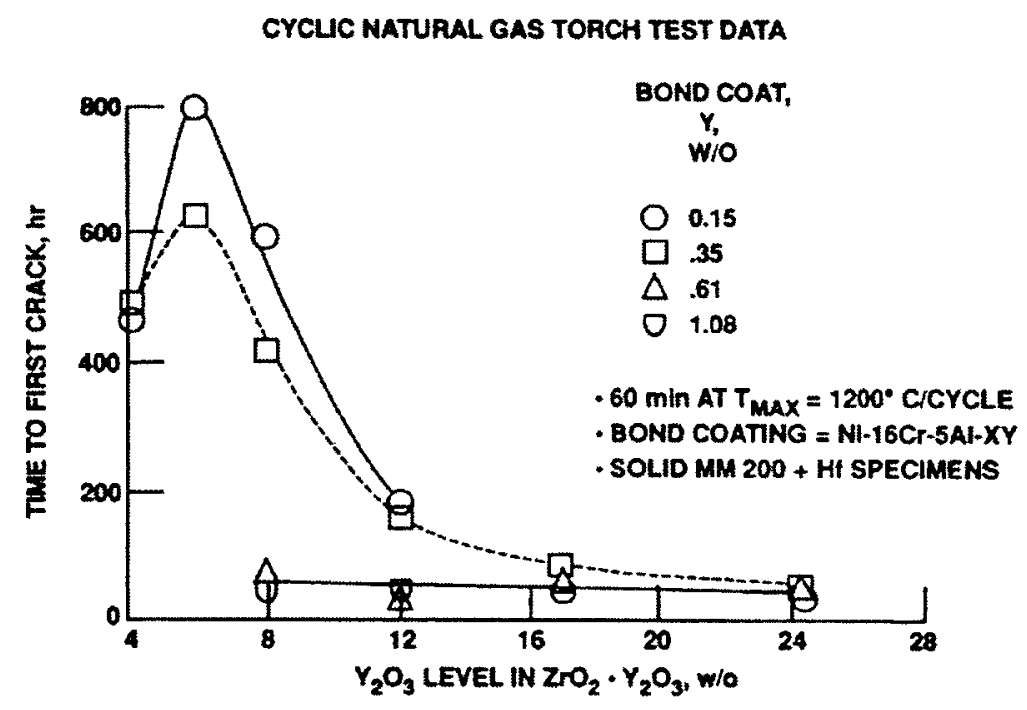

Figure 14: Effect of $\mathrm{Y}_{2} \mathrm{O}_{3}$ level in ceramic and bond coat on thermal fatigue resistance [18].

As seen in Figure 15, an YSZ coating reduces the temperature of underlying superalloy exposed to high temperature by hundreds of degrees Celsius. However, TBC's lifetime is limited by spallation $[18,24]$ due to thermal expansion mismatch stress, which 
is biaxial in the ceramic layer. Stress is compressive in the plane of the coating and tensile normal to the plane of the coating. TBC coatings also affect mechanical properties, such as thermal fatigue (TF) resistance of the substrate. This effect depends on coating strength, surface finish of the coating for high cycle fatigue resistance, and coating ductility for low cycle fatigue performance. Repeated thermal cycling increases the strains induced by thermal stresses and reduce the TF performance of the TBCs. These strains result in crack initiation and eventually spalling of the coating.

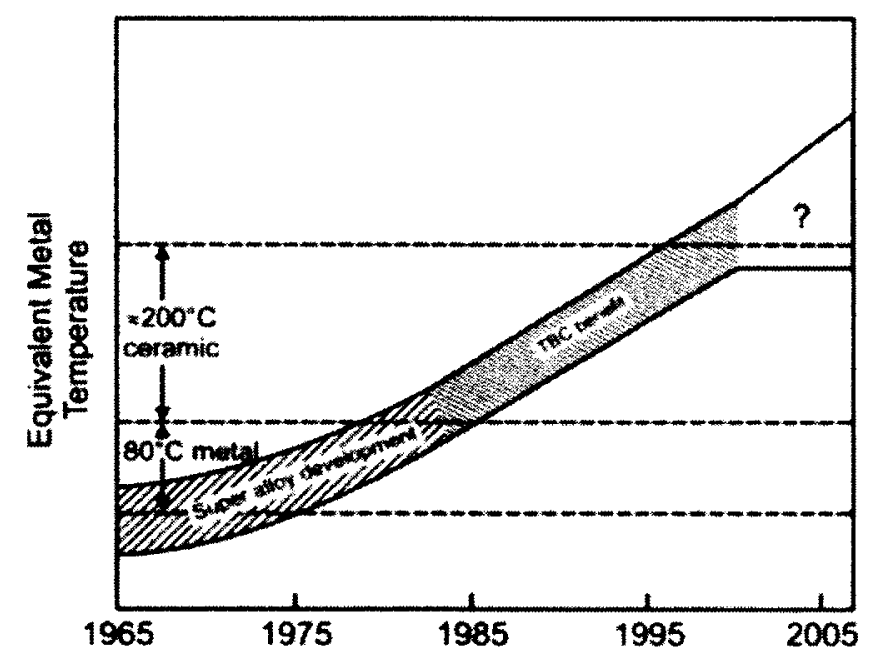

Figure 15: Schematic diagram showing the decrease in substrate metal temperature in gas turbine as a result of superalloy development $\left(\sim 80^{\circ} \mathrm{C}\right)$ and applying thermal barrier coatings $\left(-200^{\circ} \mathrm{C}\right)[25]$.

\subsubsection{Bond Coat}

At high service temperatures oxygen diffusion across the TBC can occur, therefore; a bond coat and a dense oxide layer are needed to protect the substrate from hot oxidation and corrosion. Although chromium oxide (chromia) is known for its protective scale, it evaporates at temperatures higher than $1000^{\circ} \mathrm{C}$ in the form of gaseous $\mathrm{CrO}_{3}$. Therefore, aluminum is a better choice to provide an alumina protective layer, which is 
dense and non-permeable to oxygen. This oxide layer grows during heat treatment or service temperature when oxygen diffuses through the TBC and reaches the aluminum in the bond coat (BC); hence, this layer is referred to as the thermally grown oxide (TGO) layer. However, $\mathrm{TGO}$ in $\mathrm{BC}$ has lower adhesion to the $\mathrm{Ni}$ substrate than chromia and a lower thermal expansion coefficient than the zirconia topcoat, so a thick layer of BC coat causes additional strain at its interface with the topcoat [24]. TBCs composed of $\mathrm{NiCrAlY}$ bond layers and 6-8 wt.\% $\mathrm{Y}_{2} \mathrm{O}_{3}$-stabilized $\mathrm{ZrO}_{2}$ ceramic top layers have been widely used in land-based and aircraft turbines to protect $\mathrm{Ni}$-base superalloys from high temperature and corrosion [26]. A typical three-layer TBC structure is shown in Figure 16.

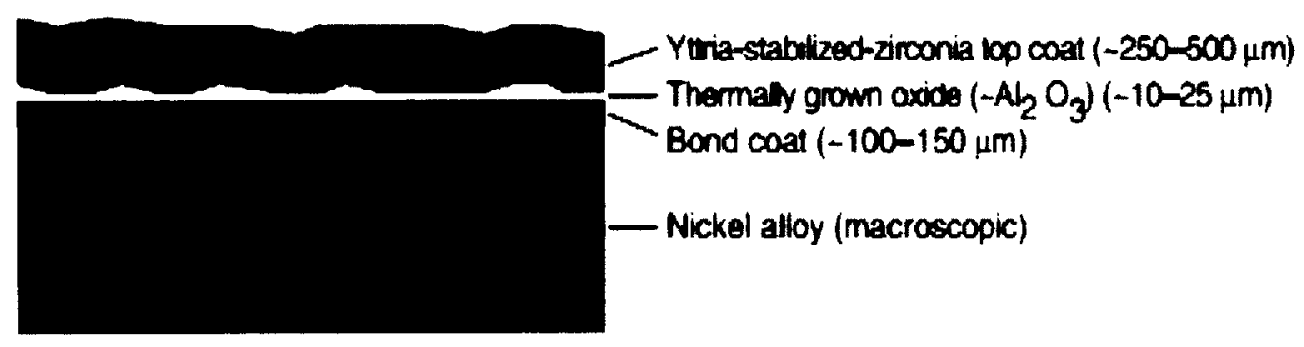

Figure 16: A schematic representation of a TBC's cross section [24].

A benefit of TBC"s is an ability to maintain a higher thermal gradient between the load bearing substrate and the top of the coat. In turbine blades this thermal gradient can only be established with internal air cooling to lower the component temperature (Figure 17). Lower substrate temperature increases lifetime of the component due to improved surface protection. creep rupture, and thermal fatigue. However, the thermal gradient between the component and TBC accelerates the spallation of the TBC. This spallation is 
due to the stresses created by thermal expansion mismatch between the ceramic and the substrate alloy and the environmental attack of the bond coat. Therefore, both beneficial and detrimental effects should be considered in design for greater component durability $[23]$.
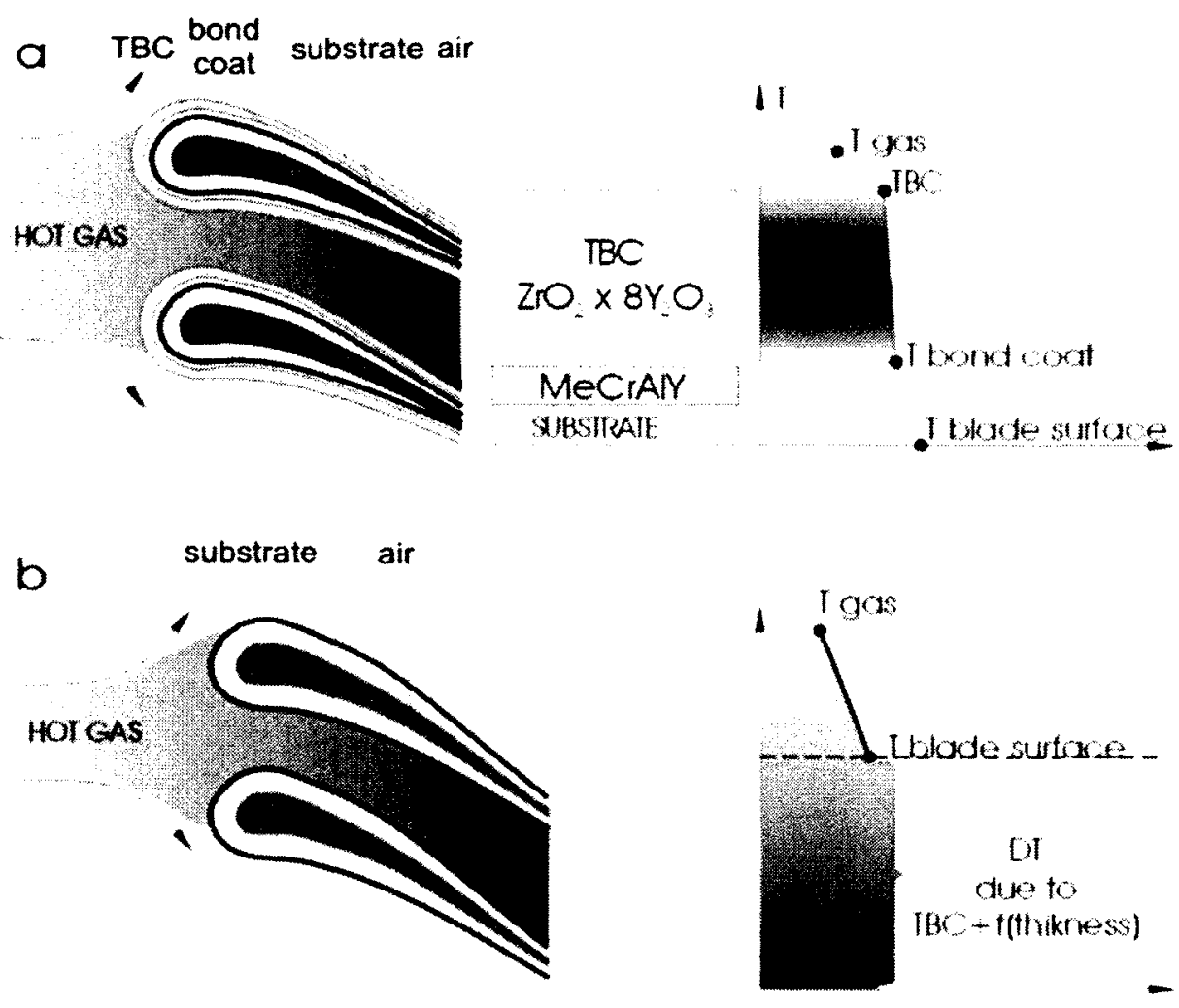

Figure 17: The concept behind the application of TBC on the air cooled turbine blade: (a) the temperature distribution on the TBC coated blade, and (b) the temperature distribution on the uncoated blade [19].

Currently, higher GTE efficiency demands (Figure 18) require the structural materials to be used under even more severe operation conditions. The TIT of GTEs has continued to increase for the improved efficiency. The TIT of the most advanced gas turbines has already exceeded the melting point of the superalloys; air cooling and TBC are essential in these applications $[19,23]$. The trend of alloy development with respect to 
gas turbine TIT is shown in Figure 18. To minimize the gap between required TIT and the material's capability, ceramics are being considered as materials capable of satisfying GTE conditions [27].

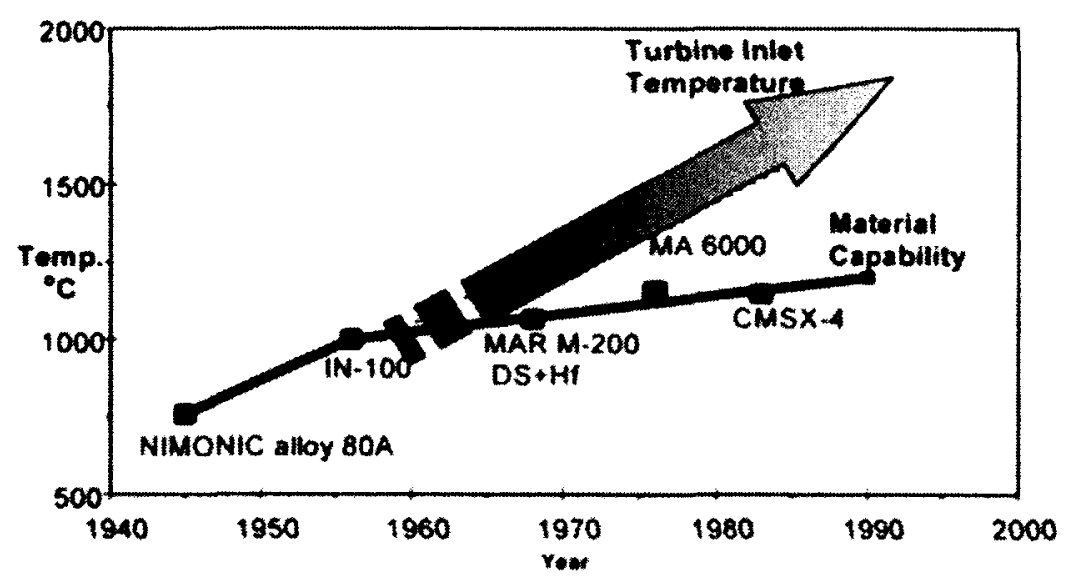

Figure 18: The trend of alloy development as compared to the gas temperature feasibility [19].

\subsubsection{Refractory Metals}

Refractory metals are characterized by having extremely high melting points, which is above those of iron, cobalt, and nickel. These metals are used in applications that require high-temperature strength and corrosion resistance. The most widely used refractory metals are molybdenum, tungsten, tantalum, and columbium (niobium). These metals are mutually soluble and form solid-solution alloys with each other in any proportion. These refractory metals and their alloys are available in mill forms as well as products such as screws, bolts, studs, and tubing [28].

Although the melting points of these metals are all above $2000^{\circ} \mathrm{C}$, they are readily degraded by oxidizing environment at moderately lower temperatures, a property that has restricted their use as high temperature materials. For instance, oxidation for tungsten in 
air occurs at $190^{\circ} \mathrm{C}$, for molybdenum at $395^{\circ} \mathrm{C}$, and for tantalum and columbium at $425^{\circ} \mathrm{C}$. Therefore, protective coatings must be applied to these metals if they are to be used at higher temperatures. Mechanical properties of the refractory metals, tensile and yield strengths as well as Young modulus, are substantially retained at high temperatures [29], (Figure 19 and Figure 20).

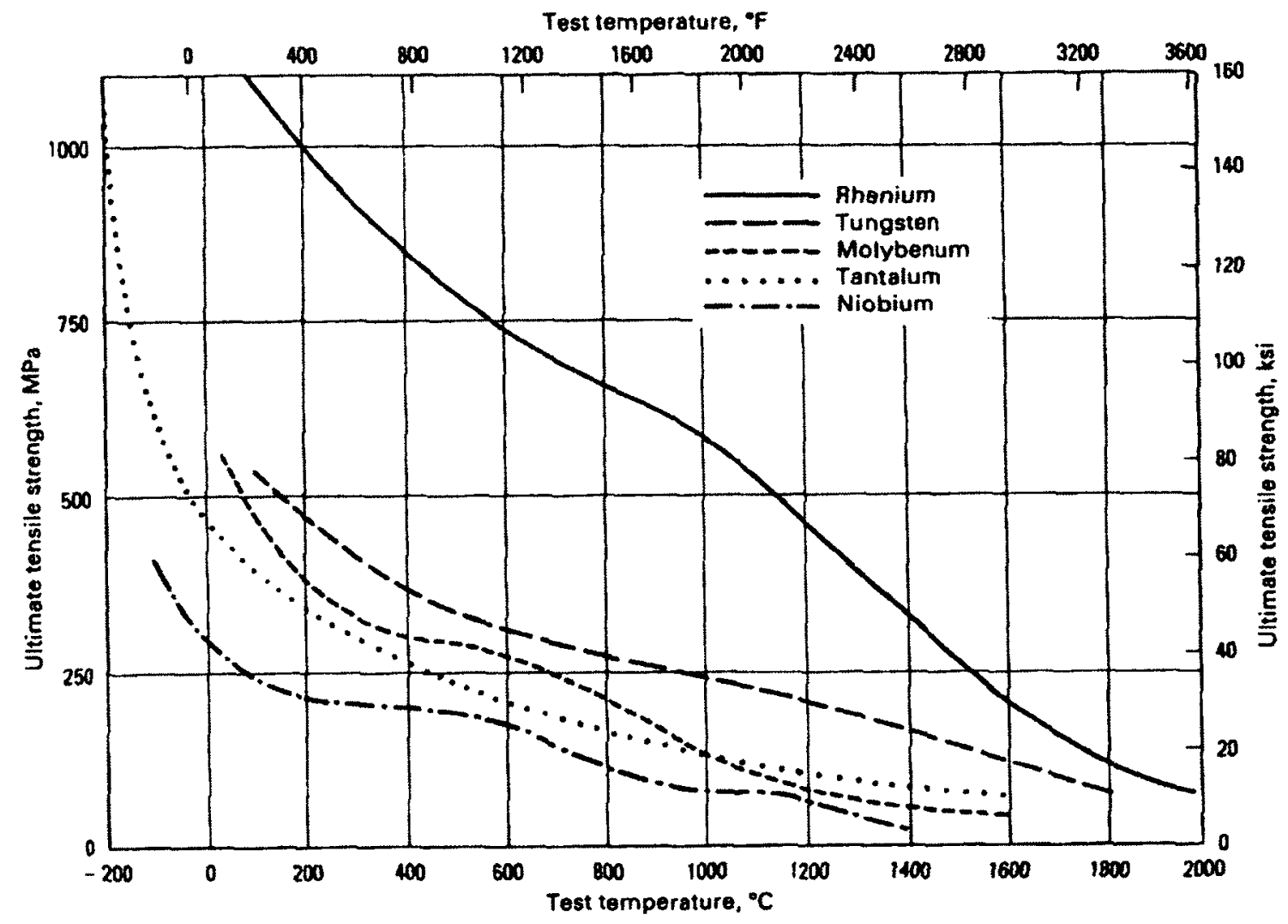

Figure 19: Dependence of ultimate tensile strength of pure refractory metals on temperature [30].

\subsubsection{Molybdenum (Mo)}

Molybdenum is a multipurpose refractory metal, combining a high melting point $\left(2610^{\circ} \mathrm{C}\right)$ with strength retention at high temperatures. It is an excellent structural material for high temperatures where it can operate in vacuum or under inert or reducing 
atmospheres. Molybdenum has a high specific elastic modulus (Figure 20), which makes it attractive for applications that require both high stiffness and low weight. The high thermal conductivity, low coefficient of thermal expansion, and low specific heat of this metal provides resistance to thermal shock and fatigue. In addition molybdenum is stable in a wide variety of chemical environments [28].

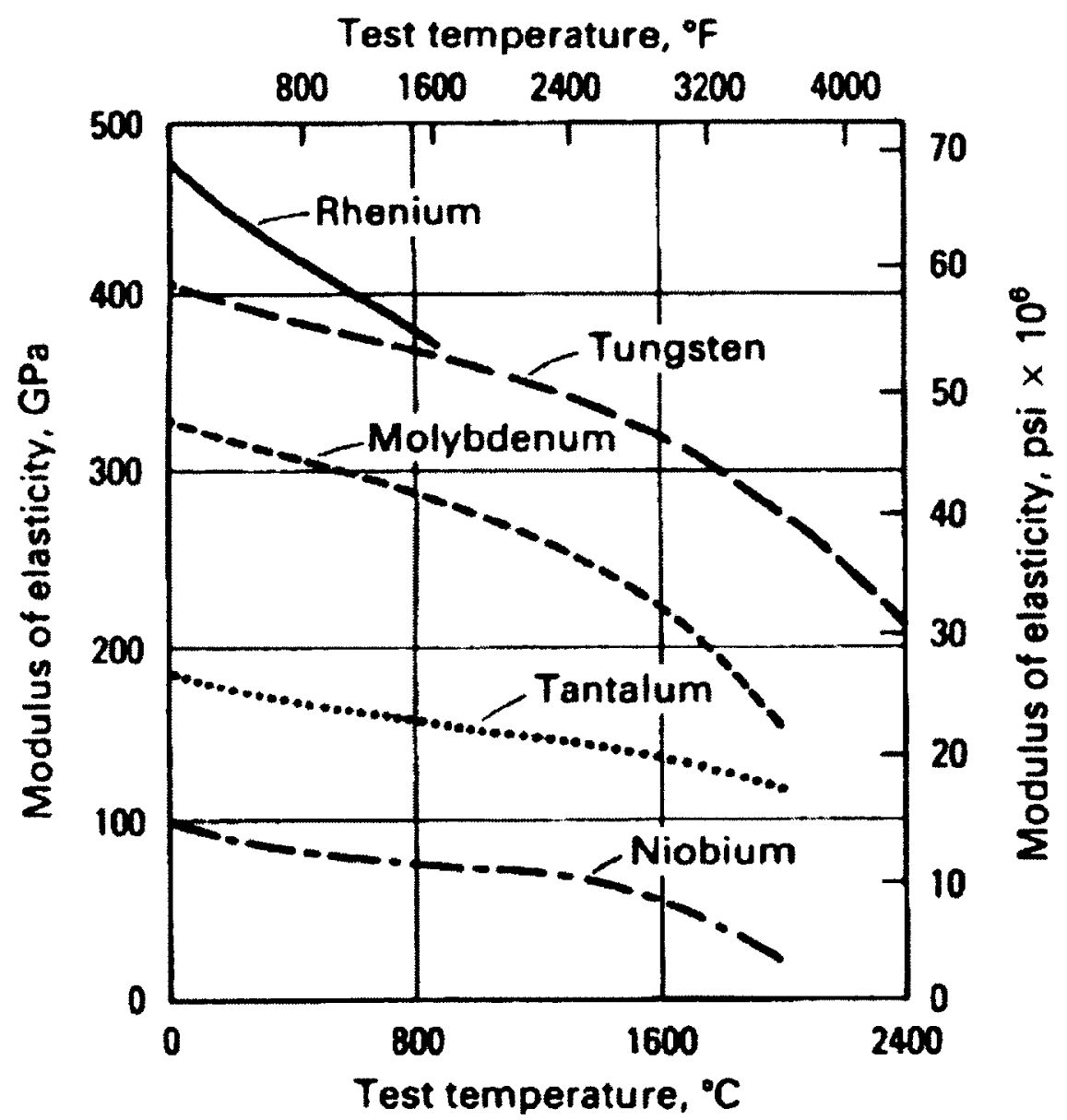

Figure 20: Modulus of elasticity versus test temperature for pure (unalloyed) refractory metals [28].

In nonoxidizing environments, molybdenum resists attack by hydrochloric, hydrofluoric, sulfuric, and phosphoric acids. Molybdenum oxidizes at high temperatures 
to produce volatile, nontoxic, molybdenum trioxide; however, parts such as nozzles have been used successfully in rocket and missile-guidance systems when exposure time to the very high temperatures of ballistic gases was brief [29]. Two oxide forms of molybdenum are $\mathrm{MoO}_{2}$ and $\mathrm{MoO}_{3}$. The Mo trioxide is the stable oxide that melts at $795^{\circ} \mathrm{C}$. Below its melting point, molybdenum trioxide has a perceptible vapor pressure and begins to sublime at about $500^{\circ} \mathrm{C}[31]$.

Molybdenum parts can be welded by inertia, resistance, and spot welding methods in air, by tungsten inert-gas (TIG) and metal inert-gas (MIG) welding under inert atmospheres, and by electron-beam welding in vacuum. The best welds are produced by inertia (friction) welding and electron-beam welding, and welds produced by the other techniques are less ductile. Heavy sections of molybdenum should be preheated and post-heated when they are welded to reduce thermal stresses [32].

Unalloyed molybdenum and its principal alloy, TZM (titanium-zirconiummolybdenum), are produced by powder-metallurgy methods and by vacuum-arc melting. Both materials are commercially available in ordinary mill product forms: forging billets, bars, rods, wire, seamless tubing, plate, strip, and thin foil. TZM is one of the most popular commercial molybdenum-based alloys. Its nominal chemical composition (in wt.\%) is $\mathrm{Mo}-0.5 \mathrm{Ti}-0.08 \mathrm{Zr}-0.03 \mathrm{C}$. $\mathrm{TZM}$ is a carbide strengthened alloy that relies on the formation of fine reactive-metal carbides to dispersion strengthens the material and to increase the recrystallization temperature above that of pure molybdenum by stabilizing the dislocation structure formed during processing. The typical areas of application of TZM include components for heat treatment furnaces, such as hot isostatic pressing, and 
moulds for light-alloy casting. The TZM alloy was developed by Climax Molybdenum, Co., U.S.A., in 1954. [33].

\subsubsection{Columbium (niobium) and tantalum}

These metals have similar working characteristics and are usually considered together. They can be fabricated by most conventional methods at room temperature. Heavy sections for forging can be heated, without protection, to approximately $425^{\circ} \mathrm{C}$. Commercial-grade tantalum alloys containing tungsten, columbium, and molybdenum generally retain the corrosion resistance of tantalum and provide higher mechanical properties. Columbium is also available in alloys containing tantalum, tungsten, molybdenum, vanadium, hafnium, zirconium, or carbon. Alloys provide improved tensile, yield, and creep properties, particularly in the 1,100 to $1,650^{\circ} \mathrm{C}$ range.

Columbium, similar to tantalum, can be welded to other metals by resistance welding and TIG welding and to itself by inert-gas arc welding. Electron-beam welding can also be used, particularly for joining to other metals. However, surfaces that are heated above $315^{\circ} \mathrm{C}$ during welding must be protected with an inert gas to prevent embrittlement [29].

Principal applications for tantalum are in capacitor anodes, filaments, gettering devices, chemical-process equipment, and high-temperature aerospace engine components. Columbium is used in superconducting materials, thin-film substrates, electrical contacts, heat sinks, and as an alloying addition in steels and superalloys [29]. 


\subsubsection{Tungsten}

In many respects, tungsten is similar to molybdenum. The two metals have about the same electrical conductivity and resistivity, coefficient of thermal expansion, and about the same resistance to corrosion by mineral acids. Both have high strength at temperatures above $1100^{\circ} \mathrm{C}$, but because the melting point of tungsten is higher, it retains significant strength at higher temperatures more than molybdenum. The elastic modulus for tungsten is about $25 \%$ higher than that of molybdenum, and its density is almost twice that of molybdenum. All commercial unalloyed tungsten is produced by powdermetallurgy methods; it is available as rod, wire, plate, sheet, and some forged shapes. For some special applications, vacuum-arc-melted tungsten can be produced, but it is expensive and limited to relatively small sections [29].

Nozzle throats of forged and machined unalloyed tungsten have been used in solid-fuel rocket engines. Unalloyed tungsten is used for filaments in vacuum-metallizing furnaces and for electrical contacts such as the distributor points in automotive ignition systems. Tungsten electrodes form the basis for TIG welding. Water-cooled tungsten tips are used for nonconsumable electrode vacuum-arc melting of alloys.

Cutting tools and parts that must resist severe abrasion are often made of tungsten carbide. Tungsten-carbide chips or inserts, with the cutting edges ground, are attached to the bodies of steel tools by brazing or by screws. The higher cutting speeds and longer tool life made feasible by the use of tungsten-carbide tools are such that the inserts are discarded after one use [29, 34]. 


\subsubsection{Ceramics}

\subsubsection{Structure and Properties of Ceramics}

The oxidation corrosion resistance ceramics attain these exceptional properties, because their crystal structure is associated with "mixed" bonding that is a combination of covalent, ionic, and sometimes metallic bonds. The majority of ceramics are compounds of metals (or metalloids) and nonmetals forming oxides, nitrides, and carbides [35]. Ceramics are being considered as an alternative for metals to be used in GTE hot sections because they can carry large compressive loads and are resistant to many harsh chemical and thermal environments. For instance, they are widely used in chemistry laboratories in contact with corrosive chemicals at high temperatures, and also they are used for compressive load-bearing applications. In the case of pure ceramics, it is necessary to ensure that the stress distributions in the ceramic are compressive, because they have low toughness. Unlike that in the metals, a stress concentration at a crack tip in a crystalline ceramic cannot be relieved by plastic deformation, and their low fracture toughness is the biggest drawback of the ceramics [36]. To improve their mechanical properties, ceramics are reinforced to improve toughness and are used as matrix in CMC composites.

\subsubsection{Engineering Ceramics}

Advanced ceramics are also referred to as engineering ceramics. They exhibit superior mechanical properties and corrosion/oxidation resistance than traditional ceramics. While traditional clay-based ceramics have been used for over 25,000 years, advanced ceramics have been developed within the last 100 years. The advanced 
ceramics show high resistance to heat, chemicals and wear; however, these characteristics make them hard to fabricate in a simple and economical way.

Monolithic ceramics have several desirable characteristics, such as high compressive strength and hardness, high temperature capability, chemical inertness and wear resistance, but they are weak under tensile and impact loading. Unlike metals, they do not show any plasticity and are prone to failure under mechanical or thermal loading. Nevertheless, their lower thermal and electrical conductivity and low thermal expansion make these ceramics important in many engineering applications [36]. Selected physical and mechanical parameters of ceramic materials are given in Table 3.

Table 3: Physical and mechanical characteristics of some ceramic materials [36].

\begin{tabular}{llllll}
\hline & $\begin{array}{l}\text { Density, } \rho \\
\mathrm{g} / \mathrm{cm}^{3}\end{array}$ & $\begin{array}{l}\text { Melting } \\
\text { Point } \\
{ }^{\circ} \mathrm{C}\end{array}$ & $\begin{array}{l}\text { Young's } \\
\text { Modulus, } \mathrm{E} \\
\mathrm{GPa}\end{array}$ & $\begin{array}{l}\text { Coefficient. Of } \\
\text { Thermal } \\
\text { Expansion } \\
10^{-6} / \mathrm{K}\end{array}$ & $\begin{array}{l}\text { Fracture } \\
\text { Toughness, } \\
\mathrm{K}_{\mathrm{IC}} \\
\mathrm{MPam}^{1 / 2}\end{array}$ \\
\hline $\mathrm{Al}_{2} \mathrm{O}_{3}$ & 3.9 & 2050 & 380 & $7-8$ & $2-4$ \\
\hline $\mathrm{SiC}$ & 3.2 & - & 420 & 4.5 & $2.2-3.4$ \\
\hline $\mathrm{Si}_{3} \mathrm{~N}_{4}$ & 3.1 & - & 310 & 3.1 & $2.5-3.5$ \\
\hline $\mathrm{MgO}$ & 3.6 & 2850 & 210 & 3.6 & - \\
\hline Mullite & 3.2 & 1850 & 140 & 5.3 & $3.5-3.9$ \\
\hline $\begin{array}{l}\text { Borosilicate } \\
\text { Glass }\end{array}$ & 2.3 & - & $60-70$ & 3.5 & $0.5-2$ \\
\hline $\begin{array}{l}\text { Soda-lime } \\
\text { Glass }\end{array}$ & 2.5 & - & $60-70$ & 8.9 & $0.5-2$ \\
\hline
\end{tabular}

For instance, magnesia $(\mathrm{MgO})$ is characterized by high melting temperature $\left(2800^{\circ} \mathrm{C}\right)$ and high thermal and chemical stability; therefore it is widely used in refractory applications. Magnesia ceramics possess high thermal stability up to $2300^{\circ} \mathrm{C}$ in oxidizing atmosphere and up to $1700^{\circ} \mathrm{C}$ in reducing atmosphere, but the main disadvantage of 
magnesia ceramic is low thermal shock resistance, which prevent its use as protective coating [37]. In the following sections, some important ceramics, as candidates for high temperature applications are briefly described.

\section{Alumina (A12O3)}

Alumina has simple, binary crystal structures with many high temperature industrial applications [36]. Seven crystallographic phases of calcined (water-free) alumina have been found. However, structural applications of alumina are limited to $\alpha$ phase ( $\alpha$ Al2O3), which is also called corundum, or its single-crystalline form, sapphire [38]. The structure of $\alpha-\mathrm{Al} 2 \mathrm{O} 3$ is shown in Figure 21. Other crystallographic phases of alumina are transitional, metastable phases such as $y, \chi, \kappa, \delta, \theta$, and $\eta$ phase. These metastable phases occur during the thermal dehydration of the precursor hydroxides such as trihydroxides $\left(\mathrm{Al}(\mathrm{OH})_{3}\right)$, gibbsite $\left(\alpha-\mathrm{Al}_{2} \mathrm{O}_{3} \cdot 3 \mathrm{H}_{2} \mathrm{O}\right)$, bayerite $\left(\beta-\mathrm{Al}_{2} \mathrm{O}_{3} \cdot 3 \mathrm{H}_{2} \mathrm{O}\right)$ [39], and monohydroxides $(\mathrm{AlOOH})$ Boehmite and Diaspore [40].
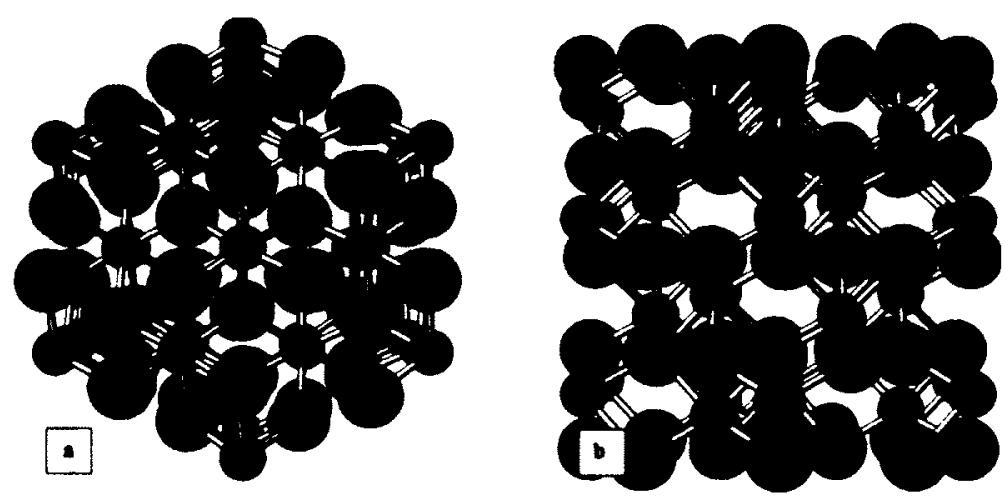

Figure 21: The $\alpha$-alumina (corundum) crystal structure viewed along: (a) the $<0001>$ direction (c plane), and (b) the $<1010>$ direction (blue spheres: oxygen atoms, and red spheres: aluminum atoms) [40].

Alumina is produced in powder form by the Bayer process. Having a melting temperature of $2050^{\circ} \mathrm{C}$, the challenge is to obtain a densified ceramic very close to the 
theoretical density with a controlled microstructure. The densified alumina must be obtained by sintering alumina powders at a temperature as low as possible to reduce expensive processing costs as well as equipment investment costs. To lower the sintering temperature, liquid phase sintering by additives that produce eutectics at low temperatures is used. Alumina with purity of 80 to $98 \%$, with the addition of $\mathrm{SiO}_{2}, \mathrm{CaO}$ or $\mathrm{MgO}$ reflectively lowers the eutectic temperature for easier processing. The $\mathrm{Al}_{2} \mathrm{O}_{3}$ $\mathrm{MgO}-\mathrm{SiO}_{2}$ system contains a eutectic that melts at $1355^{\circ} \mathrm{C}$ and the $\mathrm{Al}_{2} \mathrm{O}_{3}-\mathrm{CaO}-\mathrm{SiO}_{2}$ system has a eutectic that melts at $1170^{\circ} \mathrm{C}$. However, the most demanding applications need high purity alumina [41].

The theoretical density, $\rho_{t h}$, can be calculated from the lattice parameters using the following relation:

$$
\rho_{t h}=\frac{4 \cdot 3^{\frac{1}{2}} M}{N \cdot a_{o}^{2} \cdot c_{o}}
$$

Equation 1

where $\mathrm{M}$ is the molecular weight, $\mathrm{N}$ is Avogadro's number, and the numerical factors $\left(\alpha_{0}\right.$ and $c_{0}$ ) are determined by the particular structure of $\alpha-\mathrm{Al}_{2} \mathrm{O}_{3}$.

Alumina ceramics owe the mechanical and thermal performances to the stability of the oxide and its strong atomic bonds. However, these properties vary with the microstructure and depend highly on the temperature. Table 4 gives the experimental thermal properties of the aluminum oxide at various temperatures. 
Table 4: Summary of selected thermal properties of alumina at various temperatures [42].

\begin{tabular}{lllll}
\hline Temperature ${ }^{\circ} \mathrm{C}$ & $\begin{array}{l}\text { Specific surface } \\
\text { energy } \gamma_{\mathrm{o}}\left(\mathrm{J} / \mathrm{m}^{2}\right)\end{array}$ & $\begin{array}{l}\text { Heat Capacity } \\
\mathrm{C}_{\mathrm{p}}(\mathrm{J} / \mathrm{mol} . \mathrm{K})\end{array}$ & $\begin{array}{l}\text { Linear thermal } \\
\text { expansion }\left(10^{-6} / \mathrm{K}\right)\end{array}$ & $\begin{array}{l}\text { Thermal } \\
\text { conductivity, } \mathrm{K} \\
(\mathrm{J} / \mathrm{cm} . \mathrm{S} . \mathrm{K})\end{array}$ \\
\hline R.T. & - & 15.5 & 5.43 & 0.360 \\
\hline 400 & - & 21.7 & 7.33 & 0.128 \\
\hline 800 & - & 23.7 & 8.97 & 0.070 \\
\hline 1200 & - & 24.8 & 9.73 & 0.055 \\
\hline 1600 & - & - & - & 0.056 \\
\hline Melting point & 0.638 & - & - & - \\
\hline
\end{tabular}

In addition, Table 5 illustrates typical physical and mechanical properties of alumina with different purities.

Table 5: Typical physical and mechanical properties of $86 \%$ to $99.9 \%$ alumina [43].

\begin{tabular}{|c|c|c|c|c|c|c|c|}
\hline \multirow{2}{*}{$\begin{array}{l}\text { Property } \\
\text { Purity }\end{array}$} & \multicolumn{7}{|c|}{ Alumina Grade } \\
\hline & $86 \%$ & $94 \%$ & $97.5 \%$ & $99.5 \%$ & $99.9 \%$ & $\begin{array}{l}99 \% \\
\text { recry. }\end{array}$ & Sapphire \\
\hline Density $\left(\mathrm{gcm}^{-3}\right)$ & 3.5 & 3.7 & 3.78 & 3.89 & 3.9 & 3.9 & 3.985 \\
\hline $\begin{array}{l}\text { Thermal Conductivity } \\
\left(\mathrm{Wm}^{-1} \mathrm{~K}^{-1}\right)\end{array}$ & 15 & 20 & 24 & 26 & $28-35$ & $28-35$ & 41.9 \\
\hline $\begin{array}{l}\text { Thermal Expansion } \\
\text { Coefficient } \\
\left(20-1000^{\circ} \mathrm{C} \times 10^{-6} / \mathrm{K}\right)\end{array}$ & 7 & 7.6 & 8.1 & 8.3 & 8 & 8 & 5.8 \\
\hline $\begin{array}{l}\text { Specific Heat }\left(\mathrm{JK}^{-1}\right. \\
\left.\mathrm{kg}^{-1}\right)\end{array}$ & 920 & 900 & & 850 & & & 753 \\
\hline $\begin{array}{l}\text { Compressive Strength } \\
\text { (MPa) }\end{array}$ & 1800 & 2000 & $\begin{array}{l}1750- \\
2500\end{array}$ & & $\begin{array}{l}2200- \\
2600\end{array}$ & $\begin{array}{l}2200- \\
2600\end{array}$ & 2100 \\
\hline $\begin{array}{l}\text { Modulus of Rupture } \\
\text { (MPa) }\end{array}$ & 250 & 330 & & 262 & $\begin{array}{l}320- \\
400\end{array}$ & & 260 \\
\hline $\begin{array}{l}\text { Hardness } \\
\left(\text { Vickers kgf.mm }^{-2}\right)\end{array}$ & & & $\begin{array}{l}1500- \\
1600\end{array}$ & & $\begin{array}{l}1500- \\
1650\end{array}$ & $\begin{array}{l}1500- \\
1650\end{array}$ & $\begin{array}{l}2500- \\
3000\end{array}$ \\
\hline
\end{tabular}




\section{Yttria-Stabilized Zirconia (YSZ)}

Pure zirconium oxide (zirconia $\left.\mathrm{ZrO}_{2}\right)$ has a high melting point $\left(2,700^{\circ} \mathrm{C}\right)$ and a low thermal conductivity. Its polymorphism, however, restricts its widespread use in the ceramic industry. It exhibits monoclinic structure at room temperature, but changes to a denser tetragonal form at about $1,000^{\circ} \mathrm{C}$. This microstructure alteration involves a large volume change and creates cracks within its structures during cooling. Due to reversible change in crystal structure, pure zirconium oxide has low thermal shock resistivity. To increase this resistivity, zirconia is partially stabilized by adding other compounds, generating partially stabilized zirconium dioxide (PSZ).

PSZ is a material that combines hardness, reduced fragility, and chemical inertness with high chemical stability in aggressive environments in a wide temperature range. Under equilibrium condition it is a mixture of zirconia polymorphs. A smaller addition of stabilizer to the pure zirconia will change its structure to a tetragonal phase at room temperature. A partially stabilized zirconia, also called tetragonal zirconia polycrystal (TZP), consists of more than 2.77 wt.\% of $\mathrm{MgO}, 5.4-7.1$ wt. $\%$ of $\mathrm{Y}_{2} \mathrm{O}_{3}$, or 3.81 wt. $\%$ of $\mathrm{CaO}$. Adding more than 5.86 wt.\% $\mathrm{MgO}, 13.75$ wt. $\% \mathrm{Y}_{2} \mathrm{O}_{3}$, or 7.9 wt.\% $\mathrm{CaO}$ forms a fully stabilized zirconia with cubic solid solution structure within common application temperature range.

PSZ is a transformation-toughened material that can hinder microcracking by induced compressive stress. The microcrack originates from a difference in the thermal expansion between the cubic phase and monoclinic (or tetragonal)-phase particles in the PSZ. Coefficient of thermal expansion (CTE) for the monoclinic form is $6-6.5 /{ }^{\circ} \mathrm{C}$ up to 
$1200^{\circ} \mathrm{C}$, and for cubic it is $6-10.5 /{ }^{\circ} \mathrm{C}$. The induced stress related to tetragonal-tomonoclinic transformation impedes propagating cracks.

PSZ has been used where extremely high temperatures are required. The low thermal conductivity (about $1.12 \mathrm{~W} / \mathrm{m} . \mathrm{K}$ at $1253 \mathrm{~K}$ ) ensures low heat losses, and the high melting point permits [44]. PSZ is also used as heat engine components, such as cylinder liners, piston caps and valve seats. However, zirconia is converted in to zirconium carbide at above $1,650^{\circ} \mathrm{C}$ when in contact with carbon [45].

Among stabilized zirconia, yttria stabilized zirconia (YSZ) has become the preferred TBC layer material for gas turbine engine applications because of its low thermal conductivity, $\mathrm{k}$, and its relatively high (compared to many other ceramics) CTE. Figure 22 shows the combination of thermal conductivity and thermal expansion for several ceramics.

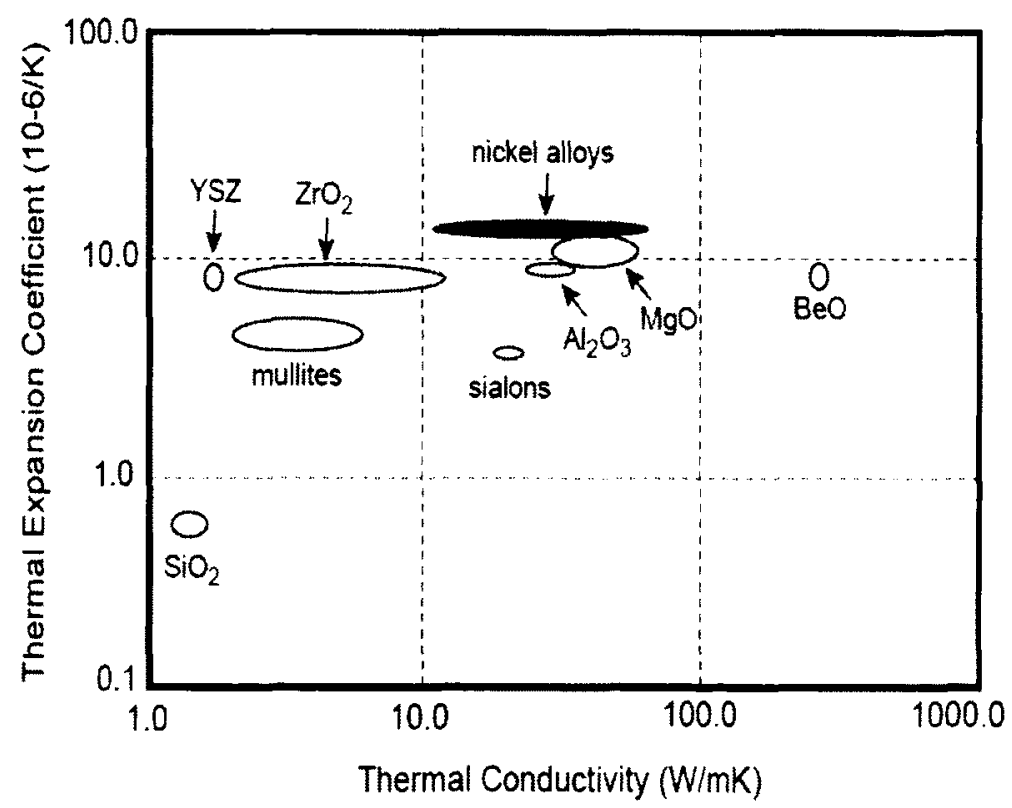

Figure 22: Comparison of thermal conductivity and thermal expansion coefficient between YSZ and other ceramics [46]. 
Materials for the TBC layer are required to have a CTE close to that of nickelbased superalloys. The nickel based alloys used for turbine blades have a CTE from 14.0 to $16.0 \times 10^{-6} \%^{\circ} \mathrm{C}$, and YSZ has a CTE equal to $9.0 \times 10^{-6} \%^{\circ} \mathrm{C}$. The low thermal conductivity of bulk YSZ results from the low intrinsic thermal conductivity of zirconia with added yttria. Yttria concentration in the range of 6 to $8 \mathrm{wt} \%$ also maximizes spallation life due to the formation of the metastable $t^{\prime}$ phase. This phase yields a complex microstructure which resists crack propagation and prevents zirconia phase transformation into the monoclinic phase during cooling [47].

\section{Other Ceramics:}

Carbon is used as a matrix with carbon fibers. Carbon can resist very high temperatures but only in the absence of oxygen or air. Generally the carbon matrix is obtained by chemical vapor deposition (CVD) process. Carbon can exist in a variety of forms: amorphous, graphitic or hexagonal form, diamond cubic form, and some newer forms called Fullerene and graphene. Carbon matrix obtained by means of CVD has a disordered structure consisting of a mixture of crystalline graphite and amorphous carbon regions. Carbon matrix obtained via pyrolysis pitch or resin is usually amorphous. Typical properties of carbon matrix include low CTE $\left(<2 \times 10^{-6} \mathrm{~K}^{-1}\right)$, low density of about $1.5 \mathrm{~g} / \mathrm{cm}^{-3}$, and relatively low Young's modulus of elasticity of $30-35 \mathrm{GPa}$ [36].

Mullite is a solid solution of alumina and silica in the compositional range of 71$75 \%$ alumina. Mullite is commonly represented by the formula $3 \mathrm{Al}_{2} \mathrm{O}_{3} \cdot 2 \mathrm{SiO}_{2}$. It has excellent strength and creep resistance, as well as low thermal expansion and conductivity. Table 3 gives the typical physical and mechanical characteristics of mullite [36]. 
Boron Nitride is formed by reaction between boron and nitrogen and can form the following BN compounds which are isostructural polymorphs:

$\alpha-\mathrm{BN}$ : this has a hexagonal, layered structure similar to graphite with a theoretical density of $2.27 \mathrm{~g} / \mathrm{cm}^{-3}$.

$\beta$-BN: This variety has a cubic, diamond-like structure and is extremely hard like diamond. Its theoretical density is $3.48 \mathrm{~g} / \mathrm{cm}^{-3}$.

$\gamma-\mathrm{BN}$ : has a hexagonal structure similar to $\alpha-\mathrm{BN}$, but with a higher density of $3.48 \mathrm{~g} / \mathrm{cm}^{-3}$.

The hexagonal variety of boron nitride shows natural lubricity because of easy cleavage.

The easy cleavage is as a result of its lamellar structure. It is frequently used as a mold release agent during hot pressing of ceramics such as silicon nitride. Boron nitride is applied generally as a paint, paste, or aerosol. $\mathrm{BN}$ also shows an excellent resistance to oxidation. Boron nitride in a powder form is also used as an additive for silicon nitride and alumina [36].

Boron carbide is another low density, high melting point, and high hardness ceramic. Boron carbide powder is produced by reacting briquettes of $\mathrm{B}_{2} \mathrm{O}_{3}$ and $\mathrm{C}$ matrix in an electric arc furnace. Boron carbide powder can be sintered to a dense material by pressureless sintering, hot pressing, or hot isostatic pressing [36].

\subsubsection{Ceramic Composite Materials}

To combine various important properties of three material classes (metals, ceramics, and polymers), composites have been developed [48]. The specific properties of the composites are expected to be higher than that for each of the constituent phases. Depending on whether metals, ceramics, or polymers comprise more than $50 \mathrm{vol} \%$ of a 
composite, they are classified as metal matrix composite (MMC), a ceramic matrix composite (CMC), or polymer matrix composite (PMC) [35]. As shown in Figure 23, the high-temperature capability of CMCs makes them very attractive for extremely hightemperature environments.

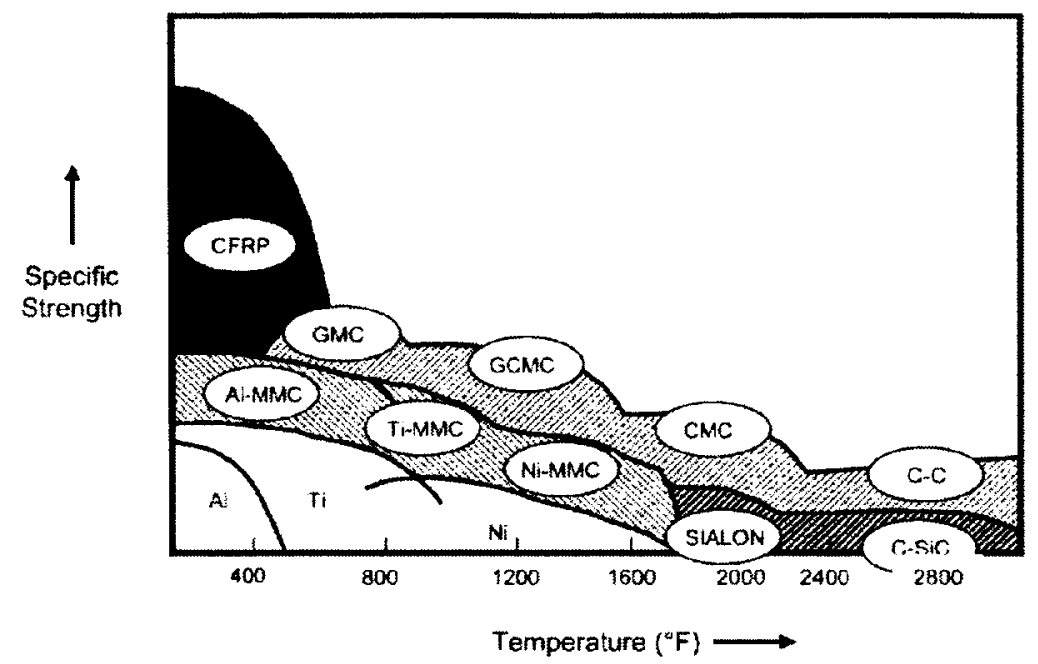

Figure 23: Relative material temperature limits: carbon-carbon (C-C), carbon fiber reinforced plastic (CFRP), ceramic matrix composite (CMC), carbon-silicon carbide (C$\mathrm{SiC}$ ), glass-ceramic matrix composite (GCMC), metal matrix composite (MMC), and silicon-aluminum-oxygen-nitrogen (SIALON) [49].

The two main constituents in composites are the reinforcement and matrix. The reinforcing phase provides the strength and stiffness. In most cases, the reinforcement is harder, stronger, and stiffer than the matrix.

\subsubsection{Reinforcement}

Continuous fibers have long aspect ratios, while discontinuous fibers have short aspect ratios. Continuous-fiber composites normally have a preferred orientation, while discontinuous fibers generally have a random orientation. Examples of continuous and 
discontinuous are shown in Figure 24 [49]. Continuous reinforcements include unidirectional, woven cloth, and helical winding, while examples of discontinuous reinforcements are chopped fibers and random mat. Continuous-fiber composites are made into laminates by stacking sheets of continuous fibers in desirable orientations to obtain the optimized strength and stiffness properties. In these composites, fiber volumes can be as high as 60 to 70 percent. As a general rule, the smaller the diameter of the fiber, the higher its strength (assuming constant vol\% of fiber), but often the cost increases as the diameter becomes smaller. In addition, smaller-diameter high-strength fibers have greater flexibility and are more responsive to fabrication processes such as weaving or forming over radii [49].

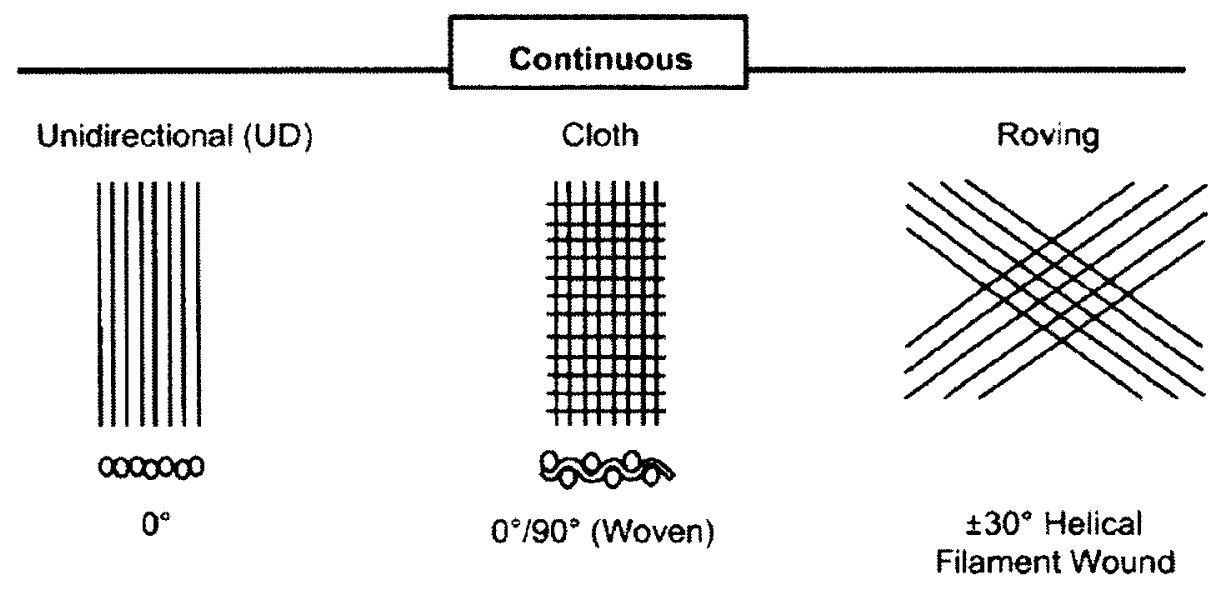

(a)

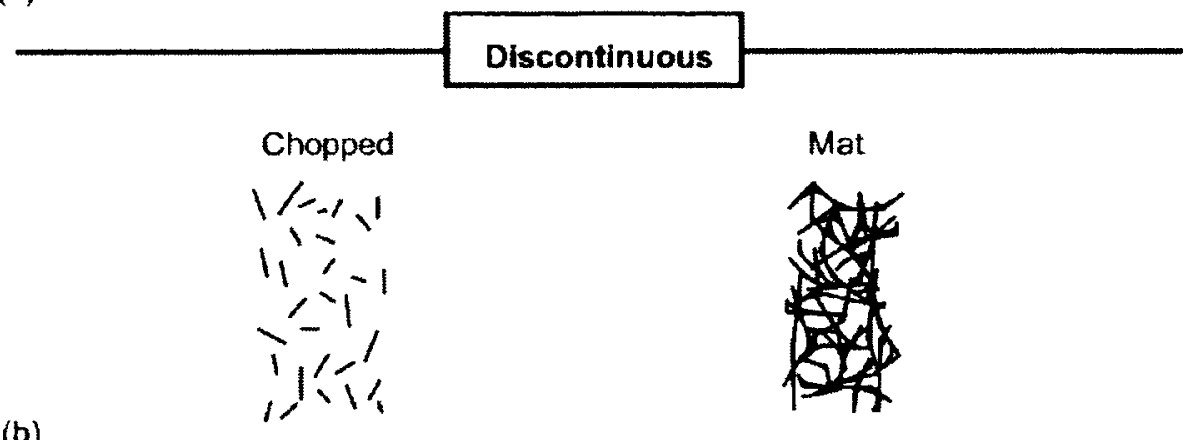

Figure 24: Typical reinforcement types [49]. 


\subsubsection{Matrix}

The continuous phase in a composite is the matrix, which can be a polymer, metal, or ceramic. Polymers have low strength and stiffness, metals have intermediate strength and stiffness but high ductility, and ceramics have high strength and stiffness but are brittle. The matrix (continuous phase) performs critical functions, including maintaining the fibers in the proper orientation and spacing, and protecting them from the environment [49]. Polymer and metal matrix composites form a strong bond between the fiber and the matrix; therefore, loads transmit from the matrix to the fibers through shear loading at the interface. However, in ceramic matrix composites, the objective is to increase the toughness rather than the strength and stiffness; therefore, a low interfacial strength bond is desired [49]. The differences between polymer matrix and ceramic matrix composites are illustrated in Figure 25.

Polymer and Metal Matrix Composites

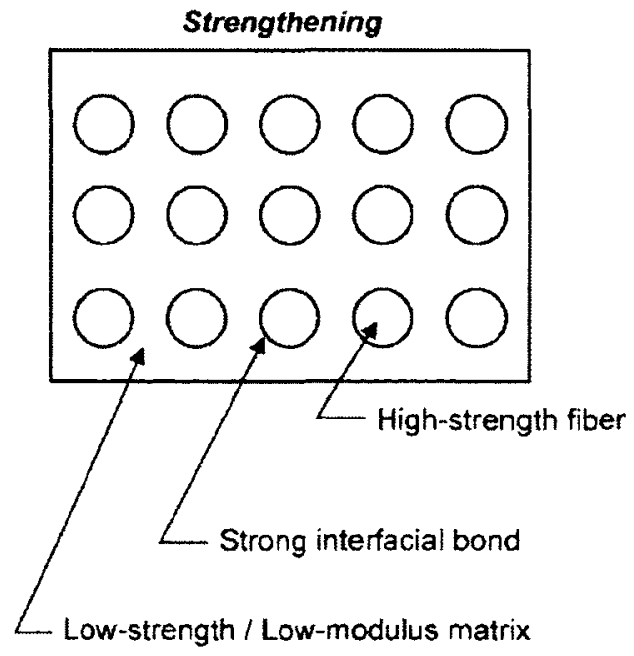

Ceramic Matrix Composites

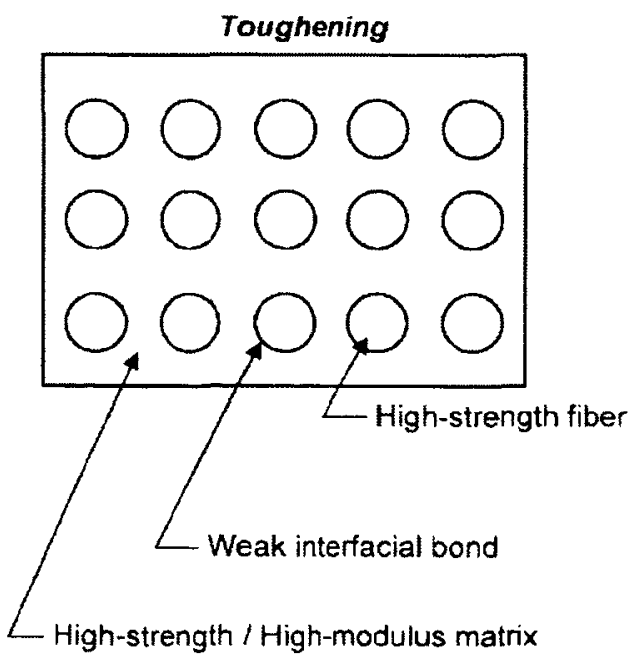

Figure 25: Comparison of polymer/metal with ceramic matrix composites [49]. 
Ceramic materials possess high strength and stiffness at elevated temperatures, and other properties such as low specific gravity and high chemical inertness. But fracture toughness of the ceramics is low and they are prone to catastrophic failures in the presence of defects, thermal shock, and service impact damages. Therefore, CMCs are basically ceramics toughened by incorporating reinforcing materials to effectively enhance their fracture toughness while maintaining high temperature strength and environment resistance [50]. The toughness increases in ceramic matrix composites are based on energy-dissipating mechanisms such as fiber-to-matrix debonding, crack deflection, fiber bridging, and fiber pull-out [49]. A theoretical stress-strain curve for a monolithic ceramic and a ceramic matrix composite is shown in Figure 26.

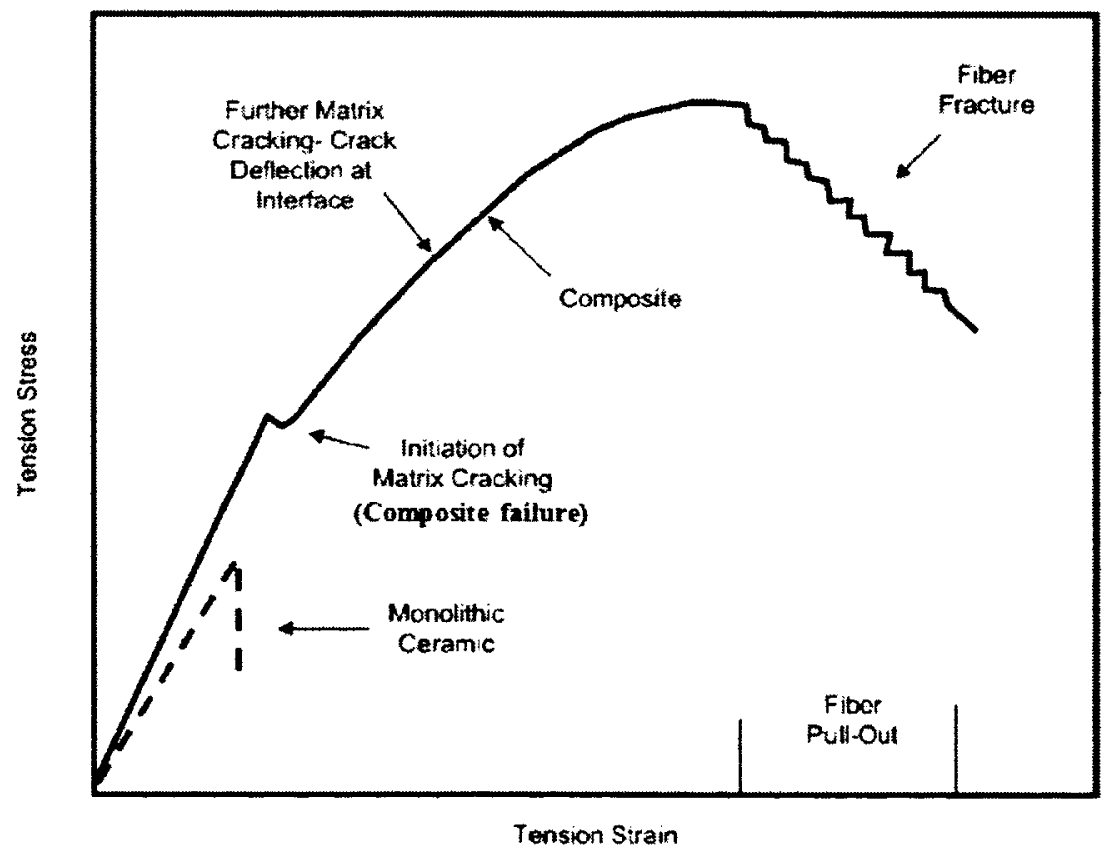

Figure 26: Stress-strain for monolithic and ceramic matrix composites [49].

Since the area under the stress-strain curve is considered an indication of toughness, a large increase in toughness for the ceramic matrix composite is evident. The 
mechanisms of debonding and fiber pull-out are shown in Figure 27. For these mechanisms to operate there must be a relatively weak bond at the fiber-to-matrix interface. If there is a strong bond, the crack will propagate straight through the fibers, resulting in little or no energy absorption. Therefore, proper control of the interface is critical. Coatings are often applied to protect the fibers during processing and to provide a weaker fiber-to-matrix bond.

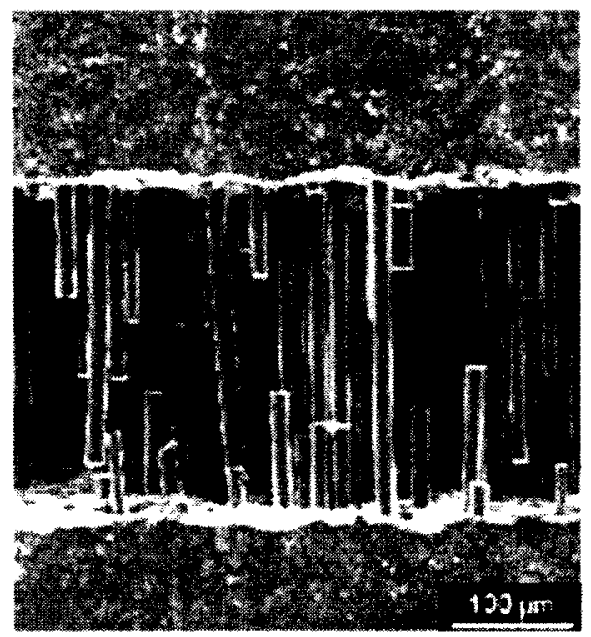

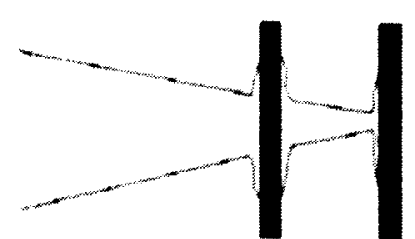

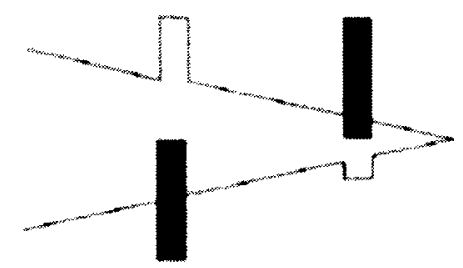

Cetanding

Fitomot

Figure 27: Crack dissipation mechanisms [49].

In selecting a fiber-matrix combination for a specific ceramic matrix composite, several factors need to be considered. First, the constituent materials need to have compatible CTE. If the CTE of the matrix is greater than the fiber, the matrix, on cooling from processing temperature, will immobilize the fibers, resulting in a strong fiber-tomatrix bond causing brittle failures in service. On the other hand, if the CTE of the matrix is less than the radial CTE of the fibers, the fibers may debond from the matrix on cooling. 
Oxide matrices include alumina $\left(\mathrm{Al}_{2} \mathrm{O}_{3}\right)$, mullite $\left(3 \mathrm{Al}_{2} \mathrm{O}_{3} \cdot 2 \mathrm{SiO}_{2}\right)$, cordierite $\left(2 \mathrm{MgO} \cdot 2 \mathrm{Al}_{2} \mathrm{O}_{3} \cdot 5 \mathrm{SiO}_{2}\right)$, and zirconia $\left(\mathrm{ZrO}_{2}\right)$. Oxide matrices are relatively low in cost, have good sinterability at moderate temperatures, and exhibit high temperature oxidation resistance. However their limitations include poor thermal expansion matches with many metal fibers, intermediate strength, and poor high temperature properties [49].

Pure zirconia $\left(\mathrm{ZrO}_{2}\right)$ changes its crystal structure with temperature. Below $1170^{\circ} \mathrm{C}$, zirconia exists in monoclinic form which transforms to tetragonal at $1170^{\circ} \mathrm{C}$. At $2370^{\circ} \mathrm{C}$ tetragonal crystal structure transforms to cubic structure. These structure transformations are accompanied by volume changes that cause cracking if cooling/heating is rapid and non-uniform. Therefore, zirconia in its pure form is not used as protective coating. Additions of some oxides, such as $\mathrm{Y}_{2} \mathrm{O}_{3}$ and $\mathrm{CaO}$, to pure zirconia hinder allotropic transformations and allow stabilization of either cubic or tetragonal structure of the material. However, the most commonly used stabilizing oxide to zirconia is yttria $\left(\mathrm{Y}_{2} \mathrm{O}_{3}\right)$, which is added in proportion of 6 to $8 \mathrm{wt} . \%$. [49].

\subsubsection{Interfacial Coatings}

Interfacial or interphase coatings are often required to: (1) protect the fibers from degradation during high-temperature processing, (2) assist in slowing oxidation during service, and (3) provide the weak fiber-to-matrix bond required for toughness. The coatings (Figure 28), ranging in thickness from 0.004 to $0.04 \mathrm{mil}(0.1$ to $1.0 \mu \mathrm{m}$ ), are applied directly to the fibers prior to processing, usually by CVD. Frequently, in addition to the interfacial coatings, an overcoating is also applied, such as a thin layer of about 
0.02 mil $(0.5 \mu \mathrm{m})$ that becomes part of the matrix later during processing. The overcoating is usually applied immediately after the interfacial coating [49].

During service, the overcoating also acts to protect the fibers and interfacial coatings from aggressive environments such as oxygen and water vapor. The interfacial coating and overcoating are sometimes repeated as multilayer coatings to provide environmental protection layers in the presence of in-service-generated matrix cracks [49].

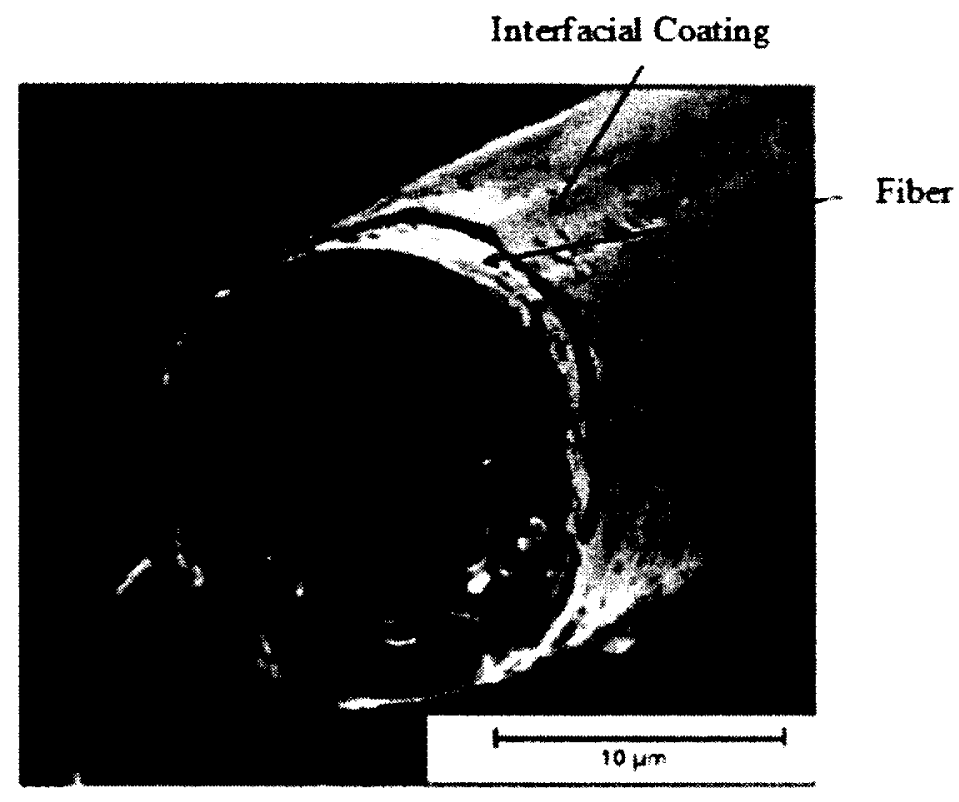

Figure 28: Interfacial coating [49].

\subsection{Material Damage Mechanisms at High Temperatures}

Resistance to oxidizing environments at high temperatures is a requirement for materials used in hot sections of gas turbine engines. These components are increasingly subjected to environmental degradation because of high temperature and salt deposits, which directly result in high temperature oxidation and hot corrosion. Hot corrosion and 
oxidation damage the turbine blades surfaces and consequently deteriorate considerably the mechanical properties of the blades and shortens their service lives [9].

\subsubsection{Mechanical Property Degradation}

Degradation mechanisms for structural materials are a function of the engine operating conditions, engine mechanical design, and the base materials. Engine operating conditions determine operating temperature and structural loads, while engine design determines the amount of air available to cool the hot structure [51]. Engines operating at elevated temperature can degrade superalloys by oxidation, alloying elements depletion, carbon pickup, and contamination.

Precipitation hardenable superalloys usually have good oxidation resistance in oxidizing atmospheres within their normal range of service temperatures. Some superalloys may require coatings in service owing to their reduced levels of chromium and/or more aggressive environments. This is particularly true for gas turbine airfoil alloys.

In addition to oxidation, exposure to high temperature environments can cause changes in the composition of the alloy near the surface. Because certain elements are preferentially consumed by the scale layers, the bulk composition can become depleted over time. Selective surface attack is another mechanism of superalloys degradation at high temperatures. A common form of selective surface attack is intergranular oxidation. Intergranular oxidation is measured as depth of intergranular penetration. Figure 29 shows the depth of intergranular oxidation that occurred on Rene 41 superalloy after being heated to different temperatures in air [52]. 


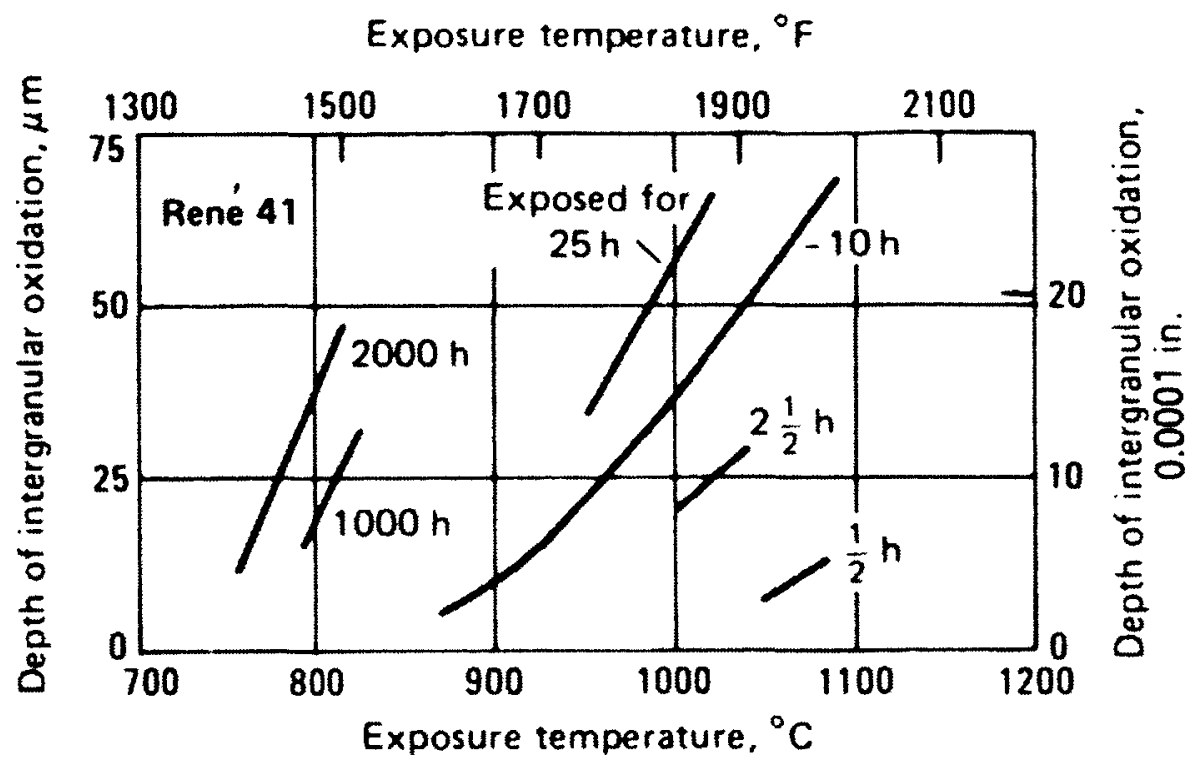

Figure 29: Effect of time and temperature on oxidation of Rene 41 precipitation-hardened nickel-base alloy [52].

Intergranular attack involves not only the preferential oxidation of chromium in the grain boundary regions but also the attack of aluminum and titanium in the constituent $\gamma^{\prime}$ and $\eta$ hardening phases by oxygen. In relation to preventing intergranular oxidation, aluminum is preferable to titanium as a hardening element, because aluminum oxide provides a denser and less permeable barrier to the diffusion of oxygen [52].

Lubricants or fuel oils that contain sulfur-bearing compounds are also sources of corrosive species; they are active in corroding the metal surface of superalloys that contain nickel and chromium. Attack occurs by first forming $\mathrm{Cr}_{2} \mathrm{~S}_{3}$ and then, as the attack progresses a $\mathrm{Ni}-\mathrm{Ni}_{3} \mathrm{~S}_{2}$ eutectic also forms, particularly at pressures less than $10^{-4}$ torr. The $\mathrm{Ni}-\mathrm{Ni}_{3} \mathrm{~S}_{2}$ eutectic phases have a melting point of $645^{\circ} \mathrm{C}$. 


\subsubsection{Oxidation}

Oxidation is the most important high temperature corrosion reaction. Metals or alloys are oxidized when heated to elevated temperatures in air or in highly oxidizing environments, such as combustion atmospheres with excess air or oxygen. Many metallic components, such as furnace heater tubes, and combustors and transition ducts in gas turbines, are subjected to oxidation. Depending on service conditions oxidation occurs in different modes. In the following sections these oxidation types are explained briefly.

\section{Isothermal oxidation}

For many industrial processes, combustion involves relatively "clean" fuels such as natural gas or No. 1 or No. 2 fuel oil. These fuels generally have low concentrations of contaminants, such as sulfur, chlorine, alkali metals, and vanadium. In many cases, excess air is used to ensure complete combustion of the fuel. The combustion products thus consist primarily of $\mathrm{O}_{2}, \mathrm{~N}_{2}, \mathrm{CO}_{2}$, and $\mathrm{H}_{2} \mathrm{O}$. Although alloys in these environments are oxidized by oxygen primarily, other combustion products, such as $\mathrm{H}_{2} \mathrm{O}$, also play a role in the oxidation behavior of the alloys. The presence of $\mathrm{N}_{2}$ in the combustion gas stream can cause significant internal nitridation attack under certain conditions [53].

Most industrial environments have sufficient oxygen potentials to allow oxidation to take place in the high-temperature corrosion reaction regardless of the predominant mode of corrosion. Alloys rely on this initial oxidation reaction to develop a protective oxide scale to resist other types of corrosion attacks, such as sulfidation, carburization, hot corrosion, etc. [53]. 


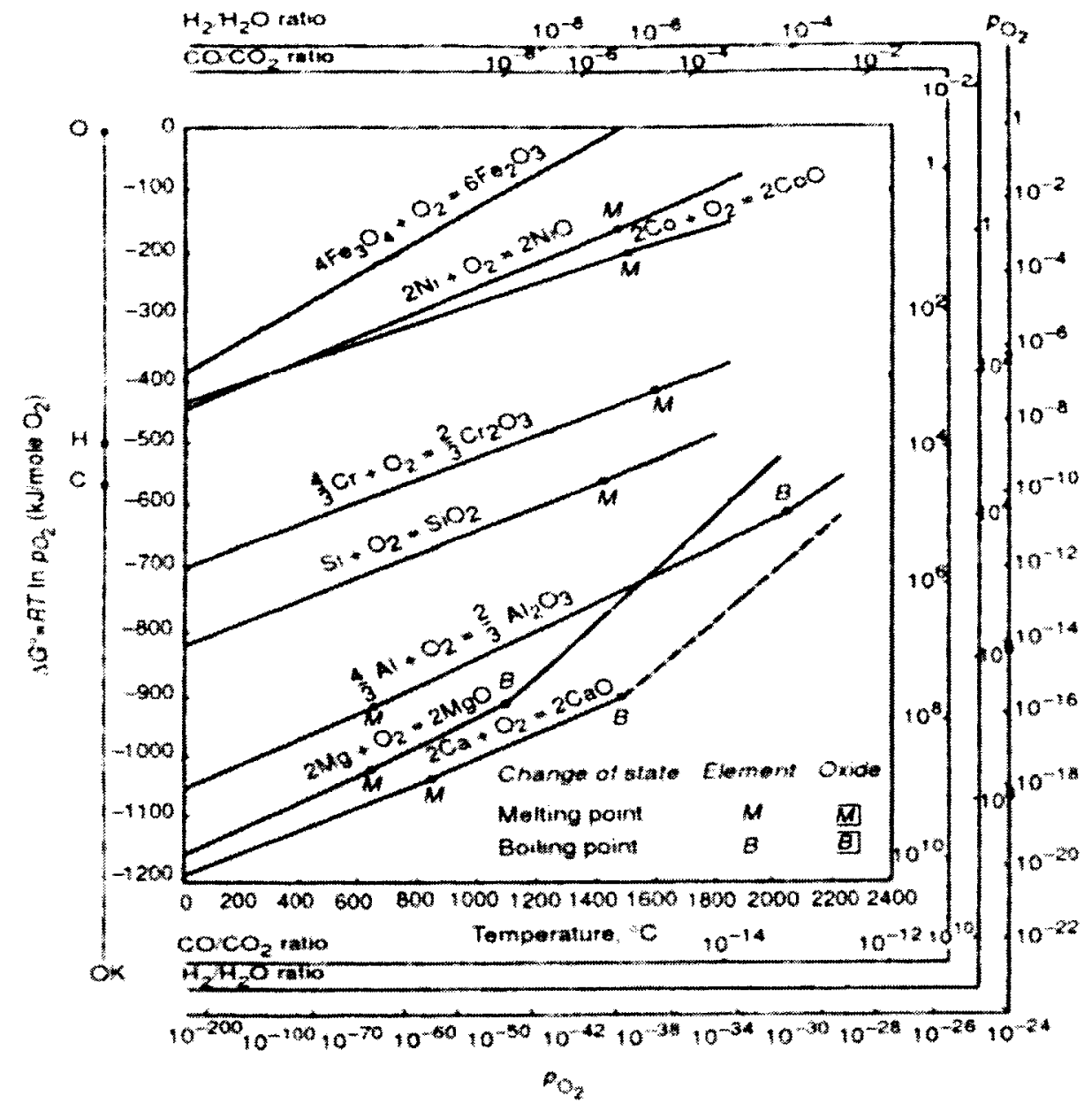

Figure 30: Standard free energies of oxide formation as a function of temperature [53].

Ellingham diagram (Figure 30) shows that oxides of iron, nickel, and cobalt, which are the alloy bases for the majority of engineering alloys and superalloys, are significantly less stable than the oxides of alloying elements, such as chromium, aluminum, silicon, etc. When one of these solute elements is added to iron, nickel, or cobalt, internal oxidation of the solute occurs if the concentration of the solute is relatively low. As the solute concentration increases to a sufficiently high level, oxidation of the solute will be changed from internal oxidation to external oxidation, resulting in an oxide scale that protects the alloy from rapid oxidation. This process is known as 
"selective oxidation". The majority of corrosion resistant iron-, nickel-, and cobalt-based alloys rely on selective oxidation of chromium to form a $\mathrm{Cr}_{2} \mathrm{O}_{3}$ scale for oxidation resistance. Some high-temperature alloys use aluminum to form $\mathrm{Al}_{2} \mathrm{O}_{3}$ scale for oxidation resistance [53]. Most of the oxides exhibit high melting points and remain in a solid state for the temperature range in which the alloys are used. If the oxide is present as liquid sate, catastrophic failure can occur [53]. Table 6 shows the melting points of selected oxides of alloying elements commonly found in these alloys.

Table 6: Melting points of selected oxides of alloying elements commonly found in hightemperature alloys [53].

\begin{tabular}{lc}
\hline Oxide & Melting Point, ${ }^{\circ} \mathrm{C}$ \\
\hline$\alpha-\mathrm{Al}_{2} \mathrm{O}_{3}$ & 2015 \\
\hline $\mathrm{CoO}$ & 1935 \\
\hline $\mathrm{Cr} \mathrm{O}_{3}$ & 2435 \\
\hline $\mathrm{FeO}$ & 1420 \\
\hline $\mathrm{Mn}_{3} \mathrm{O}_{4}$ & 1705 \\
\hline $\mathrm{MoO}_{3}$ & 795 \\
\hline $\mathrm{Nb}_{2} \mathrm{O}_{5}$ & 1460 \\
\hline $\mathrm{NiO}$ & 1990 \\
\hline $\mathrm{SiO}_{2}$ & 1713 \\
\hline $\mathrm{TiO}_{2}$ & 1830 \\
\hline $\mathrm{V}_{2} \mathrm{O}_{5}$ & 690 \\
\hline $\mathrm{WO}_{3}$ & 1473 \\
\hline
\end{tabular}

Most of the alloying elements are added for mechanical improvement purposes rather than oxidation prevention. For example, molybdenum (Mo) is strong carbide former and is used in a small amount to strengthen the low-alloy steels (e.g., Cr-Mo steels). Oxides of molybdenum $\left(\mathrm{MoO}_{3}\right)$, however, exhibit very low melting points. Due to its low concentration, it is unlikely to cause surface oxide melting. 
In addition to low melting or volatility of some of the oxides present in superalloys, the vapor pressures of several oxides related at very high temperatures (above $1000^{\circ} \mathrm{C}$ ) must also be taken into consideration. At very high temperatures oxide scale becomes less protective when their vapor pressures are high [53]. For instance, Figure 31 shows vapor pressure of several refractory metal oxides, $\mathrm{WO}_{3}$ and $\mathrm{MoO}_{3}$ in particular, exhibiting high vapor pressure at temperatures above $1000^{\circ} \mathrm{C}$.

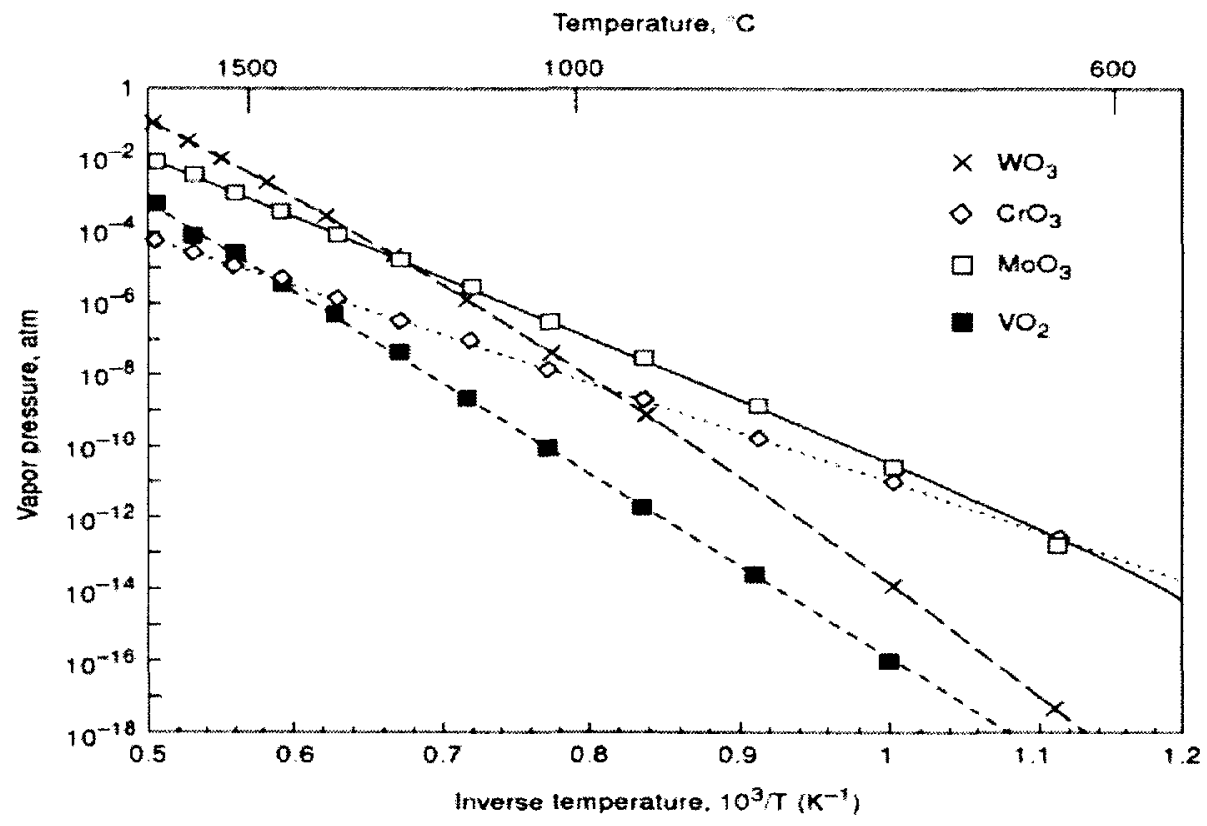

Figure 31: Vapor pressure of several refractory metal oxides (exhibiting high vapor pressures) at temperatures above $1000^{\circ} \mathrm{C}[53]$.

A greater number of engineering alloys rely on the $\mathrm{Cr}_{2} \mathrm{O}_{3}$ scale to provide resistance to oxidation. When being heated to very high temperatures (above $1000^{\circ} \mathrm{C}$ ), $\mathrm{Cr}_{2} \mathrm{O}_{3}$ can react with $\mathrm{O}_{2}$ to form volatile $\mathrm{CrO}_{3}$. At service temperatures above $1200^{\circ} \mathrm{C}$, the increasing volatility of oxides can progressively cause the oxide to lose its protective capability. $\mathrm{SiO}_{2}$ and $\mathrm{Al}_{2} \mathrm{O}_{3}$ are the only two oxides that can form very protective barriers 
against oxidation at temperatures above $1200^{\circ} \mathrm{C}$. However, the $\mathrm{SiO}_{2}$ scale may lose some protective capability by forming gaseous $\mathrm{SiO}$ at low oxygen partial pressure [54].

Alumina $\left(\mathrm{Al}_{2} \mathrm{O}_{3}\right)$ is used as a protective surface oxide on high-temperature alloys. Because of strong chemical bond strength between the $\mathrm{Al}$ and oxygen ions, alumina has a very high chemical stability, high melting point, highest hardness among oxides and high mechanical strength at room temperature. The slow growth rate of this oxide is related to its highly stoichiometric structure and its non-metallic bonding structure that makes electronic conduction difficult. During the process of growing oxide scale a dense, impermeable structure forms that increases the resistance to penetration by aggressive gases and species in harsh environments. However, the mechanical strength of alumina is reduced substantially above $1100^{\circ} \mathrm{C}[55]$.

$\mathrm{SiO}_{2}$ scale also functions as an excellent protective scale in high temperature oxidizing atmospheres. However, in atmospheres containing water vapor, the oxidation resistance of the $\mathrm{SiO}_{2}$ scale is poor. The reasons for the poor oxidation resistance based mainly on the degenerative factor of water vapor. Water vapor probably causes silicon dioxide to form volatile silicon hydroxides or oxy-hydroxides [56].

In isothermal oxidation, the kinetics of oxidation of metals and alloys generally follow parabolic, linear, logarithmic or inverse logarithmic rates, as shown in Figure 32. 


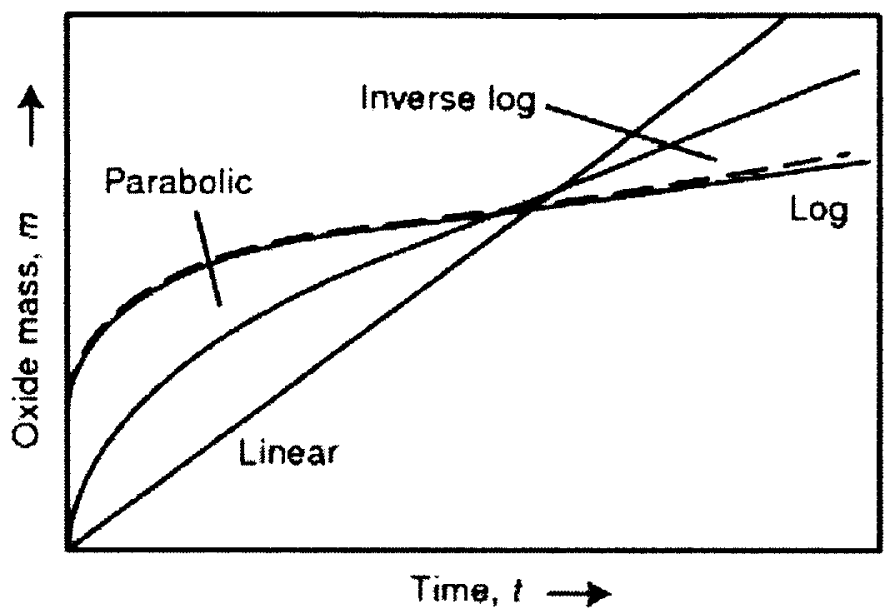

Figure 32: Different oxidation kinetics [53].

In parabolic mode, when the oxide scale forms on the metal surface, the oxidation reaction is controlled by the diffusion of ions through the oxide scale. As the thickness of the oxide scale increases, the rate of oxidation decreases with increasing time due to the increasing diffusion distance for ions. Therefore the oxidation rate is inversely proportional to the thickness of the oxide scale [53]. The governing equation is given as:

$$
\mathrm{X}^{2}=\mathrm{k}^{\prime} \mathrm{t} \quad \text { Equation 2 }
$$

where $\mathrm{X}$ is the oxide scale thickness, $\mathrm{t}$ is the exposure time, and $\mathrm{k}^{\prime}$ is the parabolic constant, determined at $\mathrm{t}=0, \mathrm{X}=0$.

In linear mode, the oxide scale forming on the metal surface provides no protective barrier due to cracking, spalling, volatility or molten oxidation products; therefore, the oxidation rate generally remains constant with increasing time. The linear oxidation kinetic rate is expressed by:

$$
\mathrm{X}=\mathrm{k}_{1} \mathrm{t} \quad \text { Equation } 3
$$

where $X_{1}$ is the mass (or thickness) of the oxide, $t$ is the exposure time, and $k_{1}$ is the linear rate constant, determined at $\mathrm{t}=0, \mathrm{X}=0$. 
Logarithmic or inverse logarithmic oxidation rate is observed at low temperatures when the oxide film forms on the metal surface. The driving force for the oxidation is the electric field across the oxide film. The logarithmic rate can be expressed by:

$$
\mathrm{X}=\mathrm{k}_{\mathrm{e}} \log (a t+1) \quad \text { Equation } 4
$$

where $\mathrm{k}_{\mathrm{e}}$ and $a$ are constants.

Oxidation can also take place in a "reducing" environment; the environment with a low oxygen potential created by combustion under a sub-stoichiometric condition [53]. This type of environment is generally characterized by low oxygen potentials. Under this condition, the oxygen potential of the environment is typically controlled by $p_{\mathrm{H}_{2}} / P_{\mathrm{H}_{3} \mathrm{O}}$ or $p_{\mathrm{CO}} / \mathrm{P}_{\mathrm{CO}_{2}}$ ratio and the oxidation kinetic is generally slow. The development of a protective oxide scale is slow in these atmospheres for most alloys that results in other modes of high temperature corrosion. Consequently, a majority of high-temperature corrosion problems in reducing environments are caused by modes of corrosion attack other than "true" oxidation.

\section{Cyclic oxidation}

In many applications of gas turbines, especially in aircraft propulsion and peaking power plants, thermal cycling and high TIT impose a major effect on oxidation behavior of alloys and coatings, and cause protective oxide spallation. TIT varies greatly in aircrafts during a typical flight cycle. The gas temperature, and therefore the metal temperature, is cycled over wide ranges as the engine is operated, for example, at idle, takeoff, climb, cruise, and thrust-reverse power requirements. TIT is largest during takeoff and climb to cruising altitude. A typical gas turbine engine is shown in Figure 33. 


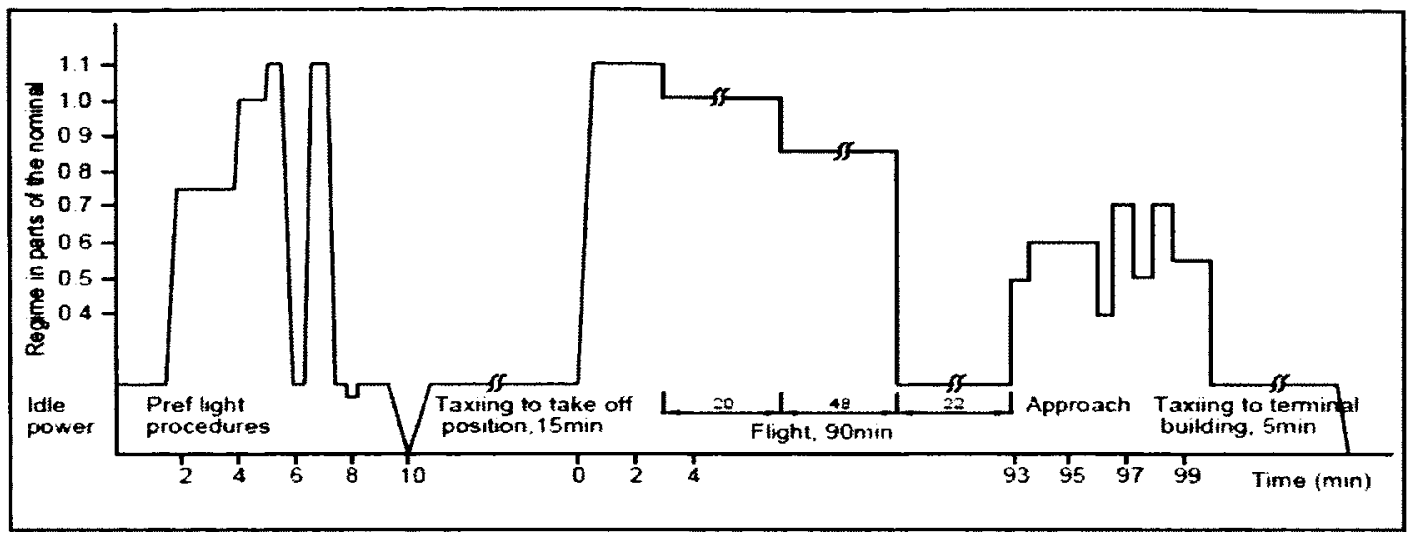

Figure 33: Operating diagram of an airliner engine [9].

In contrast, turbines for power-generating applications experience fewer startup/power-down cycles, but they operate with a higher TIT for longer periods of time. Therefore, the improvements in the efficiency of gas turbine engines, which require higher TIT, require structural materials with higher temperature durability to be utilized under severe operation conditions $[6,52]$.

As described in previous sections, high-temperature alloys rely on the dense protective surface layers formed during their early stage of exposure, usually alumina or chromia, for oxidation protection. The growth rates of these protective layers are low, and their spallation exposes the bare metal surface leading to more metal surface damage. This spallation is normally attributed to stresses arising from the differences in CTEs between the metal and the protective oxide. Spallation occurs when the oxide layers experience an in-plane compressive stress. For simple thermal loading conditions this stress occurs during cooling when the CTE of the oxide is lower than that of the substrate alloy. 
In many practical cases, a single, sudden temperature decrease will not initiate oxide spallation, but repeated cycles, will damage the protective oxidation. Understanding of the spallation process under such conditions is limited and depends largely on empirical and predictive methods such as finite element modeling [57].

\subsubsection{Hot Corrosion}

In many high-temperature applications, superalloys encounter an environment much more corrosive than that involving oxygen alone. For instance, the hot gas produced in gas turbines creates a hostile environment, especially in the combustor and turbine sections. Sulfates are formed in the gas stream from alkali or alkali earth metals in the presence of chlorides, sulfur dioxide and sulfur trioxide. Fuel is often a source providing sulfur, alkali metals, vanadium, and lead, which are then converted to sulfur oxides and sulfates. The air fed into the combustion cycle is also a source of contaminants, such as sea salt and minerals dust. Sea salt has sodium, magnesium, calcium and potassium chlorides and sulfates. Minerals enter the combustor as runway dust and produce compounds such as calcium carbonates, sea salts or iron-bearing particulates. These contaminants tend to react with existing sulfate deposits on the components to form a liquid or solid solution of sulfates or other species on the surface of hot components. A consequence of this mixture of sulfates is that the melting point of the deposits may reduce to temperatures as low as $593-649^{\circ} \mathrm{C}$ [52]. Corrosion caused by sulfur dioxide or trioxide, salts, and sulfates containing chlorides is called hot corrosion.

To reduce the impact of these unwanted compounds and elements in gas turbines, some fuel borne contaminants must be significantly reduced through improved refining, 
selection of crude oils, and controlled storage and transportation. To control airborne impurities, stationary turbines use filters, but this control for non-stationary turbines is very difficult.

Hot corrosion products are seen as patches of extremely thick scales on turbine blades; some localized and others widespread consume entire pieces of airfoils. Microstructure studies of the remaining alloy show severe alloy depletion and the presence of sulfides. In Figure 34 hot corrosion of a turbine blade and loss of a large portion of the blade edge are shown as a result of sulfate deposits.

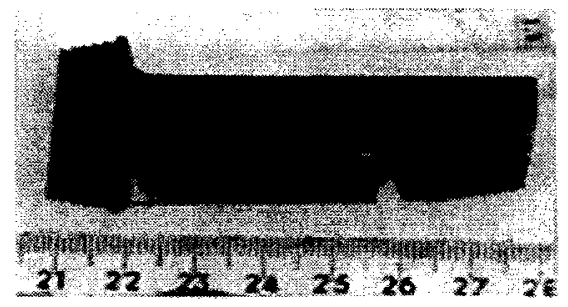

(a)

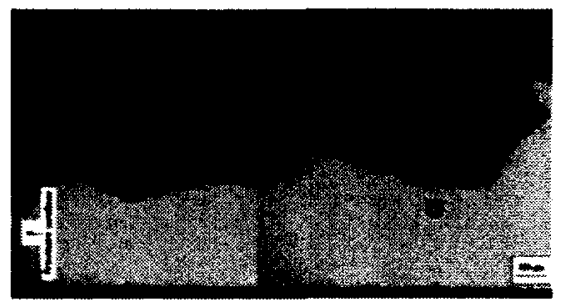

(c)

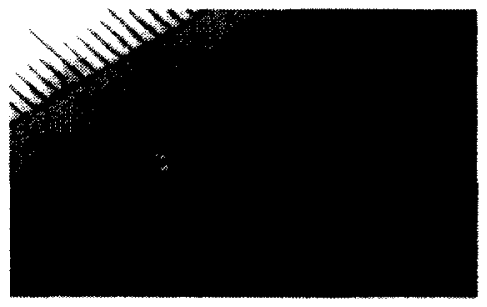

(b)

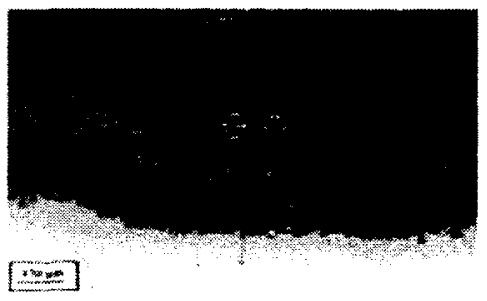

(d)

Figure 34: Hot corrosion of a stage 1 blade in PT6 engine: (a) loss of large piece of material near the leading edge of blade, (b) a crack propagation into the remainder material, (c) optical micrograph showing advanced hot corrosion attack, and (d) a secondary crack propagating from the scale into the base material [58].

The period before the onset of severe attack is called the initiation stage, whereas the process of rapid, abnormal corrosion is called the propagation stage. In general, the 
mechanisms of both initiation and propagation stages of attack vary across a single superalloy component. Regardless of the difference in corrosion behavior corresponding to different temperatures, all alloys exhibit an initiation and a propagation stage. Figure 35 is a schematic diagram that identifies the main factors determining the transition from initiation to propagation in hot corrosion [52].

Hot corrosion chronology Initiation stage
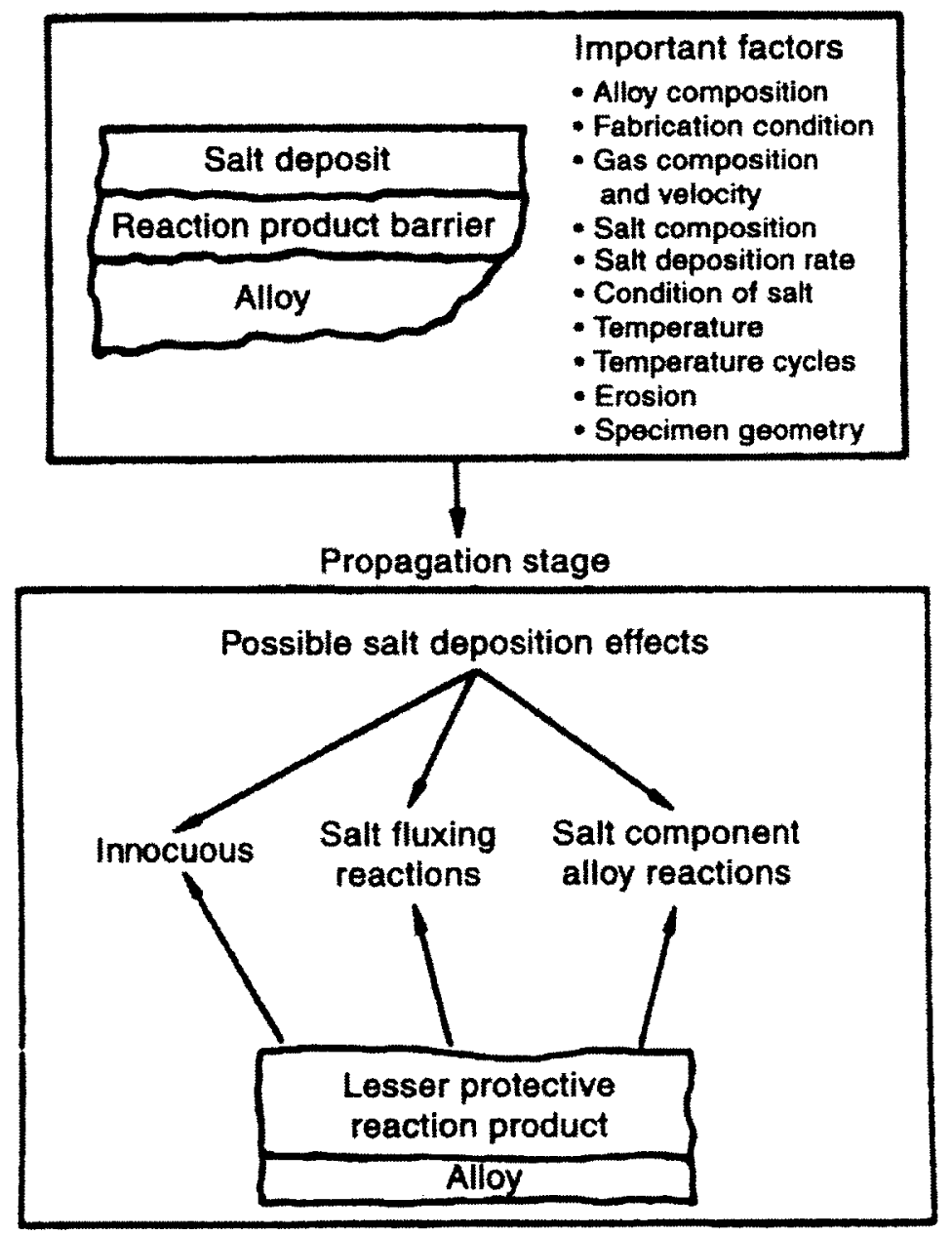

Figure 35: Schematic diagram showing factors that determine the transition from initiation stage to propagation stage [52]. 
When a normally protective oxide scale is degraded or destroyed by a salt deposit and is unable to reform, hot corrosion occurs as an accelerated oxidation process. Therefore, the oxide scales formed are porous and non-protective of the alloy surface; consequently, rapid oxidation occurs. The degradation or disruption of the normally protective oxide scales such as $\mathrm{Al}_{2} \mathrm{O}_{3}$ and $\mathrm{Cr}_{2} \mathrm{O}_{3}$ can occur by several mechanisms, including penetration and removing the scale by chemical reaction between the salt and the oxide scale. Although there is no exact temperature limit for the higher temperature regimes of hot corrosion, there is a general agreement that high-temperature hot corrosion occurs approximately in the range of $870-1010^{\circ} \mathrm{C}$. This is often referred to as "type 1 " hot corrosion, which usually has been seen in aircraft turbines in the hotter regions of blades and vanes.

The hot corrosion of superalloys containing Mo has been reported by Peters et al. [59]. The alloy containing Mo suffers catastrophic degradation. Molybdenum oxide $\left(\mathrm{MoO}_{2}\right)$ reacts with $\mathrm{Na}_{2} \mathrm{SO}_{4}$ (formed as combustion products) to produce an $\mathrm{SO}_{2}$-rich salt that leads to acidic fluxing. $\mathrm{MoO}_{3}$ can be incorporated into the $\mathrm{Na}_{2} \mathrm{SO}_{4}$ through formation of compounds such as $\mathrm{Na}_{2} \mathrm{MoO}_{4}, \mathrm{Na}_{2} \mathrm{MoO}_{4} \cdot \mathrm{MoO}_{3}$, and $\mathrm{Na}_{2} \mathrm{MoO}_{4} \cdot 2 \mathrm{MoO}_{4}$. All these phases are liquid within the operation temperature range and leave a high solubility for $\mathrm{Al}_{2} \mathrm{O}_{3}$ and $\mathrm{Cr}_{2} \mathrm{O}_{3}$. Some superalloys containing molybdenum are subjected to sub-melting point hot corrosion when covered with a sulphate - the reaction of $\mathrm{MoO}_{3}$ with the sulphate forms Molybdenum-containing melt. Therefore there is a threshold amount of molybdenum addition, for $\mathrm{Ni}-15 \% \mathrm{Cr}$ the threshold has been reported to be between $3-$ $4 \%[59]$. 
Other than optimizing alloying constituents of the superalloys, to protect the high temperature components form type 1 hot corrosion, coatings such as the diffusion aluminides are used, but they are prone to depletion of aluminum and chromium through preferential oxidation. MCrAlY coatings are also used to protect the alloy substrate from hot oxidation and corrosion. These coating systems work by elements within the MCrAlY (particularly $\mathrm{Al}$ ) reacting with oxygen and forming protective TGO $\left(\mathrm{Al}_{2} \mathrm{O}_{3}\right)$ layer. They have superior corrosion resistance with respect to substrate superalloys $[52$, $60,61]$.

There is another type of hot corrosion referred to as "type 2" hot corrosion, or "low temperature" attack. This mode of attack occurs in marine and industrial turbines, in which the temperature of the turbine is lower. Type 2 hot corrosion is due to acidic fluxing and occurs in the range of approximately $650-800^{\circ} \mathrm{C}$ [52]. In general, the aluminide coatings, which have good resistance at higher temperature, have poor resistance to this type of attack. Similarly, the performances of many overlay coatings, especially CoCrAlY coatings, have been poor for these low-temperature applications [52].

\subsection{Plasma Spraying Process}

Plasma spraying is one of the thermal spraying processes, which includes methods such as flame spray, electric arc spray, and plasma arc spray. These thermal energy sources are used to heat the coating material in powder, wire, or rod form to a molten or semi-molten sate. The resultant heated particles are accelerated and propelled toward a prepared substrate by either process gases or atomization jets. 
A major advantage of thermal spray processes is the extremely wide variety of materials that can be used to produce coatings. Another advantage is the ability to apply coatings without significant heat input to substrates. Thus, materials with very high melting points can be applied to fully heat treated parts without changing the properties of the part and without excessive thermal distortion of the part. A third advantage is the ability to strip off and recoat worn or damaged coatings without changing part properties or dimensions. The disadvantage of this type of coatings is the line-of-sight nature of the deposition processes. It means the gun can only coat the surfaces that are directly exposed to the flow of plasma and what the torch or gun can "see". It is impossible to coat small, deep cavities or surfaces that are not accessible or shielded by forward-facing surfaces [62]. Reactive elements may also be oxidized during the spraying process [63].

In conventional plasma process or atmospheric plasma spray (APS) (Figure 36), the plasma temperature in the powder heating region, range from about 6000 to $15000^{\circ} \mathrm{C}$, significantly above the melting point of any known material. To generate the plasma, an inert gas (typically argon or an argon-hydrogen mixture) is superheated by a DC arc. Powder is introduced by an inert carrier gas and is accelerated toward the workpiece by the plasma jet, and substrate temperature is maintained between 90 to $205^{\circ} \mathrm{C}$. Spray rates greatly depend on gun design, plasma gases, powder properties and characteristics such as size, distribution, melting point, morphology, and apparent density $[62,64]$. 


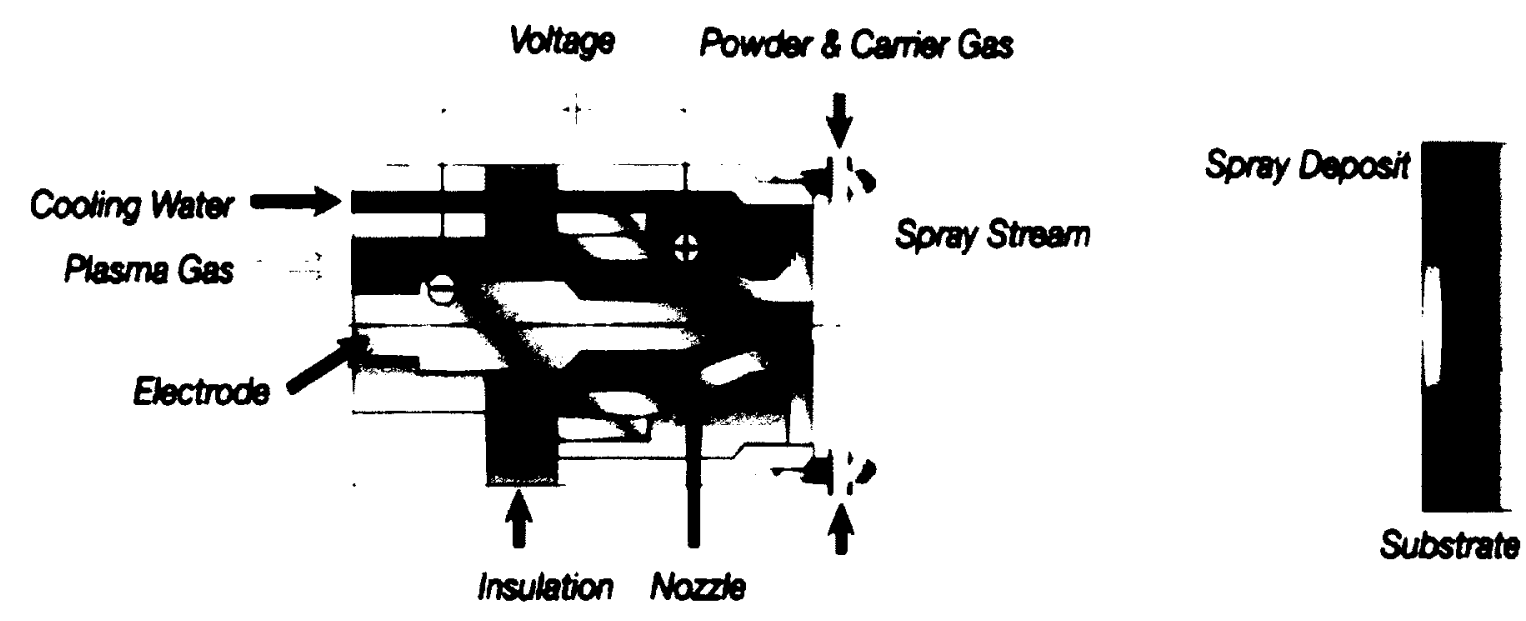

Figure 36: Schematic diagram of an atmospheric plasma process [65].

In the plasma spray process, molten droplets or particles are accelerated to speeds in the range of 50 to $>1000 \mathrm{~m} / \mathrm{s}$. The high particle temperature and speeds achieved result in significant droplet deformation on impact at the surface, producing thin layers or lamellae, often called splats that adhere to the substrate. Solidified droplets build up rapidly, particle by particle, as a continuous stream of droplets impact to form continuous rapidly solidified layers. Individual splats are generally thin $(1$ to $20 \mu \mathrm{m})$, and each droplet cools at very high rates $\left(>10^{6} \mathrm{~K} / \mathrm{s}\right.$ for metals) to form very fine grained polycrystalline coatings or deposits [62].

The tensile strength of as-sprayed deposits can range from 10 to $60 \%$ of those of cast or wrought materials. Spray conditions leading to higher oxide levels and lower deposit densities result in the lower strength to about $60 \%$ and requires post-deposition heat treatment to achieve near $100 \%$ strength properties [62].

As a novel thermal spray system, Mettech Axial III system has an axial powder injection system. in which powder is carried through the center powder port and ejects co-axially with the plasma gases, whereas, conventional plasma spray systems inject 
powder through the radial powder port. Higher particle temperature and higher particle velocity are the advantages of the Mettech Axial III ${ }^{\mathrm{TM}}$ system over conventional plasma spray system. The greater thermal and kinetic energy enhances adhesion between the coating and substrate and produces denser coatings with reduced oxides [66]. Also, the direct introduction of the powder in the plasma jet increases the overall deposition efficiency [63].

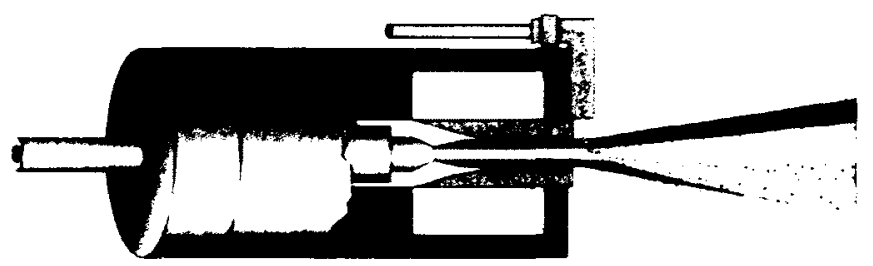

Traditional Radial Plasma Gun
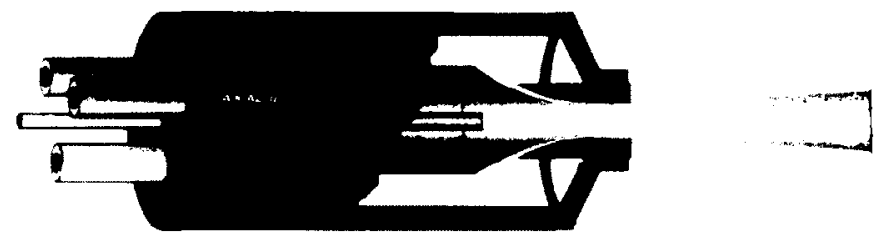

Axial III Plasma Gun

Figure 37: Traditional radial plasma gun and Axial III gun.

\subsection{Summary}

Nickel-based superalloys are the most advanced superalloys used in high temperature applications. Using this class of materials in GTEs provides higher efficiency and increased component life because they are more resistant to loading under static, fatigue, and creep conditions than other classes of superalloys. Hastelloy X, a nickel based alloy, has been especially tailored for hot temperature applications and has 
excellent combination of oxidation resistance, fabricability and high-temperature strength. Hastelloy $\mathrm{X}$ is also exceptionally resistant to stress-corrosion cracking and exhibits good ductility after prolong exposures.

Modern gas turbines have turbine inlet temperatures exceeding the melting point of the current superalloys; therefore, hot section components require materials with higher melting point, mechanical strength, oxidation/corrosion resistant. Applying high temperature coatings, such as diffusion aluminide, MCrAlY and TBCs, on superalloys increases the service temperature of the superalloys and the oxidation/corrosion resistance. However, there are drawbacks in using these methods. For instance, coatings are often inhomogeneous [67] and CTE mismatch exists between the coatings and substrates, both of which result in coating degradation and spallation. In addition, demand for higher efficiency and reduced emission requires still higher operating temperatures and in turn calls for materials with higher melting point and higher chemical and mechanical stability.

In contrast, advanced ceramics have some exceptional properties including very high melting point, good mechanical properties such as high hardness, elastic modulus, and compressive strength. Because of these properties, ceramics are considered to be potential materials for high temperature applications. To be considered as alternatives for metals, ceramic materials must improve their fracture toughness/damage tolerance - both of which are currently preventing the wide use of the ceramics for structural applications [36]. To improve the mechanical properties, ceramics must be reinforced to provide the required toughness which is the primary goal of this study. 


\subsection{Thesis Objectives and Scope}

The purpose of this thesis is to explore the possibility of improving the damage tolerance of monolithic ceramic material through the use of embedded metallic mesh reinforcement. This research is an 'evolutionary' process since ceramics have been reinforced in the past with whiskers, short fibers as well as continuous fibers. Therefore, the use of a metallic mesh can be seen as a step forward to the creation of a "two dimensional' continuous fiber reinforcement.

To achieve the objectives outlined in this work, the following activities were carried out:

- Design and manufacturing of fixtures to weave the meshes from $0.5 \mathrm{~mm}$ molybdenum and $1 \mathrm{~mm}$ Hastelloy $\mathrm{X}$ wires.

- Weaving the meshes and spot welding the mesh wires at warp and weft intersections.

- Fabricating metal-ceramic composite materials using the plasma spray technique which applies a NiCrAlY bond coating and a 7YSZ ceramic coating (as ceramic matrix).

- Evaluating cyclic and isothermal oxidation resistance, and mechanical properties of the composites.

- Proposing optimum designs for metal-ceramic composites based on the experimental results.

- Preliminary investigation of three dimensional metal reinforced ceramic materials. 
Thus this thesis forms the beginning of research investigating the efficiency of using metallic mesh to improve the damage tolerance of ceramic materials. Two different high temperature wire materials were used as mesh core in the first phase of the project: pure Mo and Hastelloy X alloy. Bond coating and overlay ceramic matrix materials were kept the same for both types of produced CMCs. The damage tolerance of CMCs, particularly their room temperature bend and impact strength, and high temperature isothermal and cyclic oxidation resistance were evaluated. The ultimate goal of this research is to provide alternative materials for high temperature and eventually ultra-high temperature structural applications. 


\section{Materials and Experimental Procedures}

\subsection{Materials}

\subsubsection{Hastelloy $\mathbf{X}$}

Hastelloy $X$ is the registered trademark name of Haynes International, Inc., a developer and manufacturer of high-performance nickel- and cobalt-based alloys. Hastelloy ${ }^{\circledR} \mathrm{X}(\mathrm{HX})$ alloy is a nickel-chromium-iron-molybdenum alloy developed for high temperature applications. The nominal composition of $\mathrm{HX}$ and its typical physical properties are shown in Table 7 and Table 8 respectively. This alloy possesses a combination of good oxidation resistance, fabricability and high temperature strength. HX shows good ductility after prolonged exposure to high temperatures up to $870^{\circ} \mathrm{C}$, and has excellent forming and welding characteristics. $\mathrm{HX}$ alloy has a wide use in gas turbine engines for combustion zone components such as transition ducts, combustor cans, spray bars and flame holders as well as afterburners, tailpipes and cabin heaters. It also is recommended for use in industrial furnace applications because it has unusually high resistance to oxidation in reducing and neutral atmospheres [68].

Table 7: Nominal chemical composition of Hastelloy X in wt.\% [68].

\begin{tabular}{llllllllll}
\hline $\mathrm{Ni}$ & $\mathrm{Cr}$ & $\mathrm{Fe}$ & $\mathrm{Mo}$ & $\mathrm{Co}$ & $\mathrm{W}$ & $\mathrm{C}$ & $\mathrm{Mn}$ & $\mathrm{Si}$ & $\mathrm{B}$ \\
\hline $\mathrm{Bal}$ & 22 & 18 & 9 & 1.5 & 0.6 & 0.10 & $<1$ & $<1$ & $<0.008$ \\
\hline
\end{tabular}


Table 8: Typical physical properties of Hastelloy X [68].

\begin{tabular}{lcc}
\hline & Temperature, ${ }^{\circ} \mathrm{C}$ & Metric Units \\
\hline Density & 22 & $8.22 \mathrm{~g} / \mathrm{cm}^{3}$ \\
\hline Melting Range & $1260-1355$ & - \\
\hline Thermal Conductivity & 21 & $9.1 \mathrm{~W} / \mathrm{m}-\mathrm{K}$ \\
\hline Specific Heat & Room & $486 \mathrm{~J} / \mathrm{Kg}-\mathrm{K}$ \\
\hline Mean Coefficient of Thermal & $25-700$ & $13.0 \times 10^{-6} \mathrm{~m} / \mathrm{m}-{ }^{\circ} \mathrm{C}$ \\
Expansion & & \\
\hline Poisson's Ratio & 22 & 0.320 \\
\hline $\begin{array}{l}\text { Dynamic Modulus of } \\
\text { Elasticity }\end{array}$ & Room & $205 \mathrm{GPa}$ \\
\hline
\end{tabular}

\subsubsection{Molybdenum (Mo)}

Molybdenum is a hard transition metal, but is softer and more ductile than tungsten. Discovered in 1778, Mo has one of the highest melting points of all pure elements $\left(2610^{\circ} \mathrm{C}[69]\right)$. It also has a high specific elastic modulus, which makes it attractive for applications that require both high stiffness and low weight. The high thermal conductivity, low CTE, and low specific heat of this metal provide resistance to thermal shock and fatigue. Molybdenum is used as an alloying element in alloys, electrodes and catalysts. Molybdenum is an important alloying agent with physical properties shown in Table 9; it contributes to the hardenability and toughness of quenched and tempered steels [70]. Almost all ultra-high strength steels with minimum yield points up to 2068 $\mathrm{MPa}$ contain molybdenum in amounts from 0.25 to $8 \%$. Molybdenum oxidizes at elevated temperatures and is not suitable for continued service in an oxidizing atmosphere at temperatures above $500^{\circ} \mathrm{C}$ unless protected by an adequate coating. In inert atmospheres, it is unaffected up to $1760^{\circ} \mathrm{C}$. Molybdenum is relatively inert in hydrogen, ammonia, and nitrogen up to about $1100^{\circ} \mathrm{C}$, but a thin nitride case may be 
formed in ammonia or nitrogen. The metal is also used in nuclear energy applications and for missile and aircraft parts. It has found applications as a filament material in electronic and electrical applications [71].

Table 9: Properties of molybdenum, $99.95 \mathrm{wt} \% \%$ pure, rolled at $1000^{\circ} \mathrm{C}[69]$.

\begin{tabular}{ll}
\hline Density & $10200 \mathrm{~kg} \cdot \mathrm{m}^{-3}$ \\
\hline Young's Modulus & $325 \mathrm{GPa}$ \\
\hline Yield Strength $0.2 \%$ Proof & $550 \mathrm{MPa}$ \\
\hline Ultimate Tensile Strength & $620-690 \mathrm{MPa}$ \\
\hline Elongation & $10-20 \%$ \\
\hline Vickers Hardness & 250 \\
\hline Thermal Conductivity & $137 \mathrm{~W} \cdot \mathrm{m}^{-1} \cdot \mathrm{K}^{-1}$ \\
\hline Coefficient of Thermal Expansion & $5.1 \times 10^{-6} \mathrm{~K}^{-1}$ \\
\hline Recrystallization Temperature & $1100^{\circ} \mathrm{C}$ \\
\hline Melting Temperature & $2623^{\circ} \mathrm{C}$ \\
\hline
\end{tabular}

\subsubsection{MCrAlY}

MCrAlY (where $\mathrm{M}=\mathrm{Ni}, \mathrm{Co}$, or both) overlay coatings have been developed to protect superalloys in hot sections of gas turbine components against high temperature oxidation and hot corrosion. The MCrAlY bond coat plays an important role in protecting the underlying alloy against high temperature oxidation and providing better adhesion of the top coat to the substrate. The major advantage of overlay coatings, compared with diffusion coatings which have properties that strongly depend on the substrate composition, is that their properties can be better controlled and balanced for a specific application since wide range of coating compositions, independent of the substrate composition, can be produced [72]. MCrAlY can be specifically tailored to provide the required environmental resistance and compatibility with substrate (microstructure and 
physical properties such as $\mathrm{CTE}$ ). In general, overlay coatings have better oxidation and corrosion resistance than diffusion coatings and can be used at higher temperatures [72, 73]. The MCrAlY coatings usually form a protective $\mathrm{Al}_{2} \mathrm{O}_{3}$ scale by interaction with the oxidizing environment of the combustion gases. The adherence of this scale in thermal cycling conditions is promoted by the incorporation of active metals such as yttrium [74]. The chemical composition and CTE for the NiCrAlY powder used in this study are listed in Table 10 and Table 11, respectively.

Table 10: Chemical composition (in wt.\%) of NiCrAlY bond coat.

\begin{tabular}{lllll}
\hline NiCrAlY & $\mathrm{Ni}$ & $\mathrm{Cr}$ & $\mathrm{Al}$ & $\mathrm{Y}$ \\
\cline { 2 - 5 } $\mathrm{Ni}-246-4$ & $\mathrm{Bal}$ & 13 & 12 & 0.65 \\
\hline
\end{tabular}

Table 11: Coefficient of thermal expansion of NiCrAl powder [75].

\begin{tabular}{ll}
$\mathrm{CTE}$ & $10 \times 10^{-6} \mathrm{~K}^{-1}\left(800^{\circ} \mathrm{C}\right)$ \\
\hline
\end{tabular}

\subsubsection{Yttrium Stabilized Zirconia: 7YSZ}

As the TIT climb close to $1300^{\circ} \mathrm{C}$, to avoid structural failure by melting, creep, oxidation, thermal fatigue, or hot corrosion, compressor discharge air is injected to cool the component. 7YSZ TBC layer on the components decreases the surface temperature, reducing severe damages. These $\mathrm{TBC}$ layers have a tendency to spall upon thermal cycling. Nevertheless, Yttria stabilized zirconia (6-8 wt.\% $\left.\mathrm{Y}_{2} \mathrm{O}_{3}\right)$ has the longest spallation life at temperatures above $982^{\circ} \mathrm{C}$. Chemical composition, mechanical and physical properties of typical YSZ are given in Table 12 and Table 13 [76]. 
Table 12: Chemical composition (in wt.\%) of 7YSZ used in this research.

\begin{tabular}{lll}
\hline 7YSZ & $\mathrm{ZrO}_{2}$ & $\mathrm{Y}_{2} \mathrm{O}_{3}$ \\
\cline { 2 - 3 } ZRO-271-3 & Bal. & 7.5 \\
\hline
\end{tabular}

Table 13: Mechanical and physical properties of $\mathrm{YSZ}\left(\sim 8 \mathrm{wt} . \% \mathrm{Y}_{2} \mathrm{O}_{3}\right)$.

\begin{tabular}{llllll}
\hline YSZ & $\begin{array}{l}\text { Density } \\
\left(\mathrm{g} / \mathrm{cm}^{3}\right)\end{array}$ & $\begin{array}{l}\text { Young's } \\
\text { Modulus } \\
(\mathrm{GPa})\end{array}$ & $\begin{array}{l}\text { Thermal } \\
\text { Conductivity } \\
(\mathrm{W} / \mathrm{m}-\mathrm{K})\end{array}$ & $\begin{array}{l}\text { CTE [77] } \\
\left(10^{-6} /{ }^{\circ} \mathrm{C}\right) \\
\left(800^{\circ} \mathrm{C}\right)\end{array}$ & $\begin{array}{l}\text { Max. Use } \\
\text { temp }\left({ }^{\circ} \mathrm{C}\right)\end{array}$ \\
\hline & 6.02 & 200 & 2.2 & -10.3 & 2400 \\
\hline
\end{tabular}

\subsection{General Manufacturing Steps to Fabricate Mesh Reinforced CMCs}

The manufacturing efforts were comprised of three parts dealing with mesh fabrication, bond coat application and final ceramic deposition.

\subsubsection{Mesh Fabrication}

The first step was to choose the fabrication process for the mesh; this included wire cutting, weaving, welding, and removed from the jig. The mesh, as a reinforcement structure, was manufactured by first cutting and inserting wires into the jig and then spot welding the wires. To produce a repeatable reinforcement structure, a jig was created that could hold the wires in place during spot welding operation. To reduce the flexibility and increase the rigidity of the metallic mesh, the warp (lengthwise) and weft (crosswise) wires were spot welded at their intersecting joints. The reinforcement structures used in the Mo/7YSZ and HX/7YSZ CMC materials were square molybdenum and Hastelloy X wire mesh, respectively. Using the jig shown in Figure 38 and Figure 39, a wire spacing 
of 18 wires per inch for $0.5 \mathrm{~mm}$ Mo wire and a wire spacing of 10 wires per inch for 1 $\mathrm{mm} \mathrm{HX}$ wire was maintained. Once the wires were secured in the jig, a Miyatchi Unitek resistance spot welding machine (CA, USA) was used to individually weld each wire intersection in the mesh. Resistance spot welding was performed under a flow of argon gas to reduce any possible surface oxidation of the wires. After welding, meshes were released from the jig, ultrasonically cleaned for 30 minutes, and then rinsed with water and then acetone.

Resistance welding is one of the oldest of the electric welding processes used by industries. The resistance weld is achieved by a combination of heat and pressure. The electrical resistance of the material to be welded causes a localized heating in the part. The pressure exerted by the tongs and electrode tips, through which the current flows, holds the parts to be welded in contact before, during, and after the welding current is passed through. The required amount of welding time is determined by material type and thickness, the current, and the cross-sectional area of the welding tip contact surfaces. The advantages of spot welding include efficient energy use, limited part deformation, high production rates, easy automation, no filler materials required, low heat input to weld metal and no need for skilled welder. This weld provides high strength in shear than the more costly mechanical fastening method [78]. Figure 38 to Figure 40 show the AutoCAD drawing of the wooden jig, actual woven mesh, and spot welded mesh respectively. In Figure 40 the spot welded Hastelloy $\mathrm{X}$ mesh before and after removing from the wooden fixture is shown. To maintain an even and uniform aperture size during spot welding, a feeler wire tool was used to measure the clearance between two adjacent wires while meshes were being fabricated. 


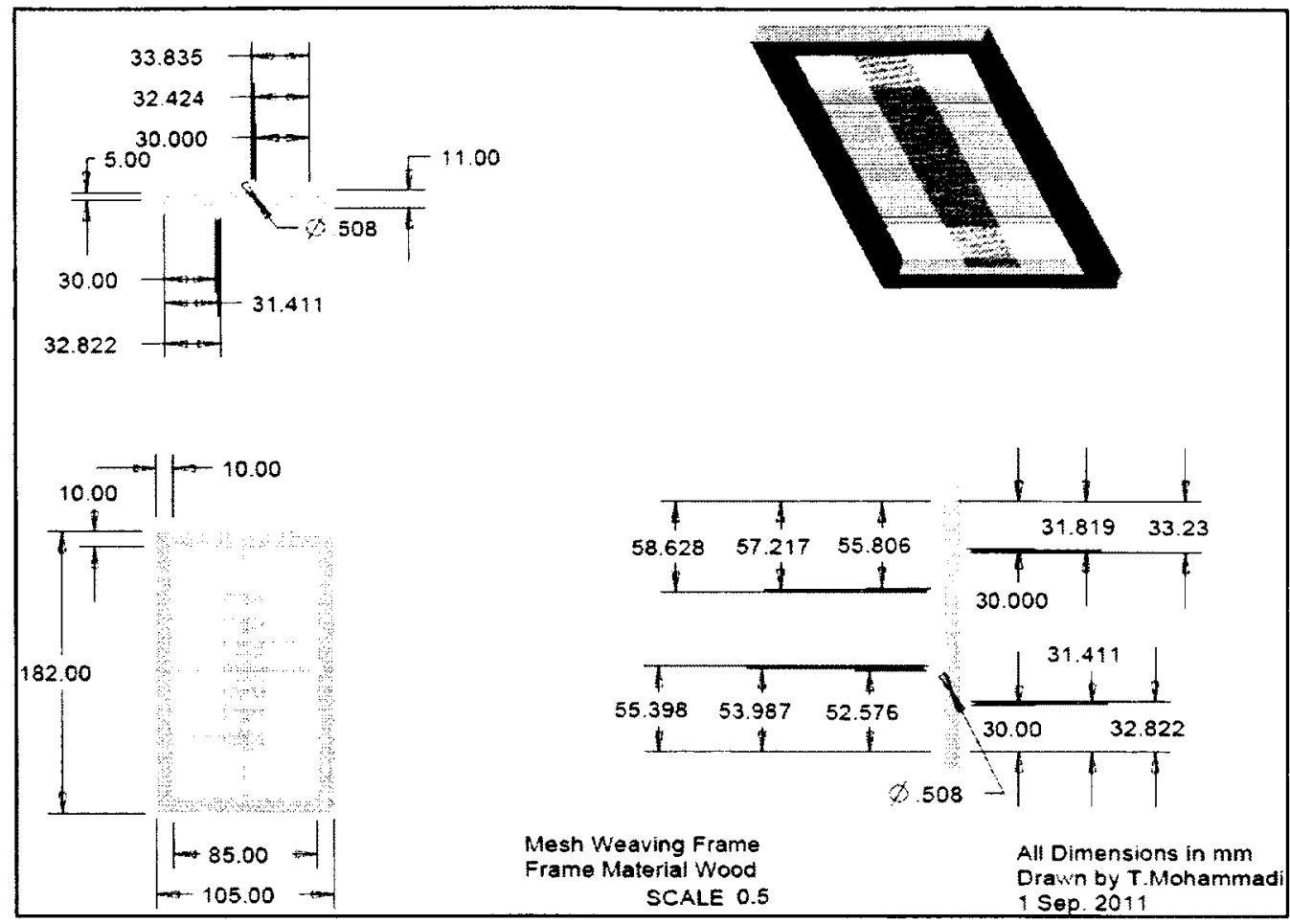

Figure 38: AutoCAD drawing of Mo mesh weaving frame; same weaving frame was used to weave the HX mesh.

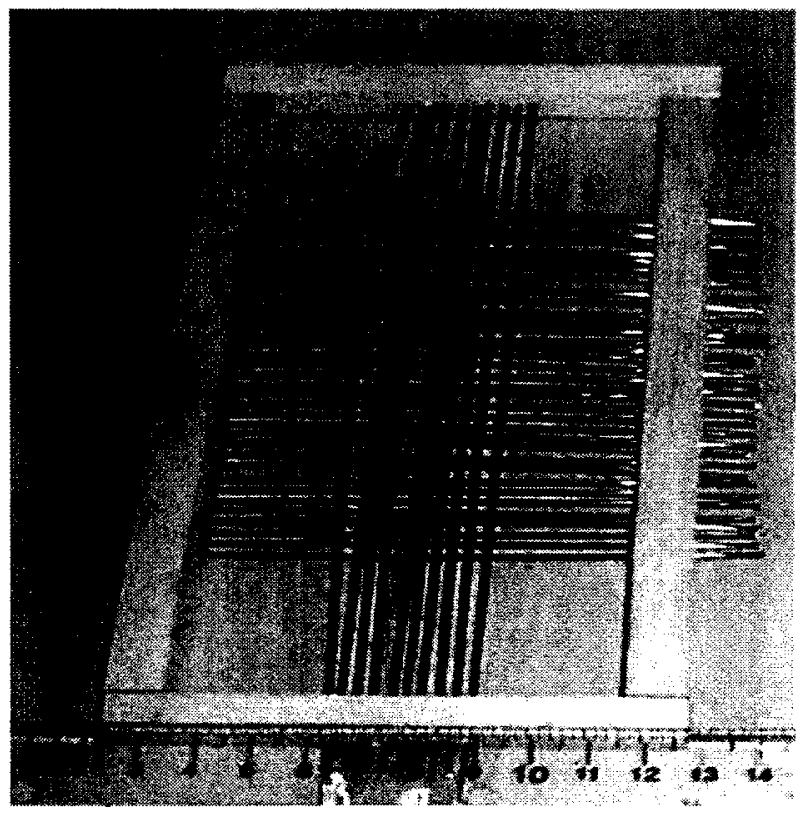

Figure 39: Wooden mesh weaving frame. Inside the frame, Hastelloy $\mathrm{X}$ woven wires are ready for spot welding. 


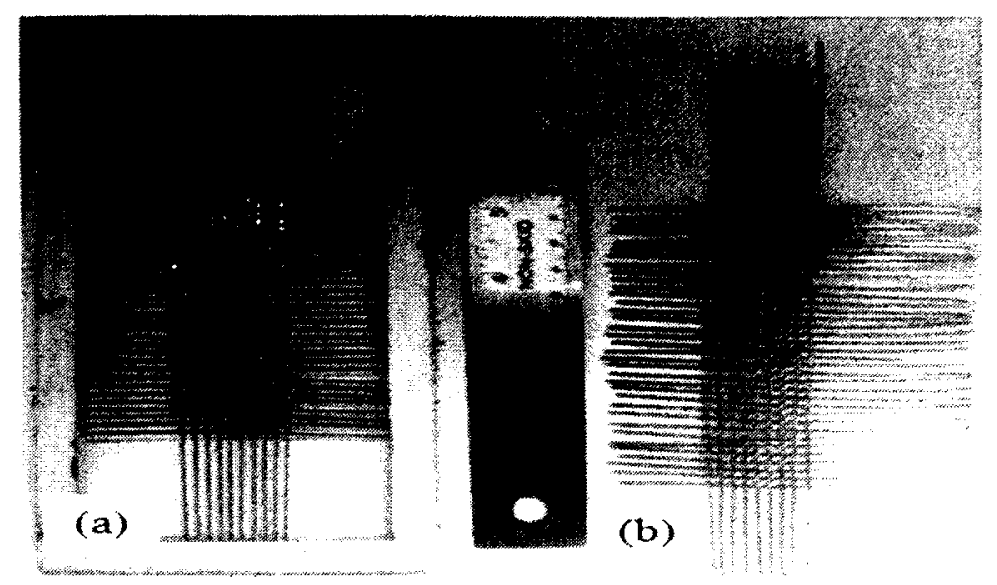

Figure 40: Spot welded Hastelloy $\mathrm{X}$ wire mesh: (a) before, and (b) after releasing from the jig.

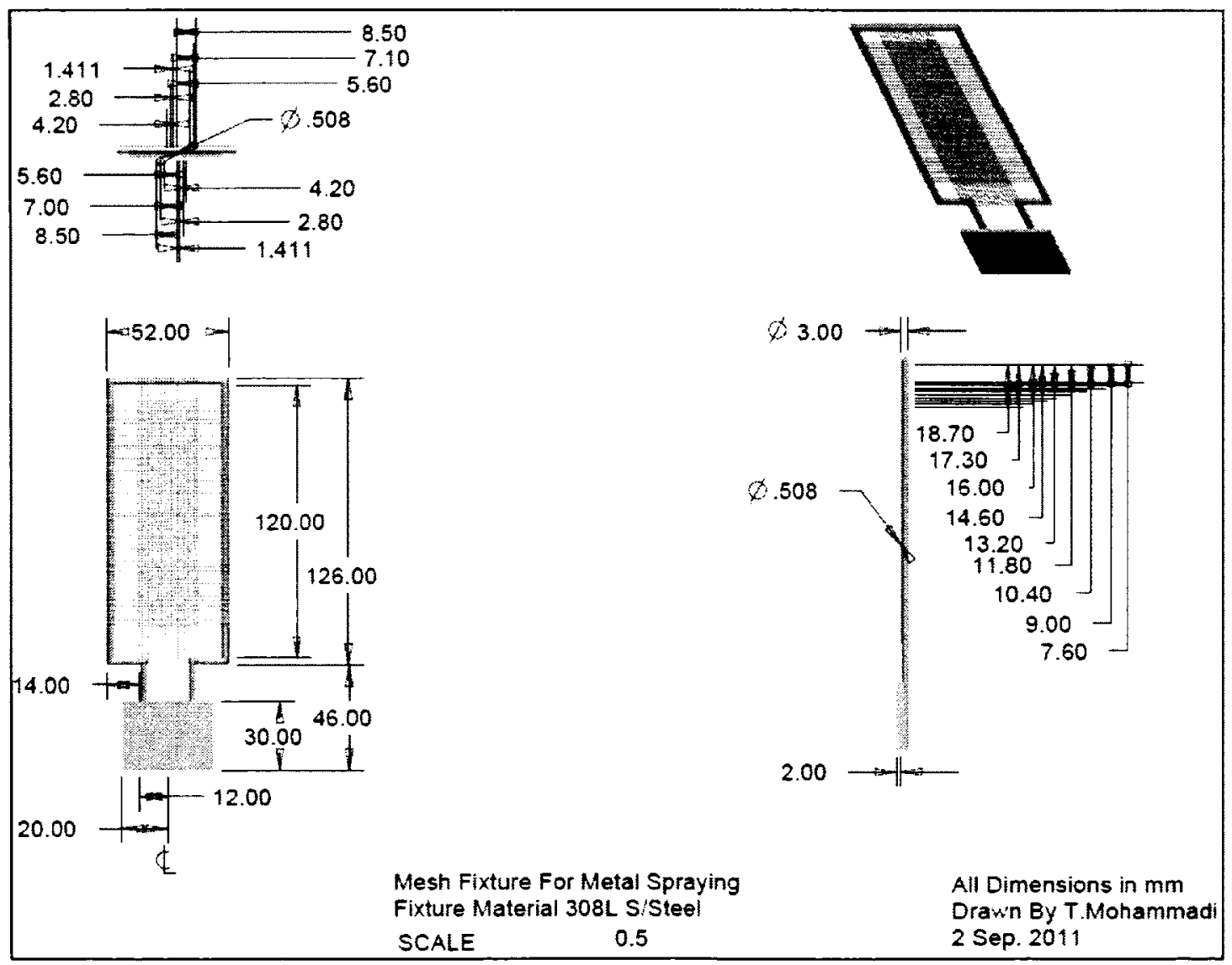

Figure 41: AutoCAD drawing of mesh fixture for plasma spraying when Mo wires are fixed on fixture; same fixture was used to fix the $\mathrm{HX}$ mesh in place for plasma spraying. 
To have sufficient stability and rigidity during plasma spray, meshes were attached onto a stainless steel fixture frame. Shown in Figure 41 and Figure 42 are the AutoCAD drawings of the fixtures to support the wire mesh and the actual fixture frame respectively. The final product before spraying with welded junctions is shown in Figure 43.

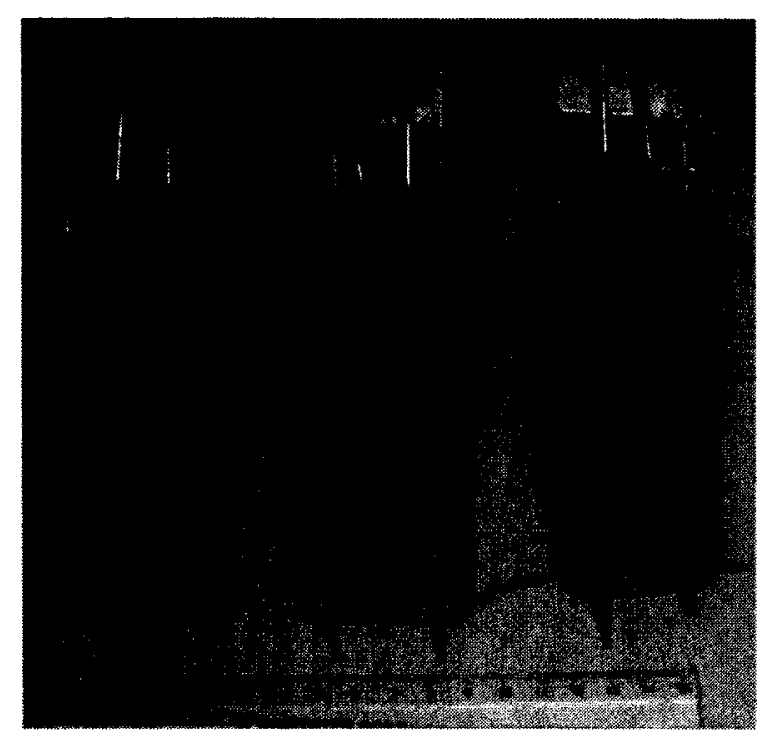

Figure 42: Mounted Hastelloy X wire meshes on fixture frames made from 308 stainless steel.
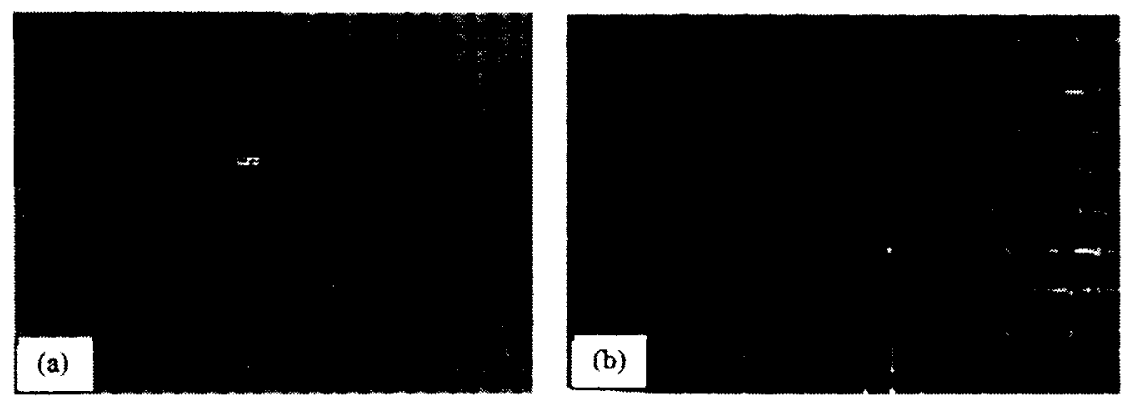

Figure 43: As-fabricated: (a) Mo mesh and welded junction (inset), and (b) Hastelloy X mesh. 
To coat the meshes with bond and ceramic coatings, a clean rough surface was required. Prior to plasma spraying the meshes were grit blasted using No. 46 Grit aluminum oxide abrasive (ALODUR) for about three minutes. Afterwards, the cleaned parts were handled using latex gloves and transferred to plasma spray machine quickly to prevent any contamination of the cleaned blasted surface. While the preparation processes up to mesh manufacturing are the same for both Mo and Hastelloy X metallic core CMC materials, sections 3.3.1 and 3.3.2 detail the work done on these two composite materials separately.

\subsubsection{Plasma Spray Coating Process and Parameters}

A Mettech Axial III plasma spray system, manufactured by Northwest Mettech Corporation (Vancouver, Canada) with a Thermach Inc. AT-1200HP powder feeder, was used to deposit the coatings (Figure 44).

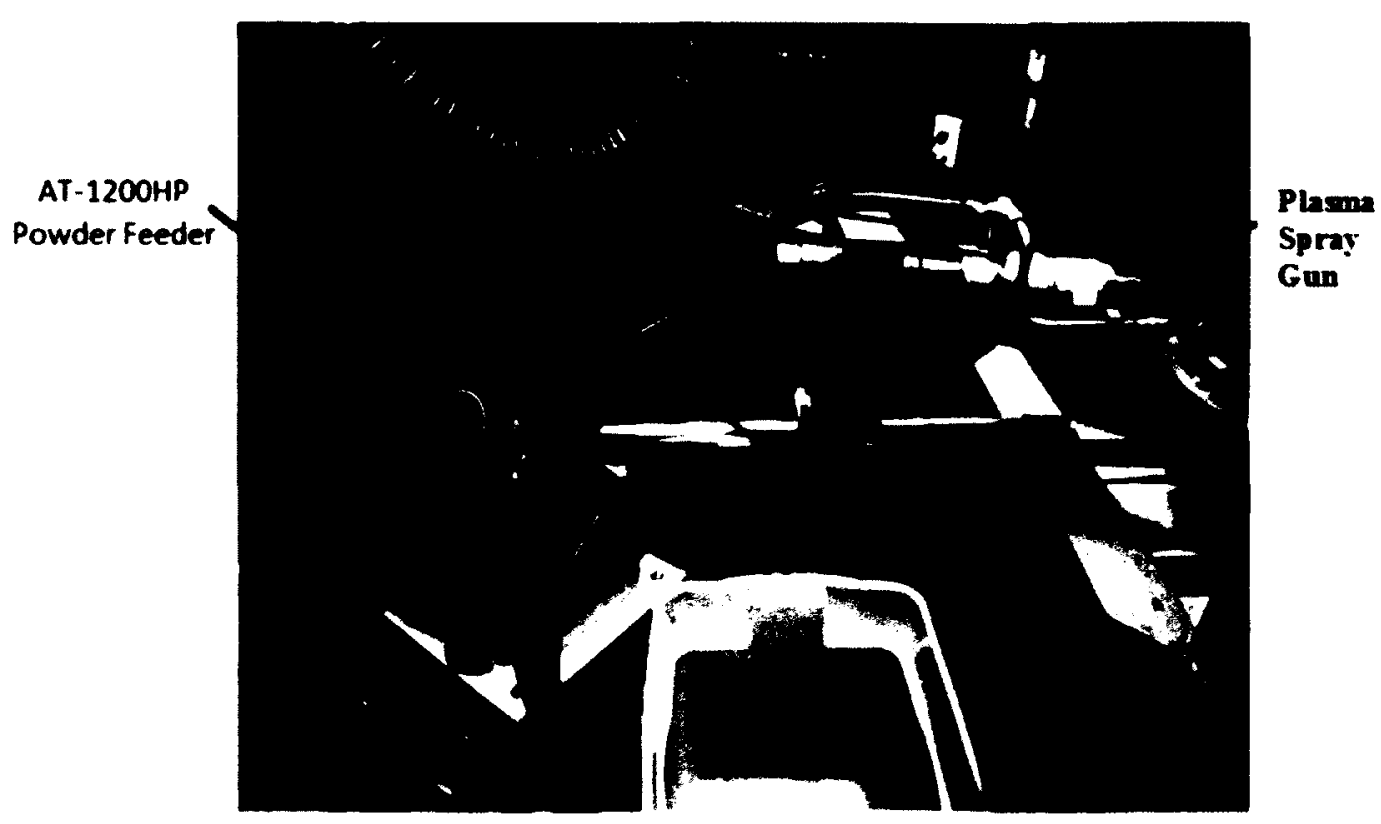

Figure 44: Plasma spray system AT-1200HP powder feeder and plasma spray gun. 
The powder compositions of NiCrAlY and 7YSZ and plasma spray parameters are provided in Table 14 to Table 16 respectively. The spray parameters were suggested by the spray manufacturer for each powder.

Table 14: Powders used for plasma spraying.

\begin{tabular}{ccccc}
\hline & Composition (wt \%) & $\begin{array}{c}\text { Powder Size } \\
\text { distribution }(\mu \mathrm{m})\end{array}$ & Trade Name & Manufacturer \\
\hline NiCrAlY & Bal. Ni, 31\% Cr, $12 \% \mathrm{Al}$, & $90 \pm 38$ & Ni-246-4 & Praxair \\
& $0.65 \% \mathrm{Y}$ & & & \\
\hline 7YSZ & $\mathrm{Bal.} \mathrm{ZrO}_{2}, 7.5 \% \mathrm{Y}_{2} \mathrm{O}_{3}$ & $45 \pm 5$ & ZRO-271-3 & Praxair \\
\hline
\end{tabular}

Table 15: Spray parameters for plasma spraying NiCrAlY.

\begin{tabular}{ll|ll}
\hline Argon & $51 \%$ & Total flow rate & $250 \mathrm{slm}$ \\
\hline Nitrogen & $10 \%$ & Powder feed rate & $\sim 50 \mathrm{~g} / \mathrm{m}$ \\
\hline Hydrogen & $39 \%$ & Carrier gas flow rate & $12 \mathrm{slm}$ \\
\hline Current & $250 \mathrm{~A}$ & Nozzle size & $3 / 8 \mathrm{in}$ \\
\hline Distance of plasma gun from substrate & $150 \mathrm{~mm}$ & Duration of single coating run & $1-2 \mathrm{~min}$. \\
\hline
\end{tabular}

Table 16: Spray parameters for plasma spraying 7YSZ.

\begin{tabular}{ll|ll}
\hline Argon & $0 \%$ & Total flow rate & $250 \mathrm{~s} / \mathrm{m}$ \\
\hline Nitrogen & $75 \%$ & Powder feed rate & $-50 \mathrm{~g} / \mathrm{m}$ \\
\hline Hydrogen & $25 \%$ & Carrier gas flow rate & $12 \mathrm{~s} \operatorname{lm}$ \\
\hline Current & $250 \mathrm{~A}$ & Nozzle size & $3 / 8 \mathrm{in}$ \\
\hline Distance of plasma gun from substrate & $150 \mathrm{~mm}$ & Duration of single coating run & $1-2 \mathrm{~min}$. \\
\hline
\end{tabular}

\subsubsection{Heat Treatment}

TBC cracking and spallation occurs at the interface between the ceramic top coat and the metallic bond coat at high temperatures. It has been found that the thermal cycle life of the interface between the 7YSZ top coat and the NiCrAlY bond coat can be 
improved by performing a vacuum heat treatment for 4 hours at $1080^{\circ} \mathrm{C}$ [79]. The vacuum heat treatment promotes the formation of a uniform $\mathrm{Al}_{2} \mathrm{O}_{3}$ TGO layer at the interface. This TGO alumina layer subsequently reduces the growth of other undesirable oxides such as chromia, nickel oxide and spinel (a class of minerals of general formulation $\mathrm{AB}_{2} \mathrm{O}_{4}: \mathrm{A}$ and $\mathrm{B}$ are metals) [80]. Therefore, half of the $\mathrm{Mo} / \mathrm{YSZ} \mathrm{CMC}$ and HX/YSZ CMC, and reference specimens were heat treated in an OXY-GON vacuum furnace (Figure 45) for 4 hours at $1080^{\circ} \mathrm{C}$ in a vacuum less than $2 \times 10^{-5}$ torr. These specimens are referred to as heat treated specimens in this report; whereas, the other half of the CMCs are referred as as-sprayed.

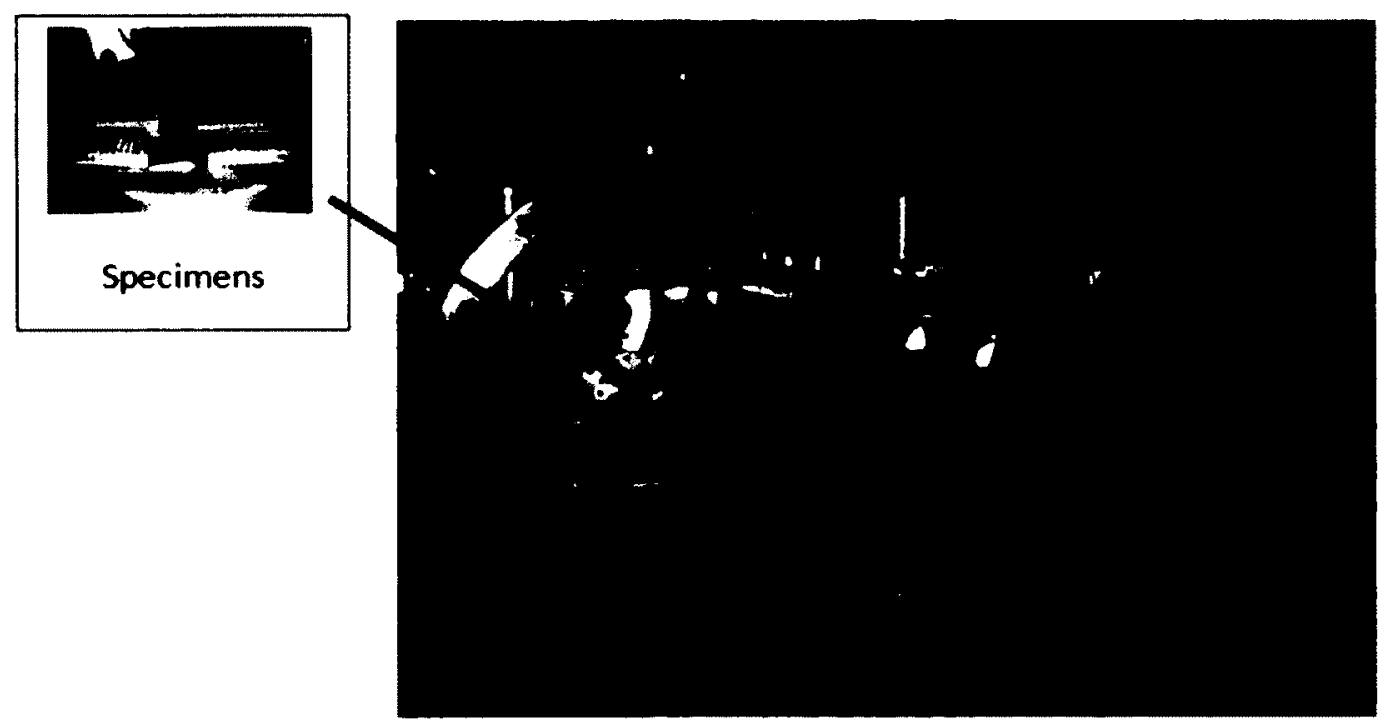

Figure 45: OXY-GON vacuum furnace.

\subsection{Detailed Manufacturing Process for Metal Reinforced CMC}

\section{Samples}

\subsubsection{Molybdenum Mesh Reinforced CMC}


At high temperatures Mo oxidizes rapidly in air at roughly $700^{\circ} \mathrm{C}$. At around $450^{\circ} \mathrm{C}, \mathrm{MoO}_{3}$ becomes volatile [81]. Furthermore, Mo becomes brittle if it contains even modest concentrations of impurities such as oxygen, carbon and nitrogen, which occupy interstitial sites in the metal [82]. To prevent oxidation and diffusion of other impurities into the Mo wire, a NiCrAlY bond coat was applied to all sides of the Mo mesh by plasma spraying [79]. After coating the Mo mesh with a NiCrAlY bond coat, the plasma spray technique was also employed to apply the $7 \mathrm{YSZ}$ matrix material to the mesh.

Before plasma spraying of NiCrAlY, all of the Mo meshes were vacuum heat treated at $700^{\circ} \mathrm{C}$ for 3 hours. This heat treatment was performed to allow stress relief at the weld points. To avoid damaging the meshes, the temperature was kept below the melting point of the native oxide $\mathrm{MoO}_{3}$, which is $795^{\circ} \mathrm{C}$ [83]. All Mo meshes were then mounted on a stainless steel fixture frame and grit blasted to create a clean rough surface prior to plasma spraying. Grit blasting was done using No. 46 Grit aluminum oxide abrasive (ALODUR) for about 5 minutes and then the clean samples were handled using latex gloves and transferred to plasma spray machine promptly to prevent any contamination on the blasted surface.

The NiCrAlY bond coat was plasma sprayed on both sides of the Mo mesh, with an average thickness of $0.6 \mathrm{~mm}$ on each side. Afterwards, $7 \mathrm{YSZ}$ partially-stabilized zirconia with a thickness of $1.14 \mathrm{~mm}$ was applied to each side in a total of 12 two-minute runs. The spraying process was broken into small runs to avoid overheating the equipment and to monitor the coating thickness. By the sixth run, all voids between the mesh wires had been filled (Figure 46), and subsequent runs served to build up the matrix material 
thickness. The final result of thickness of the composite specimens was $4.8 \mathrm{~mm}$, as shown in Figure 47.

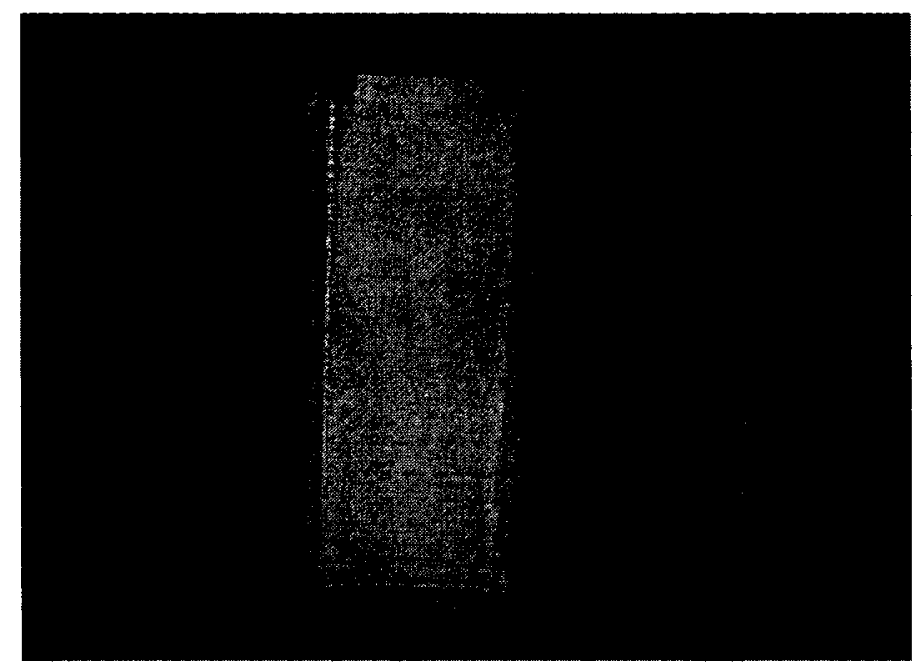

Figure 46: Mo mesh wire after 6 runs of 7 YSZ spraying operation.
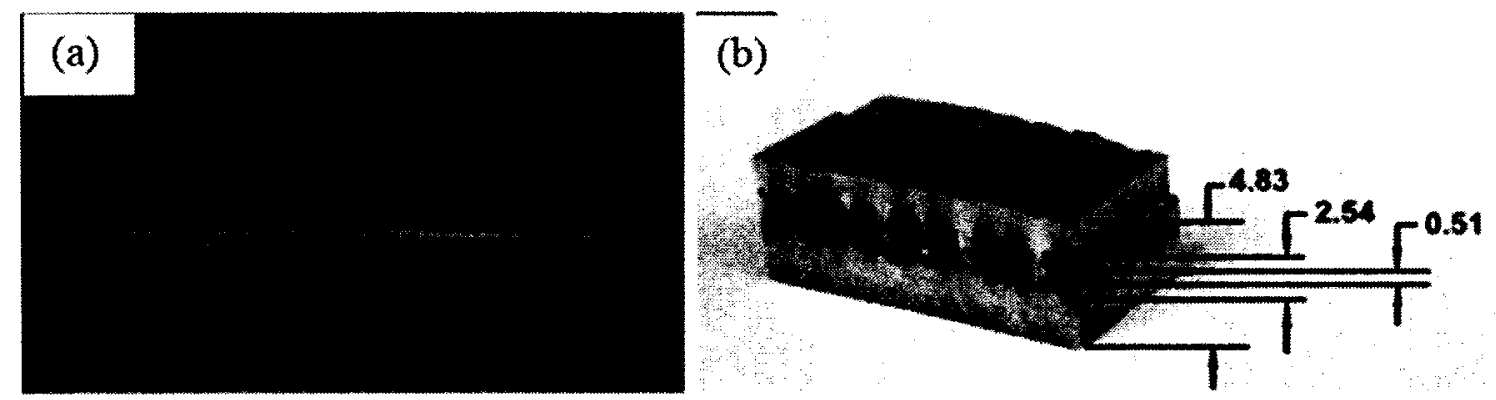

Figure 47: (a) Final Mo/YSZ specimen, and (b) composite dimensions (in mm).

Monolithic 7YSZ specimens were also prepared without Mo reinforcement and served as reference specimens to compare with the reinforced 7YSZ (Figure 48). To produce the reference specimens, $7 \mathrm{YSZ}$ powder was plasma sprayed onto a mild steel plate. After the plasma spray process was completed, the 7YSZ coating was removed from the plate to form a stand-alone specimen. 


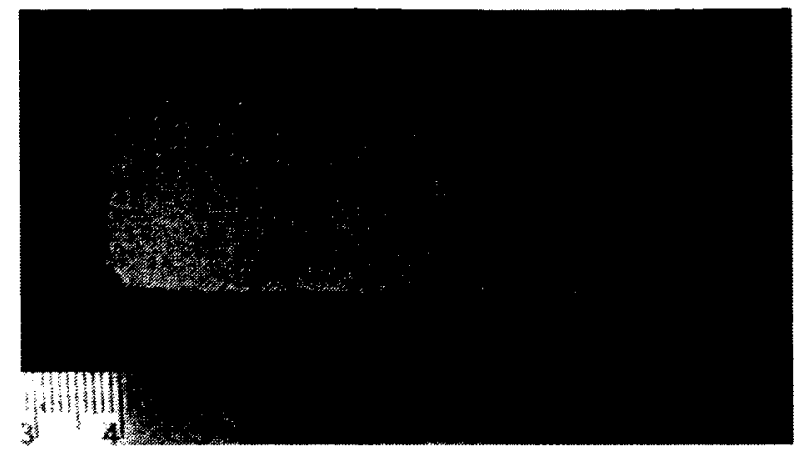

Figure 48: Final monolithic 7YSZ specimen.

\subsubsection{Hastelloy X Mesh Reinforced CMC}

The HX mesh after grit blasting is shown in Figure 49. The average thickness of NiCrAlY bond coat on HX mesh after plasma spraying was about $0.6 \mathrm{~mm}$ on each side.

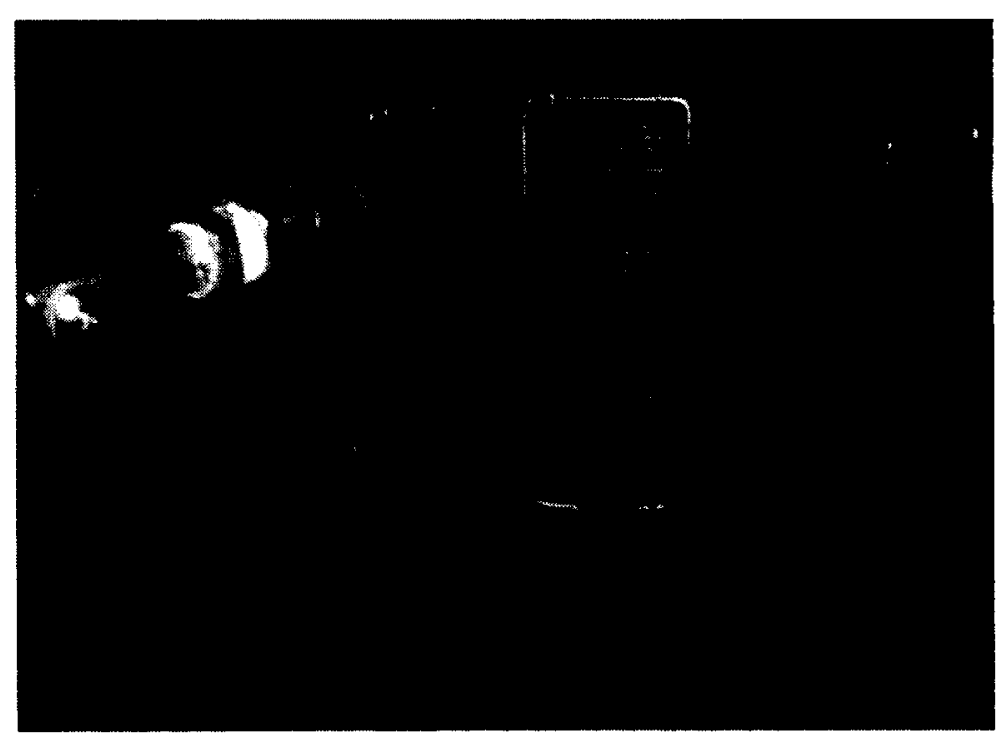

Figure 49: Bare Hastelloy X mesh in plasma spray set up for $\mathrm{NiCrAlY}$ bond coating.

After the bond coat, 7YSZ partially-stabilized zirconia with a thickness of 1.49 $\mathrm{mm}$ was applied to each side in a total of 14 two-minute runs. Figure 50 shows the plasma spraying operation and Figure 51 (a) and (b) the coating process after 3 and 4 runs 
spraying. Because of a delay between applying bond coat and 7YSZ coat, the bond coated meshes were heated for 2 hours at $200{ }^{\circ} \mathrm{C}$ in an Electrical Laboratory box Furnace (Model: 51894) to remove any possible absorbed moisture from the bond coat.

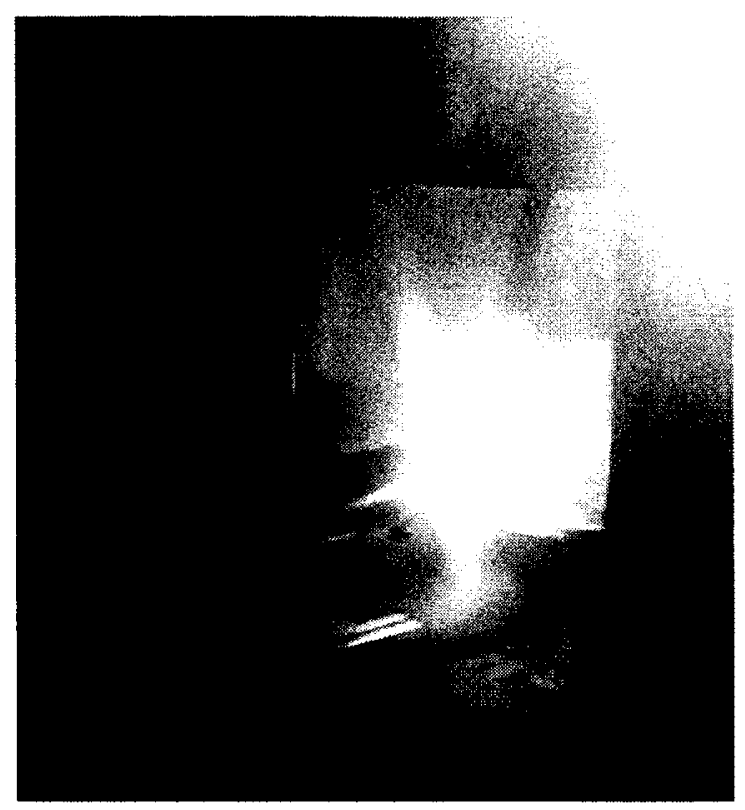

Figure 50: Plasma spray operation during 7YSZ coating.
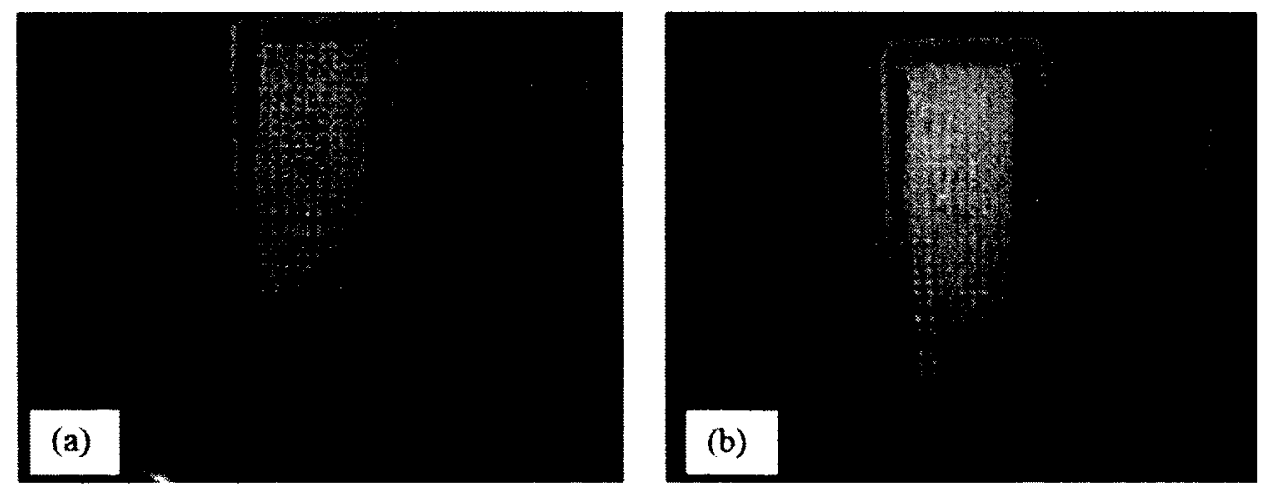

Figure 51: 7YSZ coating results: (a) after 3 runs, and (b) after 4 runs on each side. 
The HX mesh, compared to Mo mesh, had bigger aperture size. This required more 7YSZ ceramic deposition to fill the openings and fully cover the mesh surface. Two extra two-minute runs, compared to $\mathrm{Mo} / 7 \mathrm{YSZ}$ samples, served to smooth the CMC surface. The spraying process was broken into small runs to avoid overheating the equipment and to monitor the coating thickness. By the eighth run, all openings between the mesh wires had been filled, and subsequent runs served to build up the matrix material thickness and flattening the ripples on the surface. The final thickness of the composite specimens after completing the depositions was $6.15 \mathrm{~mm}$ as shown in Figure 52.

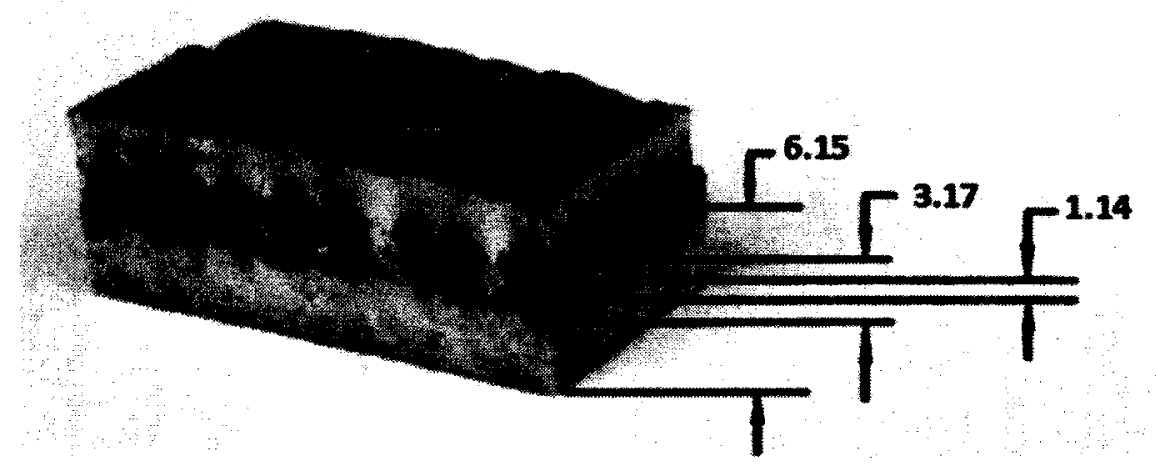

Figure 52: Final HX/7YSZ specimen's dimensions (in mm). 


\section{Test procedures for Mo/7YSZ and HX/7YSZ}

Four specimens with original dimensions of $4 \times 1 \frac{1}{2} \times 1 / 4$ inch from each of 7YSZ ceramic, Mo/7YSZ and HX/7YSZ composite materials were manufactured in this project. By cutting these specimens, four $2 \times 1 / 2 \times 1 / 4$ inch test samples were prepared. In Figure 53 the sectioning locations in HX/7YSZ composite specimen are shown. Half of the samples were vacuum heat treated (thereafter called as heat treated samples) and the rest of the samples were kept in the as-sprayed condition.

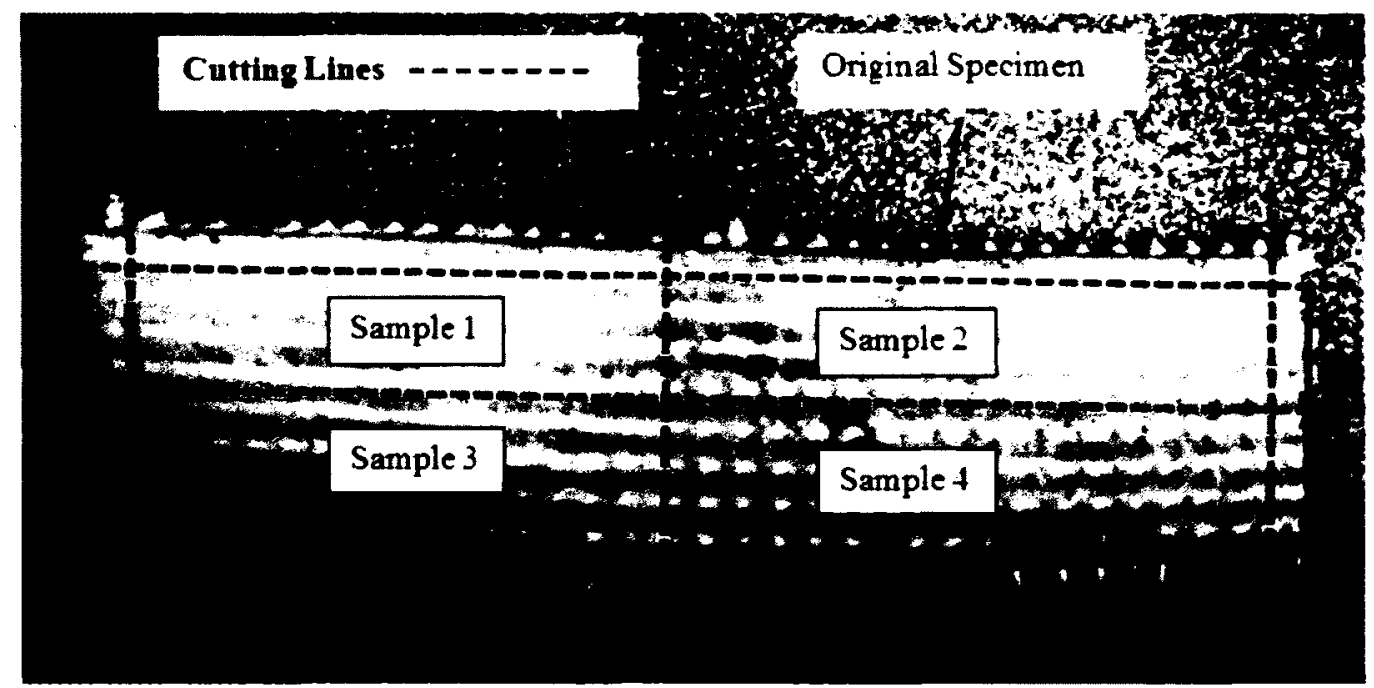

Figure 53: Sketch showing where the four $2 \times 1 / 2 \times 1 / 4$ inch samples from each HX/7YSZ original specimen were sectioned from.

To perform three-point bending test, samples of as-sprayed and heat treated were used. To examine the samples after isothermal and cyclic oxidation tests, sections from both external and internal parts of each sample were required. These sections are called directly exposed to air and not-directly exposed to air sections, respectively. The internal sections were also prepared by cutting the samples in longitudinal and transverse directions as shown in Figure 54. 


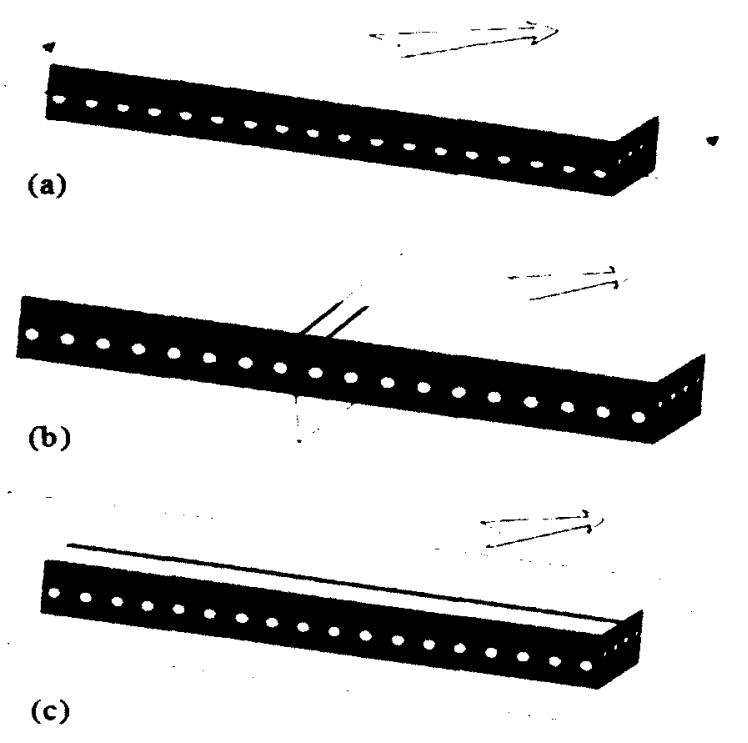

Figure 54: (a) Sketch showing directly exposed samples and cutting planes revealing (b) transverse and (c) longitudinal cross sections in not-directly exposed to air sections.

\subsection{Bend Testing}

The major difference between the three point and four point flexural tests is the location of the bending force. The four point bending method allows for uniform stress distribution between the two loading noses, whereas the stress in three point bending method is located under the loading nose. Four point bending test measures flexural strength or the force required to bend a plastic beam. This test method is used for reinforced or un-reinforced materials that do not break or fail on the outer surface within the limits of a loading test. Three point bending method is used primarily for brittle materials that break at relatively small deflections [84]. Three point bending test was selected for this research and carried out to determine the effect of reinforcement on the strength of monolithic ceramic and CMC.

The bending strength of the Mo/YSZ and HX/7YSZ composites as well as reference 7YSZ ceramic were assessed using a MTS 810 Material Test System machine with 
maximum capacity of $25 \mathrm{kN}$. From each $\mathrm{CMC}$, two 0.5 inch wide test strips were prepared; one in the as-sprayed and the other in the as heat treated condition. Reference 7YSZ ceramic, 0.5 inch wide strip, was also prepared.

An extensometer (model MTS 634.12E-24) was used to accurately record the displacements during testing. All the test data including time (s), axial displacement $(\mathrm{mm})$, axial strain $(\mathrm{mm} / \mathrm{mm})$, and axial force $(\mathrm{N})$ were recorded for evaluation and comparison of the strength of the samples.

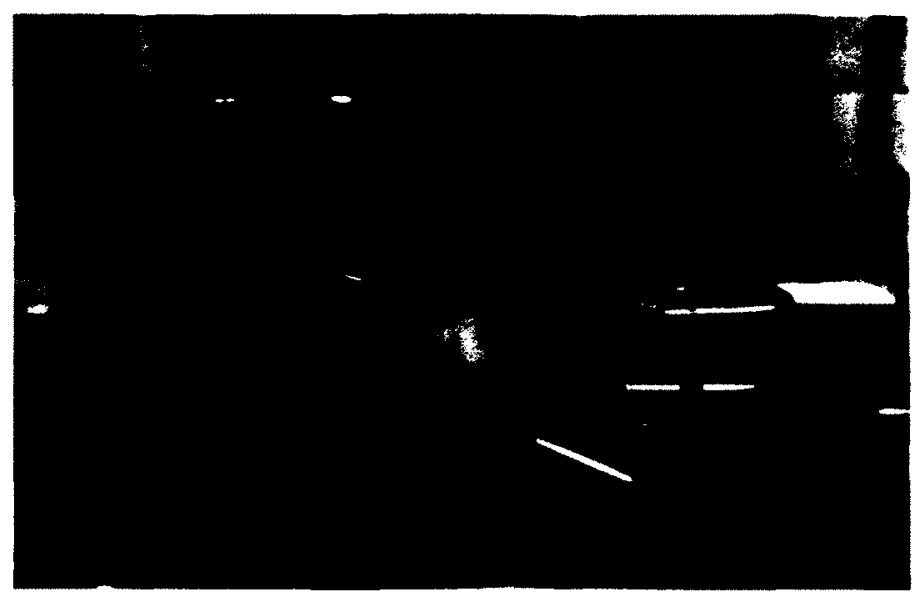

Figure 55: Three-point bend test of as-sprayed HX/7YSZ sample using MTS 810 machine.

The fracture surfaces of the broken specimens were used to investigate the effects of reinforcement and vacuum heat treatment on 7YSZ monolithic ceramic, Mo/7YSZ and HX/7YSZ samples.

\subsection{Charpy Impact Testing}

Charpy impact tests were carried out only on Mo/7YSZ composite and reference 7YSZ ceramic samples to assess the impact behaviour. These tests were carried out using a Tinius Olsen impact testing machine. Three test strips, having a width of 0.5 inch were 
cut from as-sprayed $\mathrm{Mo} / \mathrm{YSZ}$ composite strip, heat treated $\mathrm{Mo} / \mathrm{YSZ}$ composite strip and one reference strip of 7YSZ ceramic. The impact energy absorption was recorded and impact surface morphology was examined. Because the reference ceramic strip had a smaller thickness than the composites, the energy that is required for fracture needed to be normalized based on the cross-sectional area of the test strips.

The samples used in this test were smaller than the standard specimen sizes outlined by ASTM Standard E23 for Charpy impact testing [85]. As a result, the fracture energy recorded by testing machine would be low, which may compromise the accuracy of the measurements. Therefore, it was determined that the Charpy impact test should not necessarily be carried out on Hastelloy X samples.

\subsection{Isothermal Test}

This test was performed to determine the influence of static thermal exposure on degradation and failure of composite material manufactured in this project. Both assprayed and heat treated specimens of $\mathrm{Mo} / 7 \mathrm{YSz}$ and $\mathrm{HX} / 7 \mathrm{YSZ}$ composites were placed in a Lindberg Type 51442 furnace for an isothermal heat exposure of $1050^{\circ} \mathrm{C}$, Figure 56. To prevent any thermal shock to the composites the heating rate of the furnace in isothermal test, from room temperature to $1050^{\circ} \mathrm{C}$, was chosen as $1.8^{\circ} \mathrm{C} / \mathrm{min}$. To be matched with the time spent in the thermal cycling test, described below, Mo/7YSZ samples were exposed for 660 hours and HX/7YSZ samples 1000 hours. Groups of Mo/7YSZ specimens were removed at 165 hour intervals and HX/7YSZ were removed after 500 and 1000 hours for metallographic examinations. At $1050^{\circ} \mathrm{C}$ the color of the samples turned orange as expected [35], and after each interval two specimens, one as- 
sprayed and one as heat treated, were removed for metallographic examination. To reduce the likelihood of the coat cracking the furnace was turned off and the specimens were allowed to cool to ambient temperature by furnace-cooling before their removal from the furnace.

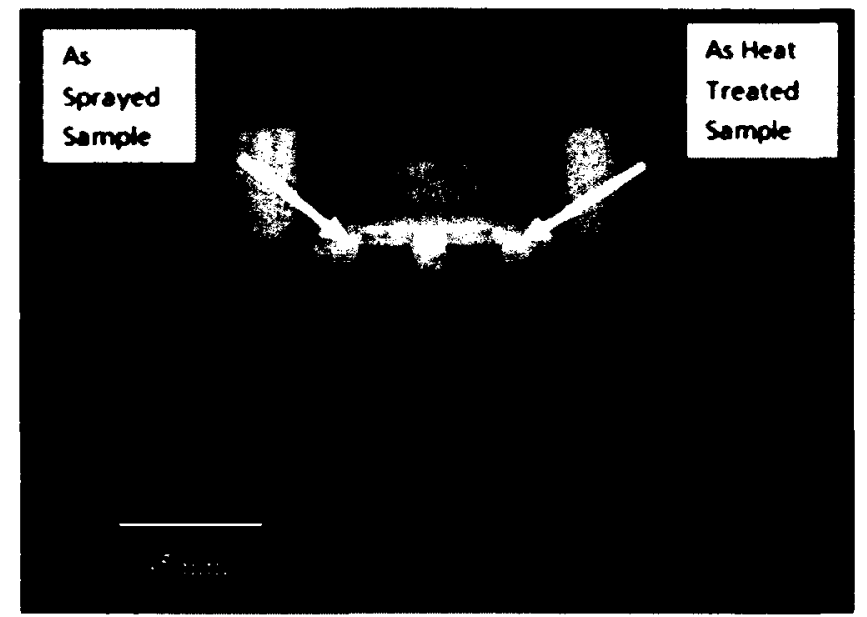

Figure 56: HX/7YSZ samples in a Lindberg Type 51442 electric air furnace at $1050^{\circ} \mathrm{C}$.

\subsection{Thermal Cycling}

To simulate thermal cycling, as-sprayed and heat treated Mo/YSZ and HX/7YSZ CMC samples, and 7YSZ reference specimens were placed horizontally on the ceramic bed of the Rapid Temp Furnace (CM Inc., Bloomfield, N.J.) shown in Figure 59. This cyclic oxidation system features a robotic platform which can be programmed to repeatedly raise the specimens into the heated furnace section for a specific interval, and then lower the specimens into a fan-cooled area at ambient temperature, Figure 57. 
The temperature profile for Mo/7YSZ samples is shown in Figure 58 with a 120 minute isothermal segment at $1050^{\circ} \mathrm{C}$. The target test length was 300 cycles, which took a total of 660 hours.

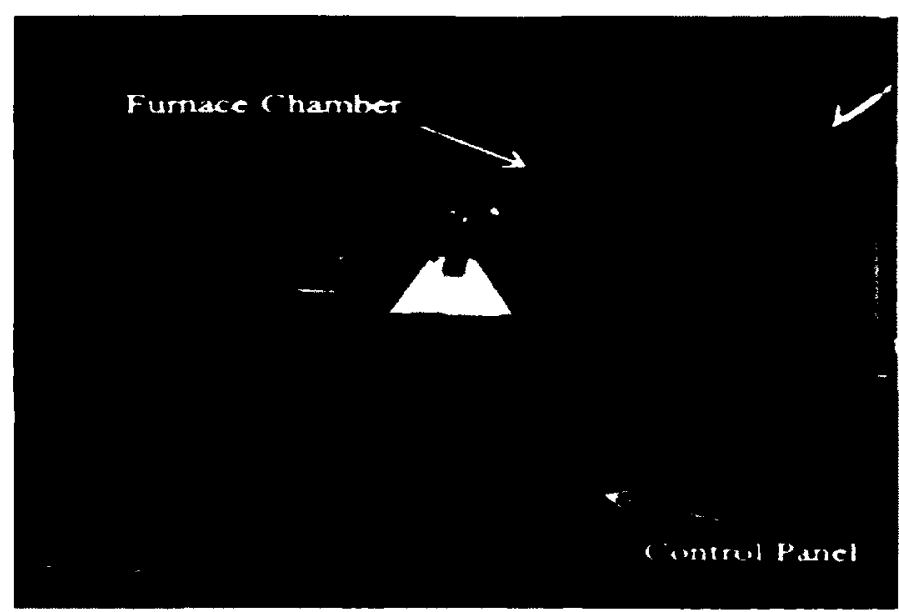

Figure 57: CM 1800 Rapid Temp Furnace at NRC.

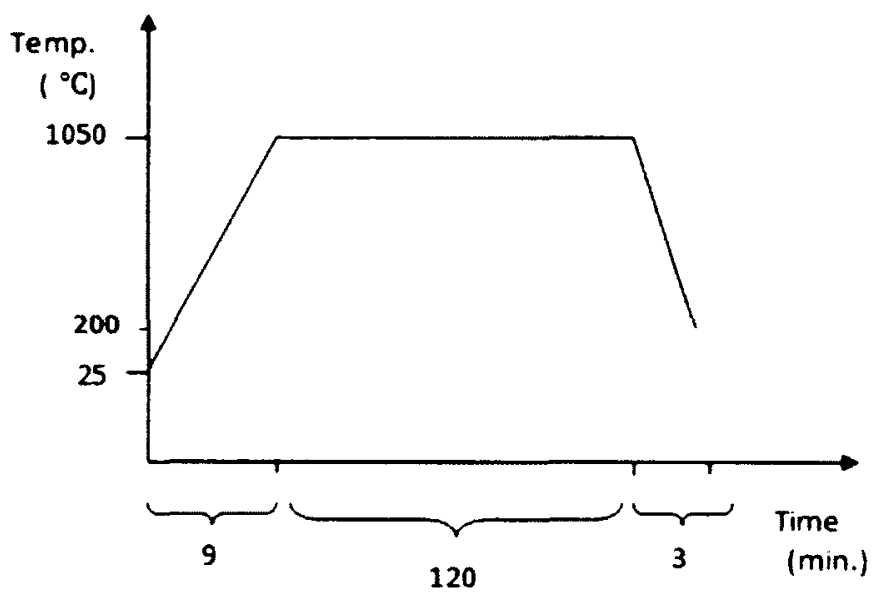

Figure 58: Cyclic test temperature profile for Mo/7YSZ samples.

Based on the results from Mo/7YSZ samples, HX/7YSZ specimens were tested using a different thermal cycling temperature profile. This profile consisted of 9 minutes heat-up, 48 minutes hold at $1050^{\circ} \mathrm{C}$, and 3 minutes cooling by forced air. After every 100 
cycles (or 100 hours) the specimens were visually examined for spallation. The total test duration was set to last up to 1000 cycles. More detailed examinations using SEM, EDS and XRD techniques were carried out after removing samples from the furnace subsequent to 500 cycles and 1000 cycles. The temperature profile applied to HX/7YSZ samples is shown in Figure 58 and Figure 60.

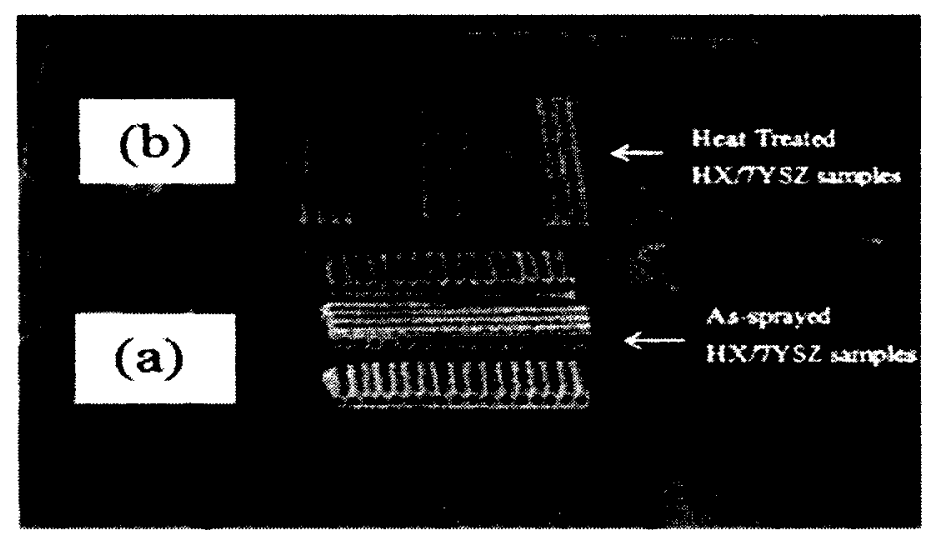

Figure 59: (a) As-sprayed, and (b) heat treated HX/7YSZ CMCs (before cyclic oxidation test) in rapid temp furnace.

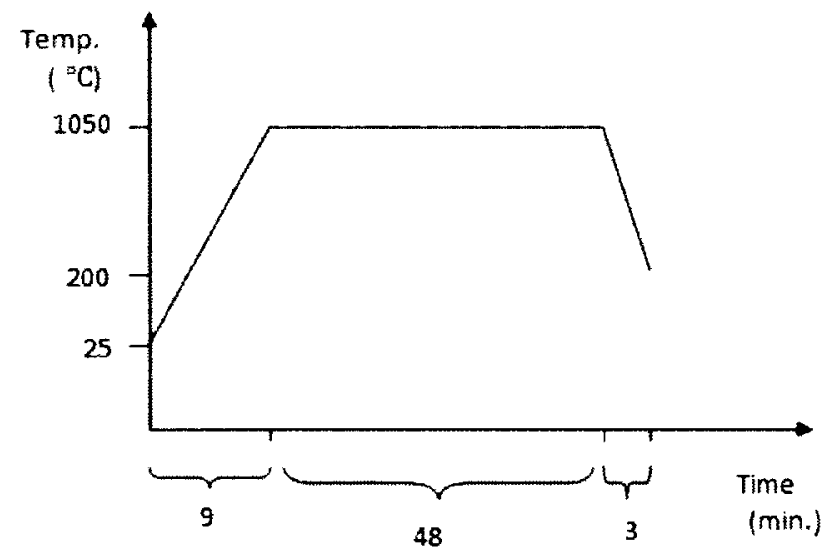

Figure 60: Cyclic test temperature profile for $\mathrm{HX} / 7 \mathrm{YSZ}$ samples.

\subsection{Characterization Procedures}


In this work Mo/7YSZ, HX/7YSZ and monolithic 7YSZ samples were characterized by the following procedures. The result and discussion sections detail the outcomes of these assessments.

\section{Visual inspection}

Throughout the thermal cycling and isothermal tests, the as-sprayed, heat treated and ceramic reference samples were examined by naked eye to identify changes in their appearance and surface conditions. This examination also was done for the samples which were subjected to bending and Charpy impact tests to visualize the response of different parts of the composite materials to the applied forces.

\section{Optical Microscope (OM)}

Following each test, more detailed examinations of the as-sprayed and heat treated samples were carried out by optical microscope. Fracture surfaces of the impact tested samples were examined using the Nikon SMZ1000 stereomicroscope. The Olympus PMG 3 optical microscope was also used with the Clemex Vision PE software to examine the microstructure of polished samples. To obtain detailed information on cross sections, samples were prepared as follows:

- Cutting the specimens in their longitudinal and transverse sections using BUEHLER ISOMET 1000 Precision Saw, Model No. 11-2180.

- Grinding the samples consecutively to $240,320,400$, and 600 grit $\mathrm{SiC}$ abrasive papers in Handimet Grinder BUEHLER hand polisher.

- Grinding the specimens with a rotary grinder to a 1200 grit finish and then polishing using $3 \mu \mathrm{m}$ diamond suspension. 


\section{Scanning Electron Microscope (SEM)}

SEM was used to evaluate the microstructure of the composites materials. Tescan Vegall XMU scanning electron microscope was used to investigate the composition on different parts of the composite samples with energy dispersive spectrometer (EDS) technique and examine the morphology with secondary electron detector (SE) and backscattered electron detector (BSE) imaging. 


\section{Results and Discussion}

\subsection{Charpy Impact Test}

\subsubsection{Mo Reinforcement Ceramic Matrix Composite and Monolithic 7YSZ}

\section{Ceramic}

The fractured samples of heat treated reference sample, heat treated and as-sprayed Mo/7YSZ samples after Charpy impact tests are shown in Figure 61. Broken wires protruded from the fractured $7 \mathrm{YSZ}$ and NiCrAlY matrix in as-sprayed Mo/7YSZ are seen. In as-sprayed samples, the NiCrAlY coatings were detached from broken wires cleanly and remained adhered to the $7 \mathrm{YSZ}$, while better bonding between NiCrAlY, 7YSZ and Mo wires did not allow wire protrusion and complete NiCrAlY detachment from Mo wires in heat treated samples, Figure 62.
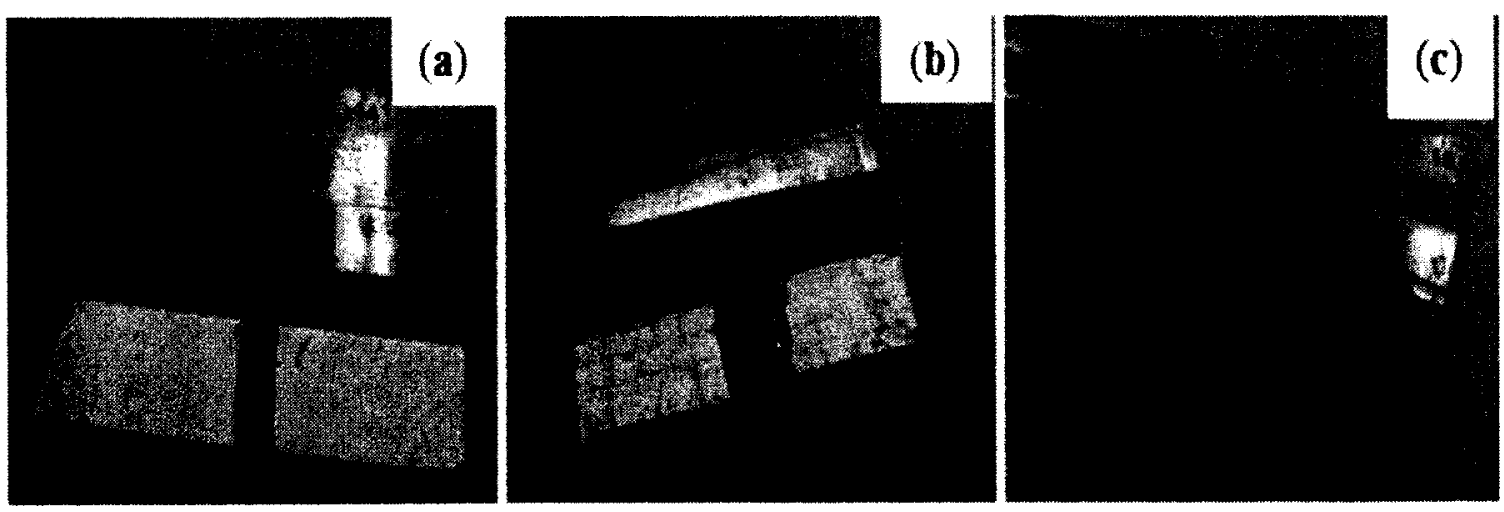

Figure 61: Charpy impact test specimens: (a) heat treated 7YSZ reference, (b) as-sprayed $\mathrm{Mo} / \mathrm{YSZ}$, and (c) heat treated Mo/YSZ. 

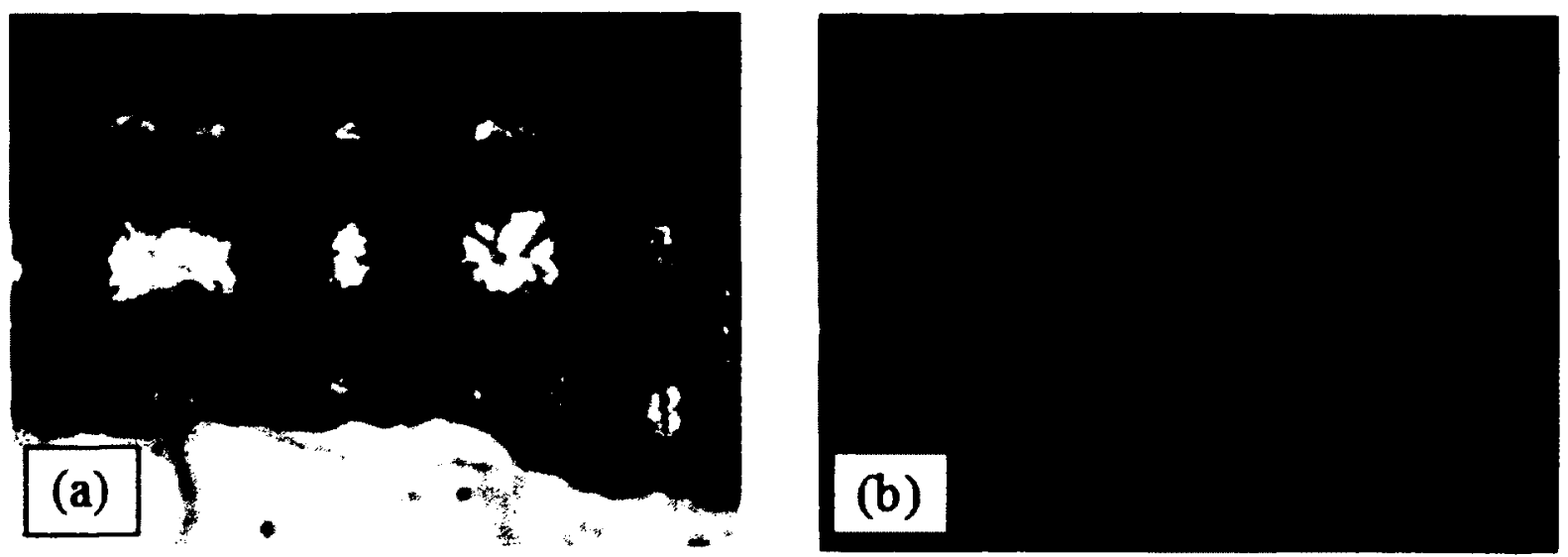

Figure 62: Mo/7YSZ samples after impact test: (a) NiCrAlY coating were detached from broken wires in as-sprayed samples, and (b) vacuum heat treated samples showed better adhesion between bond coat and wires.

The Charpy impact energies are given in Table 17. The fracture energy of each sample was normalized by the sample's cross-sectional area. Table 17 implies that the heat treated specimen had greater impact energy than the as-sprayed specimen. This result could be caused by creating a stronger bond between the Mo, NiCrAIY and 7YSZ after the heat-treatment.

Table 17: Charpy impact energy of impacted samples (the estimated errors is based on the machine accuracy).

\begin{tabular}{llll}
\hline & $\begin{array}{l}\text { Impact energy } \\
(\mathrm{J})\end{array}$ & $\begin{array}{l}\text { Cross sectional } \\
\text { area }\left(\mathrm{cm}^{2}\right)\end{array}$ & $\begin{array}{l}\text { Impact energy/ cross } \\
\text { sectional area }\left(\mathrm{J} / \mathrm{cm}^{2}\right)\end{array}$ \\
\hline 7YSZ & $1.4 \pm 0.5$ & 0.314 & 4.5 \\
$\begin{array}{l}\text { As-sprayed } \\
\text { Mo/YSZ }\end{array}$ & $2.03 \pm 0.5$ & 0.624 & 3.3 \\
$\begin{array}{l}\text { Heat treated } \\
\text { Mo/YSZ }\end{array}$ & $2.70 \pm 0.5$ & 0.626 & 4.3 \\
\hline
\end{tabular}


The fractured surface image of as-sprayed Mo/7YSZ sample is shown in Figure 63. The images of the Mo wire fracture surfaces also show that Mo has failed by intergranular and brittle fracture (Figure 64).

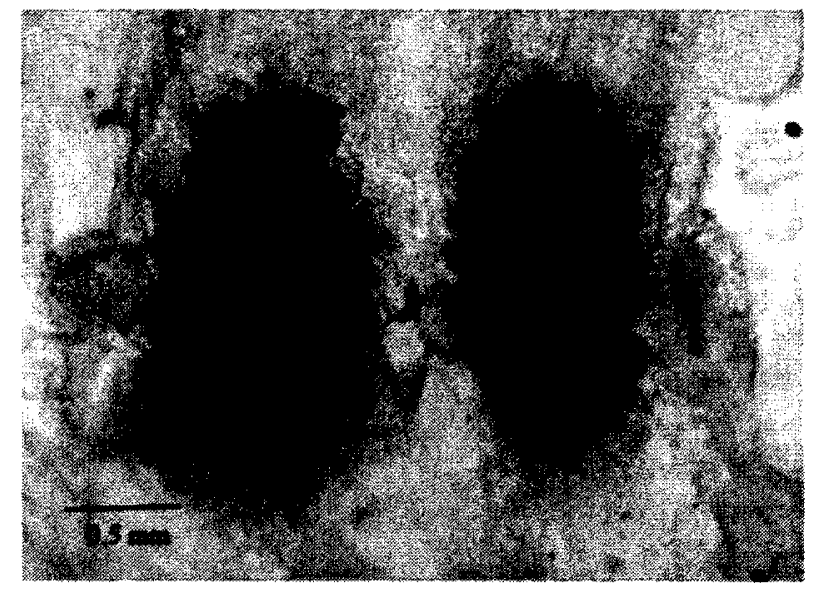

Figure 63: Charpy impact surface of the as-sprayed Mo/7YSZ sample (8X).

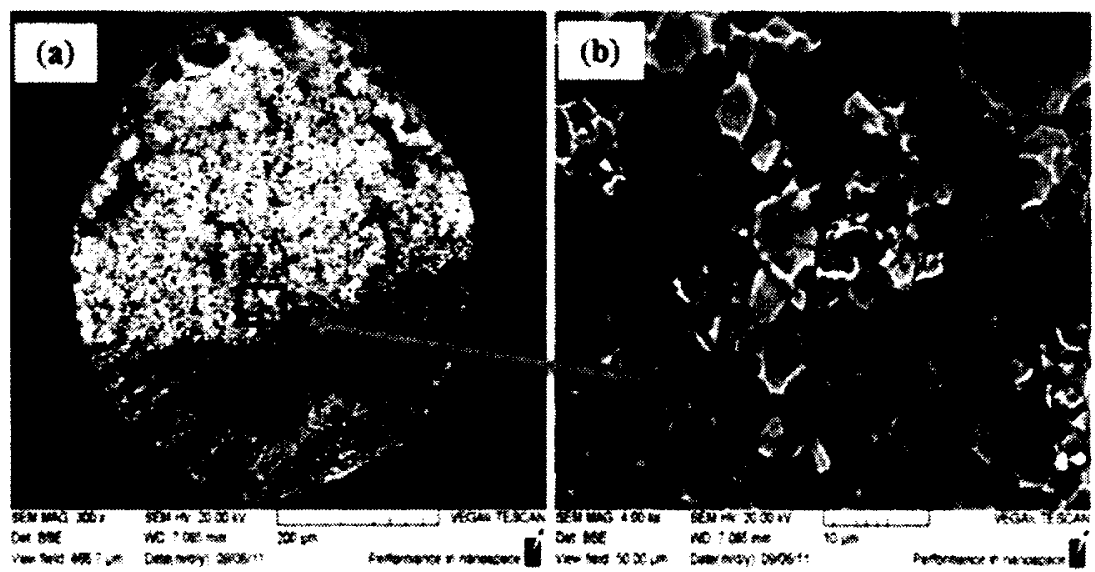

Figure 64: SEM micrograph of the Mo/7YSZ Charpy fracture surface at (a) $300 \mathrm{X}$ magnification and (b) $4000 \mathrm{X}$ magnification (indicating the location where $4000 \mathrm{X}$ is taken).

During previous microstructural analysis, it was shown that the Mo to NiCrAlY interface was weak and cracked (Figure 62). This weak bond layer suggests that the 
friction caused by Mo wire pulling out from matrix was little, and the toughness of the composite material did not benefit from pull out mechanism. The roughness of the NiCrAlY layer did not seem to have any contribution to the strength of the composite material, and the roughness on fractured surfaces was as a result of the high porosity from the plasma spray process.

Mo wire showed an intergranular fracture surface, Figure 64(b), likely due to the embrittlement of Mo wire by interstitial species $(\mathrm{O}, \mathrm{N})$ diffusing into the lattice structure [82]. As seen in the lower region of Figure 64 (a), the Mo wire has failed in a brittle mode. The chevron and beach marks created on the brittle fractured surface show the direction of this failure.

Overall, there was a lack of plastic deformation in Mo/7YSZ composite material, which means the toughening of the composite through the use of Mo wires was very limited and neither the wire pullout mechanism nor plastic deformation of the wires had any contribution to the toughening of the composite. To effectively improve the toughness, a more effective bond layer between the matrix and reinforcing structure would be needed. To prevent brittle fracture of the wires, an oxidation resistant coating would be required to hinder the diffusion of contaminants such as oxygen, hydrogen and carbon into the pure molybdenum. Alternately, a more ductile and oxidation resistant alloying system could be used as reinforcement component.

\subsubsection{Observation of the Impact Test}

The broken samples after impact test showed that the NiCrAlY coating became detached from Mo wires but were adhered to $7 \mathrm{YSZ}$ ceramic in as-sprayed samples. A 
stronger bonding between Mo, NiCrAlY and 7YSZ in heat treated samples did not allow wire protrusion and NiCrAlY detachment from Mo wires. The Charpy impact energies also suggested that the heat treated specimens had greater impact energy than the assprayed specimen, further indicating of a stronger bond between the Mo, NiCrAlY and 7YSZ.

Examining the images of fracture surfaces showed that Mo has failed by intergranular and brittle fracture, likely due to the embrittlement of Mo wire by interstitial species $(\mathrm{O}, \mathrm{N})$ diffusing into the lattice structure. Mo wires were oxidized and degraded during heating processes (thermal spraying and heat treatment).

Overall, Mo/7YSZ composite material did not show considerable plastic deformation, which means neither the wire pullout mechanism nor plastic deformation had contributed to the toughening of the composite. In terms of wire pull-out, the weak interfacial bonding between Mo to NiCrAlY suggested that the friction caused by Mo wire pulling out from matrix was little, due week bonding.

\subsection{Bending Test}

\subsubsection{Mo Reinforcement Ceramic Matrix Composite and Pure 7YSZ}

\section{Ceramic}

Bend testing was performed on three samples: as-sprayed Mo/7YSZ sample, heat treated $\mathrm{Mo} / 7 \mathrm{YSZ}$ sample, and as-sprayed $7 \mathrm{YSZ}$ monolithic reference sample. The fractured samples after the bend test are shown in Figure 65. Mo mesh reinforcement provided improved ductility in the Mo/YSZ composite; therefore, the displacement measurements for the two reinforced samples were not complete due to the working limit 
of the extensometer. The Three point bend test curve and summary of the bend test results for as-sprayed $\mathrm{Mo} / \mathrm{YSZ}$, heat treated $\mathrm{Mo} / \mathrm{YSZ}$ and monolithic $7 \mathrm{YSZ}$ samples are shown in Figure 66 and Table 18.
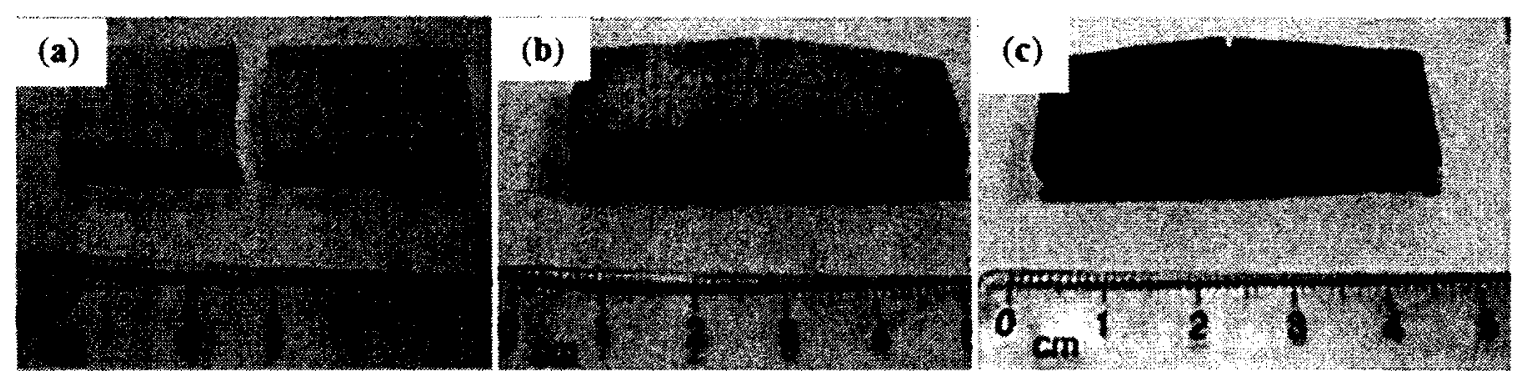

Figure 65: Images of samples after bend testing: (a) as-sprayed reference 7YSZ, (b) assprayed Mo/7YSZ, and (c) heat treated Mo/7YSZ.

Table 18: Yielding, peak and fracture load of various samples.

\begin{tabular}{llll}
\hline & 7YSZ & $\begin{array}{l}\text { As sprayed } \\
\text { Mo/YSZ }\end{array}$ & $\begin{array}{l}\text { Heat treated } \\
\text { Mo/YSZ }\end{array}$ \\
\hline Cross sectional area $\left(\mathrm{mm}^{2}\right)$ & 31.4 & 62.4 & 62.6 \\
\hline Load at yield $(\mathrm{N})$ & 55 & 170 & 263 \\
\hline Ultimate load $(\mathrm{N})$ & 55 & 220 & 182 \\
\hline Load at failure $(\mathrm{N})$ & 55 & - & - \\
\hline $\begin{array}{l}\text { Axial displacement at yield } \\
\text { (mm) }\end{array}$ & 0.215 & 0.823 & 0.473 \\
\hline $\begin{array}{l}\text { Axial displacement at ultimate } \\
\text { load (mm) }\end{array}$ & 0.22 & 2.44 & 0.92 \\
\hline \hline
\end{tabular}




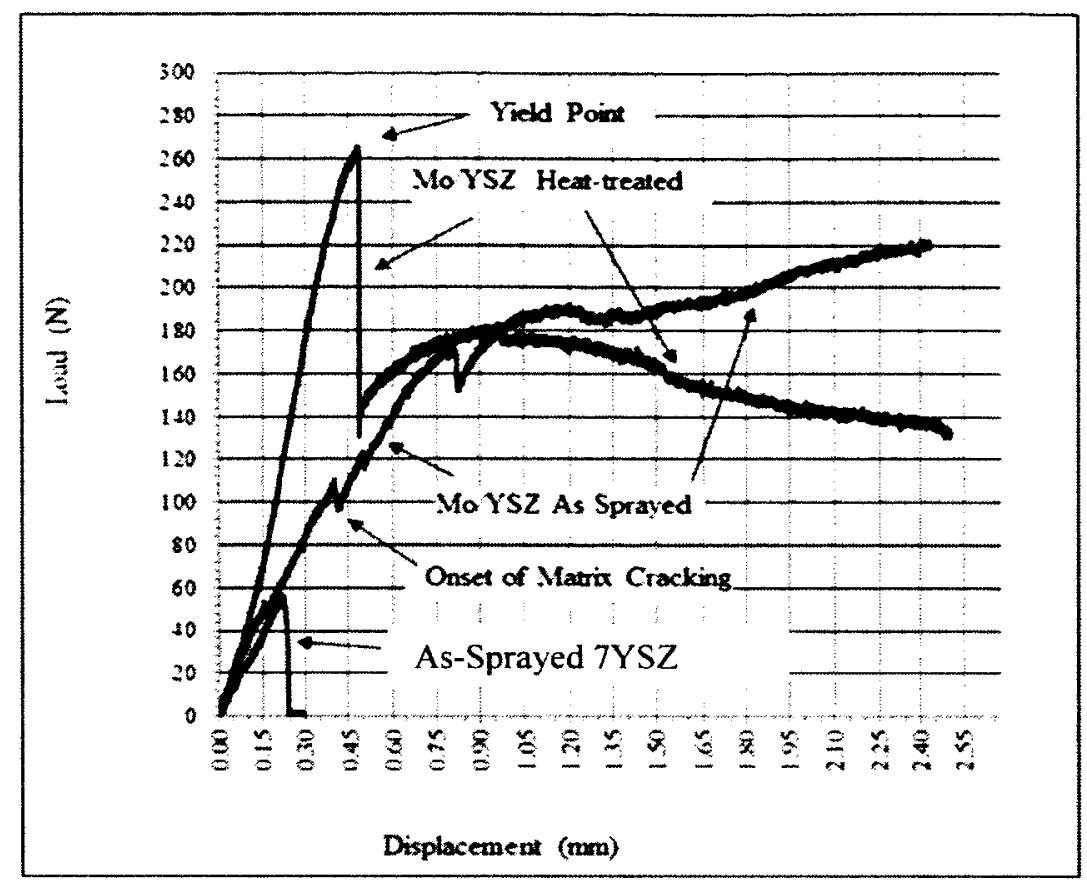

Figure 66: Three-point bend test load-displacement curves for as-sprayed and heat treated Mo/7YSZ samples.

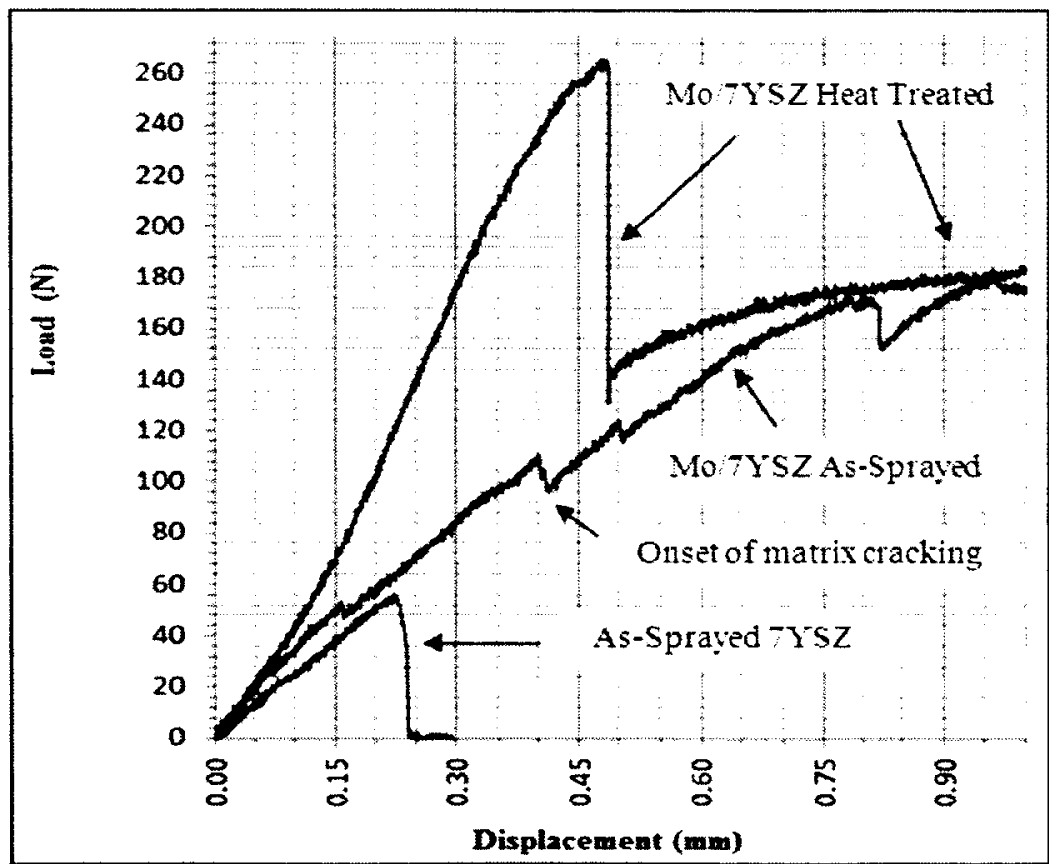

Figure 67: Enlarged load-displacement curves for as-sprayed and heat treated Mo/7YSZ samples up to $1 \mathrm{~mm}$ elongation. 
The ultimate load for as-sprayed Mo/YSZ was four times higher than 7YSZ ceramic. As-sprayed $\mathrm{Mo} / \mathrm{YSZ}$ also showed 10 times greater displacement at ultimate load than monolithic 7YSZ. The load at yielding point for the heat treated $\mathrm{Mo} / \mathrm{YSZ}$ sample showed $50 \%$ increase over that of as-sprayed $\mathrm{Mo} / \mathrm{YSZ}$. The yield point on the loaddisplacement curve is assumed where a localized maximum point was observed. The ultimate load for heat treated Mo/YSZ was slightly lower than as-sprayed Mo/YSZ but several times greater than 7YSZ. The displacement of heat treated $\mathrm{Mo} / \mathrm{YSZ}$ at yield was less than that observed for as-sprayed Mo/YSZ and the total displacement before failure for the heat-heated $\mathrm{Mo} / \mathrm{YSZ}$ was 4 times greater than $7 \mathrm{YSZ}$. Overall, the incorporation of Mo mesh in 7YSZ increased the load at yield point and ultimate load in addition to increased displacement/ductility.

As seen in broken Charpy test samples (Figure 62 (a)), surface of Mo wires in assprayed condition were oxidized during plasma spraying. The $\mathrm{MoO}_{3}$ oxide layer, which forms at low temperatures $\left(600^{\circ} \mathrm{C}\right)$ in the presence of oxygen, caused the bond coat to detach from Mo wire surface, while better bonding strength in heat treated Mo/7YSZ prevented bond coat detachment from the Mo wire. It seems during four-hour vacuum heat treatment at $1080^{\circ} \mathrm{C}$, the molybdenum trioxide sublimates and $\mathrm{NiCrAlY}$ layer finds direct bonding with Mo wire, which provides a stronger bonding.

Heat treated Mo/7YSZ showed higher yielding load and less cracks compared to as-sprayed Mo/7YSZ. As expected [79], the vacuum heat treatment may have improved the bond strength between NiCrAlY and the 7YSZ matrix and increased the yield strength of the composite structure. This improvement suggests that good quality bonding 
between NiCrAlY and the 7YSZ matrix also reduced the displacement at yield point. Longitudinal cracks and delamination of Mo mesh from 7YSZ matrix were seen on the as-sprayed Mo/YSZ, but they were not observed in the heat treated sample. After passing the yield points, strength of the composite samples were dependent on Mo mesh reinforcement properties. The Mo mesh shows more strain hardening in as-sprayed Mo/YSZ than in heat treated condition due to the degradation and embrittlement of the Mo wire during vacuum heat treatment.

\subsubsection{Hastelloy X Reinforcement Ceramic Matrix Composite}

The as-sprayed and heat treated HX/7YSZ CMC samples after bend test are shown in Figure 68. A summary of the bend test results and three-point bend test curves are shown in Table 19 and Figure 70. To increase the accuracy of the data and visualize the effect of the possible imperfections during manufacturing, two samples from each group were chosen for this test. For the duplicate test samples, the bending test results are indicated in parenthesis in Table 19, and three-point bend test curves corresponding to these data are shown in Figure 72. Similar to Mo/7YSZ samples, no longitudinal cracking were observed in heat treated $\mathrm{HX} / 7 \mathrm{YSZ}$ after bend testing, whereas both longitudinal and transverse cracks were found in as-sprayed $\mathrm{HX} / 7 \mathrm{YSZ}$ samples. Multiple crack sources on the ceramic coating in the as-sprayed samples caused the ceramic coat spallation on the compression side, Figure 69(a). 

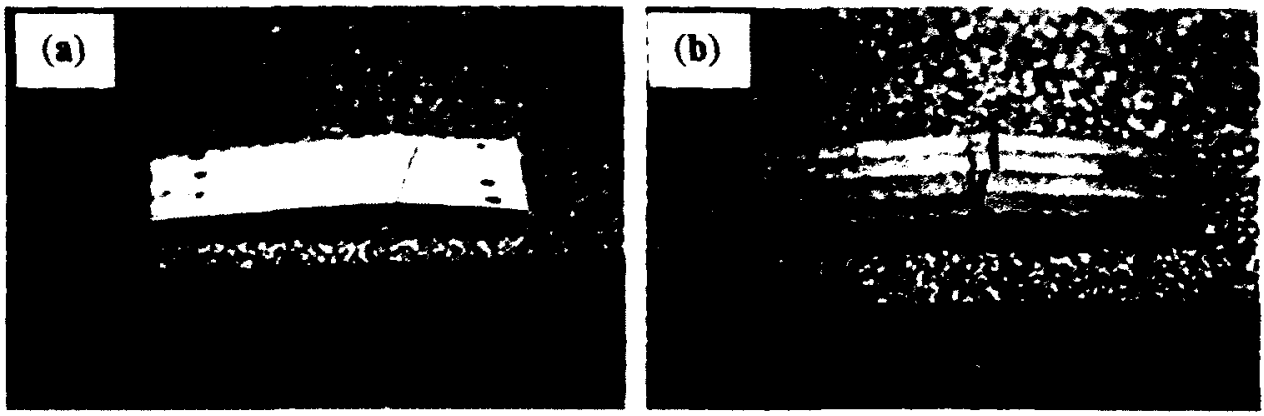

Figure 68: Images of HX/7YSZ samples after bend test: (a) as-sprayed, and (b) heat treated.
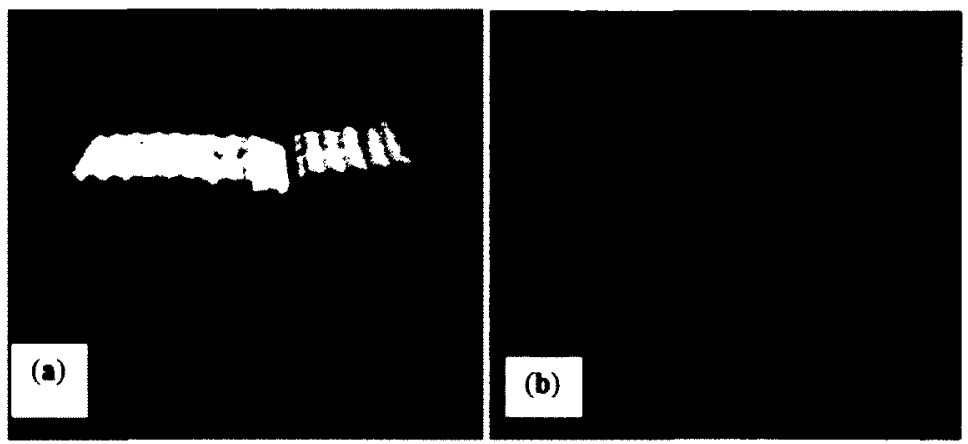

Figure 69: (a) Cracking and spallation in as-sprayed HX/7YSZ sample, and (b) transverse cracking in the heat treated samples after bend test.

Table 19: Bend test results for the solid 7YSZ, as-sprayed and heat treated HX/7YSZ.

\begin{tabular}{|c|c|c|c|}
\hline & $\begin{array}{l}\text { Monolithic } \\
7 \mathrm{YSZ}\end{array}$ & $\begin{array}{l}\text { As-sprayed } \\
\mathrm{HX} / 7 \mathrm{YSZ}\end{array}$ & $\begin{array}{l}\text { Heat treated } \\
\mathrm{HX} / 7 \mathrm{YSZ}\end{array}$ \\
\hline Cross sectional area $\left(\mathrm{mm}^{2}\right)$ & 31.4 & $63.5(67.1)$ & $64.6(66.5)$ \\
\hline Load at yield $(\mathrm{N})$ & 55 & $1637.4(1629)$ & $832(860)$ \\
\hline Ultimate load $(\mathrm{N})$ & 55 & $585(719.0)$ & $1004(978.8)$ \\
\hline Load at failure $(\mathrm{N})$ & 55 & - & - \\
\hline $\begin{array}{l}\text { Axial displacement at yield } \\
(\mathrm{mm})\end{array}$ & 0.21 & $1.208(1.70)$ & $0.213(0.24)$ \\
\hline $\begin{array}{l}\text { Axial displacement at ultimate } \\
\text { load }(\mathrm{mm})\end{array}$ & 0.215 & $2.24(2.16)$ & $2.40(1.95)$ \\
\hline Onset of matrix cracking $(\mathrm{N})$ & - & $516(540)$ & $733(740)$ \\
\hline $\begin{array}{l}\text { Displacement at cracking } \\
\text { onset }(\mathrm{mm})\end{array}$ & - & $0.143(0.14)$ & $0.17(0.16)$ \\
\hline
\end{tabular}




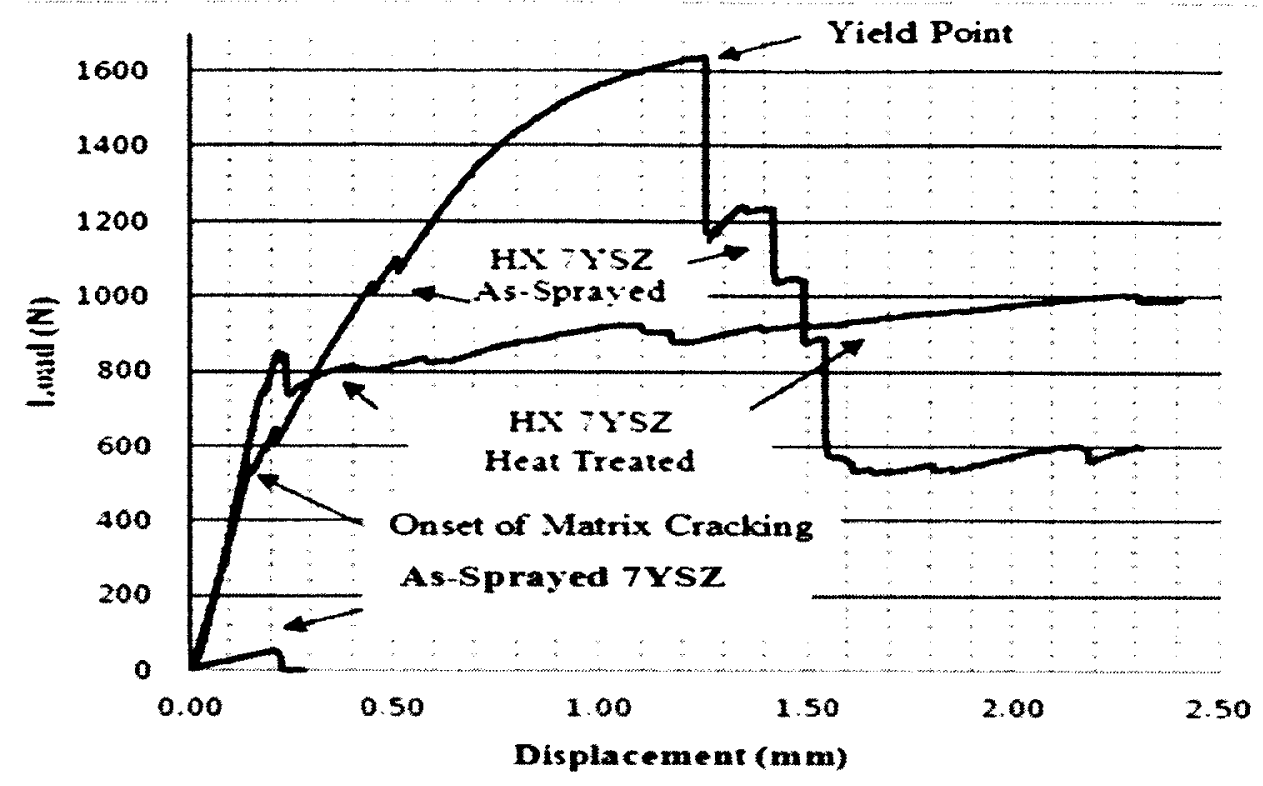

Figure 70: Load-displacement curves combining tests results for HX/7YSZ (as-sprayed and heat treated) and monolithic $7 \mathrm{YSZ}$ samples.

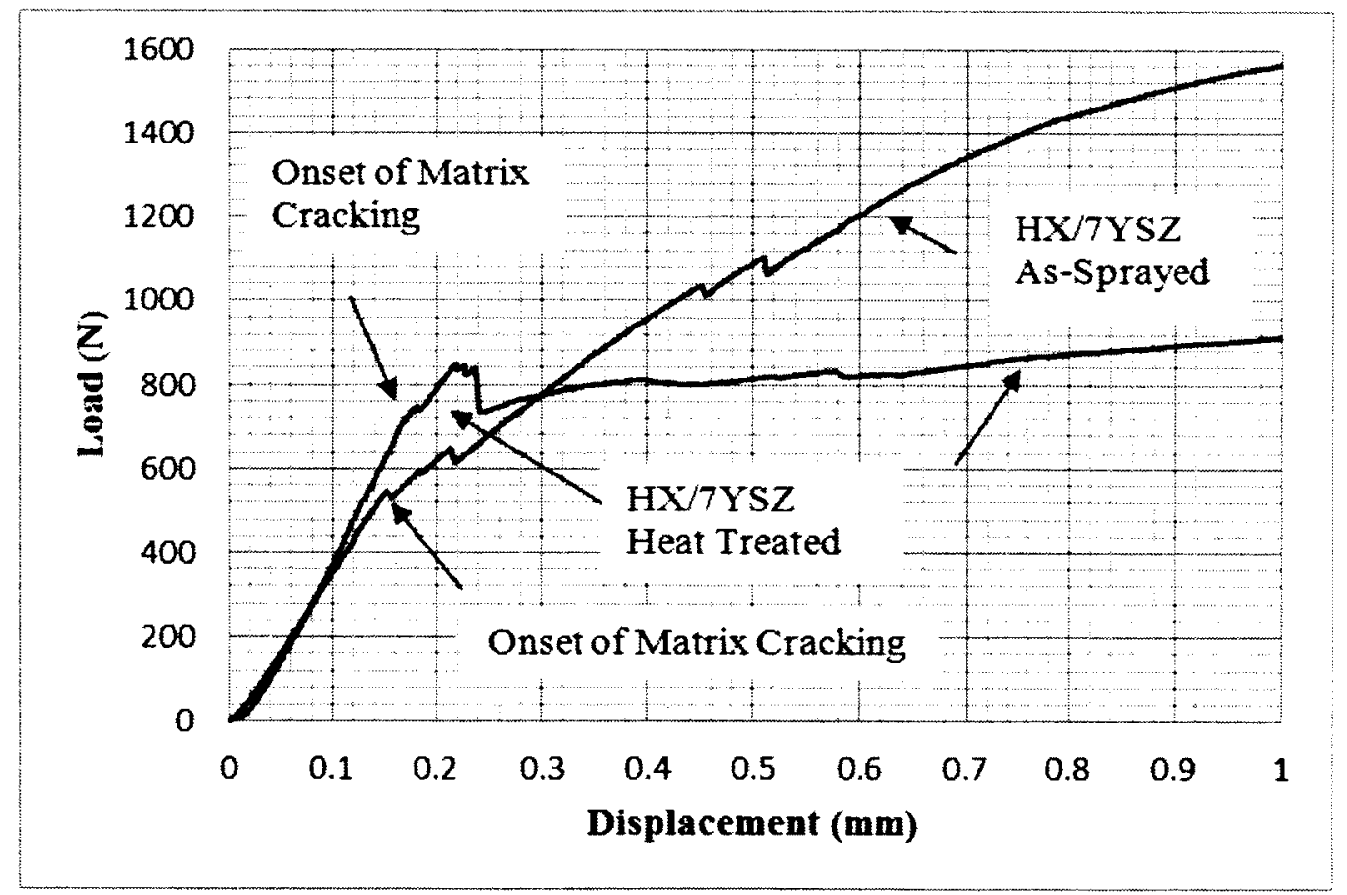

Figure 71: Enlarged load-displacement curves for HX/7YSZ (as-sprayed and heat treated) and monolithic $7 \mathrm{YSZ}$ samples up to $1 \mathrm{~mm}$ elongation. 


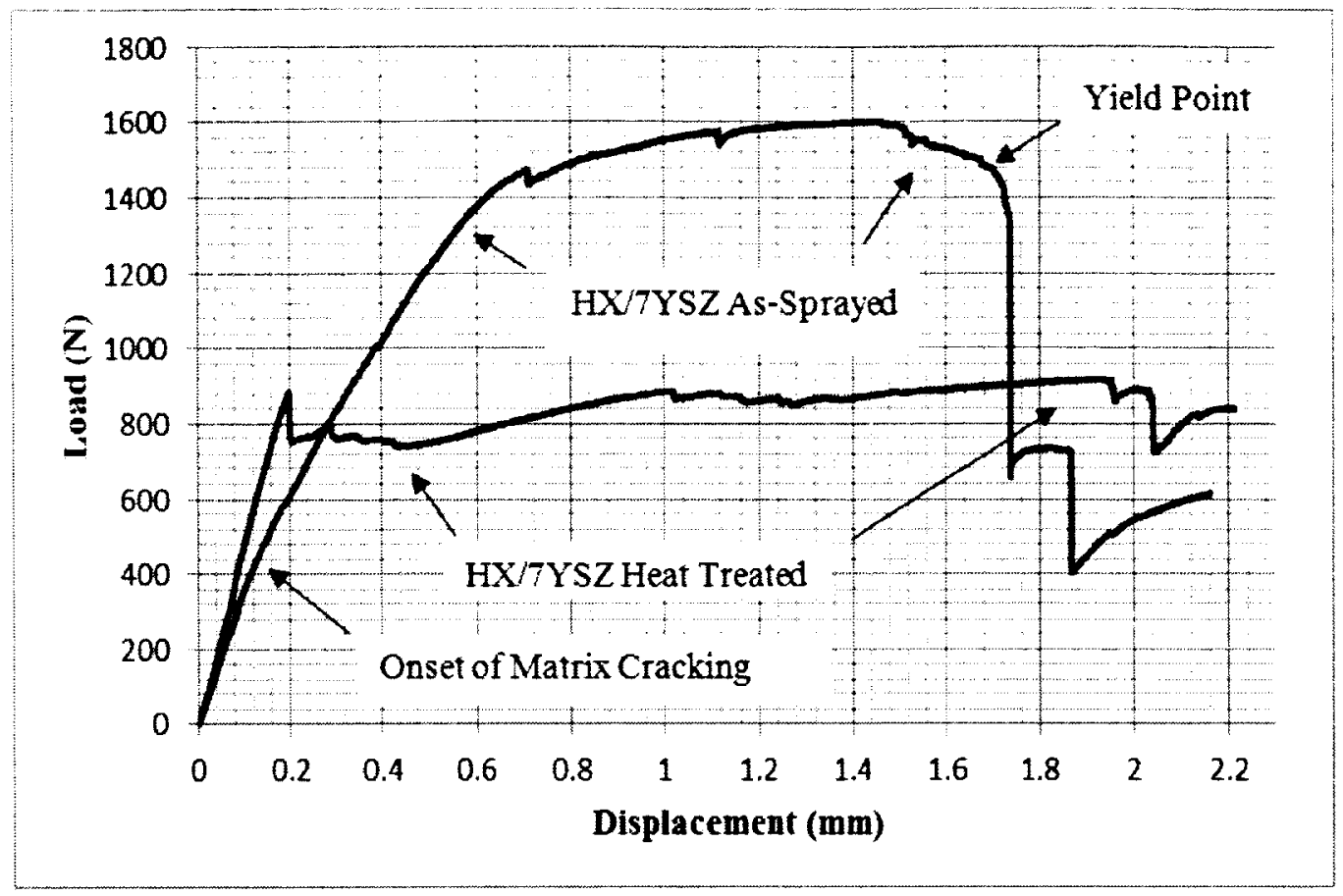

Figure 72: Three-point bend test load-displacement curves for second pair of as-sprayed and heat treated $\mathrm{HX} / 7 \mathrm{YSZ}$ samples.

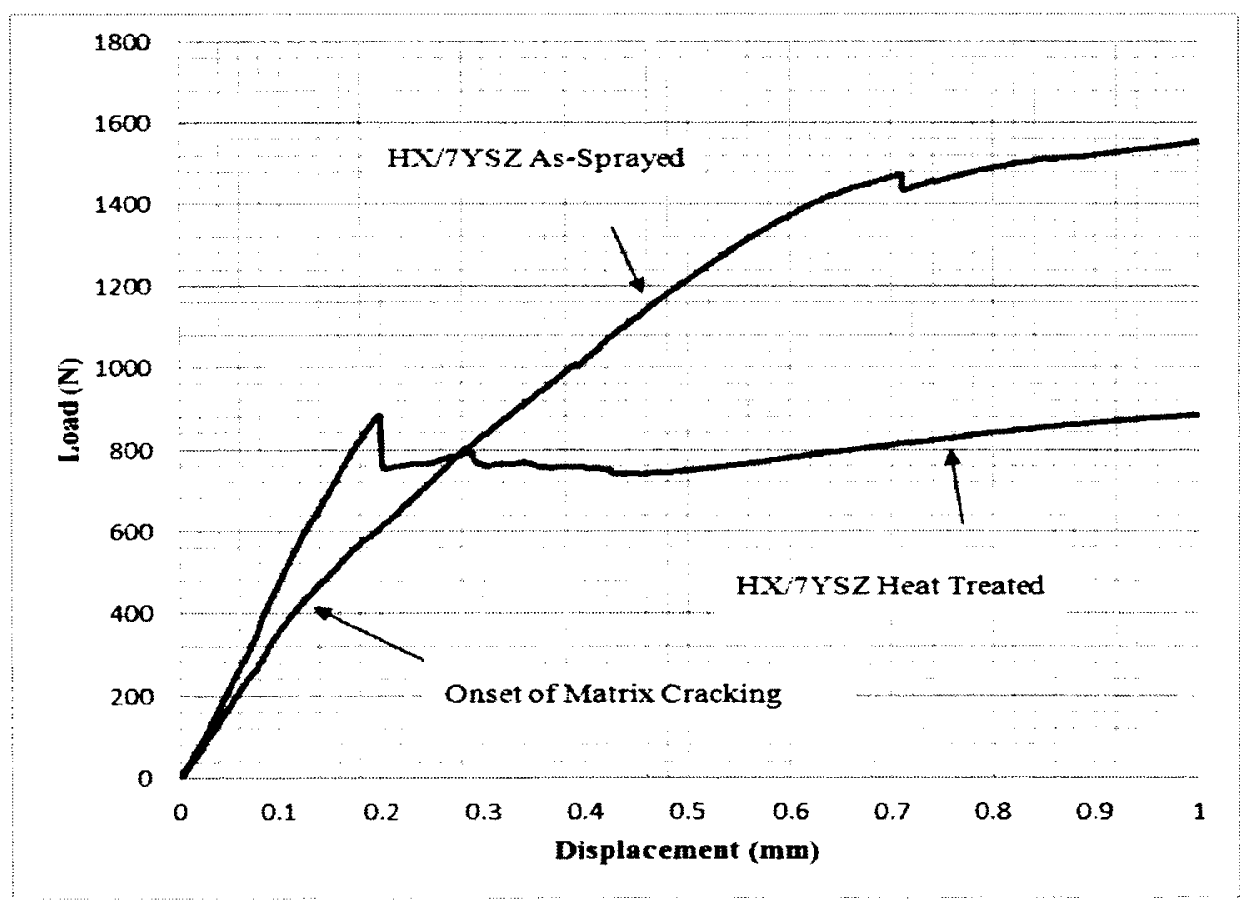

Figure 73: Enlarged load-displacement curves for second pair of as-sprayed and heat treated $\mathrm{HX} / 7 \mathrm{YSZ}$ samples up to $1 \mathrm{~mm}$ elongation. 
Figure 70 shows the ceramic matrix of the as-sprayed $\mathrm{HX} / 7 \mathrm{YSZ}$ sample started to crack at an approximate load of $516 \mathrm{~N}$, and matrix cracking and crack deflection at the interface continued up to a load of $1637.4 \mathrm{~N}$. But based on the definition of yielding point (the point where a sudden local decrease in load occurs) the yield load for as-sprayed HX/7YSZ composite material was found to be $1637.4 \mathrm{~N}$. As-sprayed HX/7YSZ showed a yield load about 30 times greater than monolithic $7 \mathrm{YSZ}$, and its displacement at the yield point was about 6 times greater than the 7YSZ. Yield load of the heat treated HX/7YSZ CMC was about $50 \%$ of the as-sprayed $\mathrm{HX} / 7 \mathrm{YSZ} \mathrm{CMC}$ and the axial displacement of the heat treated $\mathrm{CMC}$ at yield point was $0.213 \mathrm{~mm}$. Heat treated sample shows an ultimate load of $1004 \mathrm{~N}$, which is about $60 \%$ higher than the as-sprayed ultimate load . The total displacement before failure for the heat-heated $\mathrm{HX} / \mathrm{YSZ}$ was 11 times greater than $7 \mathrm{YSZ}$. Figure 74 shows the load vs. displacement curve for combined tests results of both HX/7YSZ and Mo/7YSZ CMCs.

During the bend testing before reaching the yield point, multiple small cracks in longitudinal and transverse directions were observed in $7 \mathrm{YSZ}$ ceramic in the as-sprayed HX/7YSZ sample. As the test load increased, delamination also occurred and the numbers of crack initiation sites increased. As seen in Figure 70, the very first set of cracks were created at approximately $516 \mathrm{~N}$, but the yield load for the composite material was found to be $1637.4 \mathrm{~N}$. 


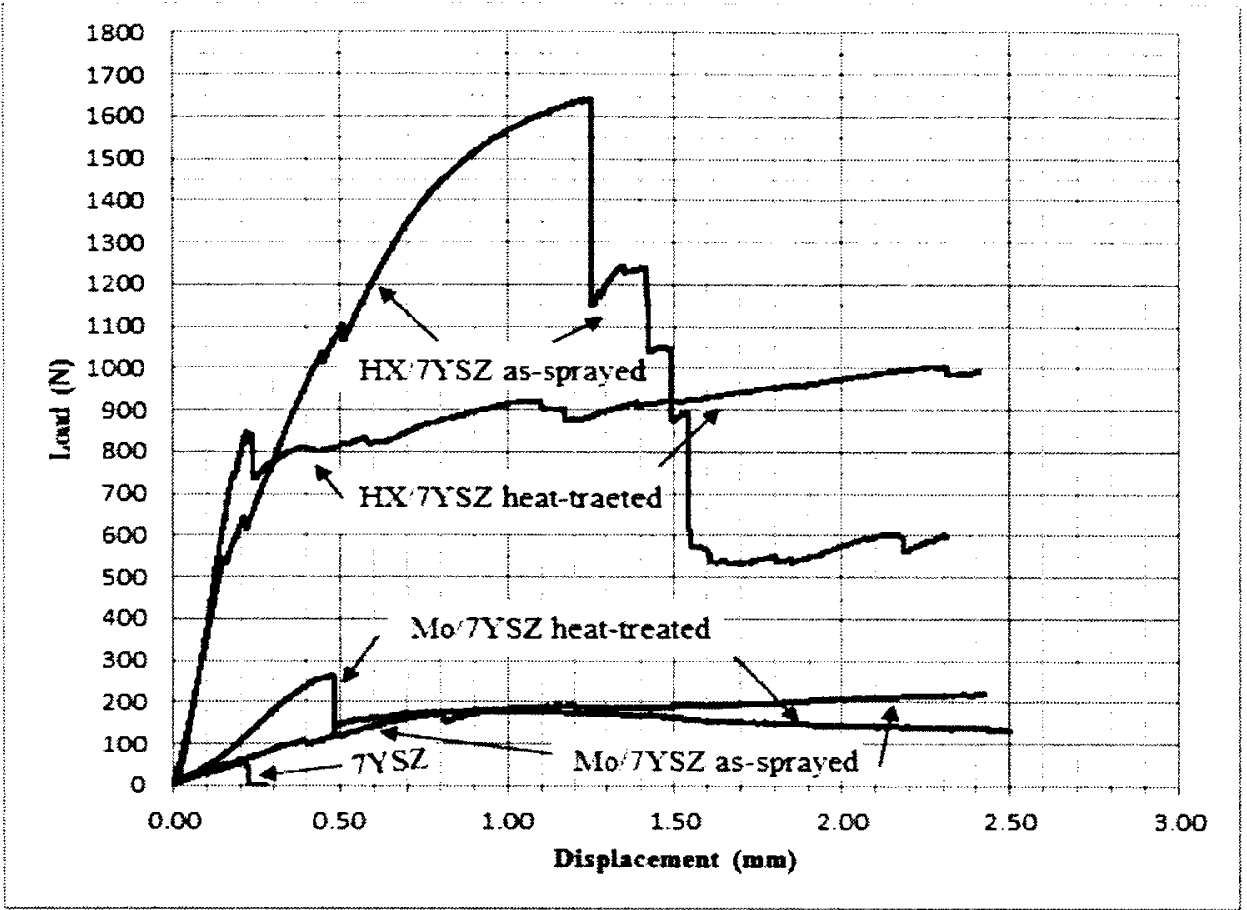

Figure 74: Load and displacement curve combining tests results for both HX and Mo reinforced CMC.

At yield point, a few large sized cracks extended from side to side (transverse direction) of the heat treated $\mathrm{HX} / 7 \mathrm{YSZ}$ sample, but no longitudinal cracking on delamination were seen. Based on the data given in Table 19, the as-sprayed sample showed higher yielding load $(1637.4 \mathrm{~N})$ than the heat treated sample $(832.15 \mathrm{~N})$. Better bonding between 7 YSZ ceramic and NiCrAlY bond coats in the heat treated samples is believed to be the reason for the improvement in load to crack initiation and decrease in axial displacement at yield point. After passing the yield point of the ceramic, the strength of the as-sprayed composite samples was governed by $\mathrm{HX}$ mesh reinforcement properties, which exhibited work hardening. In addition to $\mathrm{HX}$ mesh work hardening, $\mathrm{HX}$ wire pull-out from matrix also could be in effect in heat treated HX/7YSZ after passing the yield point resulting in a higher ultimate load than as-sprayed HX/7YSZ. 
The combined load/displacement curves in Figure 74 show that both as-sprayed and heat treated $\mathrm{HX} / 7 \mathrm{YSZ} \mathrm{CMC}$ samples have higher strength comparing to Mo/7YSZ composite and 7YSZ ceramic. Therefore, the mechanical strength of 7YSZ ceramic is substantially increased when HX mesh is embedded in $7 \mathrm{YSZ}$ ceramic as reinforcement compared to Mo mesh. However, the vol\% of Mo wire in Mo/7YSZ CMC is about 5.12 versus 14.02 vol\% of $\mathrm{HX}$ in $\mathrm{HX} / 7 \mathrm{YSZ} \mathrm{CMC}$.

\subsection{Isothermal Test}

\subsubsection{Mo Reinforcement Ceramic Matrix Composite and Reference 7YSZ Samples}

The first set of as-sprayed and heat treated Mo/7YSZ samples were removed from the furnace after 165 hours at $1050^{\circ} \mathrm{C}$. During cooling, the exposed molybdenum wire began to deform and the 7YSZ layer began to disintegrate. After reaching the ambient temperature, cracks had formed along the interface between the Mo mesh and 7YSZ layer, and several pieces of the 7YSZ matrix material had broken off the CMC specimen. The molybdenum reinforcement had disintegrated to a green powder, but its deformation during isothermal oxidation testing already had caused the separation of the upper and lower 7YSZ matrix layers. To identify the composition of the formed powders, a Bruker D8 Powder Diffractometer was used to run X-ray Diffraction (XRD) testing. This result is shown in Figure 74. 


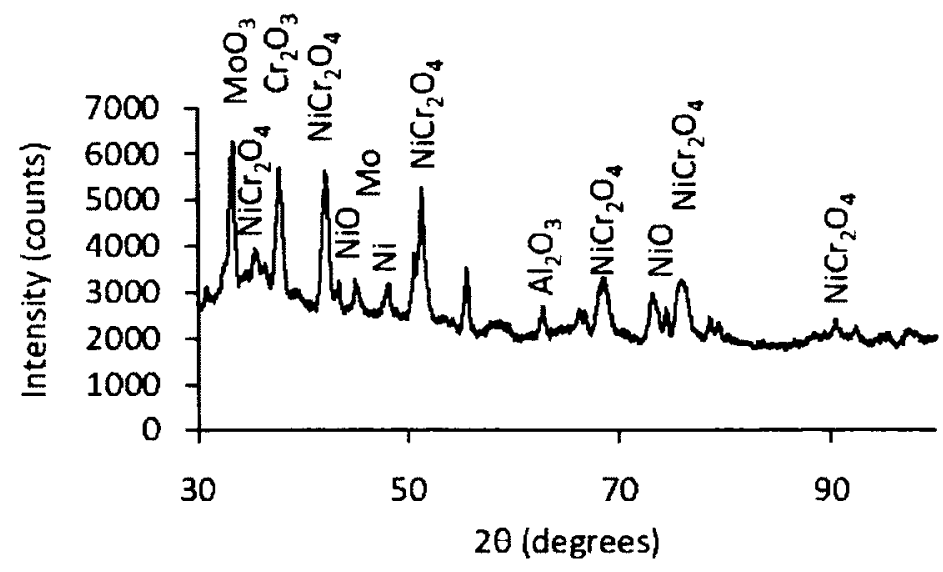

Figure 75: XRD pattern of the green powder taken from the isothermal oxidation tested $\mathrm{Mo} / 7 \mathrm{YSZ}$ specimen $\left(330\right.$ hours, $\left.1050^{\circ} \mathrm{C}\right)$.

The composition of the green powder was determined in a Philips XL 30S FEG Scanning Electron Microscope (SEM) using an EDAX Energy Dispersive X-Ray Spectroscopy (EDS) detector. The EDS analyzed locations and their relevant results are given in Figure 76 and Table 20.

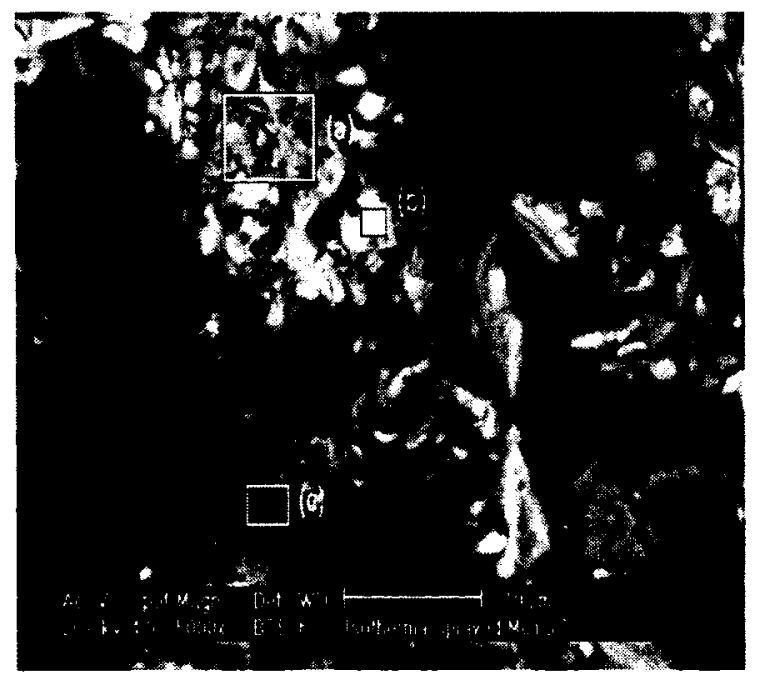

Figure 76: BSE image of the scanned locations: (a) general scan, (b) white spot, and (c) grey spot. 
Table 20: Composition of powder formed in isothermally heated then furnace-cooled specimens in wt.\%, determined by EDS.

\begin{tabular}{llll}
\hline Point & $\mathrm{a}$ & $\mathrm{b}$ & $\mathrm{c}$ \\
\hline Type & General & White Spot & Grey Spot \\
\hline $\mathrm{Mo}$ & 28.39 & 48.61 & 1.41 \\
$\mathrm{O}$ & 23.57 & 14.34 & 31.08 \\
$\mathrm{Ni}$ & 22.20 & 33.78 & 27.23 \\
$\mathrm{Cr}$ & 21.52 & 2.61 & 30.67 \\
$\mathrm{Al}$ & 4.32 & 0.67 & 9.61 \\
Total & 100 & 100.01 & 100 \\
\hline
\end{tabular}

Regular visual inspections during the test showed that the composite materials have signs of disintegration; therefore, the isothermal oxidation test was terminated after 330 hours. The appearance of the Mo/7YSZ and 7YSZ samples after 330 hours is shown in Figure 77. To reduce the thermal gradients which caused the 7YSZ layer to fracture in previous sample removal, the specimens were removed after being furnace-cooled to ambient temperature. The Mo/YSZ specimens showed cracking, and the top and bottom 7YSZ layers had separated due to the oxidation of the Mo reinforcement and thermal stress.

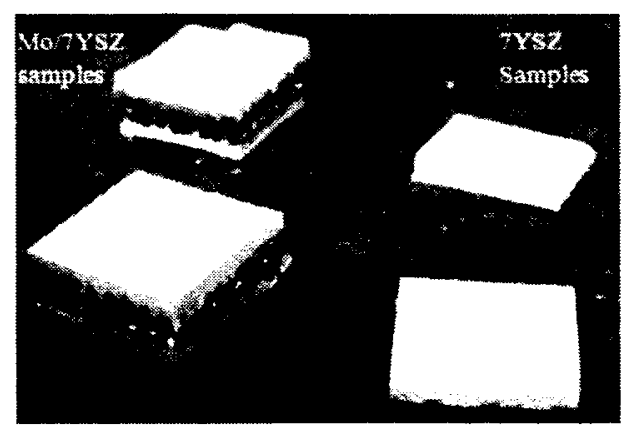

Figure 77: Isothermal tested specimens after 330 hours, showing cracking and separation of the top and bottom layers in Mo/7YSZ samples. 
The data presented in Table 20 suggest that the scanned area in Figure 76(a) consisted of combination of Mo, NiCrAlY and oxygen. The white spot in point (b) contained Mo oxide, since the large atomic number of Mo causes strong dispersion of the SEM's electron beam. And the darker grey spot in point (c) largely contained $\mathrm{Ni}$ and $\mathrm{Cr}$ oxides, as their smaller atomic radii disperse the electron beam with less intensity. The existence of oxygen in these areas indicates that the mixed powders contained oxides of the $\mathrm{Mo}, \mathrm{Ni}, \mathrm{Cr}$ and $\mathrm{Al}$ elements. This result also confirms that at high temperature the Mo wire, due to lack of proper NiCrAlY protection, oxidized and caused the radial cracking around the Mo wire and NiCrAlY delamination, as shown in Figure 65. The cracks throughout the specimens allowed rapid oxygen transportation from the environment to the Mo reinforcement, which caused oxidation of Mo. The volatile $\mathrm{MoO}_{3}$ formed could have resulted in the failure of the Mo/YSZ composite during the isothermal oxidation test. As shown in Figure 75, the oxide powders were composed of $\mathrm{MoO}_{3}, \mathrm{NiCr}_{2} \mathrm{O}_{4}$, and $\mathrm{Cr}_{2} \mathrm{O}_{3}$. Some trace amounts of $\mathrm{Al}_{2} \mathrm{O}_{3}$ were also detected. Other peaks are very small and could be disregarded as noise. Overall, it was confirmed that the Mo reinforcing wires and the NiCrAlY bond coat were oxidized at the temperature of $1050^{\circ} \mathrm{C}$. Therefore, for high temperature application an effective oxidation resistant coating would be necessary to prevent the oxidation damages of the Mo wire in Mo/7YSZ composite.

Both as-sprayed and heat treated samples suffered from radial cracking and delamination of the NiCrAlY bond coat. Mo wire oxidized in all samples, regardless of the heat treatment. The radial cracks around Mo wires and NiCrAlY delamination allowed oxygen to penetrate the NiCrAlY bond coat and directly oxidize the Mo. Also, the cracks formed around the Mo had reduced the effect of the protective $\mathrm{Al}_{2} \mathrm{O}_{3}$ layer by 
allowing oxygen diffusion through the protective layers. The reference 7YSZ samples removed from the furnace did not show any damage.

\subsection{Isothermal and Oxidation Tests of HX Reinforcement Ceramic Matrix Composite}

\subsubsection{After $\mathbf{5 0 0}$ Hours}

Two HX/7YSZ samples, one as-sprayed and one heat treated, were furnace-cooled to room temperature from $1050^{\circ} \mathrm{C}$ after 500 and 1000 hours of heating and were examined. Figure 78 and Figure 79 show BSE images of as-sprayed and heat treated CMC samples (directly exposed to air) after 500 hours isothermal oxidation test. As seen in the figures, cavities from plasma spraying process are present inside the 7YSZ layer between two wires, but it seems these cavities are not extended toward the composite surface. $\mathrm{HX}$ wire and NiCrAlY bond coat on exposed surfaces have oxidized and their colors darkened. Inspection of the samples showed that the crack development in this cross section is more severe than inside of the composite bulk (not-directly exposed to air section). Table 21 shows the composition of each layer (directly exposed to air) of the assprayed HX/7YSZ composite. Figure 79 shows the scanned areas for analyzing these compositions. A great amount of oxygen exists in all layers and their interfaces. It is suggested that the presence of large amounts of corrosion products in exposed sections and also being under a direct temperature variation could be the reasons for increased damage in this location. 


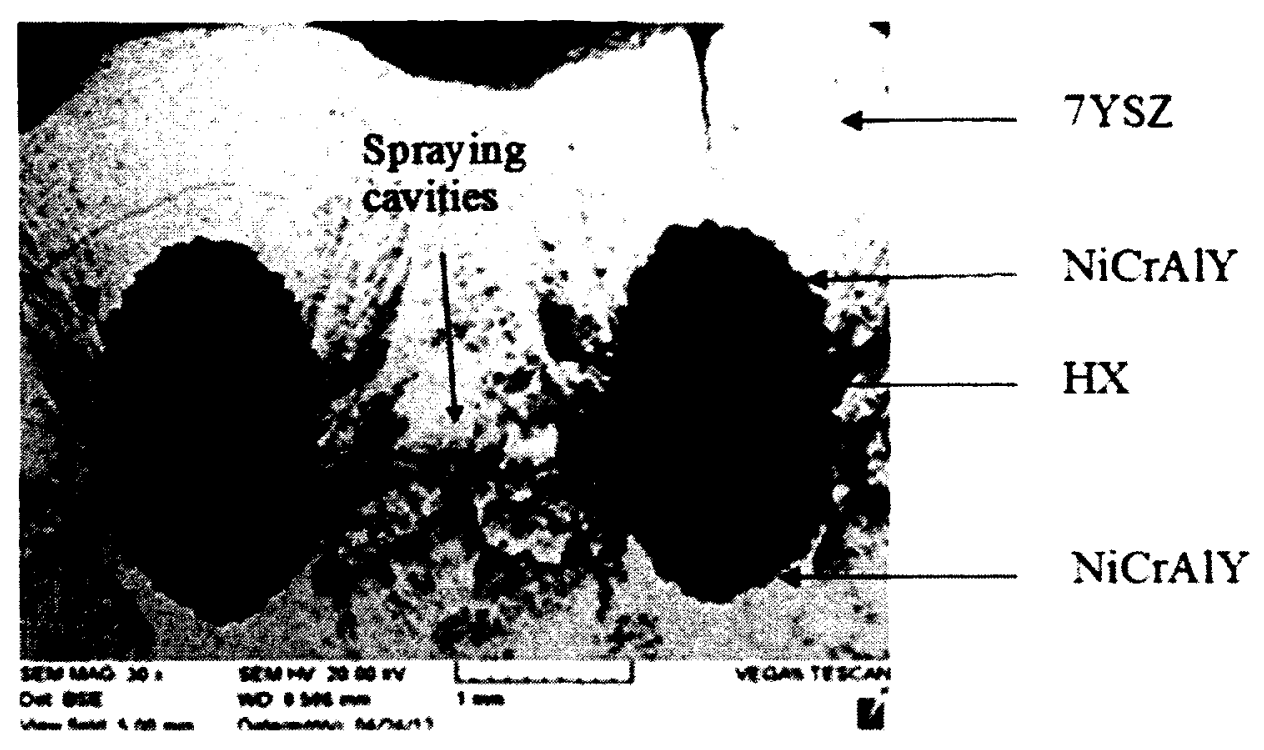

Figure 78: As-sprayed HX/7YSZ sample after 500 hours isothermal oxidation test (directly exposed to air) (30x).
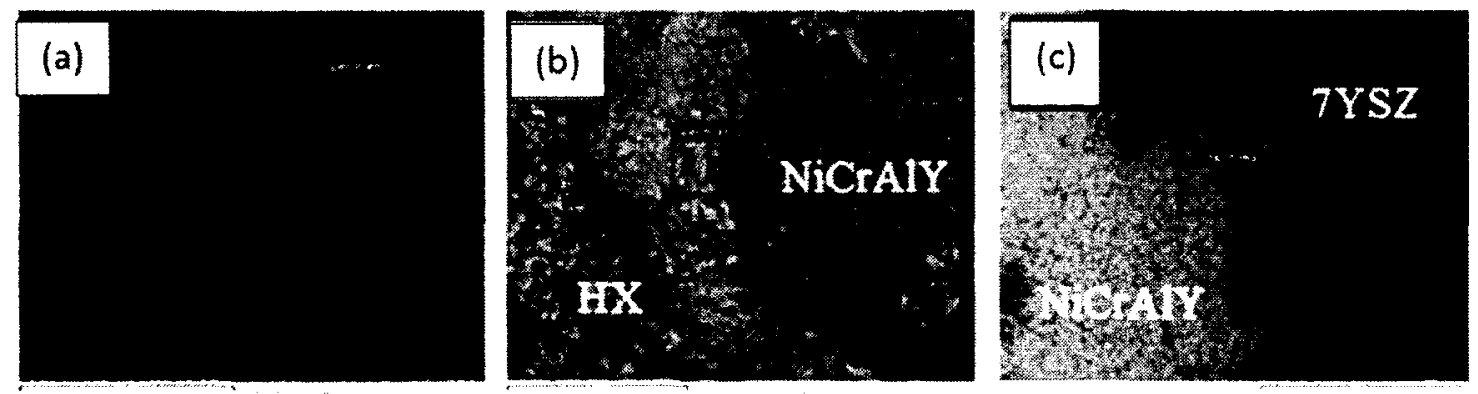

Figure 79: SEM images of as-sprayed HX/7YSZ after 500 hours isothermal test (directlyexposed to air): (a) $\mathrm{HX}$ wire, (b) $\mathrm{HX}$, NiCrAlY and interface, and (c) NiCrAlY, 7YSZ and interface. 
Table 21: Composition of the components in as-sprayed HX/7YSZ composite (in wt. \%) in directly exposed to air section after 500 hours at $1050^{\circ} \mathrm{C}$.

\begin{tabular}{llllll}
\hline & HX wire & $\begin{array}{l}\text { NiCrAlY } \\
\text { coating }\end{array}$ & $\begin{array}{l}\text { 7YSZ } \\
\text { coating }\end{array}$ & $\begin{array}{l}\mathrm{HX}- \\
\text { NiCrAlY } \\
\text { interface }\end{array}$ & $\begin{array}{l}\text { NiCrAlY- } \\
\text { 7YSZ } \\
\text { interface }\end{array}$ \\
\hline $\mathrm{O}$ & 31.55 & 48.01 & 36.09 & 39.31 & 51.59 \\
\hline $\mathrm{Cr}$ & 24.93 & 1.73 & - & 13.33 & 2.02 \\
\hline $\mathrm{Mo}$ & - & - & - & - & - \\
\hline $\mathrm{Fe}$ & 5.39 & - & - & 2.80 & - \\
\hline $\mathrm{Ni}$ & 35.86 & 1.76 & - & 20.95 & 7.12 \\
\hline $\mathrm{Al}$ & - & 46.78 & - & 17.53 & 15.77 \\
\hline $\mathrm{Co}$ & - & - & - & - & - \\
\hline $\mathrm{Zr}$ & - & - & 59.06 & 7.23 & 42.00 \\
\hline $\mathrm{Y}$ & - & - & 4.84 & 0 & - \\
\hline $\mathrm{Si}$ & - & - & - & - & - \\
\hline $\mathrm{Mn}$ & 1.95 & - & - & 6.46 & 0.93 \\
\hline $\mathrm{Ti}$ & 0.32 & - & - & - & \\
\hline
\end{tabular}

To find out the extent of oxidation damage inside the as-sprayed and heat treated HX/7YSZ CMC cross sections were cut and examined. Figure 80 shows two cross sections at $30 \mathrm{X}$ magnification. As seen, cracks exist in ceramic layers in both samples. Table 24 shows the composition of different layers on the cross section. The corresponding scan areas are shown in Figure 81 to Figure 84.

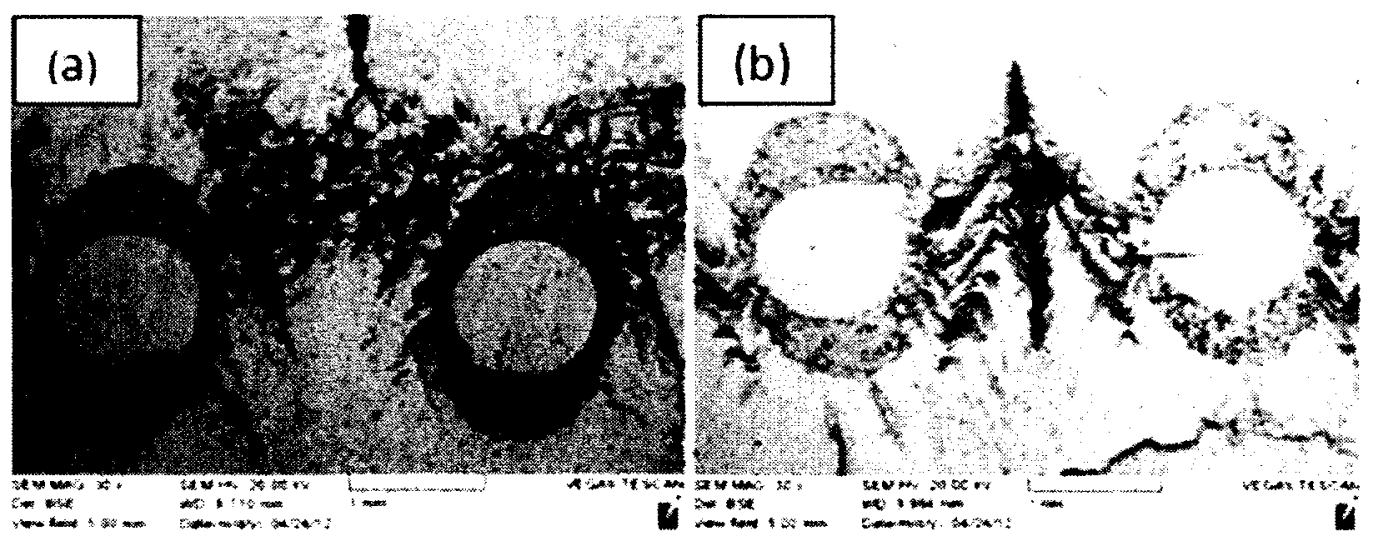

Figure 80: (a) As-sprayed, and (b) heat treated HX/7YSZ sample after 500 hours isothermal oxidation test (transverse cross section, not exposed to air directly) (30x). 

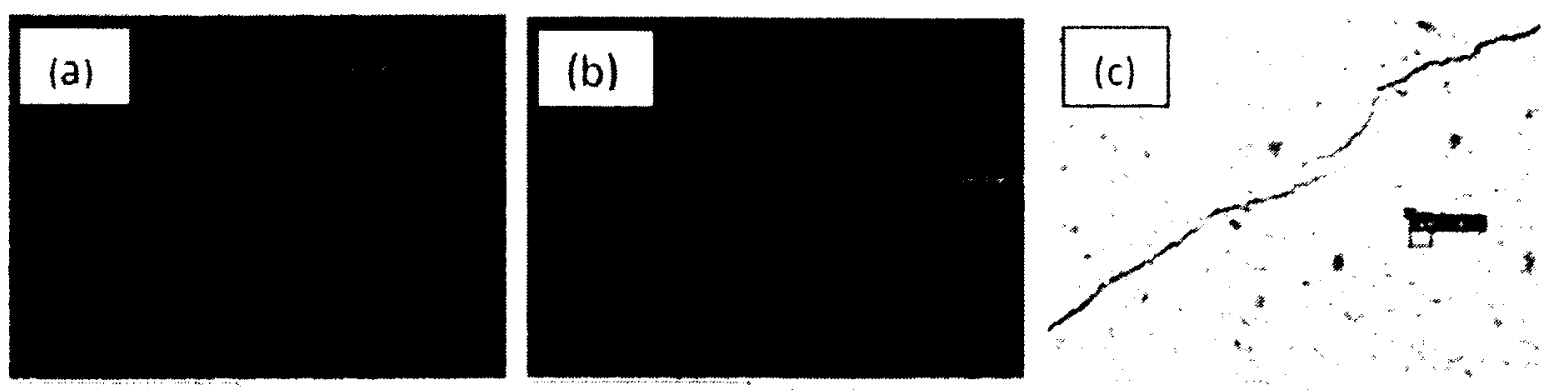

Figure 81: SEM images of as-sprayed HX/7YSZ CMC components after being exposed to air for 500 hours in isothermal oxidation test: (a) HX wire, (b) NiCrAlY coating, and (c) 7 YSZ ceramic $(5 \mathrm{kx})$.
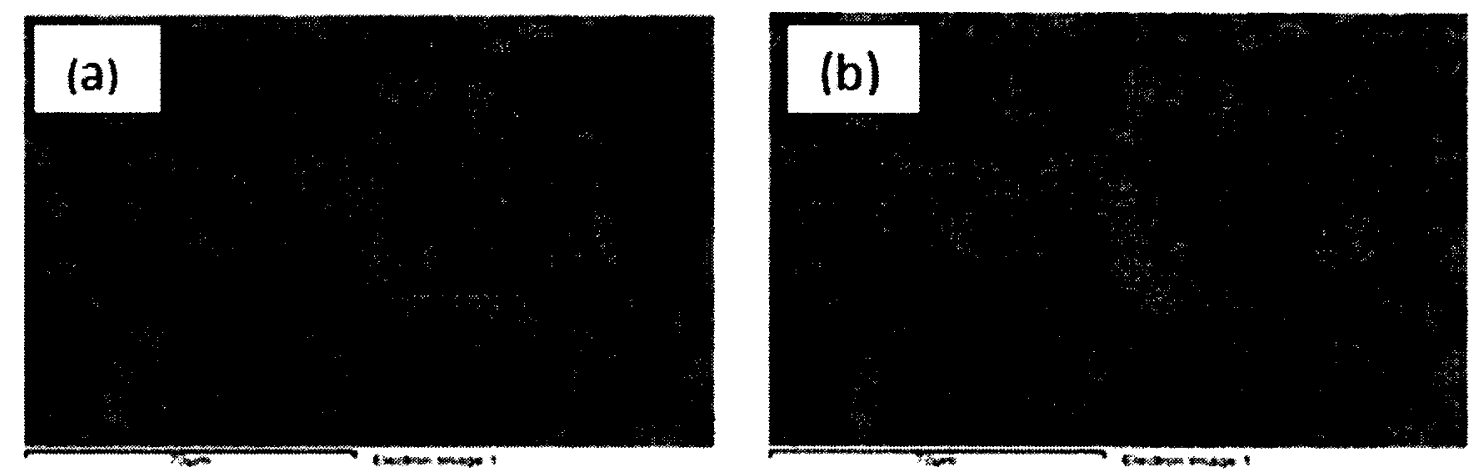

Figure 82: SEM images of Hastelloy $\mathrm{X}$ wire in the as-sprayed HX/7YSZ CMC (notdirectly exposed to air): (a) HX wire white spot, and (b) HX wire gray spot after 500 hours in isothermal oxidation.
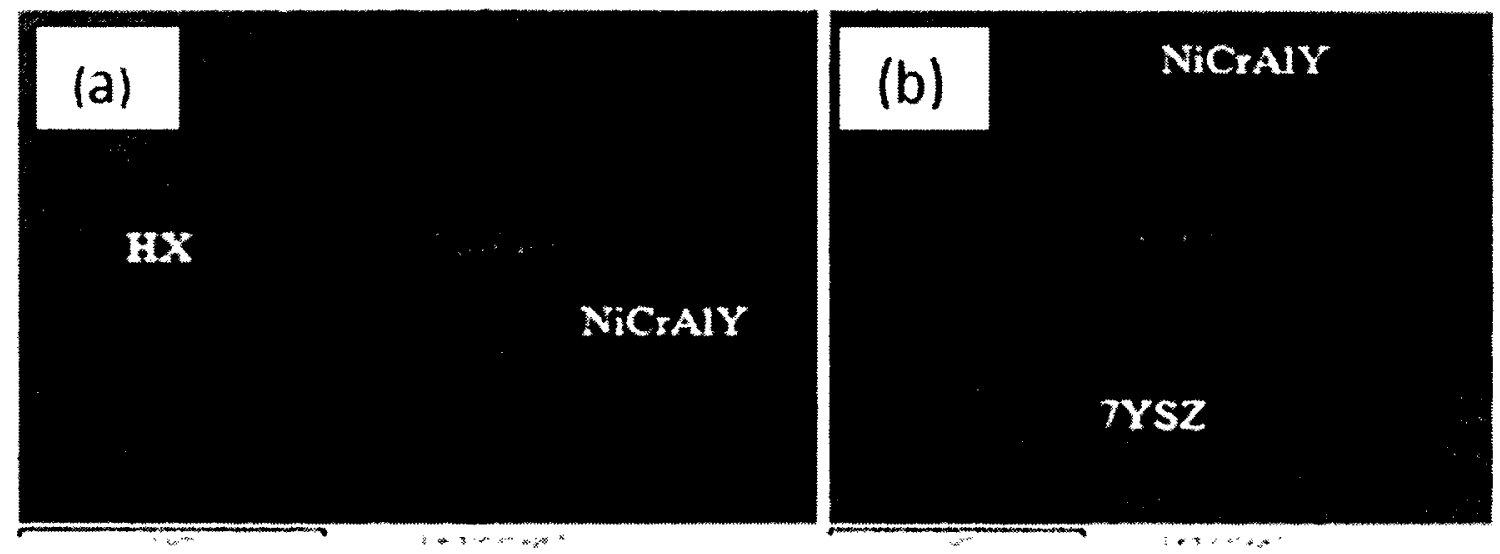

Figure 83: SEM images of as-sprayed CMC sample after 500 hours isothermal test (notdirectly exposed to air): (a) HX-NiCrAlY, and (b) NiCrAlY-7YSZ interfaces. 

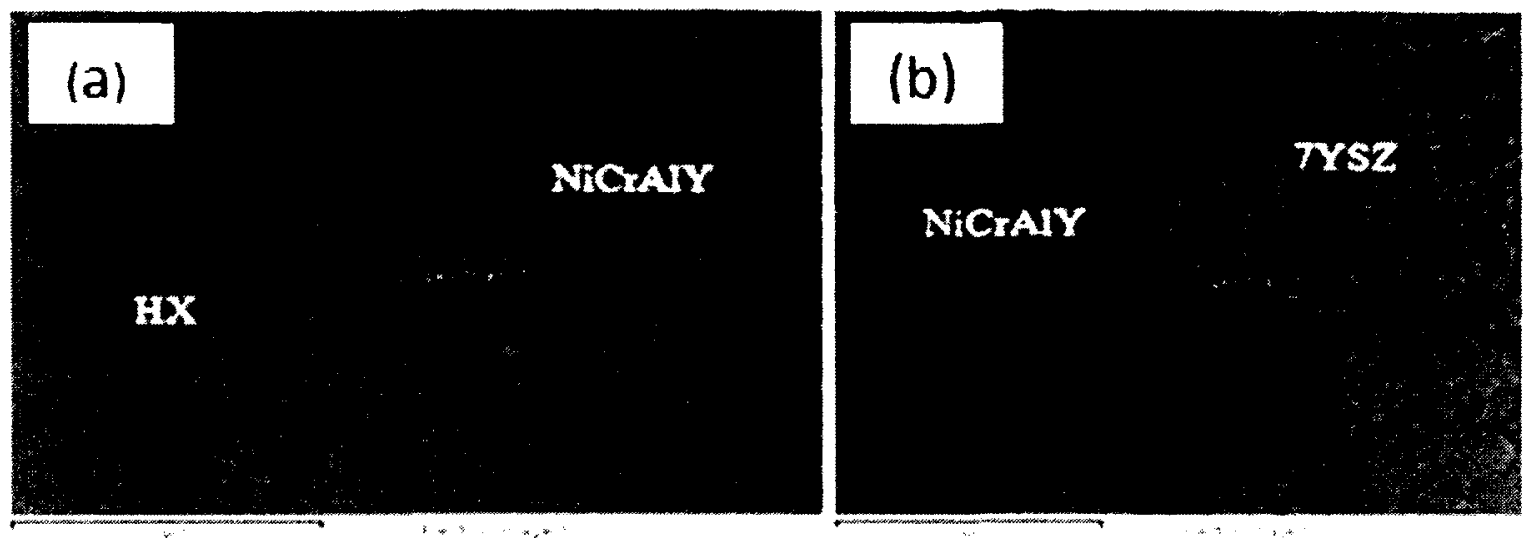

Figure 84: SEM images of heat treated CMC sample after 500 hours isothermal test (notdirectly exposed to air): (a) HX-NiCrAlY, and (b) NiCrAlY-7YSZ interfaces.

Table 22: Composition of as-sprayed HX/7YSZ CMC (not-directly exposed to air) after 500 hours at $1050^{\circ} \mathrm{C}$ (in wt. \%).

\begin{tabular}{lllllll}
\hline & $\begin{array}{l}\text { HX wire } \\
\text { White spot }\end{array}$ & $\begin{array}{l}\text { HX wire } \\
\text { gray spot }\end{array}$ & $\begin{array}{l}\text { NiCrAlY } \\
\text { coating }\end{array}$ & $\begin{array}{l}\text { 7YSZ } \\
\text { coating }\end{array}$ & $\begin{array}{l}\text { HX- } \\
\text { NiCrAlY } \\
\text { interface }\end{array}$ & $\begin{array}{l}\text { NiCrAlY- } \\
\text { 7YSZ } \\
\text { interface }\end{array}$ \\
\hline $\mathrm{O}$ & 2.87 & 2.93 & 8.29 & 27.35 & 5.65 & 18.67 \\
\hline $\mathrm{Cr}$ & 20.77 & 22.19 & 24.00 & - & 26.48 & 13.46 \\
\hline $\mathrm{Mo}$ & 27.64 & 11.57 & - & - & 3.31 & 0.93 \\
\hline $\mathrm{Fe}$ & 11.03 & 16.03 & 0.92 & - & 6.15 & - \\
\hline $\mathrm{Ni}$ & 34.28 & 44.72 & 46.48 & - & 48.38 & 22.07 \\
\hline $\mathrm{Al}$ & 0.61 & - & 4.95 & - & 5.25 & 3.50 \\
\hline $\mathrm{Co}$ & 1.51 & 1.62 & - & - & - & - \\
\hline $\mathrm{Zr}$ & - & - & 13.95 & 67.31 & 4.78 & 38.74 \\
\hline $\mathrm{Y}$ & 0 & - & 1.42 & 5.34 & 0 & 3.55 \\
\hline $\mathrm{Si}$ & 1.90 & - & - & - & - & - \\
\hline $\mathrm{Mn}$ & - & 0.94 & - & - & - & - \\
\hline
\end{tabular}

Table 22 shows the presence of oxygen in NiCrAlY bond coat which indicates the active elements $(\mathrm{Ni}, \mathrm{Cr}$, and $\mathrm{Al}$ ) have been oxidized. Also, a small amount of oxygen has been detected inside the HX wire. The concentration of oxygen in NiCrAlY-7YSZ and NiCrAlY-7YSZ interfaces are somewhat between the concentrations of the oxygen in 
each individual component. Comparing the results collected from the directly exposed to air section (sample from surface) with that of non-exposed to air cross section (sample from within the composite), it is found that despite having some cracks, 7YSZ had a beneficial effect in protecting the underlying layers in obstructing oxygen from diffusing into the bulk of the composite.

The heat treated samples after 500 and 1000 hours were analyzed with SEM. Figure 85 and Table 23 show SEM micrograph of unexposed cross section and the compositions measured from various areas.
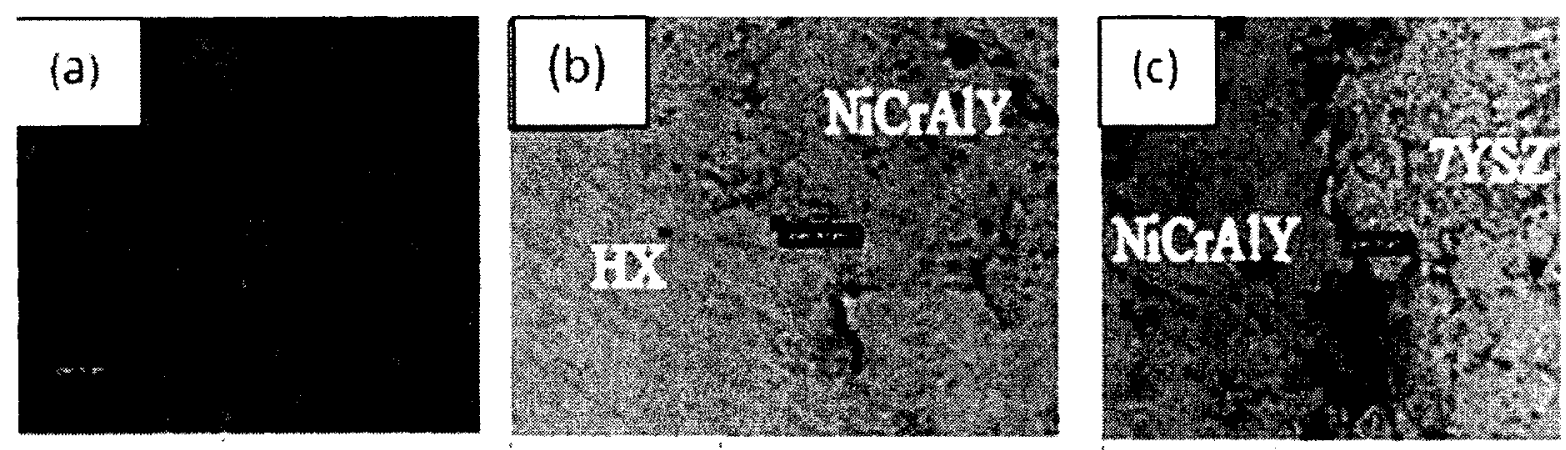

Figure 85: SEM images of heat treated HX/7YSZ CMC after 500 hours in isothermal oxidation test (not-directly exposed to air): (a) HX wire, (b) HX-NiCrAlY interface, and (c) NiCrAlY-7YSZ interface. 
Table 23: Composition of each layer on the cross section of the heat treated $\mathrm{HX} / 7 \mathrm{YSZ}$ $\mathrm{CMC}$ (not-directly exposed to air) after being exposed to air for 500 hours at $1050^{\circ} \mathrm{C}$ (in wt.\%).

\begin{tabular}{lllllll}
\hline & $\begin{array}{l}\text { HX wire } \\
\text { White spot }\end{array}$ & $\begin{array}{l}\text { HX wire } \\
\text { gray spot }\end{array}$ & $\begin{array}{l}\text { NiCrAlY } \\
\text { coating }\end{array}$ & $\begin{array}{l}\text { 7YSZ } \\
\text { coating }\end{array}$ & $\begin{array}{l}\text { HX- } \\
\text { NiCrAlY } \\
\text { interface }\end{array}$ & $\begin{array}{l}\text { NiCrAlY- } \\
\text { 7YSZ } \\
\text { interface }\end{array}$ \\
\hline $\mathrm{O}$ & - & 2.48 & 3.85 & 28.40 & 4.44 & 14.28 \\
\hline $\mathrm{Cr}$ & 20.48 & 20.67 & 26.26 & - & 27.22 & 18.02 \\
\hline $\mathrm{Mo}$ & 30.55 & 9.5 & - & - & - & - \\
\hline $\mathrm{Fe}$ & 9.48 & 14.76 & 0.61 & - & 8.06 & - \\
\hline $\mathrm{Ni}$ & 33.81 & 40.41 & 54.67 & - & 48 & 20.78 \\
\hline $\mathrm{Al}$ & 0.70 & 0.73 & 7.09 & - & 3.85 & 2.43 \\
\hline $\mathrm{Co}$ & - & 1.63 & - & - & - & - \\
\hline $\mathrm{Zr}$ & - & - & 7.53 & 65.97 & 7.15 & 40.25 \\
\hline $\mathrm{Y}$ & - & - & 0 & 5.63 & 0 & 4.25 \\
\hline $\mathrm{Si}$ & 1.82 & 0.56 & - & - & - & - \\
\hline $\mathrm{Mn}$ & - & - & - & - & - & - \\
\hline $\mathrm{W}$ & 3.14 & - & - & - & - & - \\
\hline
\end{tabular}

Comparing these results with that from cross sections of the as-sprayed samples after 500hours, it shows that the amount of diffused oxygen into NiCrAlY bond coat and HX wire are lower in the heat treated sample. This means, the TGO protective layer between bond coat and ceramic layer in heat treated samples has had a beneficial effect at shielding the NiCrAlY and HX components from oxidation than in as-sprayed CMC.

\subsubsection{After 1000 Hours}

To investigate the effect of longer exposure at $1050^{\circ} \mathrm{C}$ on as-sprayed and heat treated CMCs during isothermal oxidation tests, microstructure and composition analysis were conducted on samples tested for 1000 hours. As shown in Figure 86 to Figure 88, few cracks had developed in NiCrAlY-7YSZ interface area, similarly in all 7YSZ ceramic samples. The cracking in 7YSZ matrix (Figure 86 and Figure 87 ) could be 
because of the difference in the CTE of the HX wire, NiCrAlY and 7YSZ matrix [86] given in Table 9, Table 11 and Table 13. In some cases, circumferential cracks were also observed between the bond coat and 7YSZ ceramic layer.
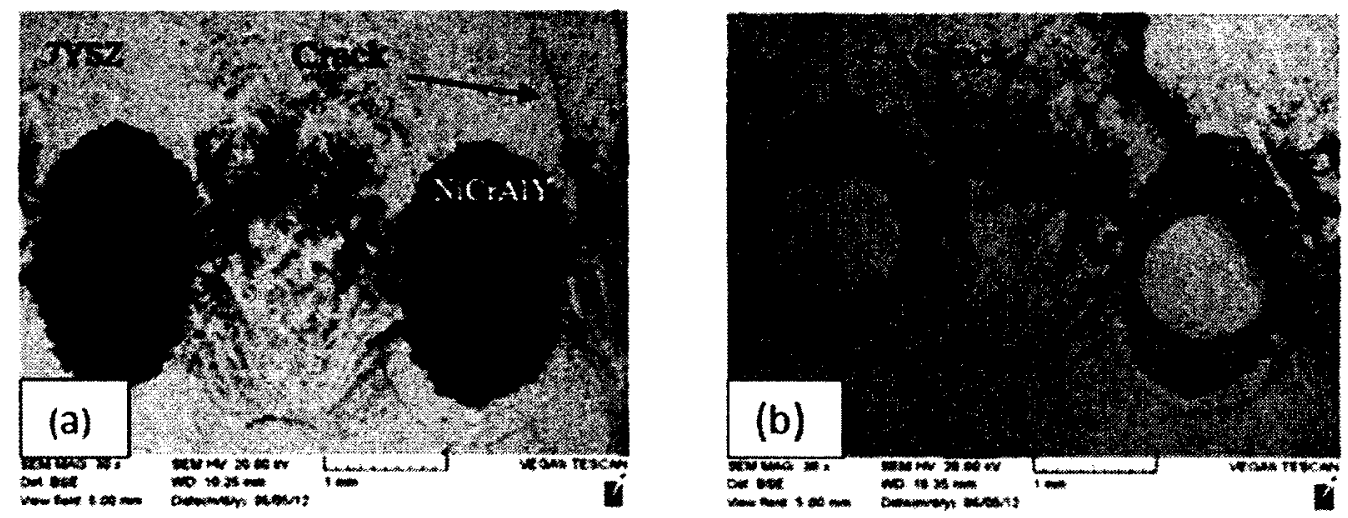

Figure 86: As-sprayed HX/7YSZ sample after 1000 hours isothermal oxidation test: (a) section directly exposed to air, and (b) cross section (30X).
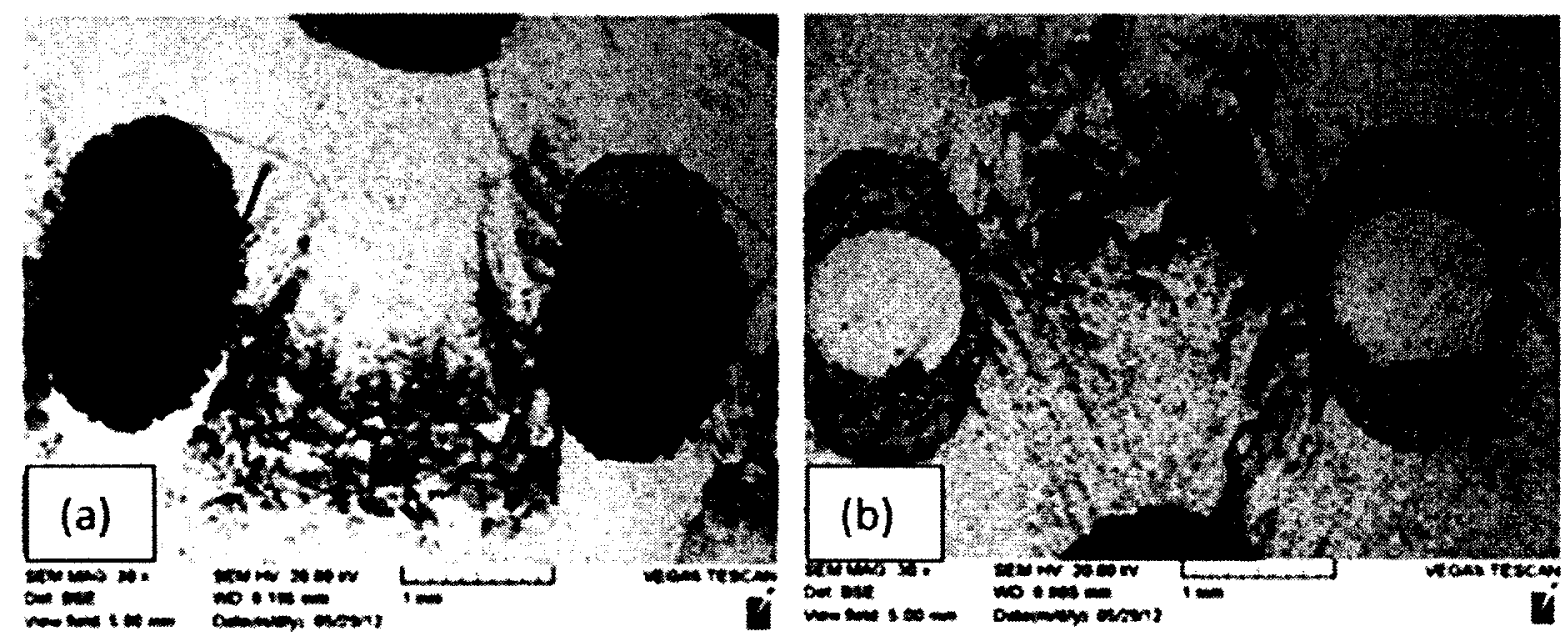

Figure 87: Heat treated HX/7YSZ samples after 1000 hours isothermal oxidation test: (a) section directly exposed to air, and (b) cross section (30X). 


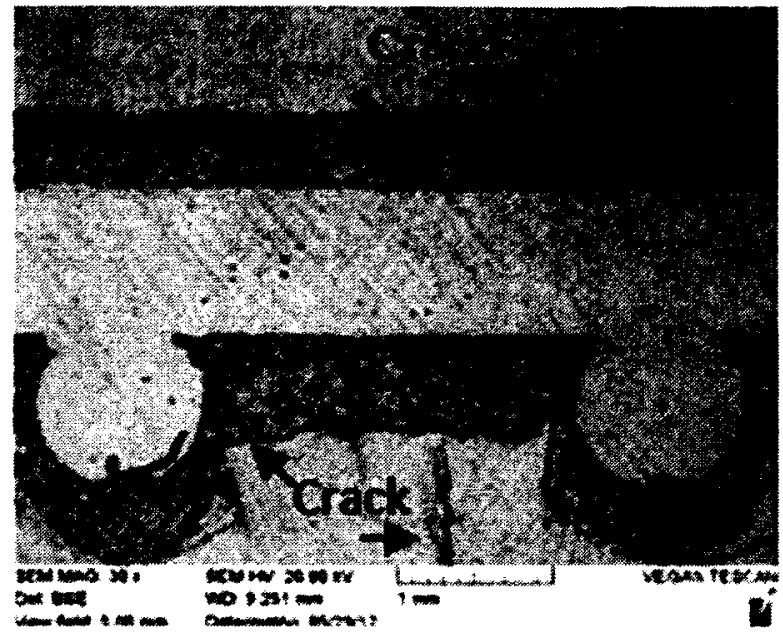

Figure 88: Heat treated HX/7YSZ sample cross section after 1000 hours isothermal oxidation test (not-directly exposed to air section) (30X).

Studying the images of the as-sprayed samples after 500 and 1000 hours show that the cracks developed in ceramic matrix in as-sprayed HX/7YSZ samples after 1000 hours are greater than that after 500 hours. Larger circumferential cracks have developed after 1000 hours at bond coat and ceramic interface locations. The compositions in different layers of this as-sprayed sample are given in Table 24 , and the corresponding locations where SEM analysis was taken are shown in Figure 89. After being exposed to air for 1000 hours, the amount of oxygen shows a slight increase in the NiCrAIY-7YSZ interface area with respect to the 500 hour test, but the oxygen concentration in $\mathrm{NiCrAlY}$ remained the same. Cracks in $7 \mathrm{YSZ}$ ceramic layer and circumferential cracks at this interface could be responsible for larger oxygen diffusion through the ceramic layer. Increasing the test time from 500 to 1000 hours allowed more oxygen diffusion through the 7YSZ ceramic allowing for additional active elements contained in surface of the NiCrAlY bond coat oxidized. 

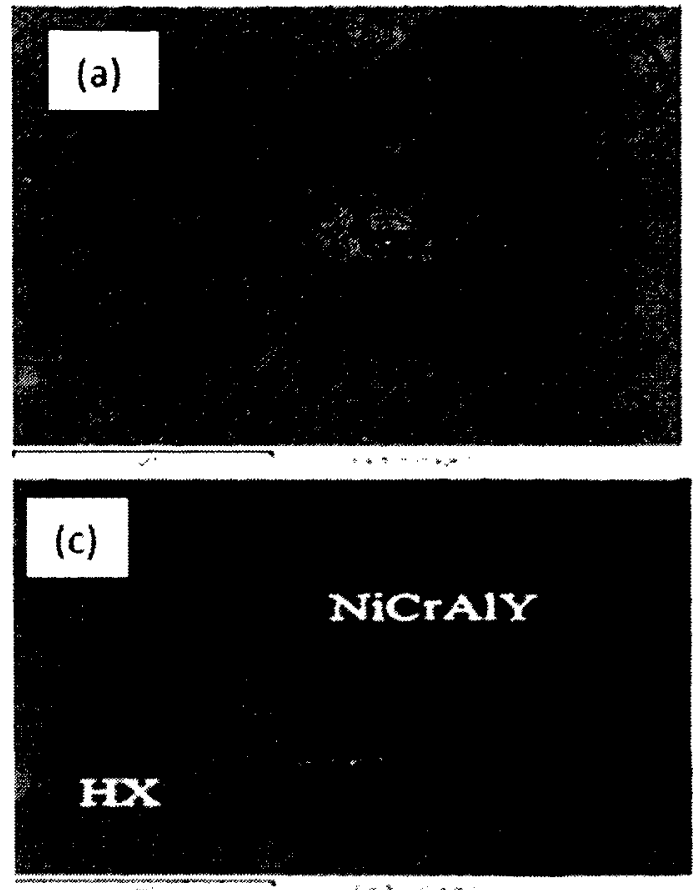

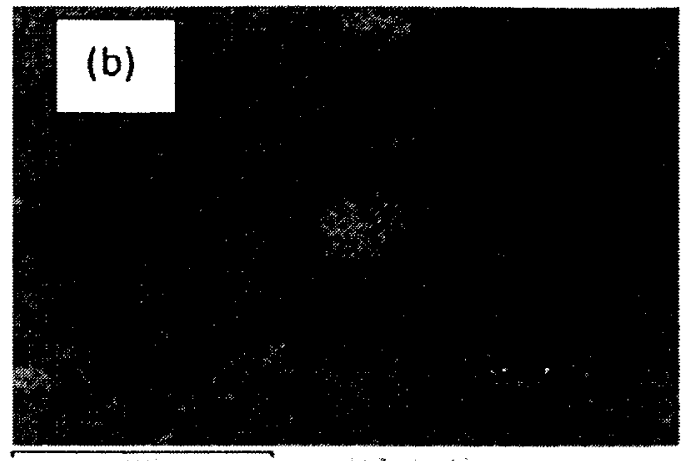

(d)

\section{NiCrAIX}

$7 \times 5 Z$

Figure 89: SEM images of as-sprayed HX/7YSZ cross section (not-directly exposed to air) after 1000 hours: (a) HX white spot, (b) HX gray spot, (c) HX-NiCrAlY interface, and (d) NiCrAlY-7YSZ interface.

Table 24: Composition of as-sprayed HX/7YSZ CMC (not-directly exposed to air) after 1000 hours at $1050^{\circ} \mathrm{C}$ (in wt. \%).

\begin{tabular}{lllllll}
\hline & $\begin{array}{l}\text { HX wire } \\
\text { white spot }\end{array}$ & $\begin{array}{l}\text { HX wire } \\
\text { gray spot }\end{array}$ & $\begin{array}{l}\text { NiCrAlY } \\
\text { coating }\end{array}$ & $\begin{array}{l}\text { 7YSZ } \\
\text { coating }\end{array}$ & $\begin{array}{l}\text { HX- } \\
\text { NiCrAlY } \\
\text { interface }\end{array}$ & $\begin{array}{l}\text { NiCrAlY- } \\
\text { 7YSZ } \\
\text { interface }\end{array}$ \\
\hline $\mathrm{O}$ & 2.76 & 3.00 & 5.02 & 27.36 & 6.88 & 20.16 \\
\hline $\mathrm{Cr}$ & 19.34 & 21.53 & 24.30 & 0.57 & 23.09 & 10.29 \\
\hline $\mathrm{Mo}$ & 23.94 & 9.78 & - & - & 6.68 & - \\
\hline $\mathrm{Fe}$ & 12.30 & 15.91 & 0.0 & - & 9.96 & - \\
\hline $\mathrm{Ni}$ & 35.67 & 42.77 & 49.59 & 0.81 & 42.57 & 17.78 \\
\hline $\mathrm{Al}$ & 0.96 & 0.80 & 6.00 & - & 4.34 & 2.64 \\
\hline $\mathrm{Co}$ & - & 1.60 & - & - & - & - \\
\hline $\mathrm{Zr}$ & - & 3.07 & 12.55 & 64.73 & 6.48 & 45.20 \\
\hline $\mathrm{Y}$ & - & - & 1.83 & 4.91 & - & 3.93 \\
\hline $\mathrm{Si}$ & 1.71 & 0.73 & - & - & - & - \\
\hline $\mathrm{Mn}$ & - & 0.81 & - & - & - & - \\
\hline $\mathrm{W}$ & 3.33 & - & - & - & - & - \\
\hline
\end{tabular}


The SEM images of different layers on the cross section of the heat treated HX/7YSZ CMC after 1000 hours isothermal test are shown in Figure 90. These are the images of the phases that were not directly exposed to air. The compositions are given in Table 25 .
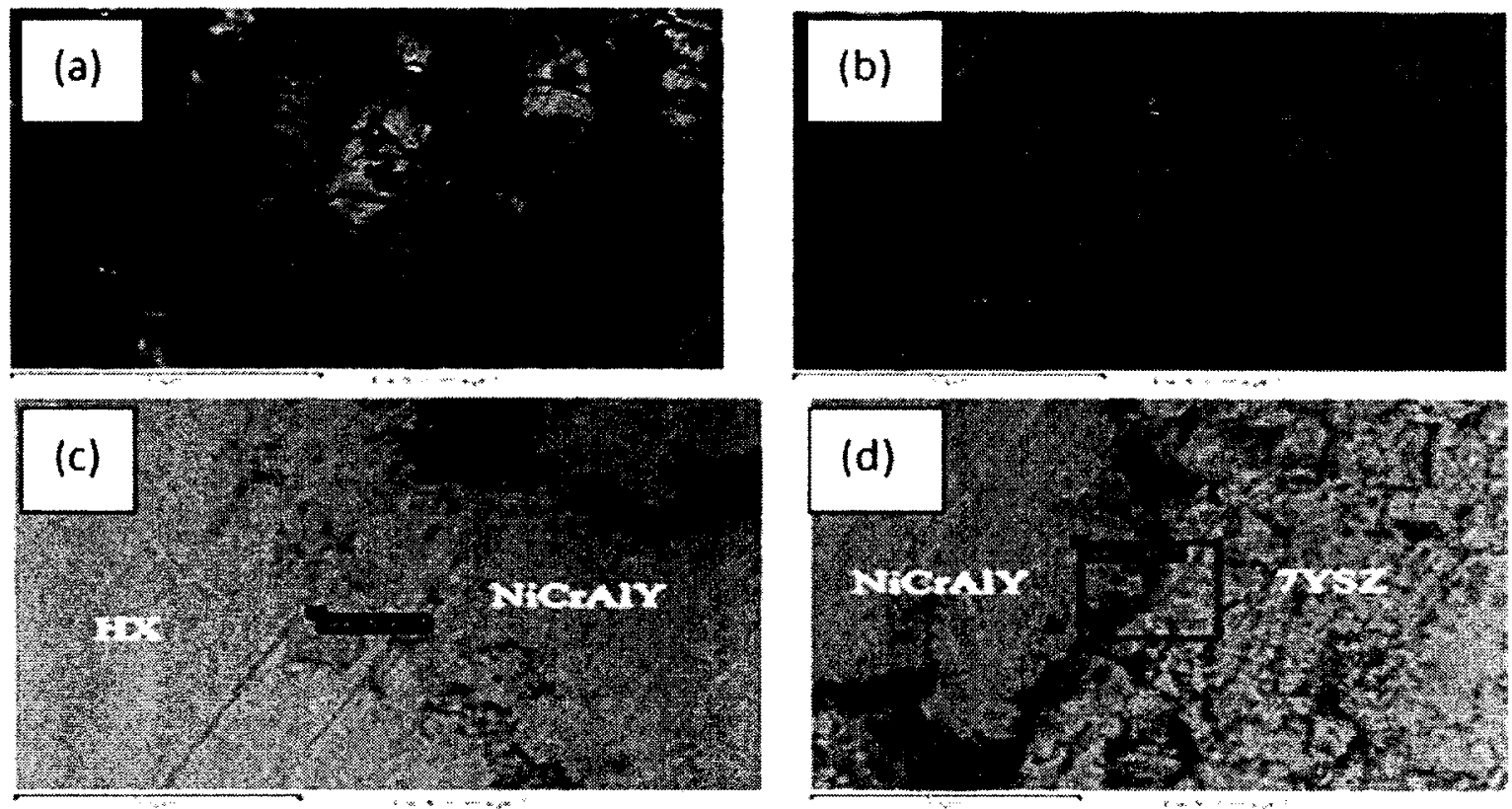

Figure 90: SEM images of different layers of the heat treated HX/7YSZ composite after 1000 hours isothermal test (not-directly exposed to air): (a) HX white spot, (b) HX grey spot, (c) HX-NiCrAlY interface, and (d) NiCrAlY-7YSZ interface. 
Table 25: Composition of heat treated HX/7YSZ CMC (not-exposed to air section) after 1000 hours in isothermal oxidation test (in wt.\%).

\begin{tabular}{lllllll}
\hline & $\begin{array}{l}\text { HX wire } \\
\text { white spot }\end{array}$ & $\begin{array}{l}\text { HX wire } \\
\text { gray spot }\end{array}$ & $\begin{array}{l}\text { NiCrAlY } \\
\text { coating }\end{array}$ & $\begin{array}{l}\text { 7YSZ } \\
\text { coating }\end{array}$ & $\begin{array}{l}\text { HX- } \\
\text { NiCrAlY } \\
\text { interface }\end{array}$ & $\begin{array}{l}\text { NiCrAlY- } \\
\text { 7YSZ } \\
\text { interface }\end{array}$ \\
\hline $\mathrm{O}$ & 2.32 & 1.36 & 1.65 & 38.47 & 5.44 & 20.44 \\
\hline $\mathrm{Cr}$ & 17.40 & 22.00 & 29.61 & - & 37.44 & 13.62 \\
\hline $\mathrm{Mo}$ & 42.65 & 7.44 & - & - & 7.79 & - \\
\hline $\mathrm{Fe}$ & 6.54 & 18.85 & - & - & 6.53 & - \\
\hline $\mathrm{Ni}$ & 23.83 & 47.80 & 68.06 & - & 35.28 & 18.01 \\
\hline $\mathrm{Al}$ & - & - & 1.49 & - & 4.08 & 3.55 \\
\hline $\mathrm{Co}$ & 1.04 & 1.63 & - & - & - & - \\
\hline $\mathrm{Zr}$ & - & - & - & 55.68 & 5.00 & 42.01 \\
\hline $\mathrm{Y}$ & - & - & 0.84 & 4.55 & 0 & 4.47 \\
\hline $\mathrm{Si}$ & 2.50 & - & - & - & - & - \\
\hline $\mathrm{Mn}$ & - & 0.92 & - & - & - & - \\
\hline $\mathrm{W}$ & 3.72 & - & - & - & - & - \\
\hline $\mathrm{Hf}$ & - & - & - & 1.30 & - & - \\
\hline
\end{tabular}

As expected, the composition results from the heat treated CMCs after 1000 hours show lower oxygen concentration in NiCrAlY and $\mathrm{HX}$ wire than the as-sprayed sample. Considering that the cracks created in both samples during this time interval are likely the same, the TGO protective layer formed during vacuum heat treatment impeded oxygen diffusion through the CMC.

The overall conditions of as-sprayed and heat treated samples after 1000 cycles appeared to be comparable. In addition, there is less oxygen found in NiCrAlY and HX wire in heat treated samples than in as-sprayed CMCs. This comparison suggests that heat treated composite materials have better oxidation resistance at $1050^{\circ} \mathrm{C}$ after 500 and 1000 hours isothermal tests. 


\subsection{Thermal Cycling}

\subsubsection{Mo Reinforcement Ceramic Matrix Composite}

All Mo/YSZ composite specimens had crumbled and failed after 100 cycles $(220$ hours) at $1050^{\circ} \mathrm{C}$. The samples after 220 hours are shown in Figure 91.

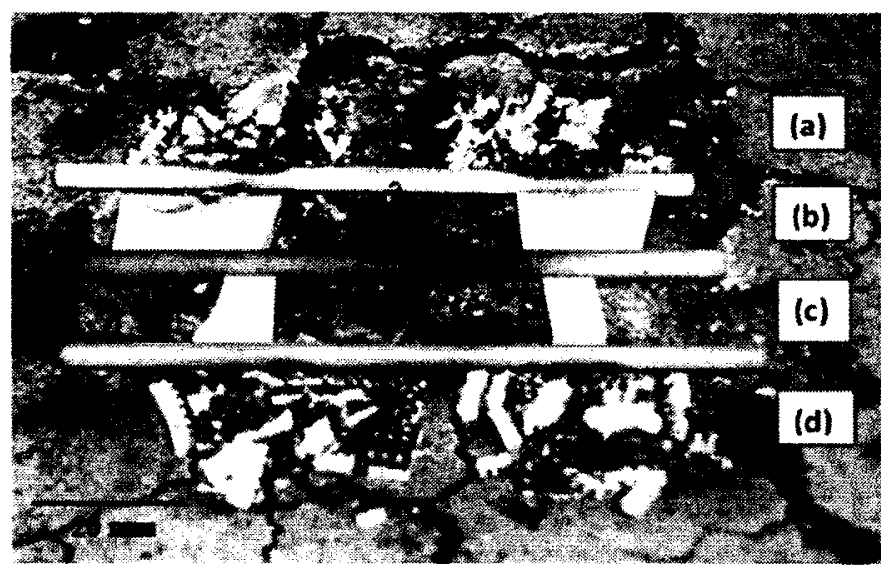

Figure 91: Cyclic oxidation test samples after 100 cycles (220 hours): (a) as-sprayed Mo/7YSZ, (b) heat treated $7 \mathrm{YSZ}$ reference, (c) as-sprayed $7 \mathrm{YSZ}$ reference, and (d) heat treated Mo/7YSZ.

From the analysis of results for samples tested under isothermal conditions, it is believed that the failure was due to the formation of $\mathrm{MoO}_{3}$. Radial cracks which formed along the Mo reinforcement allowed the oxygen diffusion to the Mo surface, thus promoting oxidation. Thermal cycling likely caused the $\mathrm{MoO}_{3}\left(\mathrm{~T}_{\text {melt }}=795^{\circ} \mathrm{C}[83]\right)$ to repeatedly melt and solidify, causing the fracture of the 7YSZ matrix.

Both as-sprayed and heat treated $\mathrm{Mo} / 7 \mathrm{YSZ}$ composite samples failed due to oxidation of the Mo reinforcement. As with the isothermal oxidation test, it is believed that oxygen was able to diffuse into the protective NiCrAlY layer due to the radial cracks at the Mo surface. For this reason, even if the heat treatment was effective in creating a protective $\mathrm{Al}_{2} \mathrm{O}_{3}$ coating at the $\mathrm{NiCrAlY}$ bond coat, the oxygen was still able to reach the Mo and 
cause oxidation. Consequently, there was no observable difference in cyclic oxidation resistance between the as-sprayed and heat treated samples.

\subsubsection{Thermal Cyclic Oxidation Test of Hastelloy X Reinforcement Ceramic}

\section{Matrix Composite}

\subsubsection{After 500 Cycles}

Both as-sprayed and heat treated HX/7YSZ samples after 500 cycles of cyclic oxidation testing are seen in Figure 92. Directly exposed and cross sections are shown in Figure 93 to Figure 96 . In directly exposed sections, after 500 cycles, profound cracking in ceramic and bond coat layers was found during visual examination. Also, both assprayed and heat treated samples delaminated with each layer fully separating from the other. Recalling the thermal cycling condition (Figure 60), the residual strain energies developed at the interfaces between layers in the CMC composite during heating and cooling cycles could be the main reason for fatigue failure and delamination. The cracking and separation in the ceramic layer was also observed in cross sections inside the composite material, but with less severity. Lower degree of damage in these cross sections suggests that less thermal shock during 500 cycles heating and cooling has been developed in this cross section. However, because the surface of the CMC cools faster than the internal part, more tension is created on the sample surface resulting in surface cracks.

Comparing the failures in cyclic and isothermal oxidation tests shows that the extent of failure in cyclic oxidation test is greater. The reason for this difference could be due to the magnitude of the thermal stress developed in the sample. In addition, the 
abrupt change in composition and CTEs at the interfaces could also worsen the failure and lead to composite layer spallation.

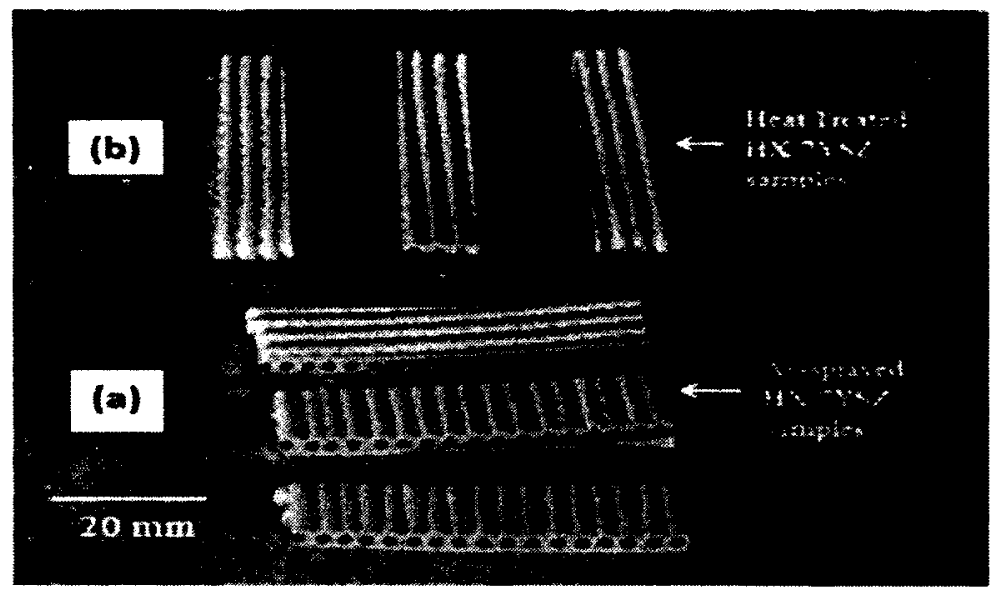

Figure 92: Cyclic oxidation test HX/7YSZ samples after 500 cycles: (a) as-sprayed, and (b) heat treated.

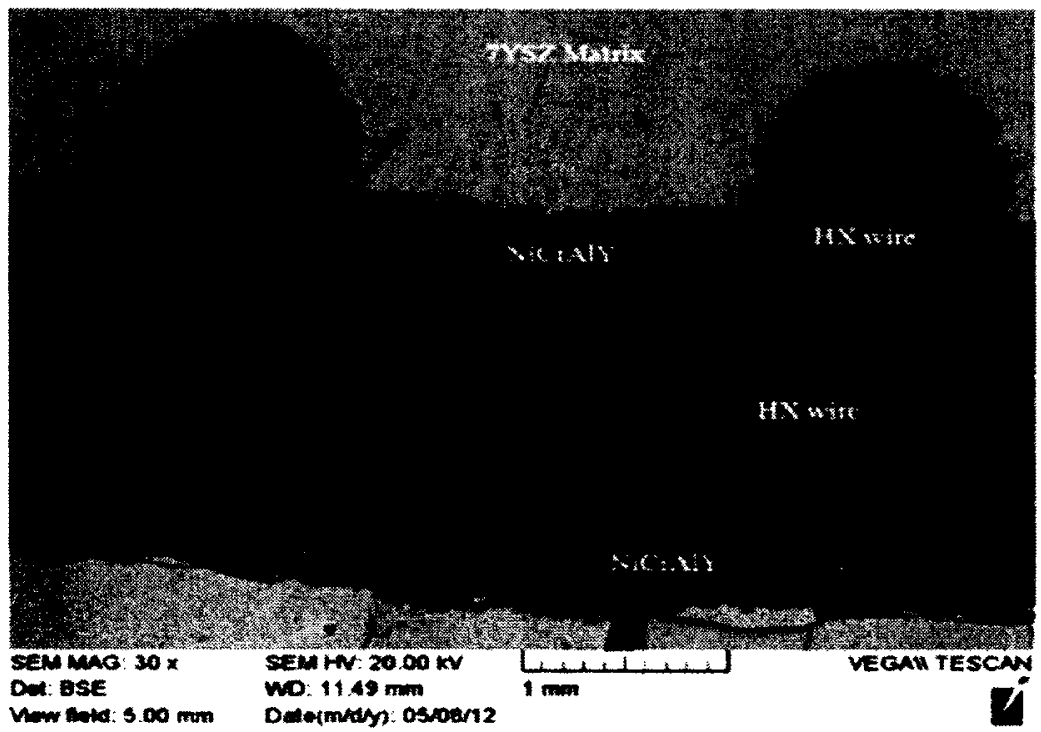

Figure 93: As-sprayed HX/7YSZ sample after 500 cycle cyclic oxidation test (directly exposed to air) (30x). 


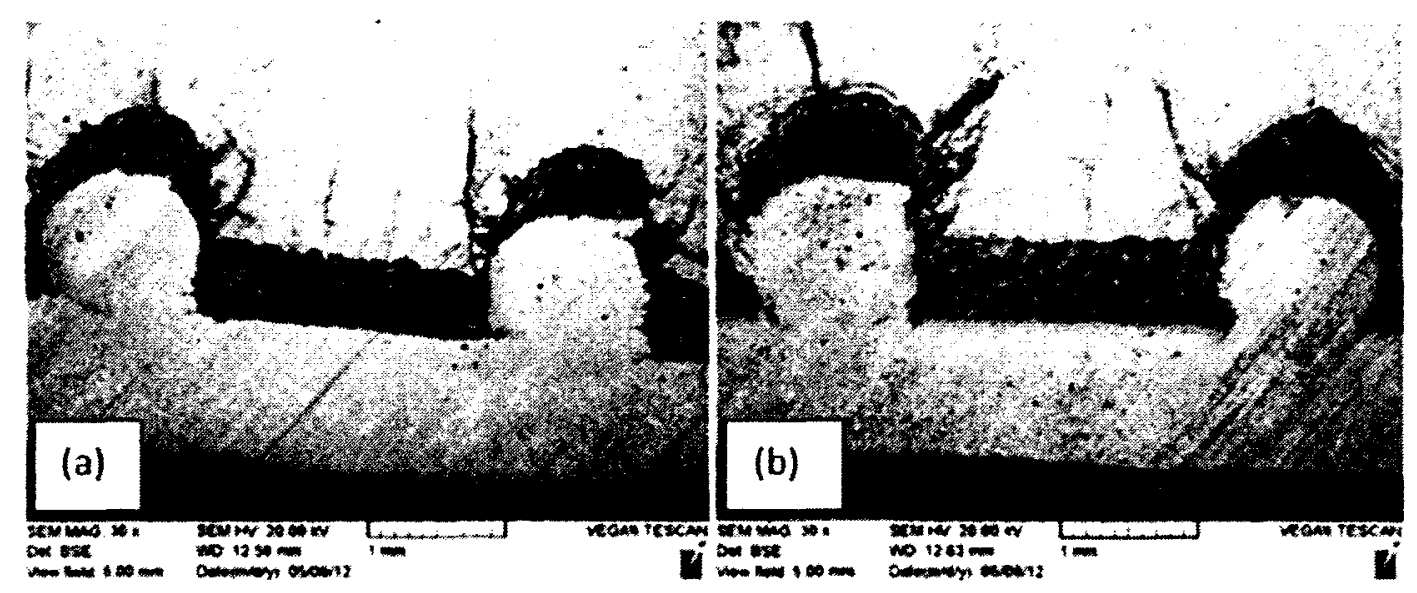

Figure 94: Cracks in as-sprayed HX/7YSZ sample after 500 cycles in cyclic test (notdirectly exposed to air): (a) longitudinal cross section, and (b) transverse cross section (30x).

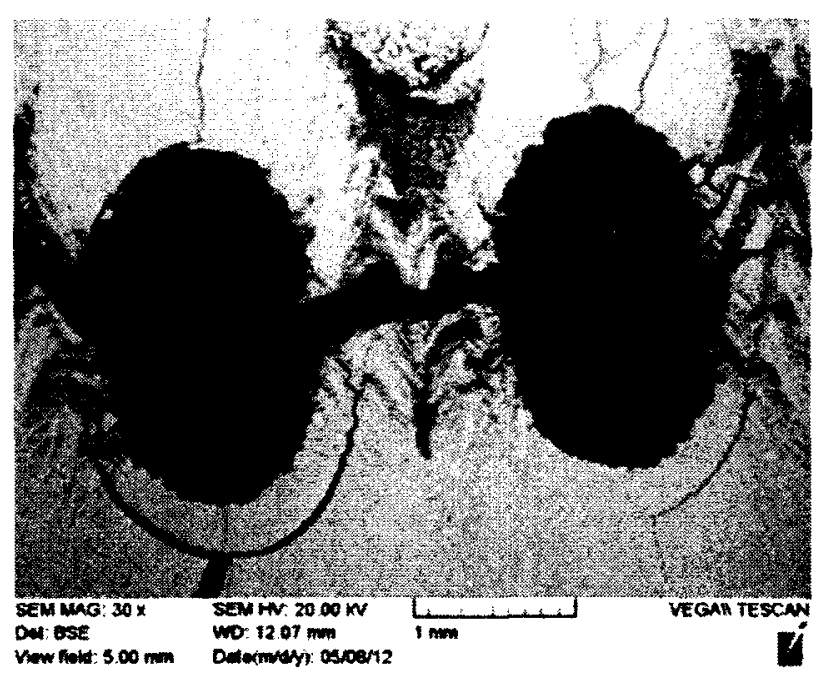

Figure 95: Cracks and delamination in heat treated HX/7YSZ sample after 500 cycles in cyclic test (directly exposed to air) (30x). 


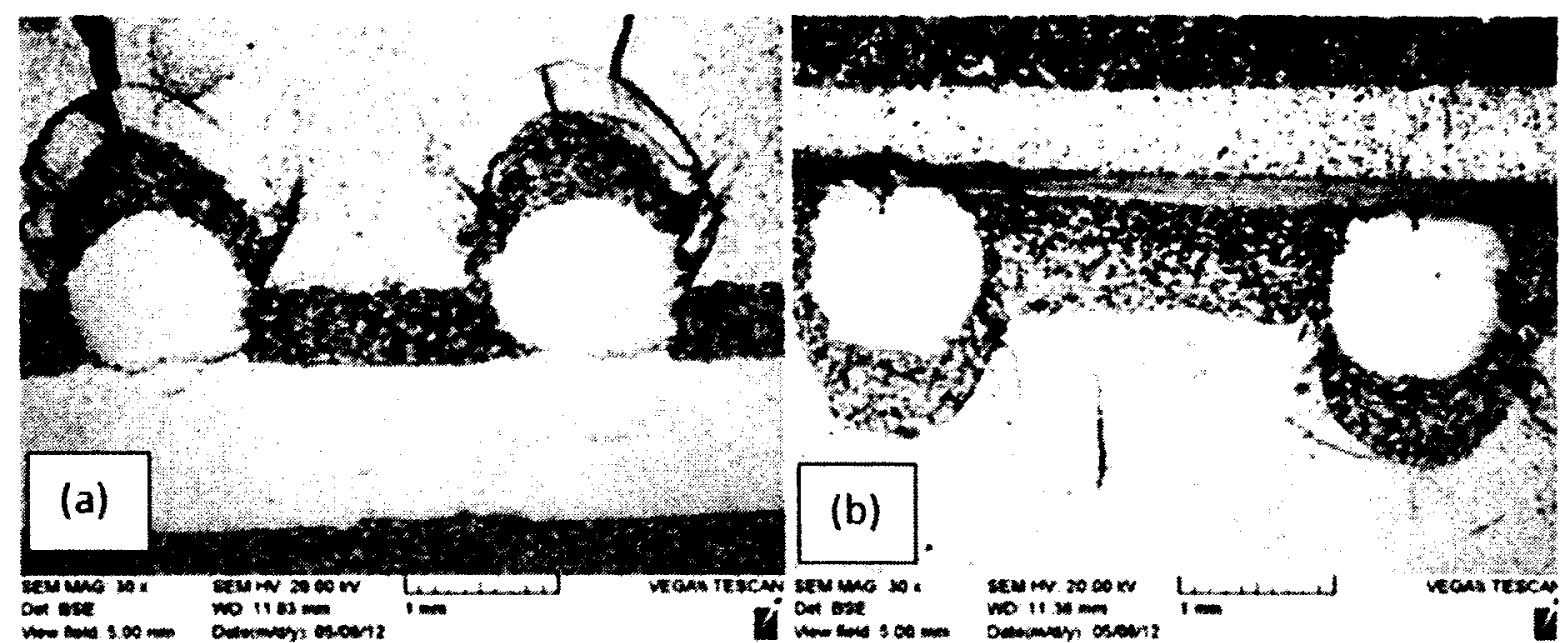

Figure 96: Cracks and delamination in heat treated HX/7YSZ sample after 500 cycles in cyclic test (not-directly exposed to air): (a) longitudinal cross section, and (b) transverse cross section (30X).

To characterize the scales formed on directly exposed sections in the heat treated HX/7YSZ sample, the composition of Hastelloy $\mathrm{X}$ wire, bond coat, and ceramic were determined and their values are given in Table 26; the corresponding locations also are shown in SEM images in Figure 97.
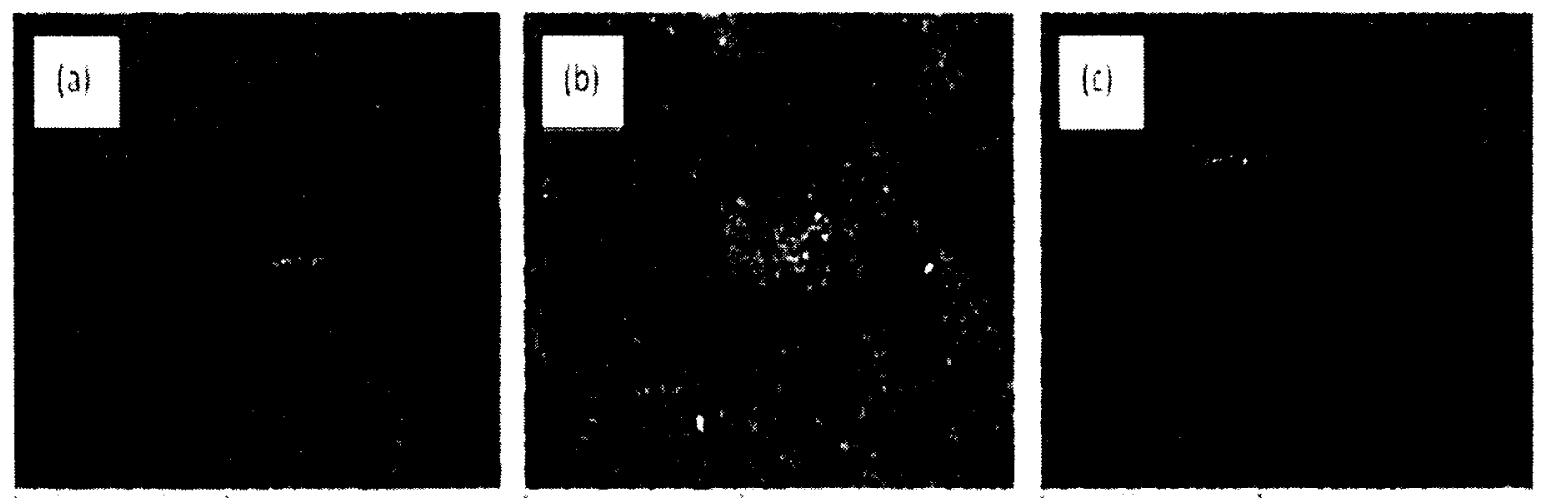

Figure 97: SEM image of heat treated HX/7YSZ sample after 500 cycles in cyclic test (directly exposed to air): (a) HX wire, (b) NiCrAlY bond coat, and (c) 7YSZ ceramic. 
Table 26: Compositions of the heat treated HX/7YSZ composite (directly exposed section) after 500 cycles in cyclic test at $1050^{\circ} \mathrm{C}$ (in wt.\%).

HX wire

NiCrAlY bond coat

7YSZ ceramic

\begin{tabular}{cccc}
\hline $\mathrm{O}$ & 29.53 & 42.43 & 29.70 \\
\hline $\mathrm{Al}$ & 0.79 & 27.01 & 0.40 \\
\hline $\mathrm{Ca}$ & 0.35 & - & - \\
\hline $\mathrm{Cr}$ & 35.95 & 9.24 & - \\
\hline $\mathrm{Mn}$ & 1.50 & 0.75 & - \\
\hline $\mathrm{Fe}$ & 10.65 & - & - \\
\hline $\mathrm{Ni}$ & 18.24 & 13.34 & - \\
\hline $\mathrm{Zr}$ & 3.00 & 5.88 & 64.61 \\
\hline $\mathrm{Y}$ & - & 1.36 & 5.29 \\
\hline
\end{tabular}

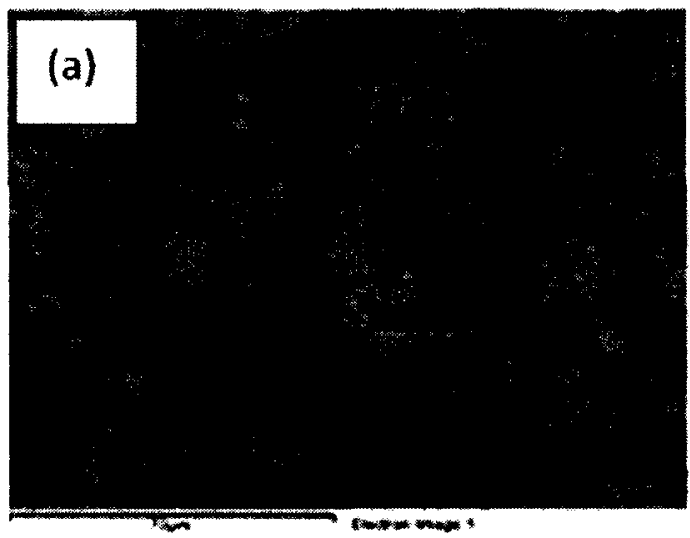

(b)

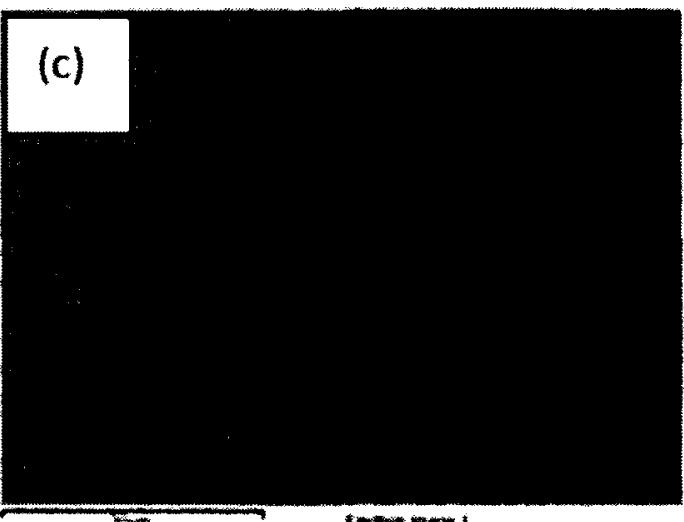

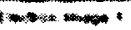

(d)

Figure 98: SEM images of as-sprayed HX/7YSZ CMC after 500 cycles of cyclic test (not-directly exposed to air): (a) HX white spot, (b) HX grey spot, (c) HX-NiCrAlY interface, and (d) NiCrAlY-7YSZ interface (5kx). 
Table 26 shows that the scales covering the $\mathrm{HX}$ and $\mathrm{NiCrAlY}$ layer contain large amount of oxygen. Table 27 presents the composition of different layers of the as-sprayed HX/7YSZ composite after 500 cycles in cyclic thermal oxidation test, including interfaces. The corresponding areas for this analysis are shown in Figure 98.

Table 27: Composition of as-sprayed HX/7YSZ CMC on the cross section after 500 cycles of cyclic test (in wt.\%).

\begin{tabular}{lllllll}
\hline & $\begin{array}{l}\text { HX wire } \\
\text { white spot }\end{array}$ & $\begin{array}{l}\text { HX wire } \\
\text { gray spot }\end{array}$ & $\begin{array}{l}\text { NiCrAlY } \\
\text { coating }\end{array}$ & $\begin{array}{l}\text { 7YSZ } \\
\text { ceramic }\end{array}$ & $\begin{array}{l}\text { HX- } \\
\text { NiCrAlY } \\
\text { interface }\end{array}$ & $\begin{array}{l}\text { NiCrAlY- } \\
\text { 7YSZ } \\
\text { interface }\end{array}$ \\
\hline $\mathrm{O}$ & 2.87 & 2.93 & 8.29 & 27.35 & 3.37 & 18.86 \\
\hline $\mathrm{Cr}$ & 20.77 & 22.19 & 24.00 & - & 25.71 & 12.55 \\
\hline $\mathrm{Mo}$ & 27.64 & 11.57 & - & - & 5.63 & - \\
\hline $\mathrm{Fe}$ & 11.03 & 16.03 & 0.92 & - & 8.34 & - \\
\hline $\mathrm{Ni}$ & 34.28 & 44.72 & 46.48 & - & 48.95 & 21.72 \\
\hline $\mathrm{Al}$ & - & - & 4.95 & - & 6.06 & 1.59 \\
\hline $\mathrm{Co}$ & 1.51 & 1.62 & - & - & - & - \\
\hline $\mathrm{Zr}$ & - & - & 13.95 & 67.31 & 3.94 & 45.29 \\
\hline $\mathrm{Y}$ & 0 & - & 1.42 & 5.34 & 0 & 3.00 \\
\hline $\mathrm{Si}$ & 1.90 & - & - & - & - & - \\
\hline $\mathrm{Mn}$ & - & 0.94 & - & - & - & - \\
\hline $\mathrm{W}$ & - & - & - & - & - & - \\
\hline $\mathrm{Ca}$ & - & - & - & - & - & 0.72 \\
\hline
\end{tabular}



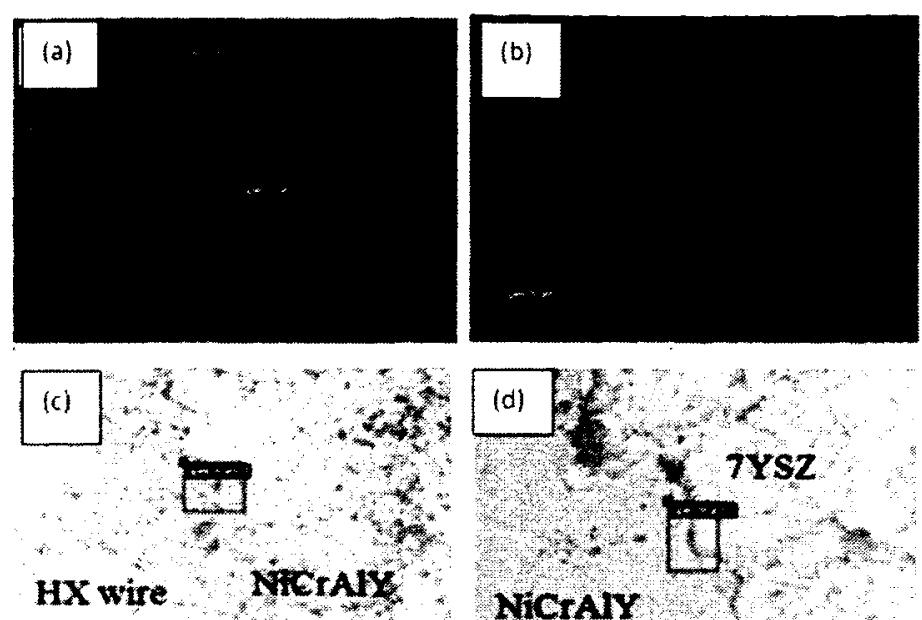

NíCraIY

Figure 99: SEM images of heat treated HX/7YSZ CMC after 500 cycle of cyclic test (not-directly exposed to air): (a) $\mathrm{HX}$ white spot, (b) $\mathrm{HX}$ grey spot, (c) HX-NiCrAlY interface, and (d) NiCrAlY-7YSZ interface (5kx).

Table 28: Composition of heat treated $\mathrm{HX} / 7 \mathrm{YSZ} \mathrm{CMC}$ on cross section after 500 cycles of cyclic test (in wt.\%).

\begin{tabular}{lllllll}
\hline & $\begin{array}{l}\text { HX wire } \\
\text { white spot }\end{array}$ & $\begin{array}{l}\text { HX wire } \\
\text { gray spot }\end{array}$ & $\begin{array}{l}\text { NiCrAlY } \\
\text { coating }\end{array}$ & $\begin{array}{l}\text { 7YSZ } \\
\text { ceramic }\end{array}$ & $\begin{array}{l}\text { HX- } \\
\text { NiCrAlY } \\
\text { interface }\end{array}$ & $\begin{array}{l}\text { NiCrAlY- } \\
\text { 7YSZ } \\
\text { interface }\end{array}$ \\
\hline $\mathrm{O}$ & - & 2.48 & 2.94 & 28.40 & 7.99 & 16.14 \\
\hline $\mathrm{Cr}$ & 20.48 & 20.67 & 51.68 & - & 24.13 & 13.92 \\
\hline $\mathrm{Mo}$ & 30.55 & 9.50 & - & - & 4.62 & - \\
\hline $\mathrm{Fe}$ & 9.48 & 14.76 & 0.73 & - & 7.58 & - \\
\hline $\mathrm{Ni}$ & 33.81 & 40.41 & 31.72 & - & 47.40 & 24.93 \\
\hline $\mathrm{Al}$ & 0.70 & 0.73 & 6.28 & - & 4.23 & 0.94 \\
\hline $\mathrm{Co}$ & - & 1.63 & - & - & - & - \\
\hline $\mathrm{Zr}$ & - & - & 6.66 & 65.97 & 4.22 & 44.40 \\
\hline $\mathrm{Y}$ & - & - & 0 & 5.63 & - & 3.08 \\
\hline $\mathrm{Si}$ & 1.82 & 0.56 & - & - & - & - \\
\hline $\mathrm{Mn}$ & - & - & - & - & - & - \\
\hline $\mathrm{W}$ & 3.14 & - & - & - & - & - \\
\hline $\mathrm{Ca}$ & - & - & - & - & - & - \\
\hline
\end{tabular}


Studying the compositions values in both as-sprayed and heat treated samples shows that less oxygen is present on the cross section(s). After cyclic tests, cracking and delamination were similar in both as-sprayed and heat treated composites. Nevertheless, the heat treated samples performed better during 500 cycle thermal oxidation test in terms of oxygen diffusion into the inner layer.

\subsubsection{After 1000 Cycles}

The effect of longer thermal cyclic condition on HX/7YSZ CMCs was studied. Assprayed and heat treated samples after 1000 cycles in cyclic oxidation tests were examined. Two samples before being removed from furnace are seen in Figure 100. Under higher magnifications, similar types of failures seen in samples after 500 cycles were evident after 1000 cycles. Figure 101 and Figure 103 show extensive circumferential cracks and separation around $\mathrm{HX}$ wires in directly exposed sections of both as-sprayed and heat treated samples. Considering the severity of the damages, 1000cycle test had worsened the cracking and delamination. Increasing the number of cycles increases the extent of fatigue failure. The failure mechanism after 1000 cycles seems to be the same as those seen after 500 cycles, but the extent of failure is greater after 1000 cycles. Radial and circumferential cracking and delamination are even visible in longitudinal and transverse cross sections (in not-directly exposed to air sections) in both as-sprayed and heat treated samples. However, the extent of cracking and delamination is lower in these cross sections because of reduced oxygen accessibility to $\mathrm{HX}$ wire and $\mathrm{NiCrAlY}$ bond-coat. The cracking and delamination along interfaces can be related to the difference in CTE of the composite components, creating thermal stress in the sample. 


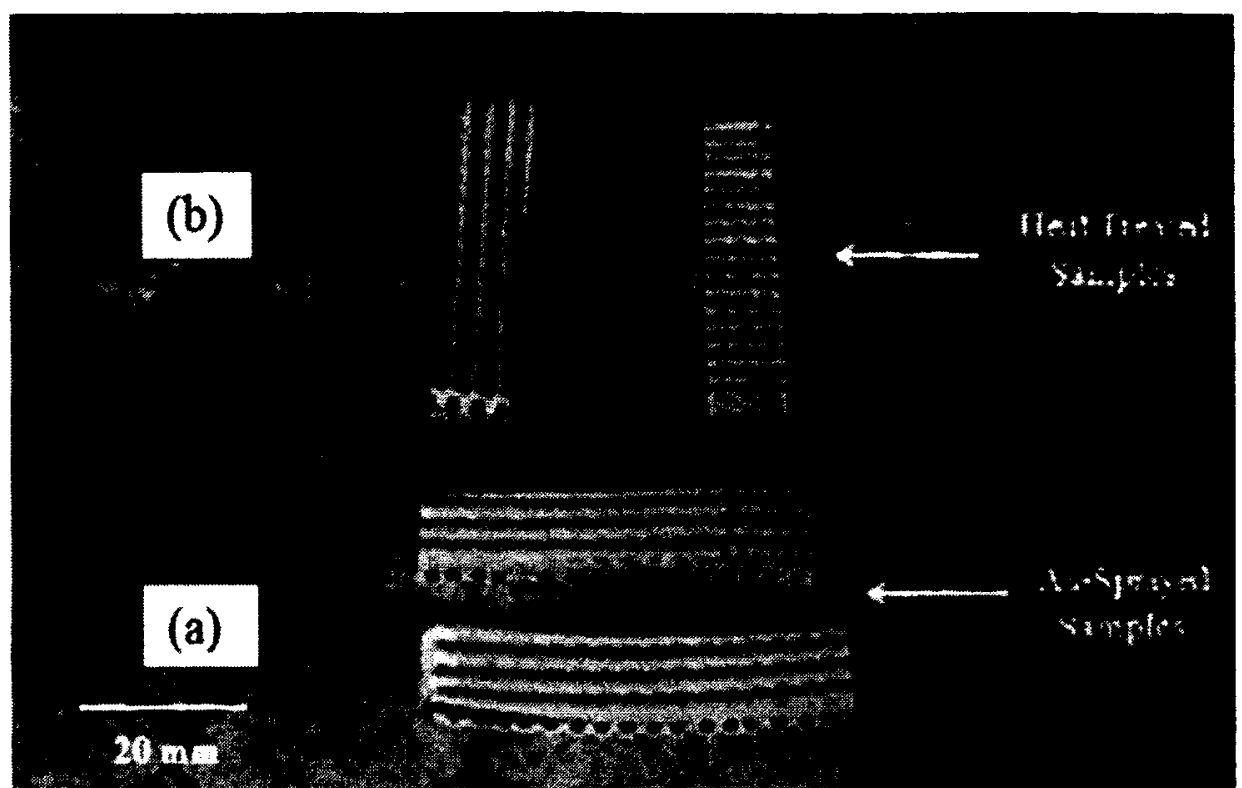

Figure 100: Cyclic oxidation test HX/7YSZ samples after 1000 cycles: (a) as-sprayed, and (b) heat treated.

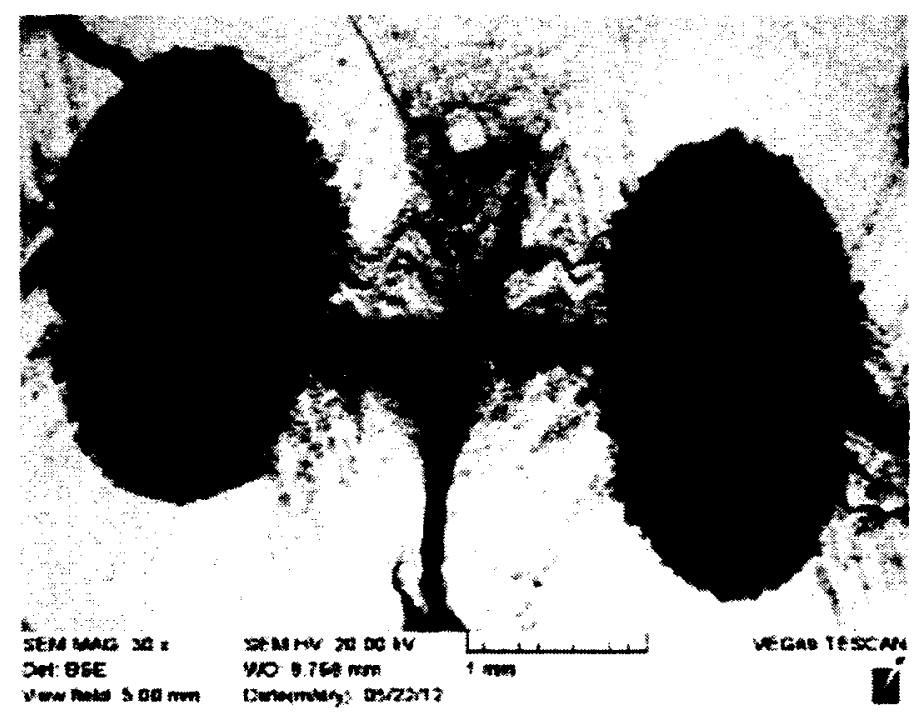

Figure 101: Cracks and delamination in as-sprayed HX/7YSZ sample after 1000 cycles in cyclic test (directly exposed to air) $(30 \mathrm{x})$. 


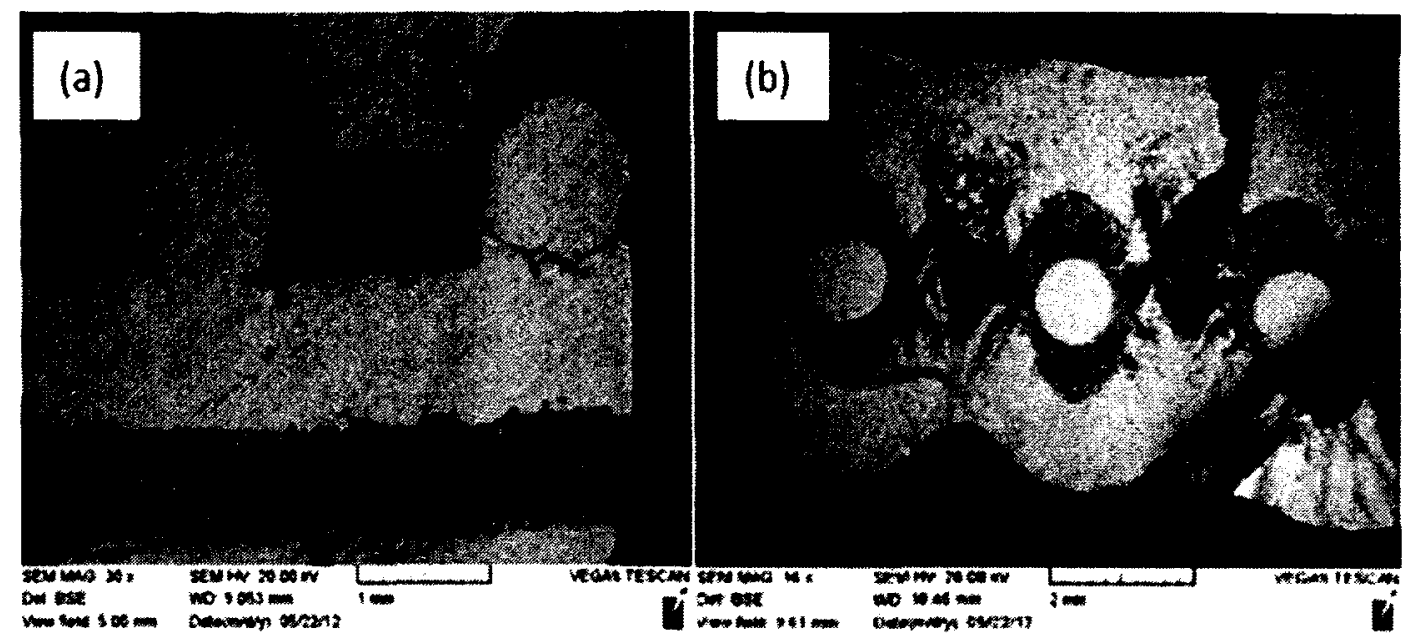

Figure 102: As-sprayed HX/7YSZ sample after 1000 cycles of cyclic test (not-directly exposed to air): (a) longitudinal cross section (30X), and (b) transverse cross section $(16 \mathrm{X})$.

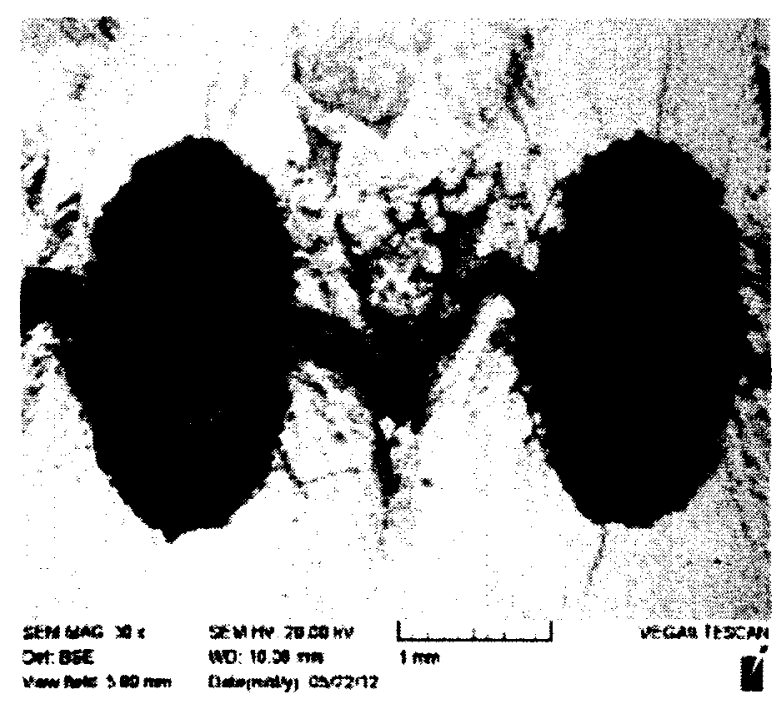

Figure 103: Cracks and delamination in heat treated HX/7YSZ sample after 1000 cycles of cyclic test (directly exposed section) (30x). 


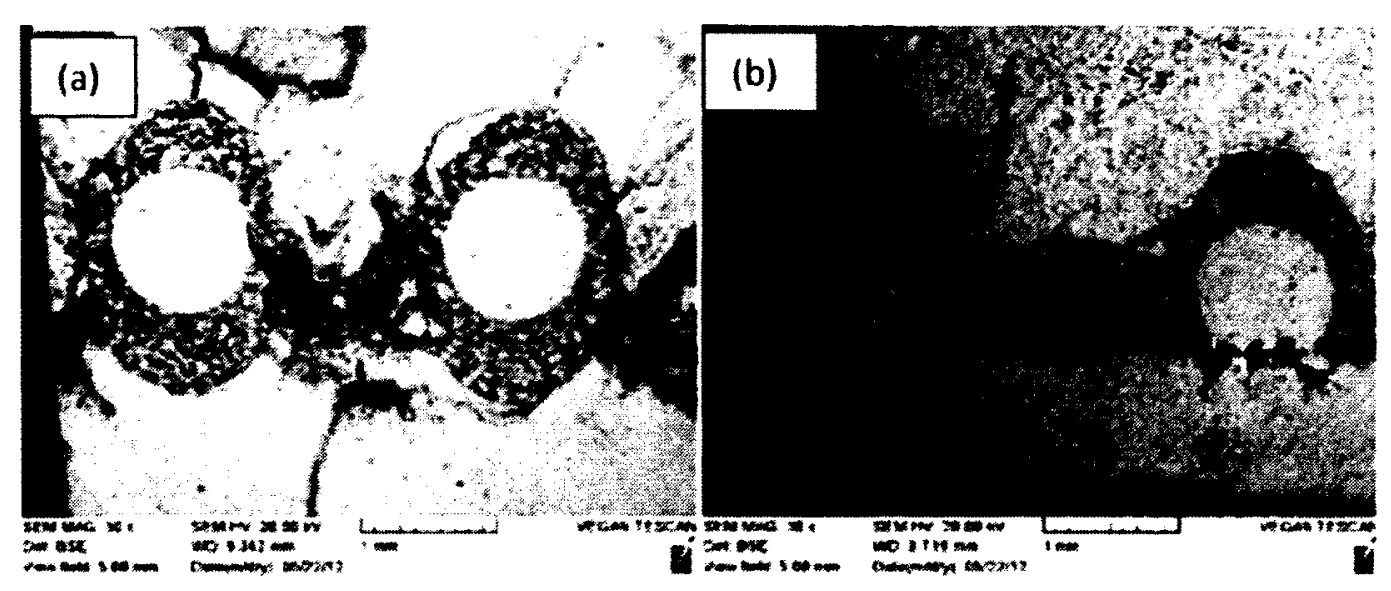

Figure 104: Cracks and delamination in heat treated $\mathrm{HX} / 7 \mathrm{YSZ}$ samples after 1000 cycles of cyclic test (not-directly exposed to air): (a) longitudinal cross section, and (b) transverse cross section $(30 \mathrm{x})$.

In addition to cracking and delamination, both as-sprayed and heat treated samples after 1000 cycles thermal oxidation were physically warped. This sample curvature was not observed in samples after 500 cycles. A closer look at the samples (Figure 105) reveals that the curvature is toward the longitudinal metal wires that have higher thermal expansion than the $7 \mathrm{YSZ}$ ceramic. The occurrence of the curvature without delamination could be a sign of good bonding between the different layers of the composite material.
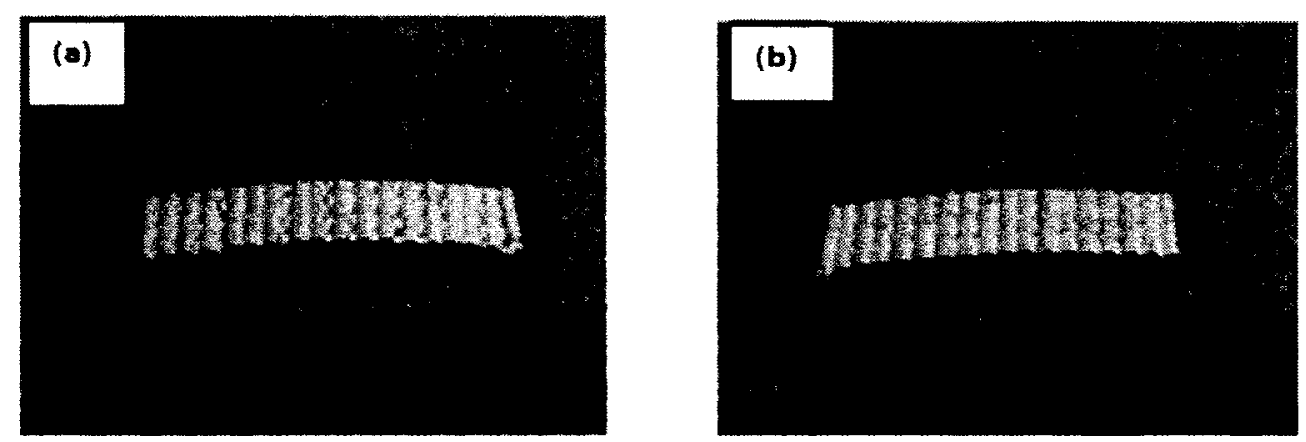

Figure 105: As-sprayed and heat treated HX/7YSZ samples in the (a) as-sprayed, and (b) heat treated conditions, showing curvature after 1000 cycles of oxidation test. 
SEM composition analyses for both as-sprayed and heat treated samples after 1000 cycles are given in Table 29 and Table 30 . The SEM images of the areas used for these measurements are shown in Figure 106 and Figure 107.
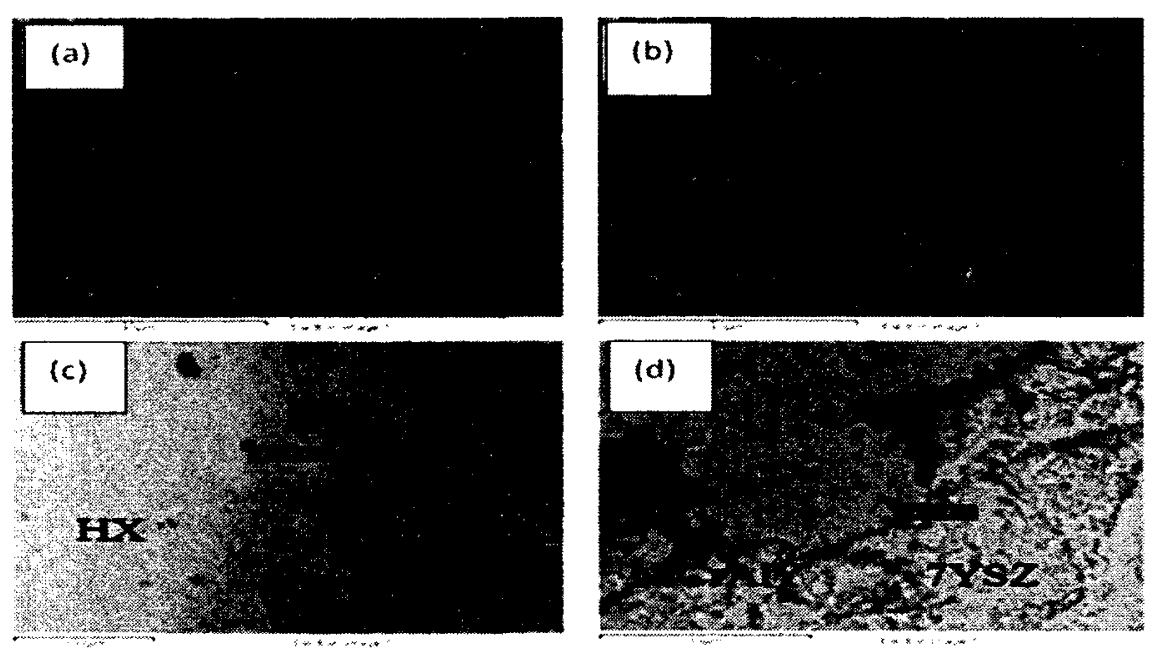

Figure 106: As-sprayed HX/7YSZ CMC layers and interfaces (not-directly exposed to air) after 1000 cycles of cyclic test: (a) $\mathrm{HX}$ white spot, (b) $\mathrm{HX}$ grey spot, (c) HX$\mathrm{NiCrAlY}$ interface, and (d)NiCrAlY-7YSZ interface $(5 \mathrm{kx})$.

Table 29: Composition of as-sprayed HX/7YSZ CMC (not-directly exposed to air) after 1000 cycles of cyclic test (in wt. \%).

\begin{tabular}{lllllll}
\hline & $\begin{array}{l}\text { HX wire } \\
\text { white spot }\end{array}$ & $\begin{array}{l}\text { HX wire } \\
\text { gray spot }\end{array}$ & $\begin{array}{l}\text { NiCrAlY } \\
\text { coating }\end{array}$ & $\begin{array}{l}\text { 7YSZ } \\
\text { ceramic }\end{array}$ & $\begin{array}{l}\text { HX- } \\
\text { NiCrAlY } \\
\text { interface }\end{array}$ & $\begin{array}{l}\text { NiCrAlY- } \\
\text { 7YSZ } \\
\text { interface }\end{array}$ \\
\hline $\mathrm{O}$ & 0 & 0 & 1.03 & 47.22 & 5.29 & 21.91 \\
\hline $\mathrm{Cr}$ & 20.04 & 22.62 & 32.5 & - & 25.65 & 12.42 \\
\hline $\mathrm{Mo}$ & 41.21 & 7.35 & - & - & 5.49 & - \\
\hline $\mathrm{Fe}$ & 6.66 & 18.94 & - & - & 7.31 & - \\
\hline $\mathrm{Ni}$ & 26.61 & 47.63 & 64.42 & - & 49.71 & 21.03 \\
\hline $\mathrm{Al}$ & - & - & 0.73 & - & 8.69 & 2.16 \\
\hline $\mathrm{Co}$ & - & - & - & - & - & - \\
\hline $\mathrm{Zr}$ & - & - & - & 47.26 & 2.95 & 49.07 \\
\hline $\mathrm{Y}$ & - & - & 1.32 & 4.18 & - & 3.59 \\
\hline $\mathrm{Si}$ & 2.74 & - & - & - & - & - \\
\hline $\mathrm{Mn}$ & - & 0.74 & - & - & - & - \\
\hline $\mathrm{W}$ & 2.75 & - & - & - & - & - \\
\hline
\end{tabular}



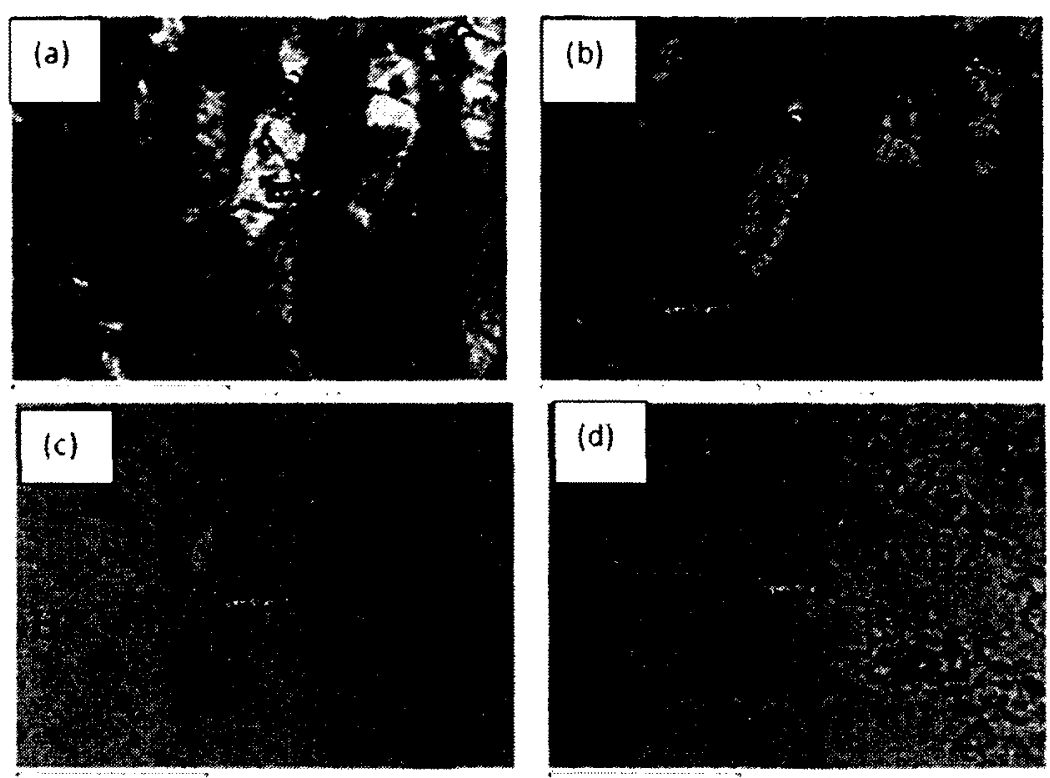

Figure 107: Heat treated HX/7YSZ CMC (not-directly exposed to air) after 1000 cycles of cyclic test: (a) HX white spot, (b) HX grey spot, (c) HX-NiCrAlY interface, and (d)NiCrAlY-7YSZ interface (5kx).

Table 30: Composition of various layers on the heat treated HX/7YSZ CMC (not-directly exposed to air) after 1000 cycles of cyclic test (in wt. \%).

\begin{tabular}{lllllll}
\hline & $\begin{array}{l}\text { HX wire } \\
\text { white spot }\end{array}$ & $\begin{array}{l}\text { HX wire } \\
\text { gray spot }\end{array}$ & $\begin{array}{l}\text { NiCrAlY } \\
\text { coating }\end{array}$ & $\begin{array}{l}\text { 7YSZ } \\
\text { ceramic }\end{array}$ & $\begin{array}{l}\text { HX- } \\
\text { NiCrAlY } \\
\text { interface }\end{array}$ & $\begin{array}{l}\text { NiCrAlY- } \\
\text { 7YSZ } \\
\text { interface }\end{array}$ \\
\hline $\mathrm{O}$ & 2.32 & 1.36 & 0 & 38.47 & 5.09 & 17.48 \\
\hline $\mathrm{Cr}$ & 17.40 & 22.00 & 29.61 & - & 28.48 & 13.70 \\
\hline $\mathrm{Mo}$ & 42.65 & 7.44 & - & - & 5.51 & - \\
\hline $\mathrm{Fe}$ & 6.54 & 18.85 & - & - & 6.77 & - \\
\hline $\mathrm{Ni}$ & 23.83 & 47.80 & 68.06 & - & 47.08 & 23.92 \\
\hline $\mathrm{Al}$ & - & - & 1.49 & - & 3.13 & 3.34 \\
\hline $\mathrm{Co}$ & 1.04 & 1.63 & - & - & - & - \\
\hline $\mathrm{Zr}$ & - & - & - & 55.68 & 4.28 & 38.67 \\
\hline $\mathrm{Y}$ & - & - & 0.84 & 4.55 & - & 3.81 \\
\hline $\mathrm{Si}$ & 2.50 & - & - & - & 0.49 & - \\
\hline $\mathrm{Mn}$ & - & 0.92 & - & - & - & - \\
\hline $\mathrm{W}$ & 3.72 & - & - & - & - & - \\
\hline
\end{tabular}




\subsubsection{Summary}

In section 5.5, the effect of cyclic thermal exposure on the degradation and failure of as-sprayed and heat treated $\mathrm{CMC}$ material were investigated. Samples were tested to 500 and 1000 cycles with the cycle specified in Figure 60 and then the microstructures were examined. Both as-sprayed and heat treated HX/7YSZ CMC after 500 cycles showed deep cracking on the exposed surfaces. The cracks were observed in ceramic coating and bond coat during visual examination. Also, the different layers in both assprayed and heat treated samples were delaminated and fully separated from each other. The repeated cyclic stresses during thermal cycling could be one of the reasons for the delamination. Comparing the failure demonstrated the extent of damage is higher after 500 cycles of cyclic oxidation test than that during isothermal test with the same duration, suggesting higher thermal stress during cyclic oxidation condition. The differences in CTEs of the adjacent layers worsen the cyclic failure and lead to spallation.

To study the effect of longer thermal cyclic condition, as-sprayed and heat treated samples after 1000 cycles also were examined. Similar to 500 cycle specimens, the amount of oxygen in the NiCrAlY bond coat and at the bond coat-ceramic interface in the heat treated specimens is lower than that in the as-sprayed specimens. Therefore, it can be concluded that vacuum heat treatment has improved the performance of HX/7YSZ CMCs during 500 and 1000 cycle thermal oxidation test.

It was found that the 1000 cycle tests worsened the failure and delamination due to the increased number of cycles. Fatigue failure and delamination were also seen in cross sections in both as-sprayed and heat treated CMCs. Due to the protection by 7YSZ ceramic, the extent of cracking and delamination in the cross sections are less than that 
directly exposed to air. In addition to cracking and delamination, another phenomenon also was observed after 1000 cycles; both as-sprayed and heat treated samples physically distorted. The curvature (Figure 105) was toward the side of longitudinal reinforcement wires in reinforcing metal which have higher thermal expansion than the 7YSZ ceramic.

\subsection{The Effect of Heat Treatment on Reinforced CMCs}

The strength of a composite material depends on the integrity of its components. To manufacture Mo/7YSZ and HX/7YSZ composites, NiCrAlY bond coat was applied directly on Mo and Hastelloy X reinforcing meshes to improve their bonding with 7YSZ ceramic. Using the bond coat could also shield the Mo and Hastelloy X against oxidation at high temperature by creating $\mathrm{TGO}\left(\mathrm{Al}_{2} \mathrm{O}_{3}\right)$ layer at bond coat-ceramic interfaces [87]. The aluminum oxide $\left(\mathrm{Al}_{2} \mathrm{O}_{3}\right)$ was formed on NiCrAlY after manufacturing by vacuum heat treatment at $1080^{\circ} \mathrm{C}$ for 4 hours [79]. $7 \mathrm{YSZ}$ is not able to prevent oxygen from passing through the structure and reaching the bond coat at high temperatures. In contrary, TGO layer in the interface is very dense and hinders the oxygen diffusion into the underneath Mo and $\mathrm{HX}$ metals. Bending tests results proved that heat treated CMCs had higher mechanical strength than non-heat treated composites (Table 18 and Table 19). This improvement in strength could be due to existence of TGO layer that maintains better adhesion between NiCrAIY and 7YSZ. To investigate the integrity of the samples, after bend test, microstructure examination of the Mo/7YSZ and $\mathrm{HX} / 7 \mathrm{YSZ}$ specimens was performed. As shown in Figure 108 and Figure 109 as-sprayed samples suffered from multiple longitudinal and transvers cracking and delamination in both Mo/7YSZ 
and $\mathrm{HX} / \mathrm{YSZ} \mathrm{CMCs}$, whereas the heat treated samples only contained a few transverse cracks after bending test.
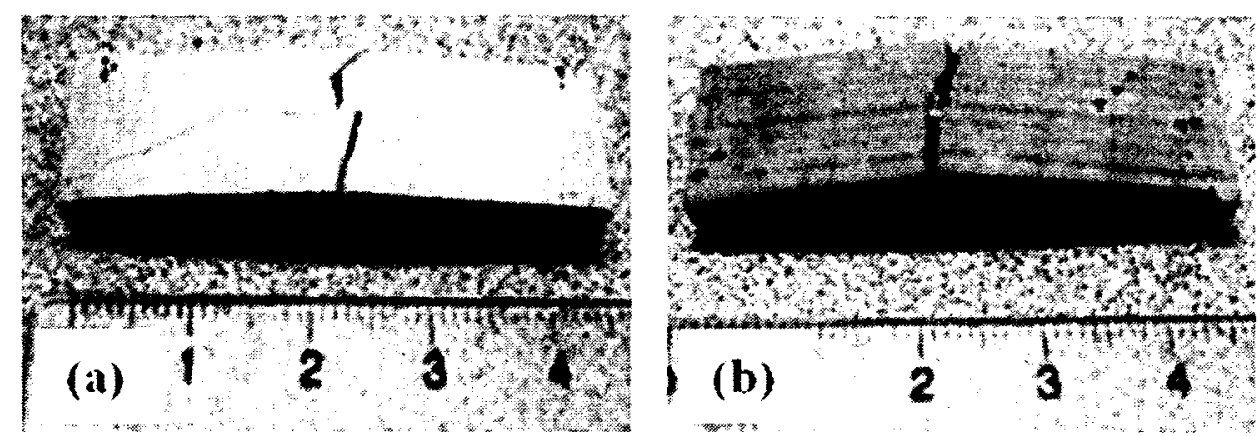

Figure 108: (a) Cracks and delamination in non-heat treated Mo/7YSZ CMC, and (b) cracks in heat treated Mo/7YSZ CMC.

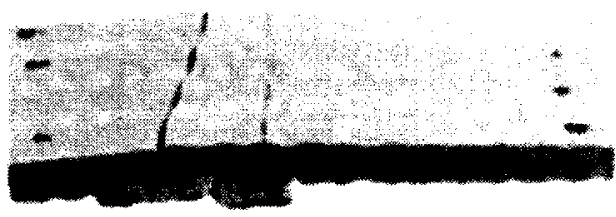

(a)

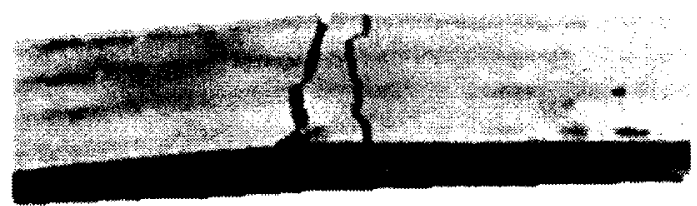

(b)

Figure 109: (a) Cracks and delamination in non-heat treated HX/7YSZ CMC, and (b) cracks in heat treated $\mathrm{HX} / 7 \mathrm{YSZ}$ CMC.

The positive effect of vacuum heat treatment on the strength of composite materials was also observed in Charpy test where heat treated Mo/7YSZ samples absorbed more energy $(2.70 \mathrm{~J})$ than as-sprayed samples $(2.03 \mathrm{~J})$. As seen in Figure 63, after impact Mo wires were pulled out in as-sprayed samples, because of weak adhesion 
between bond coat and ceramic. In the heat treated samples, the strong adhesion between the components did not allow wire pull out to happen.

As seen in metallographic examination of the as-sprayed and heat treated Mo/7YSZ composite specimens (Figure 110), the Mo to NiCrAlY bond was cracked. The cracking likely occurred during the plasma spraying process due to the difference in thermal expansion coefficient between Mo and NiCrAlY (Table 9 and Table 11). Metallographic examinations (Figure 110) also showed, the thicknesses of the sprayed $\mathrm{NiCrAlY}$ bond coats were not uniform on metallic meshes. During coating of meshes, surfaces directly exposed to spray gun received more deposition than the not-directly exposed surfaces. The non-uniformity and spray angle could affect the bonding strength and thermal stress between mesh and NiCrAlY bond coat, and also between NiCrAlY bond coat and $7 \mathrm{YSZ}$ ceramic, promoting the cracking and delamination at the interfaces.

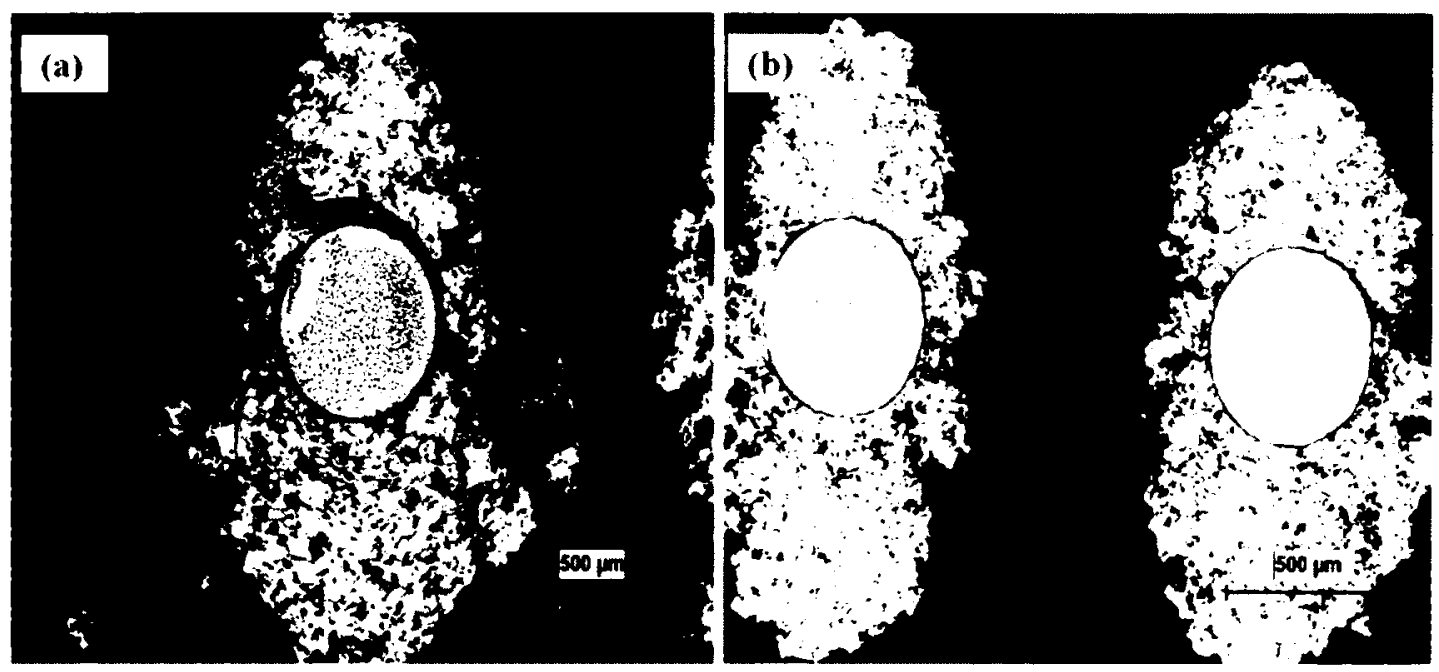

Figure 110: Optical microscope image of the microstructure of the Mo/YSZ composites, showing non-uniformity of NiCrAlY and circumferential cracking around the Mo wires in (a) as-sprayed, and (b) heat treated specimens. 
Bending and Charpy impact tests results showed better cohesion between the layers in the heat treated samples than in the as-sprayed samples. This improvement is likely due to existence of TGO layer in heat treated CMCs. However, in cyclic tests, heating and cooling the samples can weaken this bonding strength due to tensile and compressive thermal stresses. Thermal gradient and difference in CTEs of the adjacent layers are the primary reason for thermal stresses that lead to cracking and delamination. HX/7YSZ composite samples also had cracks in 7YSZ layer from the plasma spraying process, and non-uniformity in NiCrAlY thickness. However it showed better performance during isothermal and cyclic oxidation tests.

Figure 111 to Figure 113 show both as-sprayed and heat treated HX/7YSZ samples after 500 and 1000 hours in $1050^{\circ} \mathrm{C}$ isothermal test. The bonding between $\mathrm{HX}$ and NiCrAlY was mostly intact after cyclic test. Shown in Figure 114 to Figure 117, these samples have seen 500 and 1000 cycles in cyclic tests, respectively.

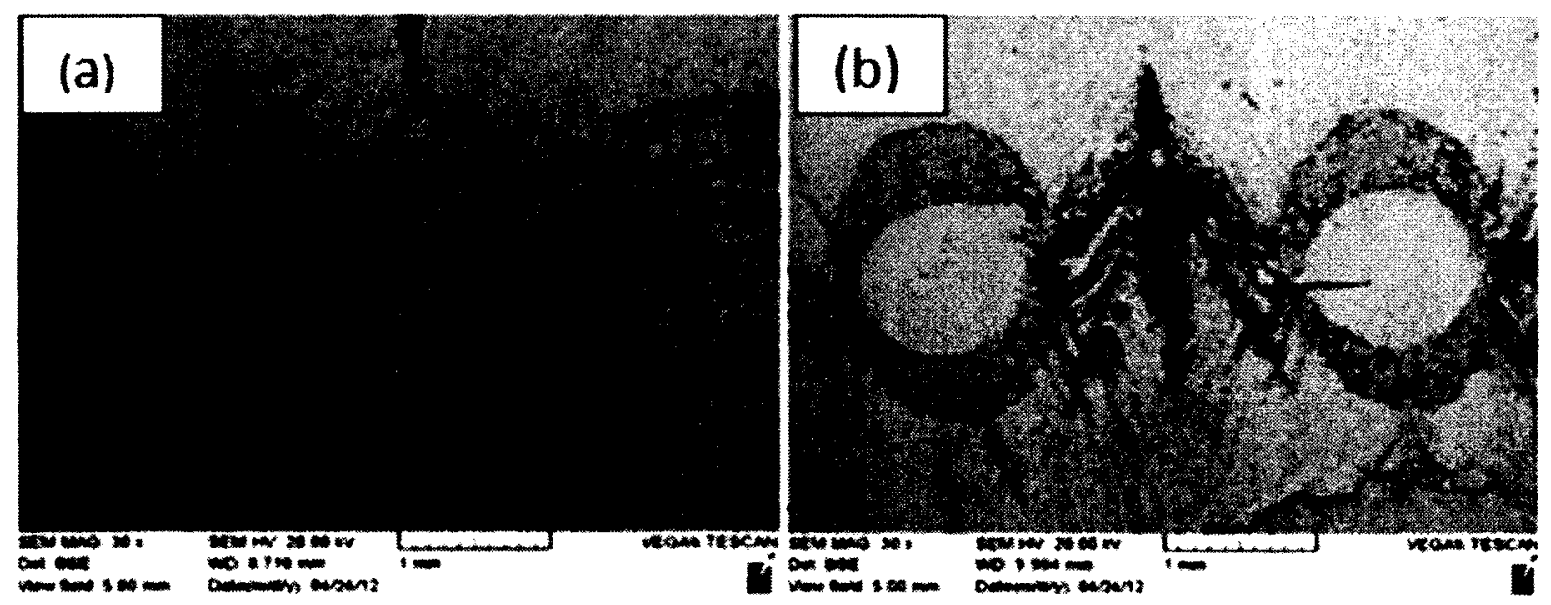

Figure 111: SEM images of not-directly exposed to air section of (a) as-sprayed and (b) heat treated $\mathrm{HX} / \mathrm{YSZ}$ after 500 hours isothermal test (30X). 

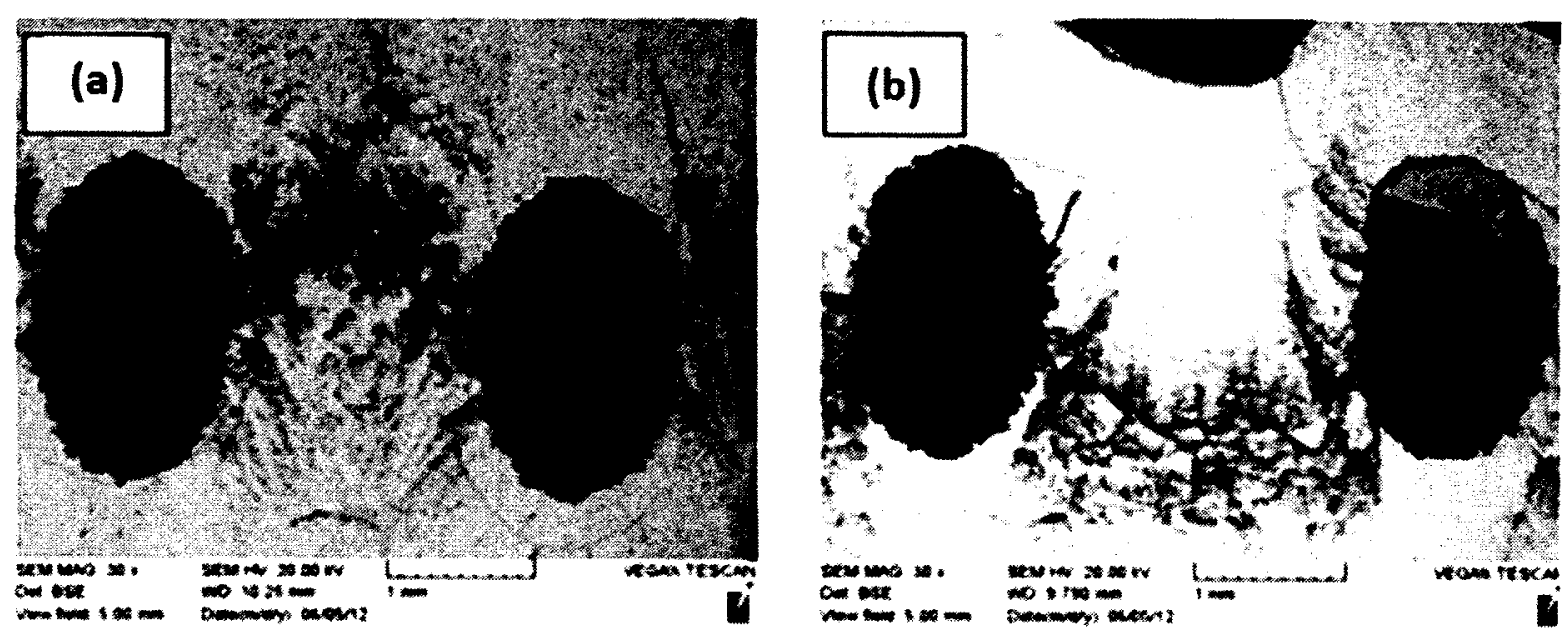

Figure 112: Directly exposed to air section of (a) as-sprayed and (b) heat treated HX/7YSZ after 1000 hours of isothermal test (30X).
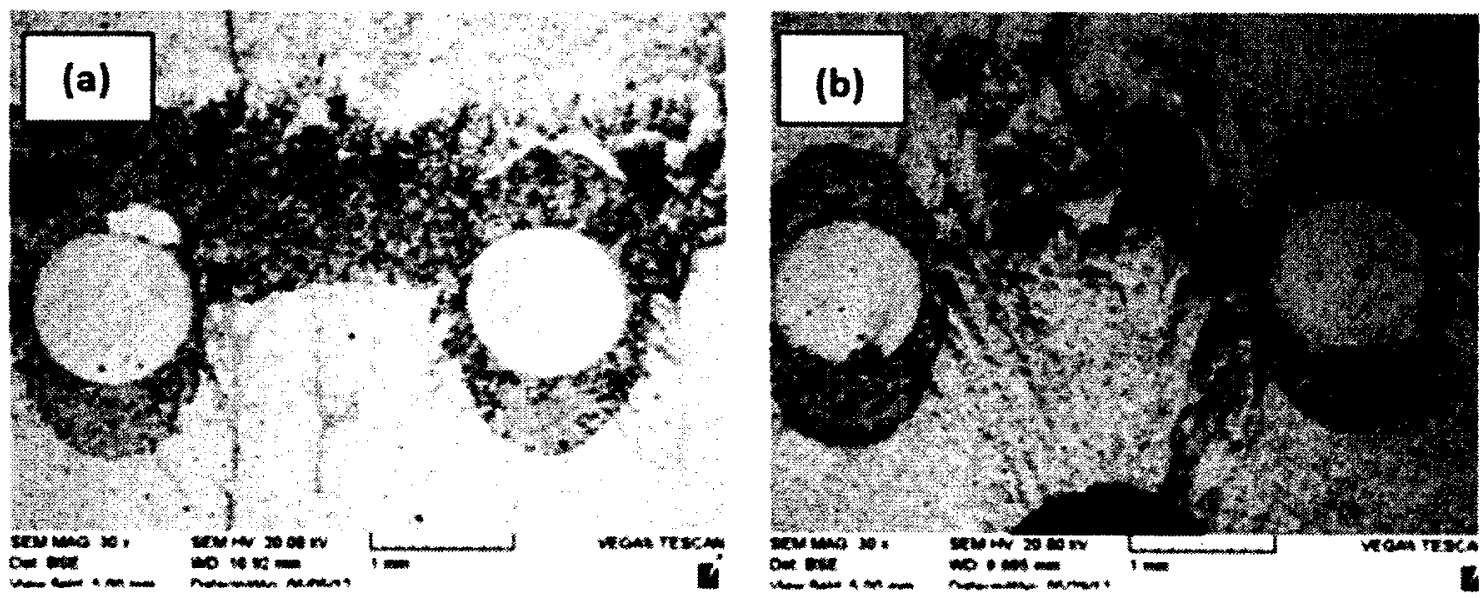

Figure 113: Not-directly exposed to air section of (a) as-sprayed and (b) heat treated HX/7YSZ after 1000 hours isothermal test (30X).

During cyclic test significant cracking was observed at the interfaces, including the NiCrAlY-7YSZ interface, in both non-heat treated and heat treated CMCs. The extent of cracking was greater in sections that were directly exposed to air and delamination prevailed. In not-directly exposed to air sections the extent of cracking was lower. 


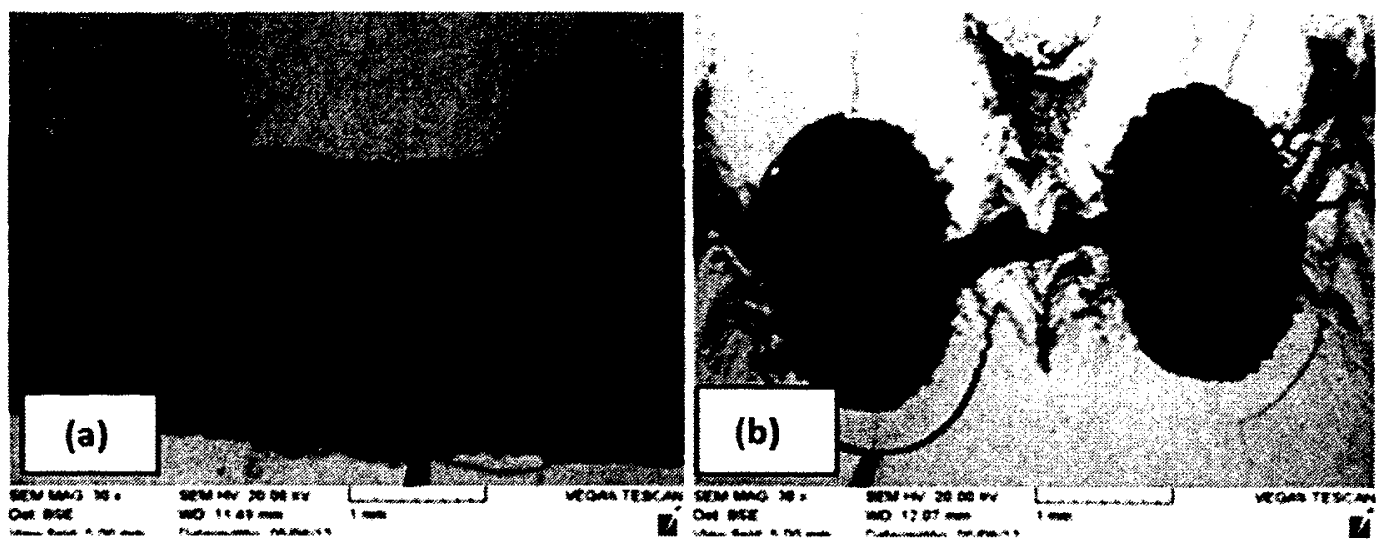

Figure 114: Cracking and delamination in directly exposed to air section of (a) as-sprayed and (b) heat treated HX/7YSZ CMCs after 500 cycles in cyclic test (30X).
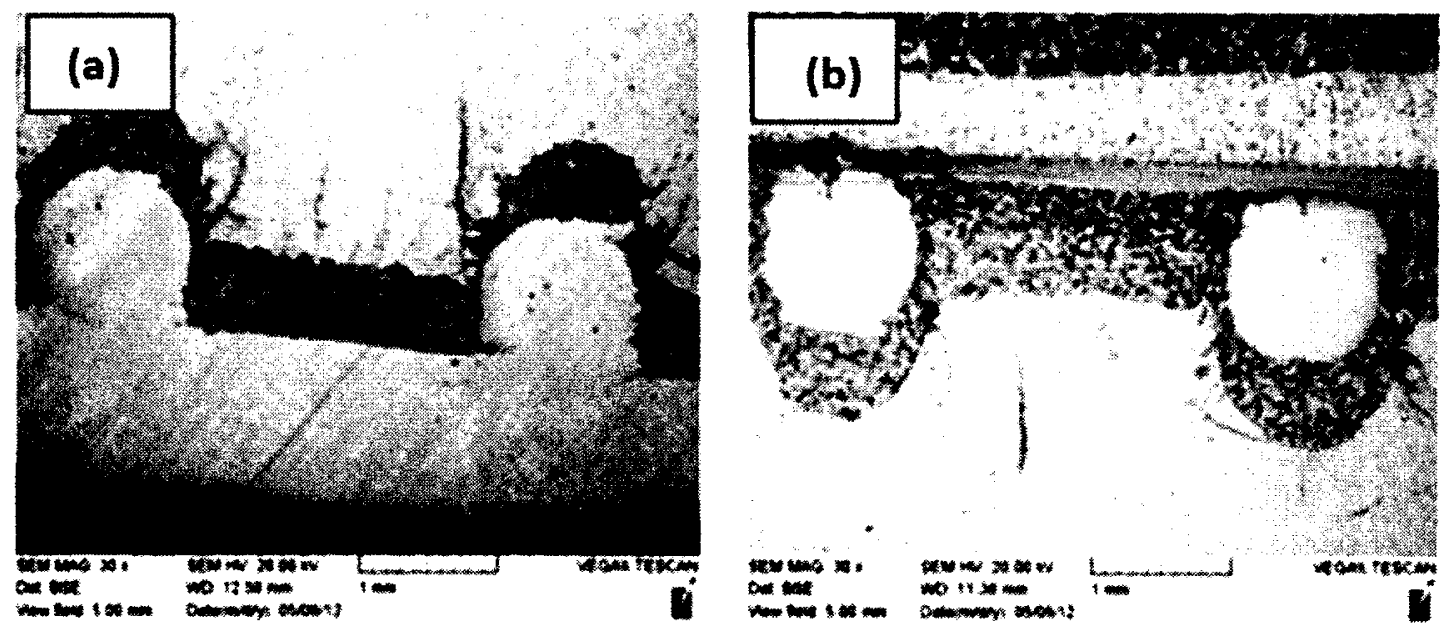

Figure 115: Cracking and delamination in not- directly exposed to air section of (a) assprayed, and (b) heat treated HX/7YSZ CMCs after 500 cycles of cyclic test (30X). 


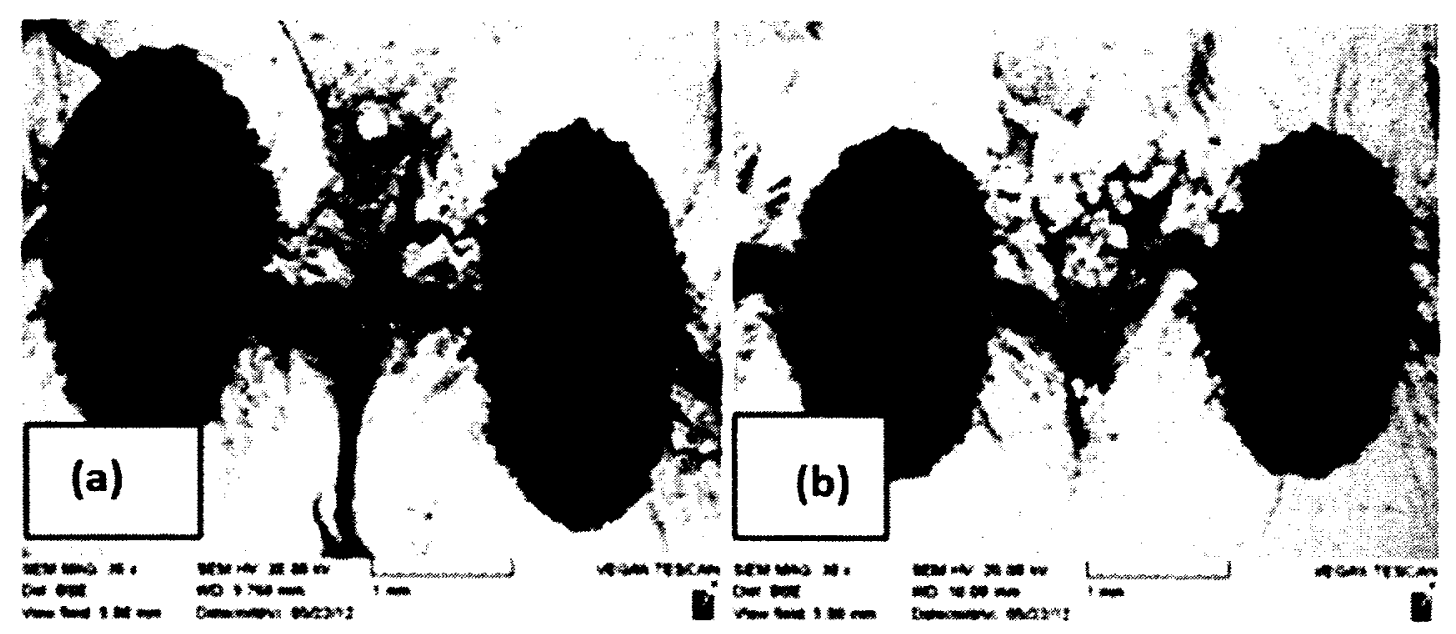

Figure 116: Cracking and delamination in directly exposed to air section of (a) as-sprayed and (b) heat treated HX/7YSZ CMCs after 1000 cycles of cyclic test (30X).
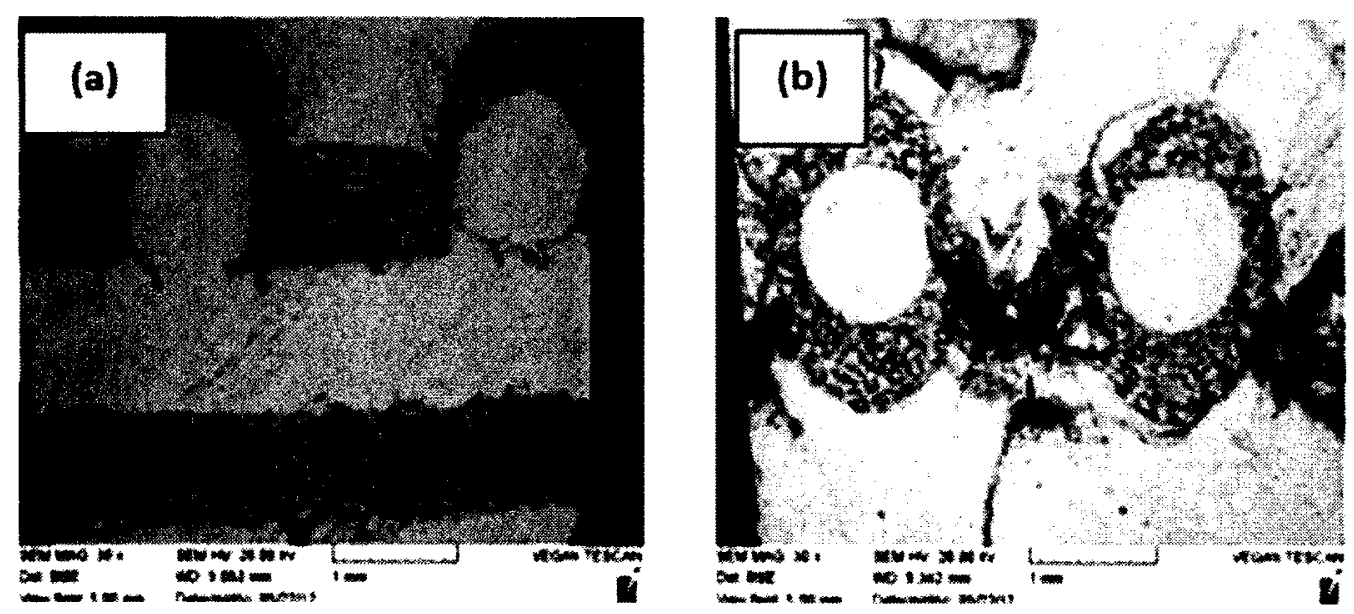

Figure 117: Cracking and delamination in not-directly exposed to air section of (a) assprayed and (b) heat treated HX/7YSZ CMCs after 1000 cycles of cyclic test (30X).

In summary, vacuum heat treatment increased the mechanical strength of the CMCs, likely due to stronger bonding between NiCrAlY and 7YSZ. However, this bonding might be weakened during cyclic test. Thermal stress due to temperature gradient in CMCs and difference in CTEs of the layers lead to cracking and eventually delamination of 7 YSZ layer in cyclic test. 


\section{Conclusions and Recommendations}

\subsection{Conclusions}

In this study, unique design and manufacturing methods for two composite materials were developed. Based on the methods, 4 samples of each type were produced and tested for their mechanical strength, through three-point bending and Charpy impact tests, and the oxidation resistance via isothermal and cyclic test. From the test results, the following conclusions can be drawn:

- Mo/7YSZ samples, in particular the heat treated samples, had higher impact energy than monolithic 7YSZ.

- As-sprayed Mo/7YSZ samples in bend test showed higher strength and improved ductility than monolithic 7YSZ. Heat treated Mo/7YSZ samples in bend test showed even higher strength and improved ductility than the as-sprayed Mo/7YSZ.

- As-sprayed HX/7YSZ samples contained multiple longitudinal and transverse cracking and ceramic spallation after bend test, while heat treated HX/7YSZ samples only contained transverse cracking and required higher crack initiation load than that for the as-sprayed samples due to better bonding between 7YSZ and NiCrAlY.

- During isothermal oxidation test, internal layers in both as-sprayed and heat treated HX/7YSZ samples had substantially reduced oxidation due to the protection offered by the ceramic matrix. Furthermore, less oxidation was observed on the heat treated $\mathrm{HX} / 7 \mathrm{YSZ}$ samples due to the formation of protective TGO layer.

- During cyclic oxidation test, both as-sprayed and heat treated HX/7YSZ samples cracked on exposed to air sections; this was due to thermal stresses arisen from the CTEs mismatch and repeated heating and cooling cycles. More delamination was 
observed on samples exposed to cyclic oxidation than that under isothermal condition. 7YSZ ceramic matrix in both as-sprayed and heat treated HX/7YSZ samples protected metallic components and reduced cracking/delamination.

\subsection{Recommendations}

Based on the promising results from the mechanical and oxidation tests, the novel HX/7YSZ composite is recommended for future evaluation. To improve the quality of the samples and to increase their damage tolerance, the following recommendations are made:

- Non-uniformity in NiCrAlY bond coat thickness could affect the interfacial bonding strength. To achieve a uniform coating on metallic meshes, it is recommended that a vapor deposition process such as pack cementation be used.

- Initial examination of the CMCs showed the 7YSZ ceramic coat contained cavities and porous region between the wires. These defects were produced during plasma spraying process (line-of-sight). Reducing the porosity will enhance the mechanical properties of the composites as well as their chemical stability at high temperatures. The powder size used in this work was $90 \mu \mathrm{m}$ for NiCrAlY and $45 \mu \mathrm{m}$ for $7 \mathrm{YSZ}$ (Table 14). Finer size $(20 \sim 30 \mu \mathrm{m})$ can be used to reduce the porosity [73]. However, a more effective way to apply $7 \mathrm{YSZ}$ will be to use slurry method followed by either pressureless sintering or HIP process. Slurry methods are able to produce full coverage and better bonding [88]. A hydrothermal hot pressing technique is another method by which hard solid bodies of powders can be produced in a short time and at a relatively low temperature under saturated vapor pressure [89]. 
- The mechanical properties of composite materials are generally anisotropic. To improve these properties, it would be beneficial to manufacture 3-dimentional composite material by using a 3-dimentional lattice block structural core. A slurry coating of $7 \mathrm{YSZ}$ must be used to coat the 3D lattice block core more uniformly. 


\section{List of References}

[1] M. R. Dorfman, L. Xie, A. Cipitria, S. Paul, I. Golosnoy, T. W. Clyne and W. Chi, "Properties and Performance of High Purity Thermal Barrier Coatings," Journal of Thermal Spray Technology, Vols. 16(5-6), pp. 804-808, 2007.

[2] F. C. Campbell, Elements of Metallurgy and Engineering Alloys, Materials Park, $\mathrm{OH}$ : ASM International, 2008.

[3] C. Y. Cui, Y. F. Gu, D. H. Ping, H. Harada, M. Osawa and A. Sato, "Effects of Ru Additions on the Microstructure and Phase Stability of Ni-Base Superalloy, UDIMET 720LI," Metallurgical and Materials Transactions, vol. 37 A, pp. 355$360,2006$.

[4] Charles A. Harper, Handbook of Ceramics, Galsses, and Diamonds, USA: McGraw-Hill Companies, Inc., 2001.

[5] M. Durand-Charre, The Microstructure of Superalloys, Amsterdam B.V.: Gordon and Breach Science Publishers, 1997.

[6] R. C. Reed, The Superalloys: Fundamentals and Applications, United Kingdom: Cambridge University Press, 2006.

[7] V. Guttmann, Phase Stability in High Temperature Alloys, Essex, London: Applied Science Publishers LTD., 1981.

[8] B. Geddes, H. Leon and X. Huang, Superalloys-Alloying and Performance, Materials Park, $\mathrm{OH}$ : ASM International, 2010.

[9] C. T. Sims, N. S. Stoloff and W. C. Hagel, Superalloys II, USA: John Wiley \& Sons, Inc., 1987.

[10] A. K. Jena and M. C. Chaturvedi, "The Role of Alloying Elements in the Design of Nickel-Base Superalloys," Journal of Materials Science, vol. 19, no. 10, pp. 31213139, 1984.

[11] R. Bowman, "Superalloys: A Primer and History," in 9th International Symposium on Superalloys, Champion, Pennsylvania, 2000.

[12] P. Visuttipitukul, N. Limvanutpong, P. Wangyao, "Aluminizing of Nickel-Based Superalloys Grade IN 738 by Powder Liquid Coating," Materials Transactions, 
vol. 51, no. 5, pp. $982-987,2010$.

[13] T. M. Pollock, "Nickel-Based Superalloys for Advanced Turbine Engines: Chemistry, Microstructure, and Properties," Journal of Propulsion and Power, vol. 22, no. 2, pp. 361 - 374, 2006.

[14] A. Onyszko, K. Kubiak and J. Sieniawski, "Turbine blades of the single crystal nickel based CMSX-6 superalloy," Journal of Achievements in Materials and Manufacturing Engineering, vol. 32, no. 1, pp. 66-69, January 2009.

[15] H. K. D. H. Bhadeshia, "Single Crystal Superalloys," University of Cambridge, [Online]. Available: http://blog.makezine.com/2012/01/16/single-crystalsuperalloys.

[16] Y. Tamarin, Protective Coatings for Turbine Blades, Materials Park, OH 440730002 : ASM International, 2002.

[17] P. J. Zhou, J. J. Yu, X. F. Sun, H. R. Guan and Z. Q. Hu, "The Role of Boron on a Conventional Nickel-Based Superalloy," Materials Science and Engineering, vol. 491, no. 1-2, pp. 159-163, September 2008.

[18] A. K. Koul, V. R. Parameswaran, J. P. Immarigeon and W. Wallace, Advanced in High Temperature Structural Materials and Protective Coatings, Ottawa: National research Counsil of Canada, 1994.

[19] M. Hetmańczyk, L. Swadźba and B. Mendala, "Advanced Materials and Protective Coatings in Aero-Engines Application," Journal of Achievements in Materials and Manufacturing Engineering, vol. 24, no. 1, pp. 372-381, 2007.

[20] Y. Itoh, M. Saitoh, K . Takaki and K . Fujiyama, "Effect of High-Temperature Protective Coatings on Fatigue Lives of Nickel-Based Superalloys," Fatigue \& Fracture of Engineering Materials \& Structures, vol. 24, no. 12, p. 843-854, 2001.

[21] Y. C. Zhou and T. Hashida, "Coupled Effects of Temperature Gradient and Oxidation on Thermal Stress in Thermal Barrier Coating System," International Journal of Solids and Structures, vol. 38, no. 24-25, pp. 4235-4264, 2001.

[22] H. C. Scott, "Phase Relationships in Zirconia-Yttria System," Journal of Materials Science, vol. 10, no. 9, pp. 1527-1535, 1975.

[23] A. G. Evans, D. R. Mumm, J. W. Hutchinson, G. H. Meier and F. S. Pettit, "Mechanisms Controlling the Durability of Thermal Barrier Coatings," Progress in 
Materials Science, vol. 46, no. 5, pp. 505-553, 2001.

[24] E. A. Jarvis and E. A. Carter, "The Role of Reactive Elements in Thermal Barrier Coatings," Computing in Science \& Engineering, vol. 4, no. 2, pp. 33-41, 2002.

[25] M. J. Stiger, N. M. Yanar, M. G. Topping, F. S. Pettit and G. H. Meier, "Thermal Barrier Coatings for the 21 st Century," [Online]. Available:

http://www.ewp.rpi.edu/hartford/ lys/EP/Supporting\%20Materials/References/stig er1999.pdf.

[26] W. G. Mao, Q. Chen, C. Y. Dai, L. Yang, Y. C. Zhou and C. Lu, "Effects of Piezospectroscopic Coefficients of 8 wt.\% Y2O3 Stabilized ZrO2 on Residual Stress Measurement of Thermal Barrier Coatings by Raman Spectroscopy," Surface \& Coatings Technology, vol. 204, pp. 3573-3577, 2010.

[27] K. Miyahara, Y. Shigegaki and T. Sasa, "High-Temperature High-Strength Ceramics," in Handbook of Advanced Ceramics, London, Elsevier Inc., pp. 267290,2003 ..

[28] J. R. Davis and Associates, Metals Handbook, Material Park, OH: ASM International, 1998.

[29] All Metals \& Forge Group, "Refractory Metals," All Metals \& Forge Group, 1994. [Online]. Available: http://www.steelforge.com/nonferrous/refractorymetals.htm. [Accessed November 2012].

[30] O. D. Neikov, S. S. Naboychenko and G. Dowson, Handbook of Nonh-ferrous Metal Powders, Amstertdam, The Netherlands: Elsevier Ltd., 2009.

[31] W. T. Elwell and D. F. Wood, Analytical Chemistry of Molybdenum and Tungsten, Elmsford, New York: Pergamon Press Ltd., 1971.

[32] J. Shields and Fafm, "Applications of Mo Metal and Its Alloys," 1995. [Online]. Available: http://www.imoa.info/_files/brochures_articles/Applications_Mo_Metal.. [Accessed November 2012].

[33] M. Nagae, T. Yoshio, J. Takada and Yutaka Hiraoka, "Improvement in Recrystallization Temperature and Mechanical Properties of a Commercial TZM Alloy through Microstructure Control by Multi-Step Internal Nitriding," Materials Transactions, vol. 46, no. 10, pp. 2129-2134, 2005. 
[34] J. Christian, R. P. S. Gaur, T. Wolfe and J. R. L. Trasorras, "Tungsten Chemicals and their Applications," June 2011. [Online]. Available:

http://www.itia.info/assets/files/newsletters/Newsletter_2011_06.pdf. [Accessed November 2012].

[35] C. B. Carter and M. G. Norton, Ceramic Materials: Science and Engineering, NY USA: Springer Science+Business Media, I.I.C., 2007.

[36] K. K. Chawla, Ceramic Matrix Composites, USA: Kluwer Academic Publishers, 2003.

[37] D. Kopeliovich, "Substances \& Technologies: Magnesia Ceramics," SubsTech, 2012. [Online]. Available:

http://www.substech.com/dokuwiki/doku.php?id=magnesia_ceramics\&s=mgo.

[38] E. Dorre and H.Hubner, Alumina: Processing, Properties, and Application, Tokyo: Springer-Verlag, 1984.

[39] T. Tsuchida and N. Ichikawa, "Mechanochemical Phenomena of Gibbsite, Bayerite and Boehmite by Grinding," Reactivity of Solids, vol. 7, no. 3, pp. 207-217, 1989.

[40] G. V. Franks and Y. Gan, "Charging Behavior at the Alumina-Water Interface and Implications for Ceramic Processing," Journal of the American Ceramic Society, vol. 90 , no. 11 , p. 3373-3388, 2007.

[41] P. Boch and J. C. Niepce, Ceramic Materials, Chippenham, Wiltshire, Great Britain: Antony Rowe Ltd, 2007.

[42] E. Dorre and H. Hubner, Alumina, Processing, Properties and Application, Tokyo: Springer-Verlag, 1984.

[43] "Materials Applications," May 2014. [Online]. Available: http://www.azom.com/Applications.aspx.

[44] P. Lawrence, P. K. Mathews and B. Deepanraj, "Experimental Investigation on Performance and Emission Characteristics of Low Heat Rejection Diesel Engine with Ethanol as Fuel," American Journal of Applied Sciences, vol. 8, no. 4, pp. 348-354, 2011.

[45] http://www.stanfordmaterials.com, Stanford Materials, retrieved on August 2011.

[46] "Thermal Barrier Coatings," August 2011. [Online]. Available: 
http://www.ipm.virginia.edu/research/PVD/Pubs/thesis6/chapter2.PDF.

[47] D. D. Hass, A. J. Slifka and H. N. G. Wadley, "Low Thermal Conductivity Vapor Deposited Zirconia Microstructures," Acta Materialia, vol. 49, pp. 973-983, 2001.

[48] B. Basu and M. Kalin, Ceramics and Composites: A Materials Science Perspective, Hoboken, New Jersey: John Wiley \& sons Inc., 2011.

[49] F. C. Campbell, Structural Composite Materials, USA: ASM International, 2010.

[50] S. C Sharma, Composite Materials, Bangalore, India: Narosa Publishing House, 2000 .

[51] "Coatings for High-temperature Structural Materials: Trends and Opportunities," in Committee on Coatings for High-Temperature Structural Materials, National Materials Advisory Board, Commission on Engineering and Technical System, 1996.

[52] M. J. Donachie and S. J. Donachie, Superalloys, A Technical Guide, Ohio: Materials Park Ohio, USA, 2002.

[53] G. Y. Lai, High Temperature Corrosion and Materials Applications, Metals Park Ohio, USA: ASM International, 2007.

[54] P. Puetz, X. Huang, R. S. Lima, Q. Yang and L. Zhao, "Characterization of transient oxide formation on CoNiCrAlY after heat treatment in vacuum and air," Surface and Coatings Technology, vol. 205, no. 2, p. 647-657, 2010.

[55] R. Prescott and M. J. Graham, "The Formation of Aluminum Oxide Scales on High-Temperature Alloys," Oxidation of Metals, vol. 38, no. 3/4, pp. 233-254, 1992.

[56] T. Nakagiri and K. Kurokawa, "Evaporation Behavior of $\mathrm{SiO} 2$ in N2-O2-H2O Atmospheres," Materials Transactions, vol. 45, no. 2, pp. 334 - 337, 2004.

[57] M. Schütze and W. J. Quadakkers, Cyclic Oxidation of High Temperature Materials: (EFC 27), Birmingham, UK: Maney Publishing, 1999.

[58] N. Eliaz, G. Shemesh and R. M. Latanision, "Hot Corrosion in Gas Turbine Components," Engineering Failure Analysis, vol. 9, no. 1, pp. 31-34, 2002.

[59] H. Singh, D. Puri and S. Prakash, "An Overview of Na2SO4 and/or V2O5 Iduced 
Hot Corrosion of Fe- and Ni-Based Superalloys," Review on Advanced Material Science, vol. 16, pp. 27-50, 2007.

[60] M. Boidot, S. Selezneff, D. Monceau, D. Oquab and C. Estournès, "Proto-TGO Formation in TBC Systems Fabricated by Spark Plasma Sintering," Surface and Coatings Technology, vol. 205, no. 5, p. 1245-1249, 2010.

[61] A. G. Evans, M. Y. He and J. W. Hutchinson, "Mechanics-Based Scaling Laws for the Durability of Thermal Barrier Coatings," Progress in Materials Science, vol. 46, pp. 249-271, 2001.

[62] J. R. Davis \& Associates, Handbook of Thermal Spray Technology, Materials Park, OH, USA: ASM International, 2004.

[63] H. W. W. Wong, "Heat Transfer Analysis of the Plasma Spray Deposition Process," PhD thesis, The University of British Colombia, 1997.

[64] P. Fauchais, "Understanding Plasma Spraying," Journal of Physics D: Applied Physics, vol. 37, p. R86-R108, 2004.

[65] Sulzer Metco, "Atmospheric Plasma Spray Solutions," 2012. [Online]. Available: http://www.sulzer.com/en//media/Documents/ProductsAndServices/Coating_Equipment/Thermal_Spray/Broc hures/Plasma_Solutions_EN3.pdf?.

[66] Z. Chen, F. Yuan, Z. Wang and S.Zhu, "The Oxide Scale Formation and Evolution on Detonation Gun Sprayed NiCrAlY Coatings during Isothermal Oxidation," Materials Transactions, vol. 48, no. 10, pp. 2695-2702, 2007.

[67] N. Voudouris, Ch. Christoglou, G.N. Angelopoulos, "Formation of Aluminide Coatings on Nickel by a Fuidised Bed CVD Process," Surface and Coatings Technology, vol. 141, pp. 275-282, 2001.

[68] "Hastelloy X Alloy," Haynes International, Inc., 1997. [Online]. Available: http://www.haynesintl.com. [Accessed June 2011].

[69] F. Cardarelli, Materials Handbook: A Concise Desktop Reference, 2nd Edition, illustrated ed., New York: Springer, 2008.

[70] "Lenntech," [Online]. Available: http://www.lenntech.com/periodic/elements/mo.htm\#ixzz26wLf4qJT. [Accessed September 2012]. 
[71] "Molybdenum," [Online]. Available: http://www.espimetals.com/tech/molybdenum.pdf. [Accessed September 2012].

[72] J.R. Nicholls and D.S. Rickerby,, "Materials and Processes for High Temperature Surface," in B278-Materials for High Temperature Power Generation and Process Plant Application, Cirencester, 1998.

[73] X. Chang, J. Wang, Y. Hao, W. Hou and Z. Hu, "Powder Microstructure and Overlay Coating Property of NiCrAlY Alloy," Journal of Materials Science and Technology, vol. 14, 1998.

[74] B. Goswami, A. K. Ray and S. K. Sahay, "Thermal Barrier Coating System for Gas Turbine Application," High Temperature Materials and Processes, vol. 23, no. 2, pp. 73-92, 2004.

[75] T. A. Taylor and P. N. Walsh, "Dilatormeter Studies of NiCrAlY Coatings," Surface and Coatings Technology, Vols. 188-189, pp. 41-48, 2004.

[76] P. Nguyen, "Slurry Sprayed Thermal Barrier Coatings for Aerospace Applications," 2010.

[77] S. Bose, High Temperature Coatings, Linacre House, Jordan Hill, UK: Butterworth-Heinemann, 2007.

[78] Miller Electric Mfg. Co., "Handbook for Resistance Spot Welding," 2012. [Online]. Available: www. MillerWelds.com.

[79] W. R. Chen, X. Wu, B. R. Marple, R. S. Lima, R. Archer, X. Huang and P. C. Patnaik, "Influence of Post-Spraying Heat Treatments on the Oxidation and Cracking Behaviour of Thermal-Sprayed Thermal Barrier Coatings," in in 12th International Conference on Fracture ICF 2009, Ottawa, Canada, 2009.

[80] H. St. C. O'neill and A. Navrotsky, "Simple spinels: Crystallographic Parameters, Cation Radii, Lattice Energies, and Cation Distribution," American Mineralogist, vol. 68, pp. 181-194, 1983.

[81] L. Northcott, Molybdenum, London: Butterworths Scientific Publications, 1956.

[82] S. Primig, H. Leitne, H. Clemens, A. Lorich, W. Knabl and R. Stickler, "On the Recrystallization Behavious of Technically Pure Molybdenum," International Journal of Refractory Metals and Hard Materials, vol. 28, no. 6, pp. 703-708, 2010. 
[83] WolframAlpha, http://www.wolframalpha.com/.

[84] ASTM D 790 - 10, "Standard Test Methods for Flexural Properties of Unreinforced and Reinforced Plastics and Electrical Insulating Materials," www.astm.org DOI:10.1520/D0790-10 ASTM International, West Conshohocken, PA 194282959. [Online].

[85] "ASTM E23-07ael Standard Test Methods for Notched Bar Impact Testing of Metallic Materials," ASTM International, West Conshohocken, PA, 2007.

[86] Z. Yu, H. Zhao and H. N. G. Wadley, "The Vapor Deposition and Oxidation of Platinum- and Yttria-Stabilized Zirconia Multilayers," Journal of the American Ceramic Society, vol. 94, no. 8, pp. 2671-2679, 2011.

[87] D. W. Seo and E. G. Na, "Finite Element Analysis of Residual Stress in NiCrAlY/yttria-stabilized Zirconia Coatings by Nanoscale Multi-layered Deposition," Key Engineering Materials, Vols. 270-273, pp. 58-63, 2004.

[88] "Praxair," [Online]. Available: http://www.praxair.com.

[89] K. Byrappa and M. Yoshimura, Handbook of Hydrothermal Technology, Norwich, NY, USA: William Andrew Inc., 2001.

[90] X. Chang, J. Wang, Y. Hao, W. Hou and Z. Hu, "Powder Microstructure and Overlay Coating Property of NiCrAIY Alloy," Journal of Material Science and Technology, vol. 14, 1998.

[91] Cm KEY to METALS, "Corrosion of Nickel-Base Alloys," [Online]. Available: http://www.keytometals.com/Articlel 8.htm. 